1993

\title{
Axial flux permanent magnet servo motor with sixteen poles
}

S. Geetha

University of Wollongong

\section{Recommended Citation}

Geetha, S., Axial flux permanent magnet servo motor with sixteen poles, Doctor of Philosophy thesis, Department of Electrical and Computer Engineering, University of Wollongong, 1993. http://ro.uow.edu.au/theses/1339 


\section{NOTE}

This online version of the thesis may have different page formatting and pagination from the paper copy held in the University of Wollongong Library.

\section{UNIVERSITY OF WOLLONGONG}

\section{COPYRIGHT WARNING}

You may print or download ONE copy of this document for the purpose of your own research or study. The University does not authorise you to copy, communicate or otherwise make available electronically to any other person any copyright material contained on this site. You are reminded of the following:

Copyright owners are entitled to take legal action against persons who infringe their copyright. A reproduction of material that is protected by copyright may be a copyright infringement. A court may impose penalties and award damages in relation to offences and infringements relating to copyright material. Higher penalties may apply, and higher damages may be awarded, for offences and infringements involving the conversion of material into digital or electronic form. 


\title{
AXIAL FLUX PERMANENT MAGNET SERVO MOTOR WITH SIXTEEN POLES
}

\author{
A thesis submitted in fulfilment of the requirements \\ for the award of the degree of
}

DOCTOR OF PHILOSOPHY

from

UNIVERSITY OF WOLLONGONG

by

S. GEETHA, B.E(HONS) M.E

Department of Electrical and Computer Engineering 1993 
Dedicated to

DON PLATT

But for whom this thesis would not have become a reality 


\section{ACKNOWLEDGEMENTS}

I would like to express my deepest gratitude to my principal supervisor, Dr. D Platt for his constant encouragement, guidance and support throughout the research. I would like to express my profound appreciation to my other supervisor Dr. B. S. P Perera for the much required moral support he provided, in the early stage of my research.

I would like to thank Professor. C.D. Cook for his support throughout the research. The work shop staff of the Department of Electrical and Computer Engineering have been most helpful and I wish to thank them all for their co-operation and timely help. I wish to thank all the staff of the Department for providing friendly atmosphere to carry out my research successfully.

I would like to thank The Energy Efficient Research Centre, University of Wollongong, Wollongong, for their financial support, without which, it would have been nearly impossible to complete this project.

Finally, I would like to thank my husband Varatharajan, my children Prithvi Ramanan, and Prem Narayan, for their patience, understanding and support. 
I certify that this thesis entitled " AXIAL FLUX PERMANENT MAGNET SERVO MOTOR WITH SIXTEEN POLES " has not been submitted previously for any other degree and that all work contained in the thesis was performed by me.

Geetha Sadagopan. 


\section{CONTENTS}

$\begin{array}{llll}\text { Chapter } & 1 & \text { INTRODUCTION } & 1\end{array}$

1.1 Electric Machines 1

1.2. Permanent Magnet Machines 1

1.3 Axial Flux Permanent Magnet Machines 4

1.4 Advantages of Axial Flux Permanent 7 Magnet Machines

1.5 Disadvantages of Permanent Magnet 10

Machines

1.6 Servo Motor 10

1.7 The New Servo Motor 11

1.8 Design Features 11

1.9 Disadvantages of the New Design 17

1.10 Analytical Problems 21

1.11 Plan of the Thesis 22

1.12 Summary 23

$\begin{array}{lll}\text { Chapter } 2 & \text { TORQUE CALCULATION OF MACHINES } 24\end{array}$ WITH PERMANENT MAGNET MATERIAL

2.1 Introduction 24

2.2 The Permanent Magnet 25

2.3 Verification of the Energy Density Expression 28

2.4 Experimental Verification 31

2.5 Torque Calculation of a Permanent 32 Magnet Machine

2.6 Torque in Terms of Space Phasors 41

2.7 Summary 43

$\begin{array}{lll}\text { Chapter } & 3 & \text { GENERALISED LINEAR MODEL }\end{array}$

3.1 Introduction 44

3.2. The Discrete Fourier Transform (DFT) 44

3.3 The Mathematical Model of a Permanent 46

Magnet Machine with Surface Mounted

Magnets Using DFT

3.4 Summary 
Contents continued

Page

$\begin{array}{llll}\text { Chapter } 4 \text { COGGING TORQUE } & 45\end{array}$

4.1 Introduction 55

4.2 Calculation of Cogging Torque 55

4.3 Results 58

4.4 Reduction of Cogging Torque 62

4.5 Summary 64

$\begin{array}{llll}\text { Chapter } & 5 & \text { USEFUL TORQUE } & 65\end{array}$

5.1 Introduction 65

5.2 Results 65

$\begin{array}{lll}5.3 & \text { Summary } & 70\end{array}$

$\begin{array}{llll}\text { Chapter } & 6 & \text { MODEL WITH SATURATION }\end{array}$

6.1 Introduction 72

6.2 The Model 73

6.3 Computer Simulation 81

6.4 Results $\quad 82$

6.5 Summary 83

$\begin{array}{llll}\text { Chapter } & 7 & \text { DESIGN OPTIMIZATION } & 84\end{array}$

7.1 Introduction 84

7.2 Tooth Tips 84

7.3 Effect of Tooth Tip Dimensions on the 89 Tooth Stem Flux Density

$\begin{array}{lll}7.4 & \text { Summary } & 96\end{array}$

$\begin{array}{llll}\text { Chapter } & 8 & \text { CONCLUSION } & 97\end{array}$

$\begin{array}{lr}\text { Author's Publications } & 98\end{array}$

$\begin{array}{ll}\text { References } & 99\end{array}$ 


\section{Contents continued}

$\begin{array}{llll}\text { Appendix } & 1 & \text { MOMENT OF INERTIA OF THE ROTOR } & 104\end{array}$

$\begin{array}{llll}\text { Appendix } & 2 & \text { FORCE, ENERGY AND } & 107\end{array}$

TORQUE CALCULATIONS

$\begin{array}{llll}\text { Appendix } & 3 & \text { TORQUE AND CURRENT IN TERMS OF } & 115\end{array}$ DISCRETE FOURIER TRANSFORM

Appendix 4 COMPUTER SIMULATION OF

COGGING TORQUE

Appendix 5 LEAKAGE FLUX CALCULATIONS AND COMPUTER SIMULATION OF SATURATION MODEL 


\section{LIST OF MAIN SYMBOLS}

$\mathrm{N}$

$\mathrm{p}$

ga

$\mathrm{gm}$

g

$\mathrm{Br}_{\mathrm{r}}$

$\mathrm{H}_{\mathrm{c}}$

$\mathrm{H}_{\mathrm{a}}$

$\mathrm{H}_{\mathrm{m}}$

$\mathrm{B}$

A

$\mathrm{R}$

L

T

$\mathrm{k}$

n

$\mathrm{v}$

i

$\mathrm{i}(\mathrm{k})$

I(n)

$\phi(\mathrm{k})$

$\mathrm{B}(\mathrm{k})$

$E_{\mathrm{ta}}(\mathrm{k})$

$\mathrm{E}_{\mathrm{tm}}(\mathrm{k})$

$\mathrm{E}_{\mathrm{S}}(\mathrm{k})$

$\mathrm{E}(\mathrm{k})$

$\theta_{t}$

$\theta$

$\psi$

$\psi_{\mathrm{a}}(\mathrm{k})$

$\mathrm{m}$

S
Number of slots per pole pair

Number of pole pairs

Length of the airgap excluding the magnet (m)

Thickness of the magnet ( $\mathrm{m}$ )

Length of airgap including the magnet $(\mathrm{m})$

Remanence of the permanent magnet $(\mathrm{T})$

coercivity of the permanent magnet $(\mathrm{A} / \mathrm{m})$

Field strength of air $(\mathrm{A} / \mathrm{m})$

Field strength of magnet $(\mathrm{A} / \mathrm{m})$

Flux density ( $\mathrm{T}$ )

Area of cross section $\left(\mathrm{m}^{2}\right)$

Mean radius of the machine ( $\mathrm{m}$ )

Stack length in (m)

Torque $(\mathrm{Nm})$

Tooth number

Harmonic number

Votage (V)

Current (A)

Current in ' $k$ ' th slot

DFT of $i(k)$

Flux crossing the ' $k$ ' th tooth $(\mathrm{Wb})$

Flux density under tooth ' $k$ ' $(\mathrm{T})$

Energy in airgap under tooth ' $k$ ' $(J)$

Energy in magnet under tooth ' $k$ ' $(J)$

Energy in the magnet opposite to the slot ' $k$ ' (J)

Total energy under tooth ' $\mathrm{k}$ ' $(\mathrm{J})$

Mean tooth pitch ( elecrical radians)

Angle around the machine (electrical radians)

Three valued function $(1,0,-1)$ which indicates the magnet's

polarity

Average value of $\psi$ over tooth ' $\mathrm{k}$ '

Number of phases

Pitch of the coil expressed in terms of number of slots

Current space phasor in the complex plane 
$\varepsilon$

Angle which defines the position of rotor with respect to stator (mechanical radians)

$\lambda \quad$ Flux linkage (Ampere Turns)

$\mu_{0} \quad$ Permeability of free space 


\begin{abstract}
The intention of this project is to design, build, analyse and test a novel form of servo motor. Axial flux permanent magnet machines are highly suitable for servo motors because of their very high torque to inertia ratio. These machine have axial flux geometry. That is, the rotor and stators are formed as discs rather than drums as is the case for conventional machines. This project deals with the development and analysis of a high performance axial flux permanent magnet servo motor using Neodymium-Iron-Boron permanent magnets.

Special problems which arise due to the geometry and high pole number of the new machine have been analysed with new mathematical models developed in this project. It was found that the computer simulation of these mathematical models solve the three dimensional field problems involved in the machine analysis without necessitating the use of any commercially available package. The analysis is found to give satisfactory results and it was also found that the new machine significantly outperforms the best servo motors currently available on the market in terms of acceleration and available torque per unit weight.
\end{abstract}




\section{CHAPTER 1}

\section{INTRODUCTION}

\subsection{Electric Machines}

Electrical machines in general are energy converters. Electrical energy is converted into mechanical energy in motors, whereas mechanical energy is converted into electrical energy in generators. "Electric motors and generators of all kinds may be classed as electromechanical energy converters. Such devices embody three essential parts: (1) an electric system, (2) a mechanical system, and (3) a coupling field " [1]. One way to classify electric motors is by the source of its coupling field. The coupling field can be produced either by current carrying conductors or by permanent magnets. Those machines with permanent magnets as a source for producing the coupling field are called permanent magnet machines.

\subsection{Permanent Magnet Machines}

Permanent magnet machines use permanent magnets as a source of flux. Direct current machines have permanent magnets on the stator, and alternating current machines have permanent magnets on the rotor. Depending on how the magnets are fixed in the machine, the ac permanent magnet machines are called either permanent magnet machines with buried magnets or permanent magnet machines with surface mounted magnets. Figures 1.1 (a) and (b) show the arrangement of magnets for a buried magnet machine and surface mounted magnet machine respectively.

The Figure1.1(a) shows that buried magnet machines, as their name indicates, have their rotor magnet buried in an iron core. Their direct and quadrature axis reactances are different, since the presence of magnets inside the rotor iron in one of the axes changes the reluctances. Figure 1.1(b) shows that the magnets are mounted on the surface of a core in the case of surface mounted magnet machines. Their direct and quadrature axis reactances are the same, provided that the rotor magnet used has the same permeability as air. It is also possible to make surface mounted magnet machines with different direct and quadrature axis reactances as shown in Figure 1.2, though this type of construction is unusual. 


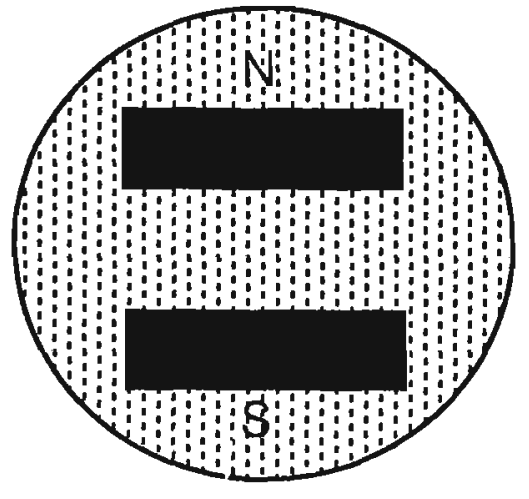

(a)

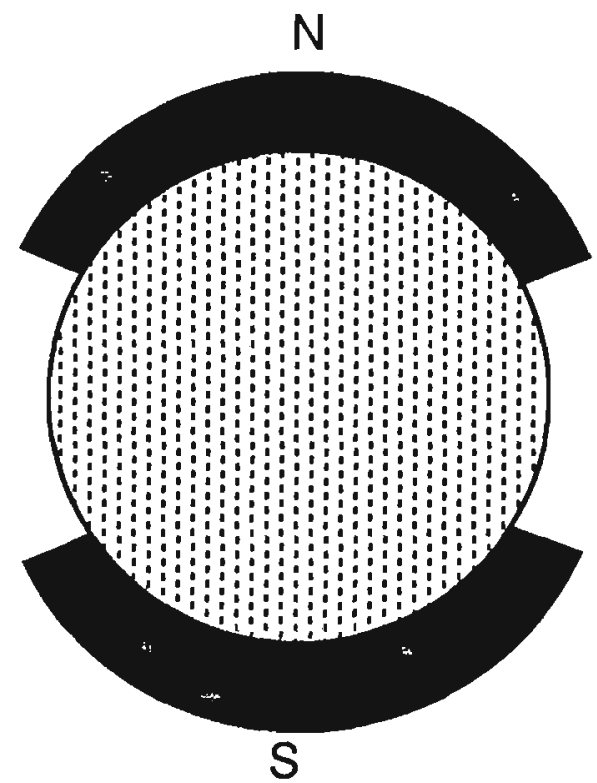

(b)

Permanent magnet

Figure 1.1 (a) Rotor of a two pole permanent magnet machine with buried magnets

(b) Rotor of a two pole permanent magnet machine with surface mounted magnets
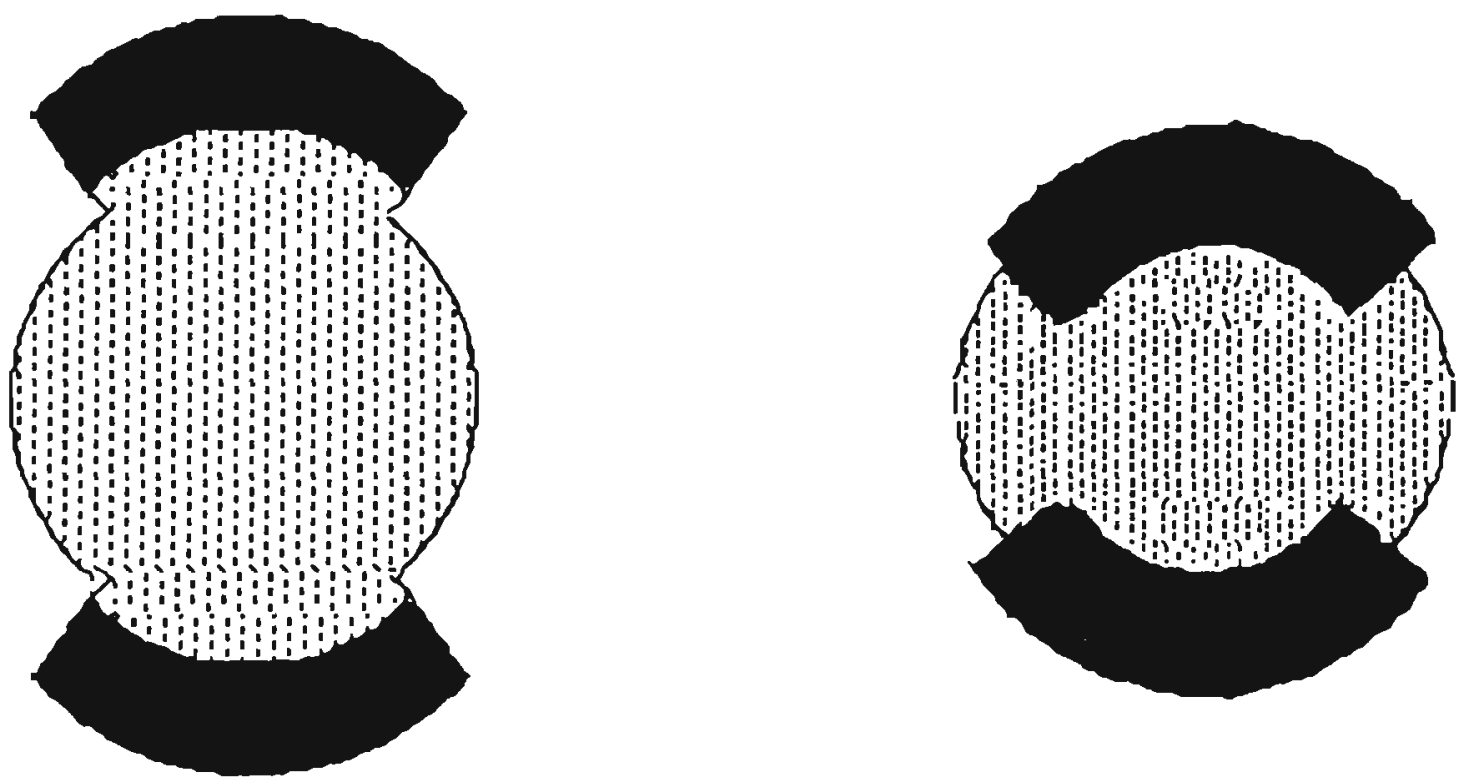

Figure 1.2 Rotor of a surface mounted magnet machines with different direct and quadrature axis reactances 
These machines can be further classified into axial and radial flux machines depending on whether the flux crosses the airgap in the axial or radial direction in the machine. Figure 1.3 (a) shows a radial flux machine. In this machine, flux from the north pole crosses the airgap radially to reach the stator, goes around the stator circumferentially, and then crosses the airgap again radially to reach the south pole and completes the path as shown in the figure. Figure 1.3 (b) shows a schematic representation of an axial flux machine .

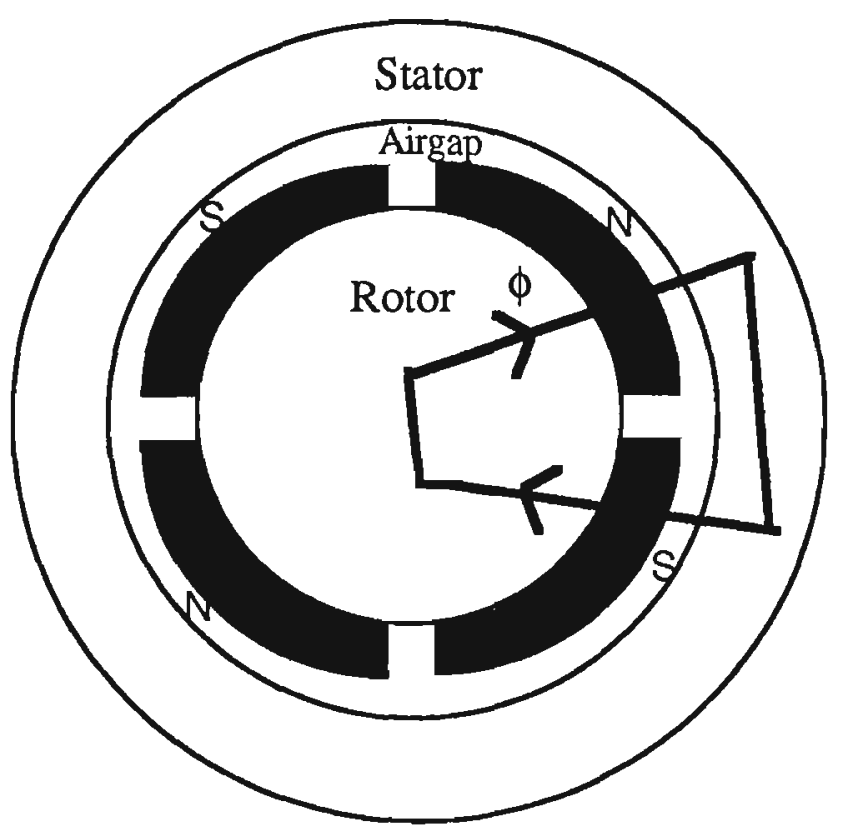

(a)

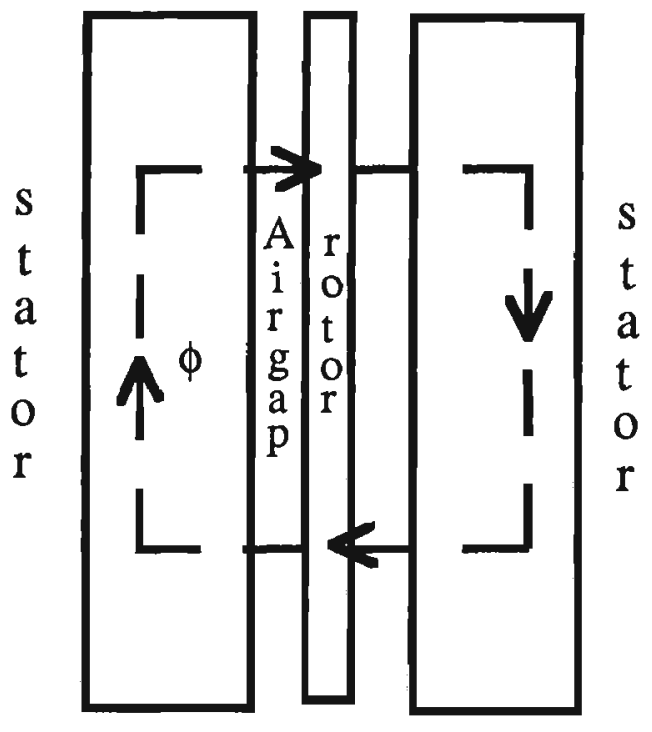

(b)

Figure 1.3 (a) Flux path for radial flux machines

(b) Flux path for axial flux machines

Flux in an axial flux machine crosses the airgap in the axial direction. Flux from the north pole crosses the airgap in axial direction, and it enters one of the two stator cores through the stator teeth, travels circumferentialy through the stator core and leaves the core through the teeth and crosses the airgap again to reach the south pole. It then enters the other stator through the teeth and follows a similar path to complete the return path as shown in Figure 1.3 (b).

Figure 1.3 (b) shows an axial flux machine with two stators. But all axial flux machines need not necessarily have two stators. They can also have one stator, and a rotor with the back iron, for some special applications. This construction produces a strong force of attraction resulting in end thrust in the bearings. The two stator design eliminates the end thrust by balancing the forces. Our analysis here is confined to the axial flux machines with two stators. 


\subsection{Axial Flux Permanent Magnet Machines [2]}

Axial flux machines have disk shaped cores and flat (plane) airgaps. Figure 1.4 shows one of the stator cores of an axial flux permanent magnet machine. The figure shows that the stator core has two radii, an inner radius and an outer radius.

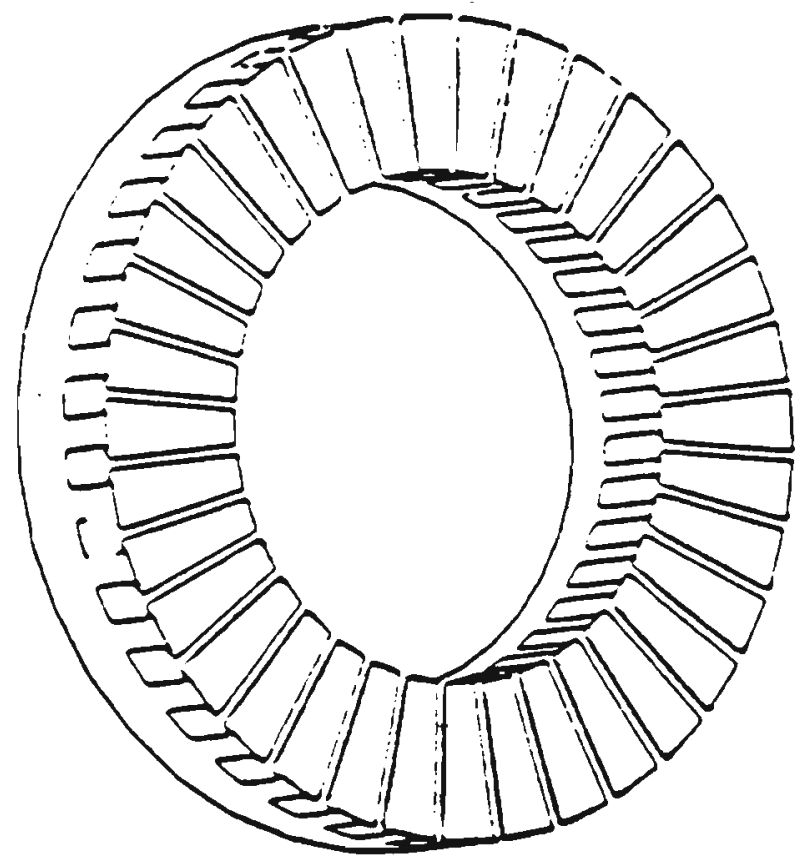

Figure 1.4

Stator core of an axial flux machine

The manufacturing process of the stator core for axial flux machine takes the following steps. A single strip of steel lamination is wound on to a circular former. Holes are then punched on them for the slots. The width of the slot is uniform throughout the radius and the sides of the slots are parallel. Therefore the distance between the slots increases with the radius of the core. Since the slot width is uniform throughout the radius, the tooth stems are very much more narrow at the inner radius of the stator core than at the outer radius.

The rotor consist of a disc mounted on a shaft. Windows are cut out of the disc to accommodate the tiles of permanent magnet. The magnets are fixed in place using epoxy and there is no back iron on the rotor. Figure 1.5 shows the rotor of a four pole machine. In the machine the rotor is sandwiched between two stators. The stator windings are located in the stator slots and run across the face of each core. Figures 1.6, 1.7 and 1.8 show photographs of the stator, the rotor and a complete axial flux machine. 


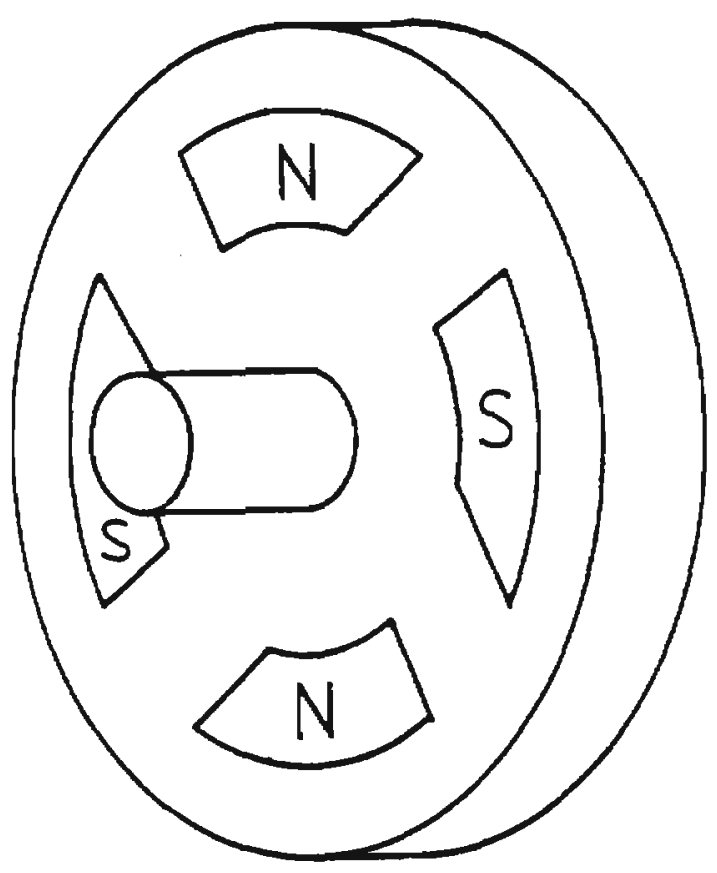

Figure 1.5

Rotor of a four pole axdal fhux machine

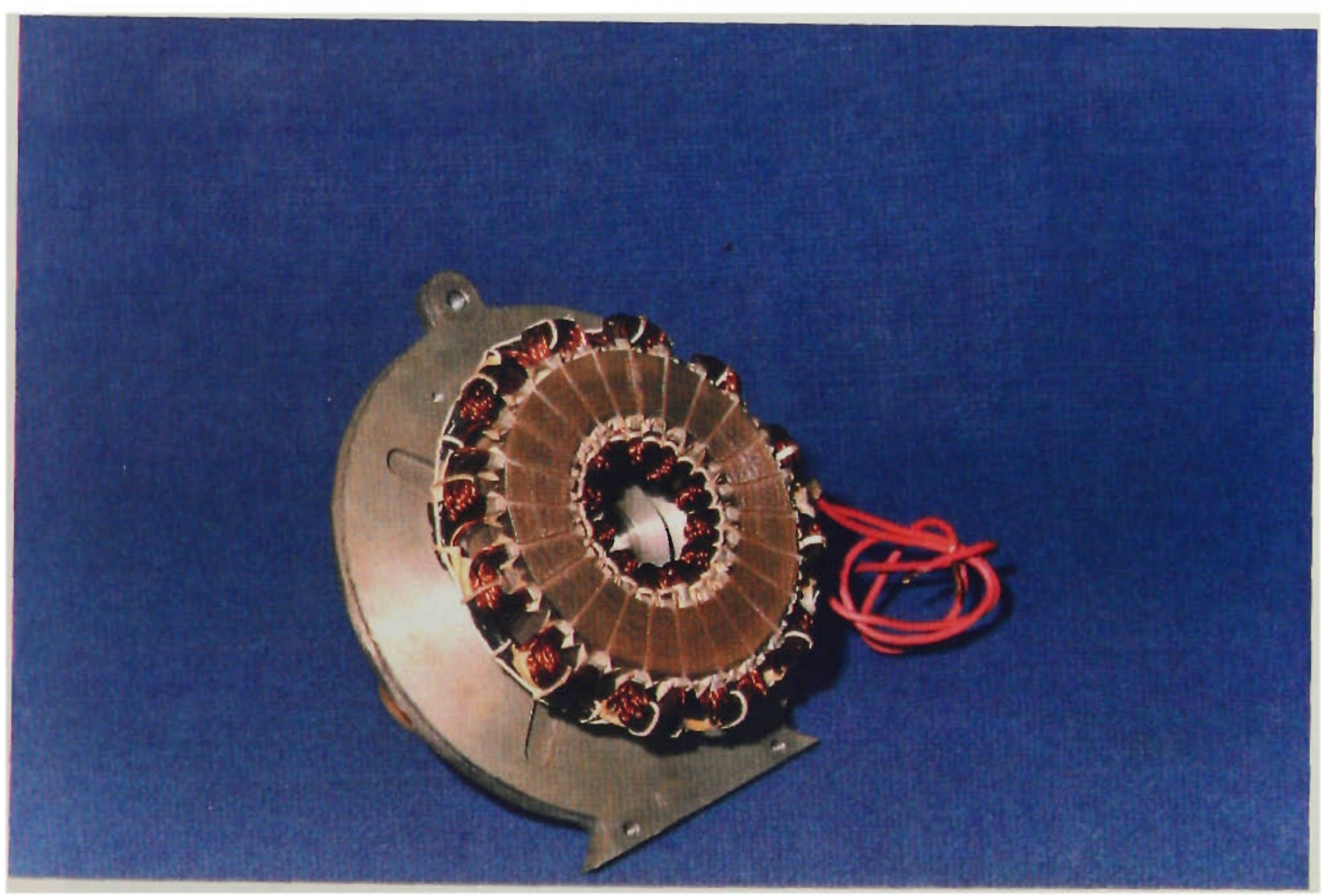



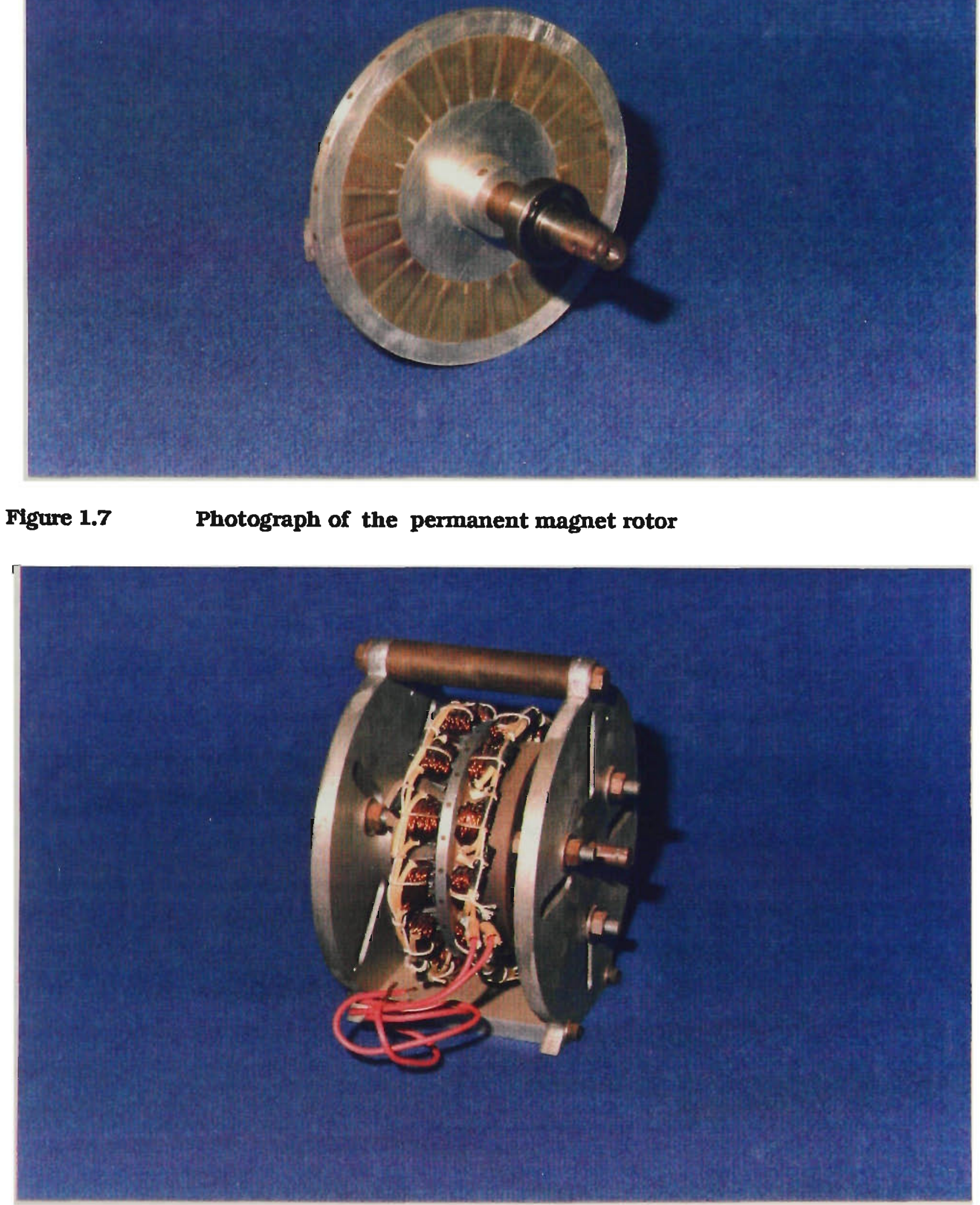
Axial flux machines can be designed for either general applications or for specific applications. In this project a servo motor is developed using the axial flux permanent magnet machine.

\subsection{Advantages of Permanent Magnet Machines}

Force on a current carrying conductor in a magnetic field is given by

$$
\mathrm{F}=\mathrm{BLI}
$$

where

$B$ is the flux density,

$\mathrm{L}$ is the length of the conductor,

and I is the current through the conductor

and $\mathrm{B}, \mathrm{I}, \mathrm{F}$ are mutually perpendicular.

Since, in a permanent magnet machine, B is set up by permanent magnets, the value of $B$ in the airgap is determined by the property of the permanent magnet material used in the machine.

Permanent magnets usually operate in the second quadrant of the B-H loop which is called the demagnetising curve of the magnet. A permanent magnet material is characterized by its remanence $\left(\mathrm{B}_{\mathrm{r}}\right)$ and the coercivity $\left(\mathrm{H}_{\mathrm{C}}\right)$ which can be directly read from the demagnetisation curve. Figure 1.9 shows the demagnetisation curve of some permanent magnets, and the Table 1.1 shows the values of $\mathrm{B}_{\mathrm{r}}$ and $\mathrm{H}_{\mathcal{C}}$ for the magnets.

Equation (1.1) suggests that the torque developed by the machine is directly proportional to the flux density in the airgap, B. B is directly proportional to the remanance of the magnet (the actual relationship between $B$ and $B_{r}$ is derived in the next chapter). Hence if a magnet material with high remanence is used then the machine will produce high torque. 


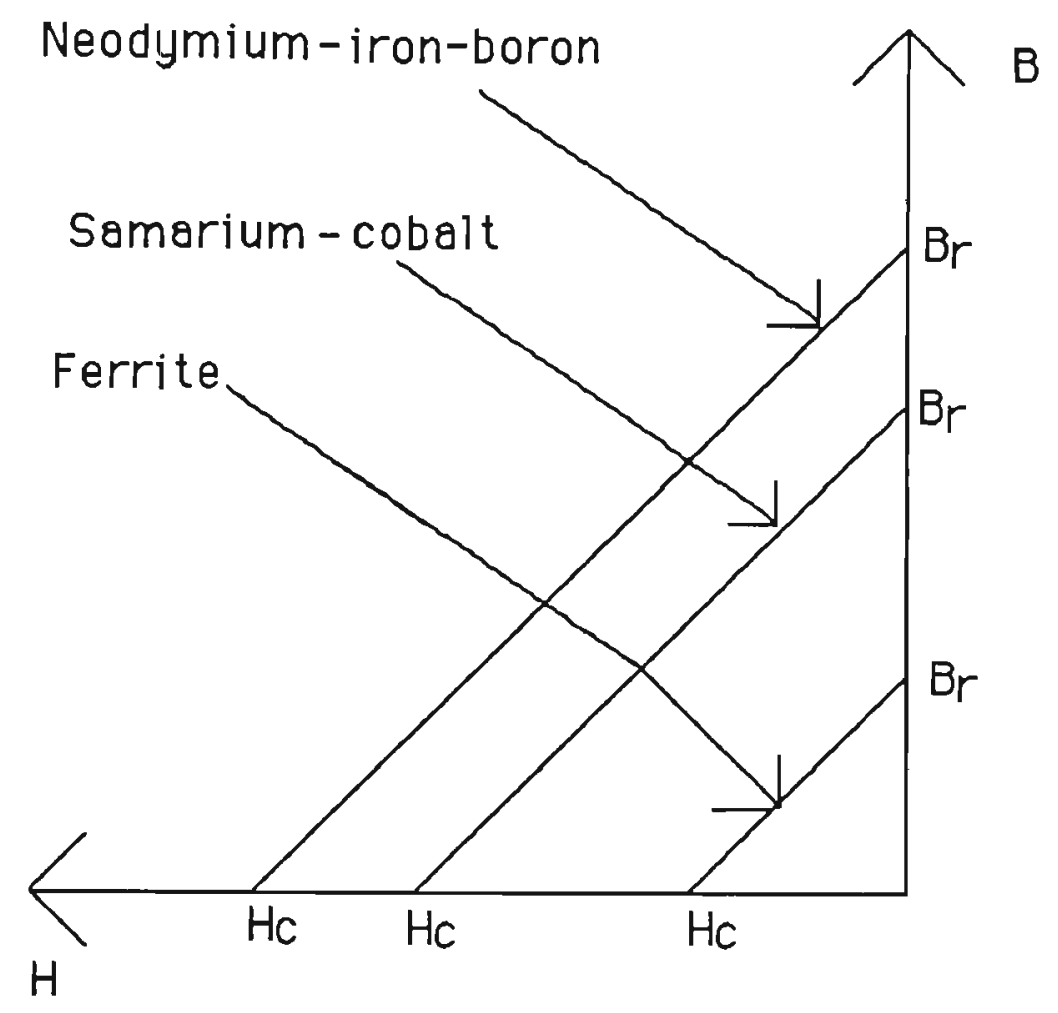

Figure 1.9 Demagnetisation curves

\begin{tabular}{|c|c|c|}
\hline PM Material & Remanence $\left(\mathrm{B}_{\mathrm{r}}\right) \mathrm{T}$ & coercivity $\left(\mathrm{H}_{\mathrm{C}}\right) \mathrm{kA} / \mathrm{m}$ \\
\hline Ferrite & 0.4 & 280 \\
\hline Sm Co & 0.9 & 720 \\
\hline $\mathrm{Nd}-\mathrm{Fe}-\mathrm{B}$ & 1.1 & 800 \\
\hline
\end{tabular}

Table 1.1 Remanence and coercivity of permanent magnet materials

The Nd-Fe-B magnets have the highest remanance amongst the permanent magnets available so far. They also have a high coercivity which means that they are less susceptible to demagnetisation when compared to other magnets. Permanent magnet machines were developed in the past using Ferrite magnets and also using more recent magnet materials. Some recent developments in permanent magnet motor technology are described below.

Hesmondhalgh and Tipping [3] describe the construction of small slotless synchronous motors using Samarium-cobalt magnets, and point out that the slotless construction is less desirable for multipole machines. Demerdash and his co-authors [4] compare the 
performance of 15 horse power Samarium-Cobalt and Ferrite based brushless dc motors. They point out that in terms of cost, the Ferrite magnets are preferable, but in terms of inertia, the Samarium-Cobalt machine will have less inertia. Demerdash and Nyamusa [5] compare the effect of overload on the performance of Samarium-Cobalt and Ferrite based machines and conclude that a machine which uses Samarium-Cobalt is better suited for high overloads because it is less susceptible to demagnetization. Sebastian and Slemon [6] analyse the the transient torque and short circuit capabilities of a surface mounted permanent magnet machine using Neodymium- Iron-Boron magnets and show that the relationship between the torque and current is linear up to the order of six times the rated current without magnet demagnetization. Slemon and Xian Liu [7] present a model of a surface mounted permanent magnet motor which uses Neodymium-Iron-Boron magnets and optimize the design for minimum total life time cost.

In conventional machines the coupling field is set up by the magnetising current. Therefore these machines have field windings, and a source, to supply the current to the windings to produce the flux in the airgap. In a permanent magnet machine, since the field is set up by permanent magnets, the field windings are absent, reducing the copper loss. So the efficiency of permanent magnet machines will be high when compared to the conventional machines of same capacity. Miyashita and his co-authors [8] describe the development of a two pole permanent magnet synchronous motor with a rated speed of 12,000 rpm. Ferrite magnets are used in the machine, and the authors claim that the efficiency of the motor is $13 \%$ higher than the conventional induction motor of the same rated output. This is a remarkable increase in efficiency considering the fact that Ferrite magnets produce weaker field, compared to recent rare earth magnets, because of its low remanence.

Computer aided design of an axial flux permanent magnet dc machine is described by Campbell and his co-authors [9]. The authors use a computer design to develop an electric wheelchair drive motor using $\mathrm{SmCo}_{5}$ magnets. Krishnan and Beutler [10] compare the radial and axial flux machines of different types and discuss the suitability of axial flux permanent magnet machine for servo drives. Platt [2] describes an axial flux permanent magnet synchronous motor and analyses the machine based on the travelling wave model of an electric motor. Takano and his co-authors [11] suggest an optimum magnet to armature winding thickness ratio of $2: 1$, to minimize the armature copper loss for axial flux permanent magnet brushless dc motors whose starting torque is fixed. They confine their analysis to the magnets with linear demagnetisation curve. Jensen and his co-authors [12] describe a low-loss axial flux permanent magnet dc 
brushless motor using tape wound Amorphous Iron and suggest that this type of machine could be more efficient than induction machines.

\subsection{Disadvantages of Permanent Magnet Machines}

1. High capital cost. For machines of high rating, the cost of the rotor magnets can be very high, making the overall capital cost of the machine high.

2. Demagnetisation of magnets. Armature reaction may partially demagnetise the rotor magnets under heavy stator current. As the stator current increases, the flux produced by the armature current increases. This flux can weaken the flux produced by the magnet. If the stator current is very high it could partially demagnetise the rotor magnets. The magnets would then have to be re-magnetised for the motor to perform to specifications.

\subsection{Servo Motor}

A servo system moves a mass from one position to another as quickly as possible. Examples of servo system applications are found in robotics, machine tools, specialised automatic equipment, aerospace, defence etc. Servo motors require very high short term torque and should be able to accelerate and decelerate very quickly. In other words, a servo motor should be able to produce high torque and its inertia must be low [13].

High torque and low inertia are conflicting requirements, since the torque as well as the moment of inertia increase with the radius of the machine. The most usual type of servo drives are high speed servo drives with gear box with a low gearing ratio. The inertia of the load is transfered to the motor side by the gear box through the square of the gearing ratio. Under these conditions, the moment of inertia of the rotor dominates the load and maximum performance is achieved by a machine with the highest possible torque/inertia ratio. Inertia is more sensitive to radius than the torque since it is approximately proportional to the fourth power of radius. Therefore to keep the inertia low, the radius of the machine has to be kept low. To compensate for the reduction in 
torque due to reduced radius, high performance machines will have long rotors, resulting in a long thin rotor.

Axial flux permanent magnet machines with two stators may be built with low inertia since they do not have iron in the rotor. If a magnet with high remanence is used, an axial flux machine will have high torque to inertia ratio. Viarouge and his co-authors [14] describe the design and construction of a brushless permanent magnet servomotor for direct drive application using Ferrite as the permanent magnet. They claim that for a torque of about $495 \mathrm{Nm}$ it is economical to use Ferrite permanent magnet material. Younkin and his co-authors [15] investigate the issues involved in applying low inertia servo motors for machine tool axis drives and identify three control alternatives for low inertia drives. Pillay and Krishnan [16] discuss the application characteristics of permanent magnet synchronous and brushless dc motors for servo drives. They base their discussion on many different criteria such as power density, torque per unit current, speed range, feedback devices etc. Slemon [17] derives general expressions to determine the major motor dimensions for specific design consideration, for a surface mounted permanent magnet radial flux motor, used for servo applications.

\subsection{The New Servo Motor [18]}

An axial flux machine may have low inertia since it has no back iron in the rotor. This is a desirable property which makes it highly suitable for servo drives [13]. This project considers a thin disc rotor design for very low inertia servo motor using axial flux machines, and suggests novel design features, which allows it to produce significantly higher performance than has been possible in the past. The permanent magnet material used in the machine is Neodymium-Iron-Boron, making it possible to achieve reasonably high levels of airgap flux density and therefore high torque.

\subsection{Design Features}

1. Low radius. The moment of inertia is proportional to the fourth power of the radius. Hence to keep the moment of inertia of the machine low, the radius is kept as low as possible. 
2. High pole number. Using equation (1.1) the torque produced by a machine with radius $R$ can be written as

Torque $=2 \mathrm{RBIL}$

Equation (1.2) shows the reduction in radius will reduce the torque, if it is not compensated by some other means. The flux density B in Equation (1.2) for a permanent magnet machine, is fixed by the property of the permanent magnet and the $\mathrm{B}-\mathrm{H}$ loop of the stator iron. Once the radius is fixed, the only other two variables remaining in the torque equation are, the current and length of the conductor. Increasing the active length of the conductor in an axial flux machine to increase the torque means increasing the radius of the machine, since the active length of the stator conductor is the difference between the inner and outer radii of the machine. Thus an increase in active length, will increase the inertia of the machine.

The other way to increase the torque is to operate the motor at high stator current. Since the mmf is directly proportional to the current, high stator current produces a high value of mmf contribution from each stator slot leading to a high peak mmf. Permanent magnets in the rotor are susceptible to demagnetisation, and a high peak $\mathrm{mmf}$ could demagnetise the magnets. The level of mmf the rotor magnets can sustain without demagnetising is directly proportional to the thickness of the magnets. If the thickness of the magnet is increased to enable high stator current operation, the inertia will increase, leading to reduced torque to inertia ratio. The situation can be improved by recognising that the peak mmf produced by the stator winding is inversely proportional to the number of poles in the winding. If the number of poles is increased the peak mmf will come down, for the same stator current. Therefore the peak mmf and necessary magnet thickness can both be reduced while maintaining the same peak torque, by simply increasing the number of poles in the winding.

3. One slot per pole per phase. With any given radius, the upper limit on the number of slots is set by the mechanical strength of the tooth stem. Because of the peculiar geometry of the axial flux machine the machine has two radii, an inner radius and an outer radius. Since the slot width is uniform throughout the radius, the width of tooth stem decreases with the radius and is narrowest at the inner radius. Figures 1.10 (a) and (b) show how the tooth shape looks at the inner and outer radii of the machine respectively, though the exact width of the tooth stem depends on the values of the radii of the machine. 

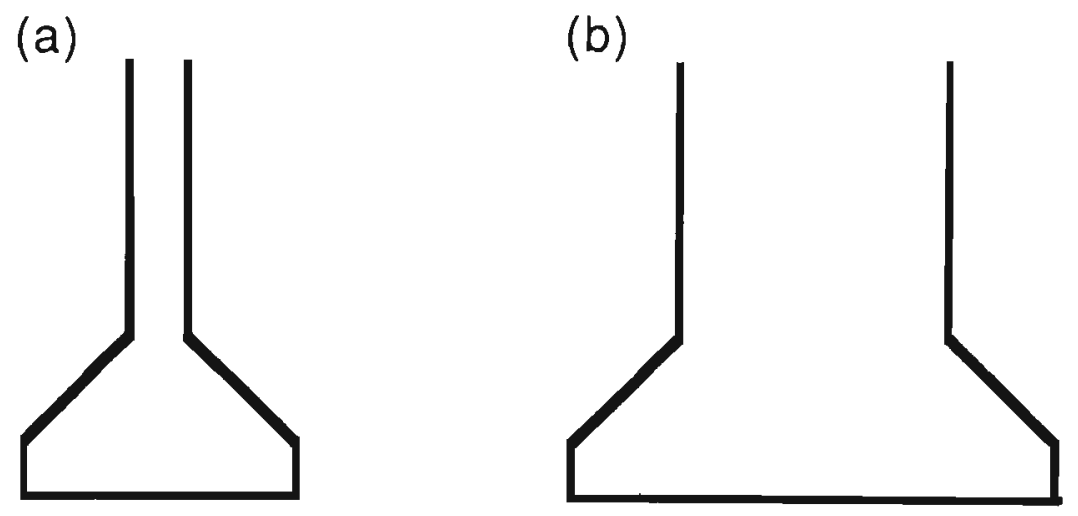

Figure 1.10

(a) Tooth shape at inner radius

(b) Tooth shape at outer radius

Thus the machine inner radius together with the slot width determines the narrowest width of the tooth stem, which applies an upper limit on the number of slots in the machine. To achieve a high number of poles, the number of slots per pole per phase should be as small as possible, that is, one.

4. One phase winding on each stator. Because of the need for high current loadings, it is usual for servo motors to have relatively deep stator slots. With a high number of poles the pole pitch is very short and a problem arises that there is not enough room for the end turns from one phase to be taken past the end turns of the other phase(s) and back into the correct slots. This situation can be improved either by having reduced number of poles, or by choosing some other way of arranging the different phases of the winding. As mentioned before, the higher the number of poles, the better it is for the servo motor. Therefore the reduction of the number of poles is not a good solution. On the other hand, since the axial flux machine has two stators, one phase can be wound in each stator, resulting in a two phase machine. Then the end winding from one phase does not interfere with the other phase at all and the end turns can be arranged in a very compact form (Figure 1.11). This allows the inner radius of the stators to be little more than the radius of the shaft of the motor. This technique constitutes an inherent advantage for the "thin disc" machine over the "long thin rotor" machine.

5. Coil form. Figure 1.12 shows the photograph of the two stator winding arrangements. Out of the two stators shown, the small stator with thinner rotor ( machine in the right) is the stator of the new machine. The shape of the phase winding of the new machine allows several advantages over the other one shown in Figure 1.12. 

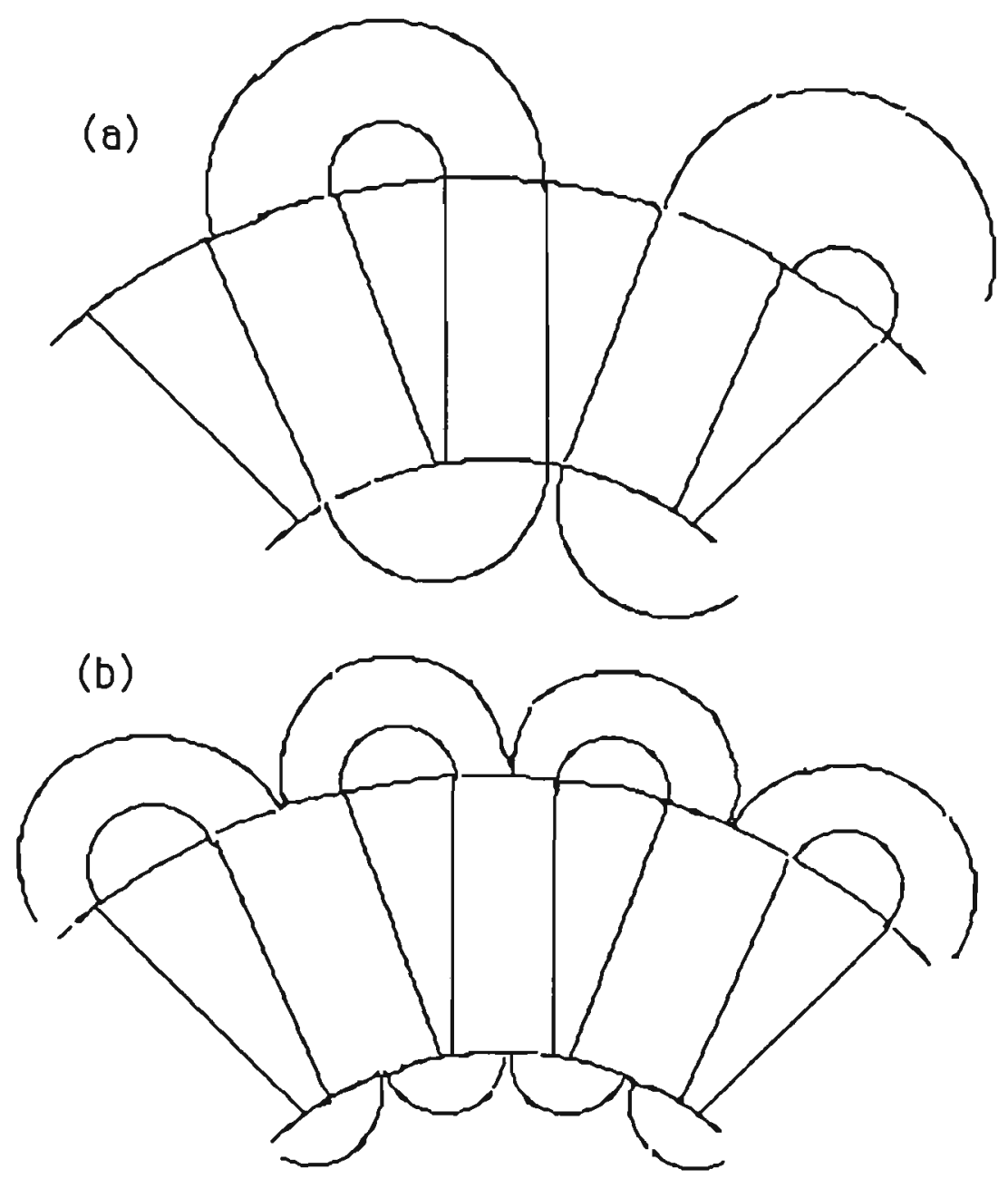

Figure 1.11 Formation of coils

(a) The conventional arrangement

(b) The new arrangement

Figure 1.12 shows that the winding of the new machine has less overhang of the end turns compared to its counterpart. So the new machine is clearly more compact. This allows the rotor to be built closer to the shaft, giving reduced moment of inertia, and also allows the enclosure of the machine to have a smaller diameter. In the new winding arrangement more surface area of the winding will be exposed for cooling and must therefore permit a higher continuous current rating.

The current response of the machine depends on the inductance of the machine. Servo motors require very fast current response since they have to accelerate and decelerate very quickly. In the new winding arrangement the original coils shown in Figure 1.11(a) are split into 2 parts and connected in series as shown in Figure 1.11(b). The end turn inductance of a coil is proportional to the square of the number of turns. Therefore if the coils of the conventional winding arrangement have $2 \mathrm{~T}$ turns, the end turn inductance of the conventional winding will be proportional to $4 \mathrm{~T}^{2}$, whereas the 
inductance of the windings of the new machine will be proportional to $2 \mathrm{~T}^{2}$. Thus the end turn inductance of the new machine windings will be only half of the end turn inductance of its counterpart.

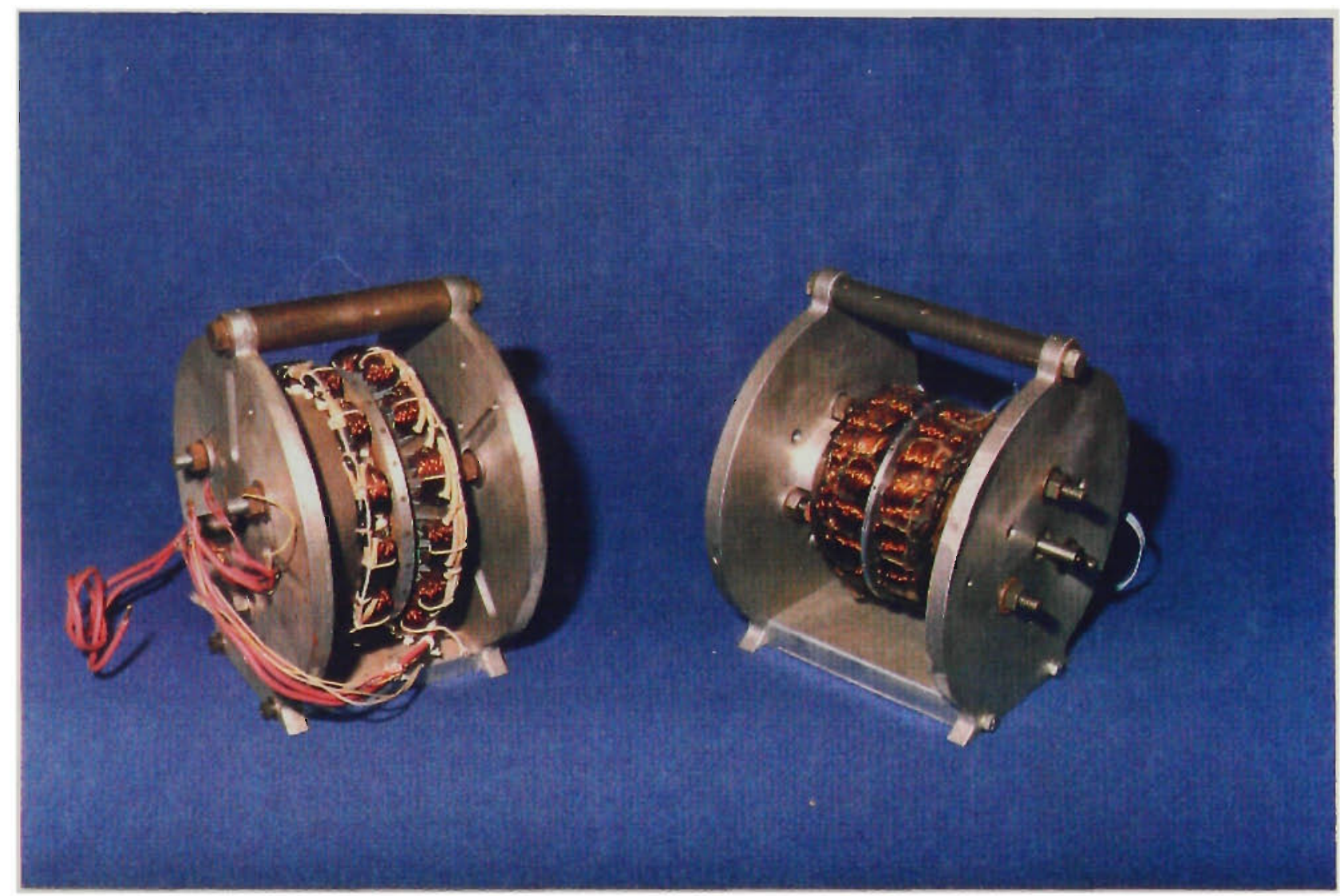

Figure 1.12 Photograph of the winding arrangement

The new machine incorporates all the design features described above. The machine has an inner radius of $24 \mathrm{~mm}$ and an outer radius of $51 \mathrm{~mm}$. There are sixteen slots in each stator. Figure 1.13 shows a photograph of the rotor of the machine.

The rotor is a thin disc with a thickness of $3.4 \mathrm{~mm}$. It has sixteen poles and the rotor magnets are skewed to reduce cogging. The moment of inertia of the rotor has been calculated to be $261 \times 10^{-6} \mathrm{~kg} \mathrm{~m}^{2}$ (the calculation is presented in Appendix 1). The peak torque produced by this machine is found to be $18 \mathrm{Nm}$. The acceleration available from this machine is the peak torque divided by the moment of inertia, which is approximately $70,000 \mathrm{rad} \mathrm{sec}^{-2}$. This may be compared with $37,500 \mathrm{rad} \mathrm{sec}^{-2}$ for a conventional high performance servo motor rated for the same peak torque [19]. This is a very considerable increase in performance. Figure 1.14 shows a photograph of the complete machine. 


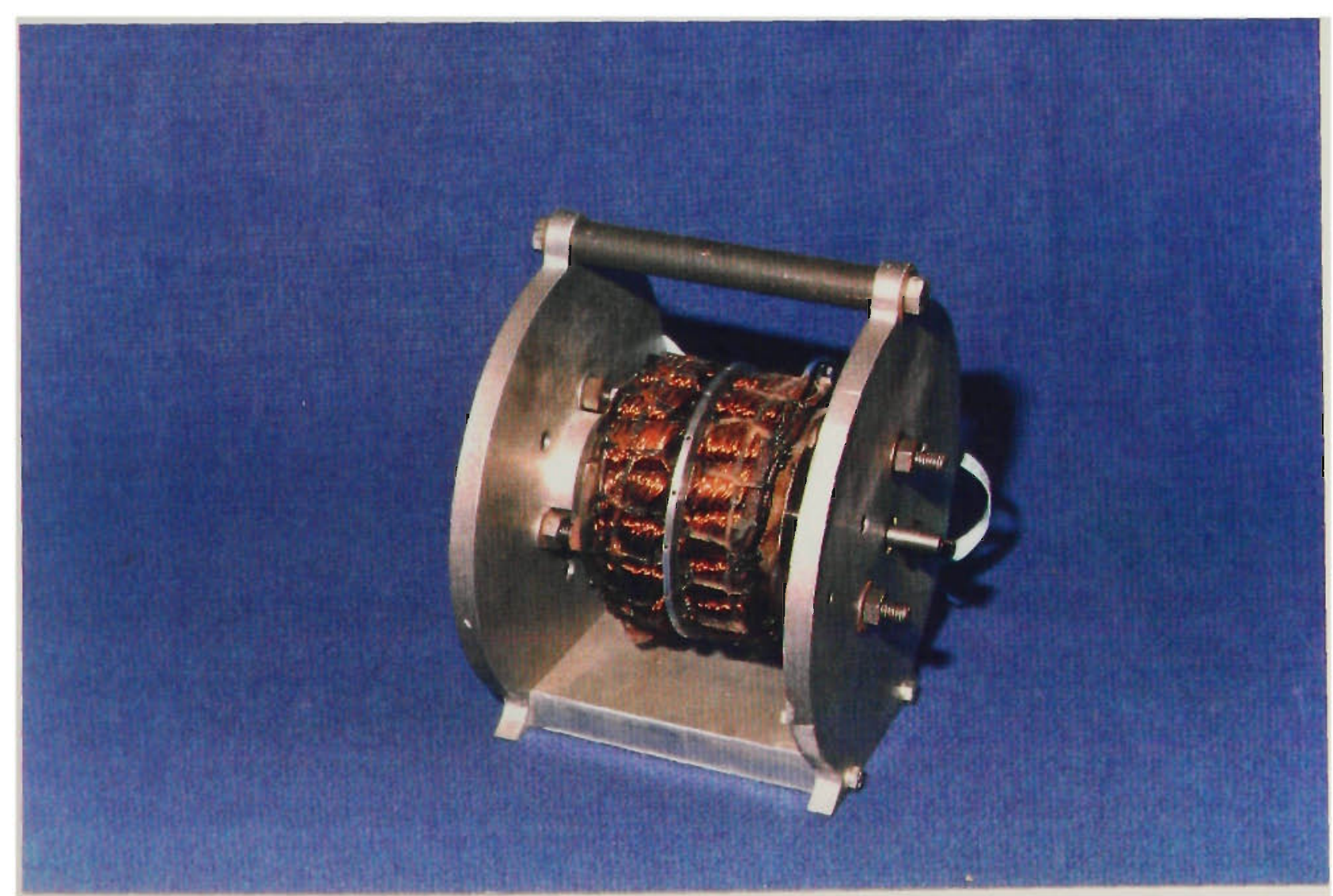

Figure 1.14 Photograph of the the new servo motor 
The machine has two phases with one phase on each stator. To give a space shift of 90 degrees between the phases of the two phase windings, one stator of the machine is shifted by half a slot pitch with respect to the other stator. So in the machine, the two stator teeth will not directly face each other, instead a slot of one stator will be facing the centre of a tooth on the other stator. Figure 1.15 shows the developed layout of the new servo motor.

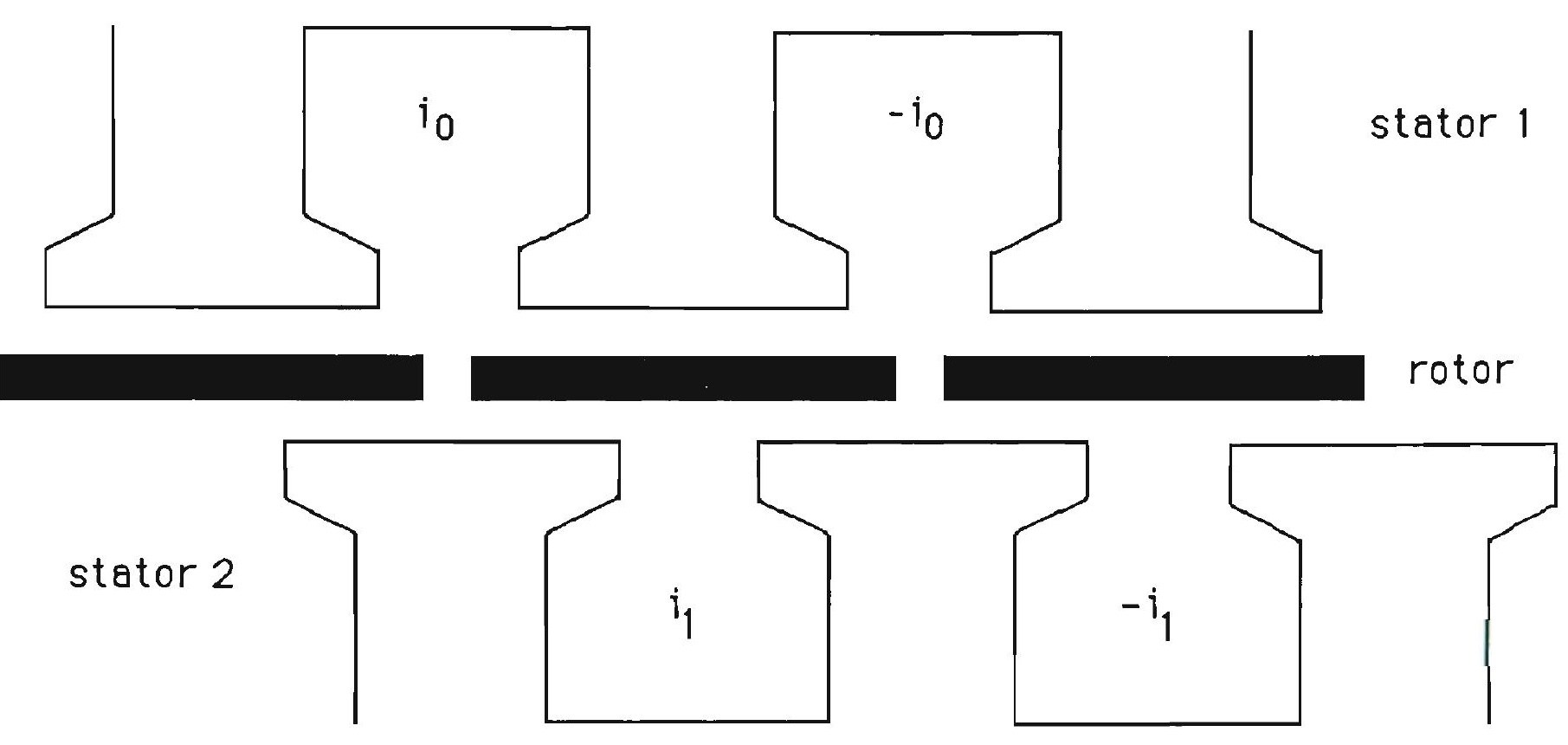

Figure 1.15 The developed layout of the new axial flux servo motor

\subsection{Disadvantages of the New Design}

Owing to the peculiarities of the design, it has a number of disadvantages of which other machines are free. They are mostly as a result of the very low number of slots per pole.

1. Skewing. Permanent magnet machines in general have cogging torque. This arises due to the interaction of rotor magnets with the stator teeth. Permanent magnet motors with a high number of poles tend to have more cogging torque. This is an undesirable torque and should be reduced by proper design.

In order to minimise cogging torque, permanent magnet and other machines are customarily skewed by one slot pitch to spread the magnet over the slot as well as the tooth. Since the slot pitch is $2 \pi / \mathrm{N}$ electrical radians where $\mathrm{N}$ is the number of slots per pole pair, in machines with a large number of slots per pole, the skewing angle is less 
compared to machines with a small number of slots per pole. If $\gamma$ is the skew angle in electrical radians, the useful torque is multiplied by a factor of $2 \sin (\gamma / 2) / \gamma$ due to skewing. A conventional value of $\gamma$ may be $\pi / 9\left(20^{\circ}\right)$ giving a multiplying factor of 0.995 . The useful torque is multiplied by this factor and therefore it is reduced.

In the case of the new machine, as the teeth of the stator cores are not directly facing each other, the slot pitch, which is the angle between the edge of one tooth and the adjacent tooth becomes $90^{\circ}$ (since there is a slot in the second stator), instead of the normal $180^{\circ}$ which would be the case when the slots are directly opposite to each other. Hence for the new machine a skew of $90^{\circ}$ electrical is required. If $\gamma$ is $\pi / 2\left(90^{\circ}\right)$, as required in the new design, the multiplying factor becomes 0.900 . That is, torque is reduced by $10 \%$ by the effect of skewing in the new machine. The effect of skewing of rotor magnets is discussed by Alhamadi and Demerdash[20]. They use the finite element technique for analysis.

2 Q-axis flux. Permanent magnet servo motors are operated so that all current is load current, or q-axis current. The flux set up in the machine by the stator current is therefore in the q-axis (Figure 1.16). This is comprised of leakage flux and q-axis magnetising flux. In a conventional machine, there are enough teeth in one pole pitch for this flux to add to the d-axis flux in vector fashion, at $90^{\circ}$. If the fluxes in the two axes are represented by $\phi_{\mathrm{d}}$ and $\phi_{\mathrm{q}}$, the total flux is $\sqrt{\phi_{\mathrm{d}}^{2}+\phi_{\mathrm{q}}^{2}}$ and this is the flux which must be carried by the stator teeth and back iron.

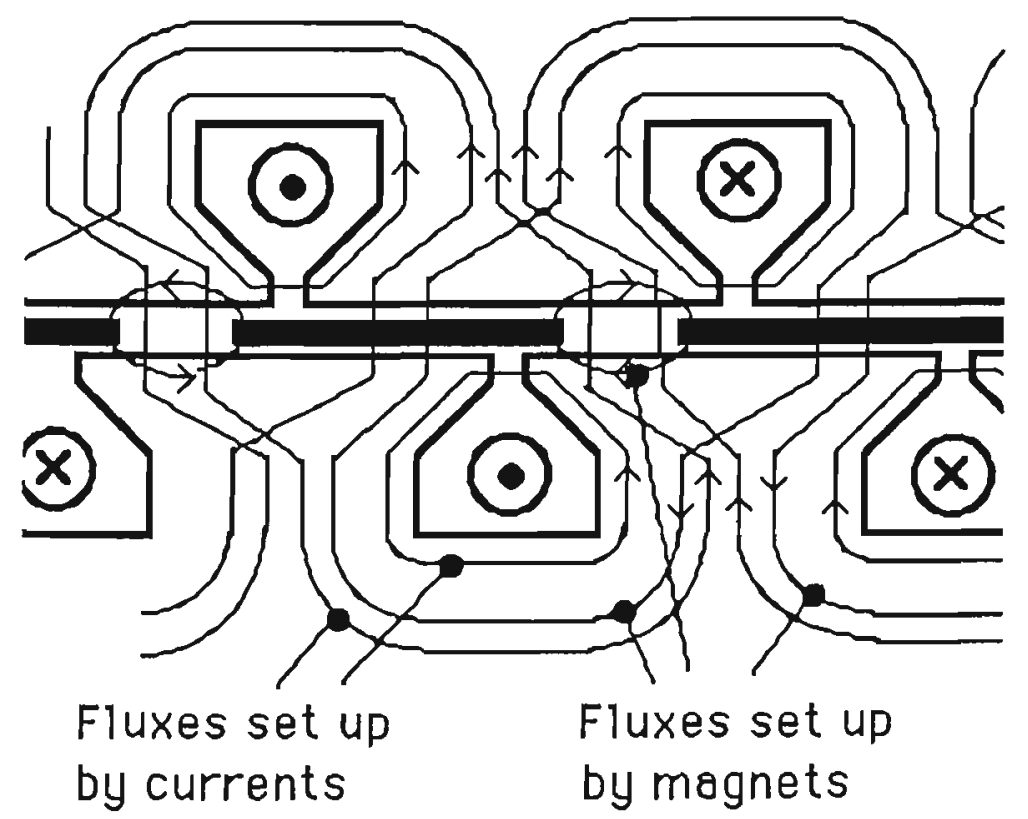

Figure 1.16 Load currents equally shared between two phases 
The new machine is illustrated in Figure 1.16 at the point where both phases are carrying the same current. Skewing of the rotor has been ignored.

Since the number of slots per pole per phase is one, the adjacent slots carry the phase current in opposite directions. The fluxes produced by these currents are shown in the Figure 1.16. The fluxes set up by the magnets are indicated separately. It can be seen that the tooth stems in the upper stator carry the sum of the fluxes whereas the tooth stems in the lower stator carry the difference between them. That is, because of the very discrete nature of the magnetic circuit, the fluxes add in an algebraic fashion.

In addition, it can be seen that fluxes also add in algebraic fashion in the tooth tips, so that one tip of each tooth in the upper stator may become heavily saturated, whereas the other tip is relatively lightly fluxed.

\section{Flux set up by currents}

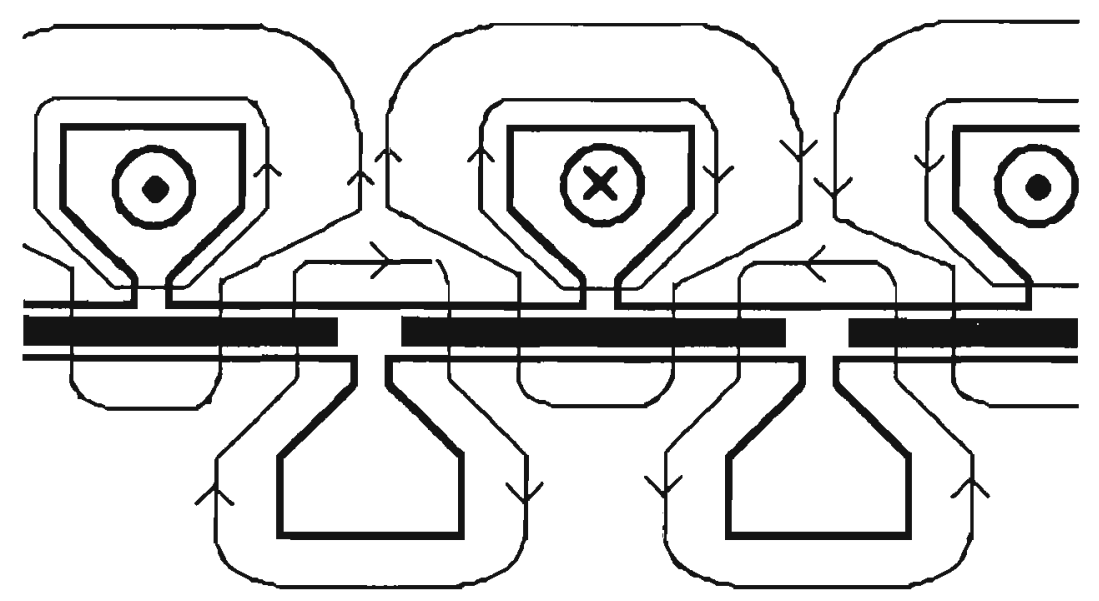

Flux set up by magnets

\section{Fig. 1.17 Load current in one phase only}

Figure 1.17 illustrates the machine with the rotor moved $90^{\circ}$ from the rotor position of Figure 1.16, and the current carried in one phase only. In this situation, with the same current space phasor, the current in the upper stator is $\sqrt{2}$ times the currents indicated Figure 1.16. The significant magnetic stresses again occur in the upper stator. The leakage flux is increased because of the greater phase current but the magnetising current is decreased because, now, the algebraic sum of the two phase currents is reduced. The tooth stems will not experience heavy saturation, but one tip of each tooth in the upper stator will be heavily saturated since it carries flux due to the magnets and the stator currents, all in the same direction. In the practical case, the rotor is skewed and therefore intermediate cases also occur. 
3 Two phase winding. The machine must be driven by a high performance inverter and this can be achieved in two obvious ways. One way is to use two separate single phase drives, incorporating a total of eight power switches. The other is to connect the two phases together at one terminal and use a six switch inverter, with one pair of switches rated for $\sqrt{2}$ times the current of the others. These possibilities are illustrated in Figure 1.18

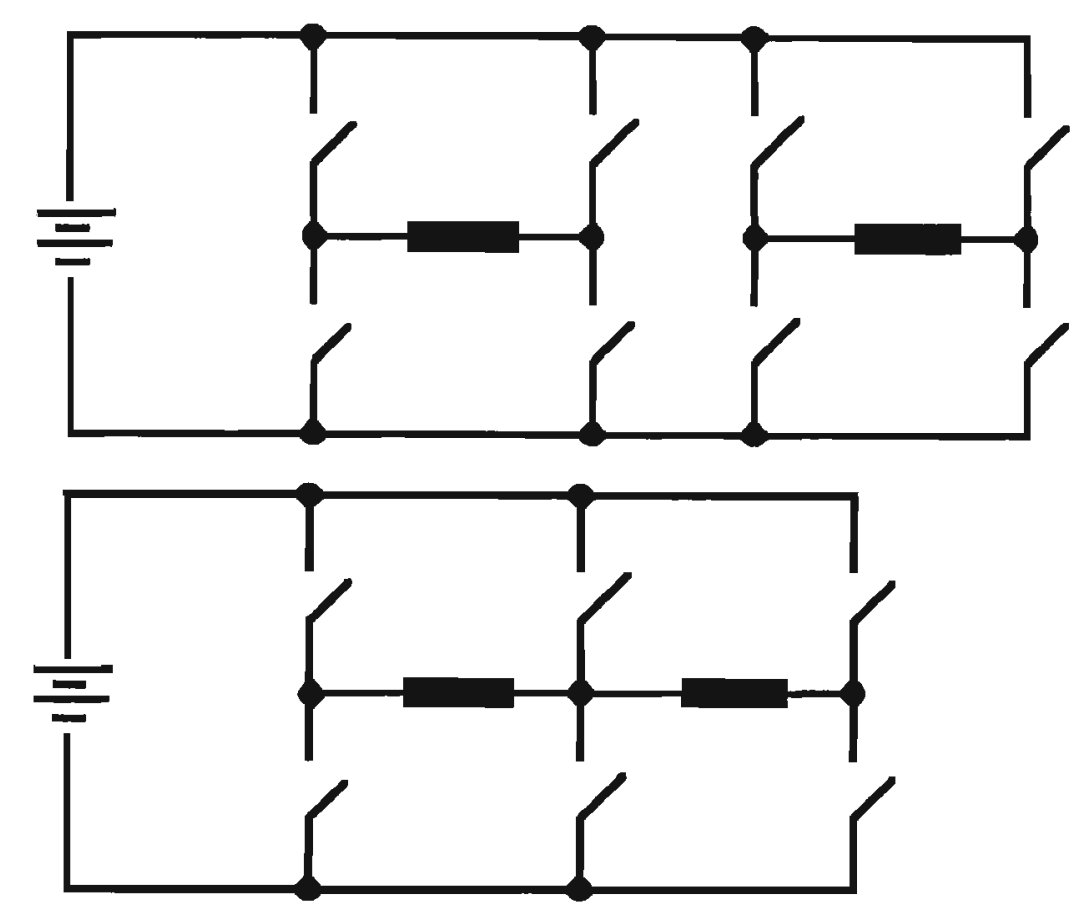

\section{Figure 1.18 Drive circuits for two-phase motor}

The voltage space phasors which these circuits make available to drive the motor are illustrated in Figure 1.19. The phasors missing from the second case are the result of the inability of the common point to be connected to the positive and negative rails at the same time.
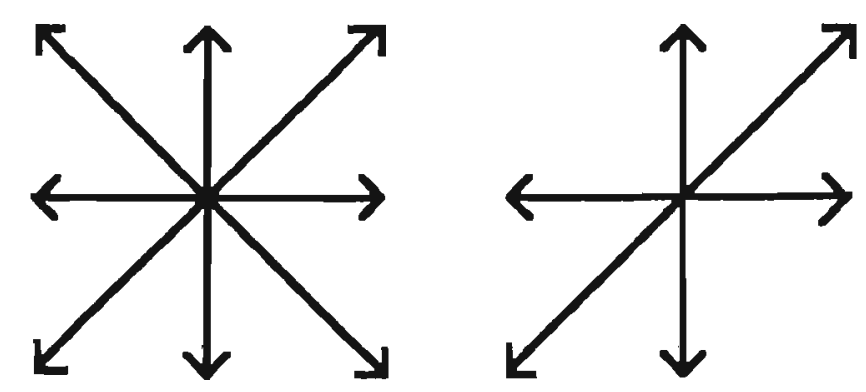

Figure 1.19 Voltage space phasors for two phase inverters

It seems clear that either of these configurations are less desirable than the conventional three phase inverter. 


\subsection{Analytical Problems}

The following analytical problems arise in the new servo motor.

1. The high pole number leads to a discrete winding. Therefore one would not be confident to apply the conventional ideal sinusoidal winding analysis to this machine.

2. Permanent magnet machines tend to have cogging torque. It is important that servo motors used for position control have low cogging since cogging torque affects the performance especially at low speeds.

3. Because of the the geometry of the axial flux machine, the tooth stem at the inner radius will be more saturated than the outer stem. At the inner radius the stems of the teeth become quite narrow, and if airgap flux density is uniform, then the tooth stem at the inner radius can become heavily saturated. Also, when heavy load current is drawn by the motor, the main airgap flux combined with the tooth tip leakage flux can saturate the tooth tip heavily and reduce the peak torque.

All the above problems make the prediction of the performance of the machine difficult. Permanent magnet machines in general, have been analysed using different approaches in the past. Honsinger [21] predicts the performance of permanent magnet machines using a phasor diagram and the concept of machine admittance. Demerdash and Nehl [22] present a transient model for simulation of the instantaneous performance of a power conditioner fed Samarium-Cobalt permanent magnet brushless dc machine. Rahman and Little [23] predict the transient performance of a permanent magnet synchronous machine by numerical solution of the machine dynamic equations. The effect of saturation is included in their analysis. Hesmondhalgh and Tipping [3] predict the maximum torque per unit length for a small synchronous motor from the solution of Laplace's equation. The same authors [24] later predict the peak torque by integrating the product of flux density and stator current density waves. Sebastian, Slemon and Rahman [25] used an equivalent circuit to model a surface mounted, and a buried permanent magnet motor. Sebastian and Slemon [26] later modelled the transient behaviour and performance of a variable speed surface mounted permanent magnet motor using a d-q equivalent circuit. De La Ree and Boules [27] predict cogging and useful torque using the flux density distribution and the change of energy in the airgap.

To predict the performance of the new machine, two mathematical models are developed in this project. Firstly, a linear model which takes into account the discrete nature of the machine has been developed using the Discrete Fourier Transform to 
handle the first analytical problem mentioned. It succeeds in predicting the behaviour of the machine when the currents are relatively low.

The effect of skew on cogging torque for a brushless permanent magnet dc machine was dicussed by Kwang-Heon Kim and his co-authors [28]. The effect of cogging on permanent magnet machines and its elimination by proper choice of machine dimensions are discussed by Li and Slemon [29], and Ackermann and his co- authors [30]. In this thesis, the cogging torques of the new machine which has a skew, and a laboratory axial flux machine without a skew have been predicted using the linear model and a design criterion for alleviating the cogging has been suggested.

Platt [2] in his travelling wave model of an axial flux machine includes the effect of saturation in the tooth stem of the machine. Parasiliti and Poffet [31] discuss the effect of saturation in buried magnet synchronous motors using finite element techniques. Boules [32] provides a mathematical model which optimizes motor volume, weight, or efficiency of permanent magnet dc motors. His model uses a two-dimensional closed form solution, and takes the effect of saturation into account.

In this project, to address the problem of saturation at different radii of the axial flux machine, a second model which takes into account the saturation in the tooth stem and tooth tips of the stator at high current levels has been developed. This model succeeds in predicting the behaviour of the machine at high current levels. It was found that the computer simulation of the two mathematical models could handle the three dimensional field problems involved in the machine analysis without necessitating the use of any commercially available package to solve them. Finite element analysis is time consuming and tedious when it comes to three dimensional problems and therefore it was not used for the analysis of this machine.

\subsection{Plan of the Thesis}

Chapter 2 In this project, the torque is to be calculated using energy transfer equations. To achieve this, a knowledge of energy density in the magnet is needed. This chapter derives an expression for the energy density of the hard magnetic material and verifies it experimentally. Torque of a permanent magnet motor is derived using energy considerations and compared with the torque derived using the conventional approach. The torque is expressed in terms of current and magnet space phasors. 
Chapter 3 For highly discrete machines, ideal sinusoidal winding analysis can not be applied. This chapter develops a mathematical model for permanent magnet machines using the Discrete Fourier Transform, ignoring saturation.

Chapter 4 Permanent magnet machines have cogging torque. An expression for cogging torque of a permanent machine is derived in this chapter and the cogging torque of two axial flux permanent magnet machines is predicted in this chapter and compared with the experimental results. A design criterion has been suggested to reduce cogging torque.

Chapter 5 The useful torque of the new servo motor is predicted in this chapter using the model developed in Chapter 2, for different values of phase currents and compared with the measured torque.

Chapter 6 Since servo motors tend to operate with high current it is important to predict their performance under saturated condition. This chapter develops a model taking saturation into account, predicts the torque developed by the machine using the model at high stator currents, and compares it with the experimental results.

Chapter 7 This chapter uses the model developed in chapter 6, to find a set of tooth tip dimensions that gives the maximum torque, keeping other parameters of the machine constant.

\subsection{Summary}

In this chapter the suitability of axial flux permanent magnet machines for servo motors is explained. Design features of a new servo motor are presented with the advantages and disadvantages of the new design. The analytical problems of the new machine are identified. 


\section{CHAPTER 2}

\section{TORQUE CALCULATION OF MACHINES WITH PERMANENT MAGNETIC MATERIALS}

\subsection{Introduction}

Different views seem to exist about the energy density of permanent magnets. Macaig [33] discusses energy relations in hard and soft magnetic materials, saying that the energy density at the remanence point on closed circuit is not zero. Gauthier and Wiederick [34] treat permanent magnets like air and say that the energy density of the magnet field is $\mathrm{B}^{2} / 2 \mu_{0}$. "Energy seems such a well established concept that it may seem surprising that differing views about the energy relations of permanent magnets should have been expressed. What is not always made clear is whether the the energy $\mathrm{BH} / 2$ inside the magnet exists in addition to the energy $\mathrm{H}^{2} / 2 \mu_{0}$ outside or whether it is another method of calculating the same energy" [35]. "The calculation of energy inside the permanent magnet material is likely to be complicated and unreliable. To try to derive force from a change of energy then becomes an almost impossible undertaking“ [36]. These comments lead to a feeling that the energy density of a permanent magnet is very complicated and is almost impossible to calculate. Therefore, for machines using permanent magnets the expression for torque is mostly derived by replacing the magnets by a surface current density [37] producing the same flux density and using the force equation $\mathrm{F}=\mathrm{BIL}$. This approach assumes that the machines do not have slots, and the conductors are in the airgap. A more fundamental approach would be to use the energy transfer equation,

Electrical energy input $=$ Mechanical energy output + Stored energy

For a permanent magnet machine, this requires the knowledge of the energy density of the magnet. In this chapter an expression for the energy density of permanent magnets will be first derived and then verified using experimental results. Using the expression for energy density, the torque of a simple permanent magnet machine will then be derived from the stored energy concept. This expression will be compared with the expression derived using the conventional approach. The torque of the machine will be expressed in terms of stator current and rotor magnet space phasors. 


\subsection{The Permanent Magnet}

\subsubsection{The demagnetization curve}

The quality of a permanent magnet is characterized by [38],

1. its demagnetization curve, and

2. the value of magnetic energy per unit volume of the permanent magnet.

The most recent rare-earth permanent magnet developed is $\mathrm{Ne}-\mathrm{Fe}-\mathrm{B}$ and has outstanding permanent magnet properties. The demagnetization curve of the $\mathrm{Ne}-\mathrm{Fe}-\mathrm{B}$ magnets is a straight line as shown in Figure 2.1.

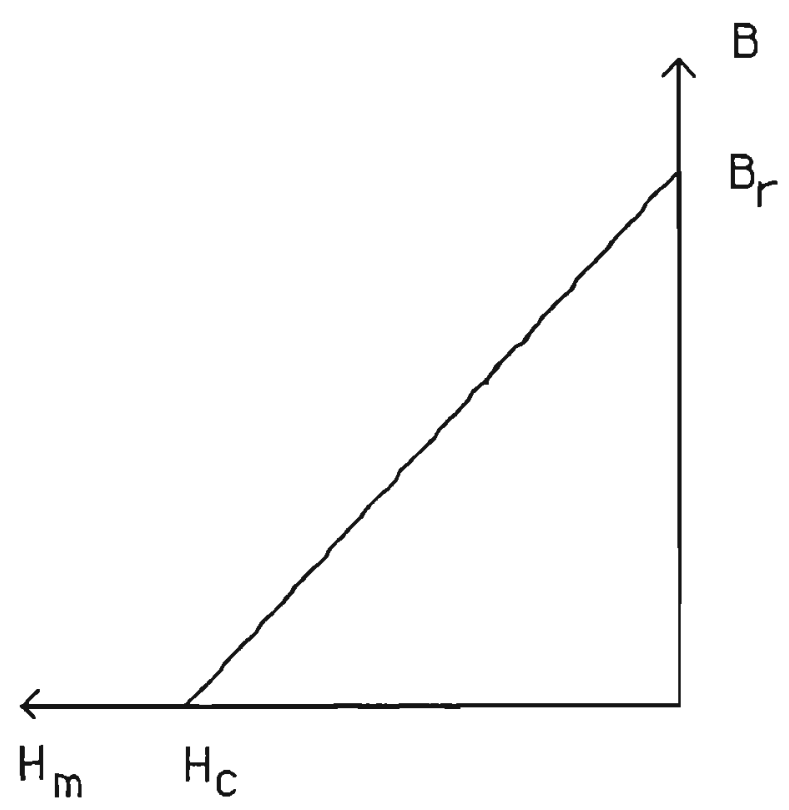

$$
\begin{aligned}
& B_{r}=1.1 \mathrm{~T} \\
& H_{c}=-830 \mathrm{kA} / \mathrm{m}
\end{aligned}
$$

Figure 2.1 The demagnetization curve of Nd-Fe-B

The equation of this demagnetization curve is given by

$\mathrm{B}=\mu_{0} \mathrm{H}_{\mathrm{m}}+\mathrm{B}_{\mathrm{r}}$

The equation of the demagnetization curve for a magnet of opposite polarity to the one represented by the above equation would be

$\mathrm{B}=\mu_{0} \mathrm{H}_{\mathrm{m}}-\mathrm{B}_{\mathrm{r}}$

When there is no magnet at all, then the line goes through the origin and the equation (for air) becomes 
$\mathrm{B}=\mu_{0} \mathrm{H}_{\mathrm{m}}$

In general the demagnetization curve can be written as

$\mathrm{B}=\mu_{\mathrm{o}} \mathrm{H}_{\mathrm{m}}+\psi \mathrm{B}_{\mathrm{r}}$

Where $\psi$ is a three valued function which takes the values 1,0 or -1 depending on the polarity and presence or absence of the magnet.

\subsubsection{The energy density}
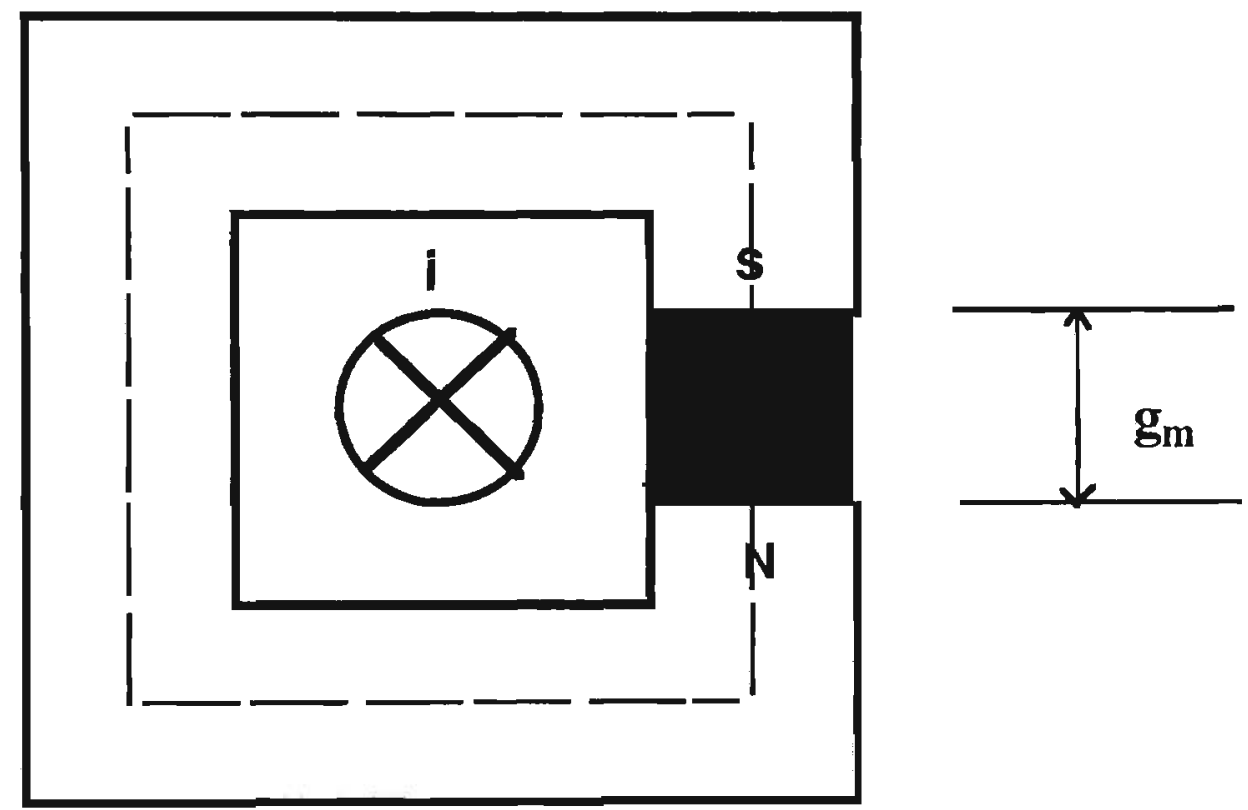

\section{Magnet}

\section{Figure 2.2 A magnetic system with permanent magnet}

Consider the system shown in Figure 2.2. It has a $\mathrm{C}$ core, and a permanent magnet with an area of cross section $\mathrm{A}$, and length of $\mathrm{g}_{\mathrm{m}}$. The $\mathrm{C}$ core and the magnet enclose a current, i. (The following analysis assumes a value of 1 for $\psi$ for simplicity)

For the loop shown by the dotted line in Figure 2.2, the

current enclosed by the loop $=\mathrm{mmf}$ drop around the loop

$\mathrm{i} \quad=\mathrm{H}_{\mathrm{m}} \mathrm{g}_{\mathrm{m}} \quad$ (assuming that the reluctance of the $\mathrm{C}$ core is negligible) 
$=\left(\frac{B}{\mu_{0}}-H_{c}\right) g_{m}$ (using the demagnetisation curve)

That is,

B $\quad=\frac{\mu_{\mathrm{O}}}{\mathrm{g}_{\mathrm{m}}}\left(\mathrm{H}_{\mathrm{c}} \mathrm{g}_{\mathrm{m}}+\mathrm{i}\right)$.

Equation (2.3) shows that the system looks as if it has two current sources, (Firstly, the magnet producing an equivalent current of $\mathrm{H}_{\mathrm{c}} \mathrm{g}_{\mathrm{m}}$ and secondly the current $\mathrm{i}$ ) and an airgap $g_{m}$. When the current is zero, Equation (2.3) becomes

$$
\begin{aligned}
B \quad & =\frac{\mu_{0}}{g_{m}}\left(H_{c} g_{m}\right) \\
& =B_{r} .
\end{aligned}
$$

This means that when the current is zero, the flux density of the system is equal to the remanence of the permanent magnet used in the system.

If there is a change of current, $\mathrm{di}$, in the system, in time $\mathrm{dt}$,

the incremental electrical energy in the system would be

$$
\begin{aligned}
\text { vidt } & =\operatorname{id} \phi \quad \text { (where } v \text { is the voltage and } \phi \text { is the flux) } \\
& =\quad \mathrm{AdB} \\
& =\left(\frac{\mathrm{B}}{\mu_{\mathrm{O}}}-\mathrm{H}_{\mathrm{c}}\right) \mathrm{g}_{\mathrm{m}} \mathrm{AdB} \quad \text { (after substituting for } \mathrm{i} \text { from Equation(2.2)) }
\end{aligned}
$$

This energy change is equal to the change in energy in the permanent magnet. The total energy change will be obtained by integrating the incremental energy, with $B_{r}$ as the lower limit (the flux density for zero current) and B as the upper limit (the flux density at any current).

$$
\begin{aligned}
\text { The total energy change in the magnet } & =\int_{B_{r}}^{B} g_{m} A\left(\frac{B}{\mu_{0}}-H_{c}\right) d B \\
& =\frac{g_{m} A}{2 \mu_{0}}\left(B-B_{r}\right)^{2}
\end{aligned}
$$


From Equation (2.1)

$$
\mathrm{H}_{\mathrm{m}}=\frac{\left(\mathrm{B}-\mathrm{B}_{\mathrm{r}}\right)}{\mu_{\mathrm{o}}}
$$

Substituting this in Equation(2.4)

Total change in energy $\quad=\quad \frac{g_{\mathrm{m}} \mathrm{A} \mu_{\mathrm{o}} \mathrm{H}_{\mathrm{m}}{ }^{2}}{2}$

In this expression $\mathrm{g}_{\mathrm{m}} \mathrm{A}$ represents the volume of the magnet

Therefore energy density in a permanent magnet $=\frac{\mu_{0} \mathrm{H}_{m}^{2}}{2}$

\subsection{Verification of the Energy Density Expression}

\subsubsection{Magnetic system with a permanent magnet}

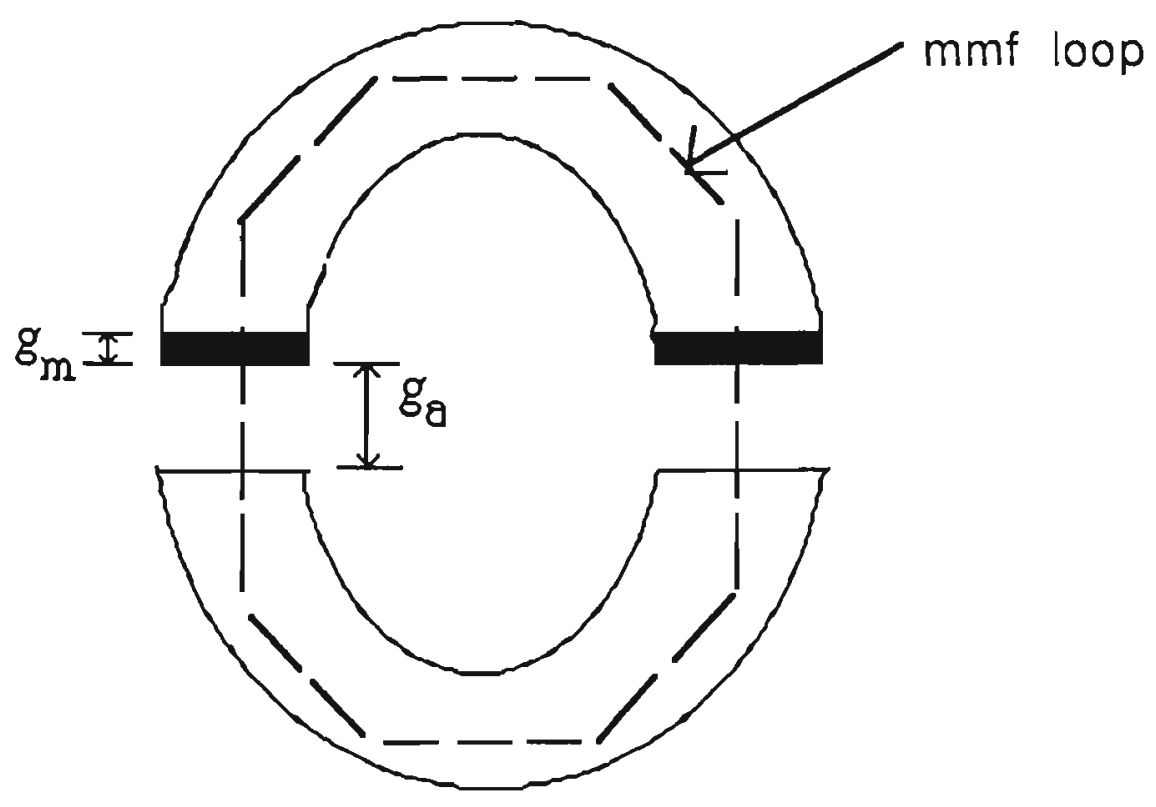

Magnet

Figure 2.3 A system with permanent magnet

Figure 2.3 shows a simple magnetic system with two $\mathrm{C}$ - cores, magnets and airgaps. Let the length of each airgap and each magnet be $\mathrm{g}_{\mathrm{a}}$ and $\mathrm{g}_{\mathrm{m}}$ respectively. For the following analysis it is assumed that the same permanent magnet material is used on 
either side and they push flux in the same direction. Since the same magnet material is used, $\mathrm{H}_{\mathrm{m}}$ is the same on either side for a given flux density.

Ignoring the reluctance of the iron, for the loop shown in Figure 2.3

Mmf drop along the loop = Current enclosed by the loop

ie, $\quad 2 \mathrm{H}_{\mathrm{a}} \mathrm{g}_{\mathrm{a}}+2 \mathrm{H}_{\mathrm{m}} \mathrm{g}_{\mathrm{m}}=0$

where $\mathrm{H}_{a}$ is the field intensity in the airgap and $\mathrm{H}_{m}$ is the field intensity in the magnet.

For the magnet,

$\mathrm{B}=\mu_{\mathrm{o}} \mathrm{H}_{\mathrm{m}}+\psi \mathrm{Br}$

and for the airgap,

$\mathrm{B}=\mu_{\mathrm{o}} \mathrm{H}_{\mathrm{a}}$

Substituting for $\mathrm{H}_{\mathrm{m}}$ and $\mathrm{H}_{\mathrm{a}}$ in Equation (2.6)

$B=\frac{\psi B_{r} g_{m}}{g_{m}+g_{a}}$

If " $A$ " is the cross sectional area faced by the flux in the airgaps and in the magnets then,

Energy in the magnets $=\left(\frac{\mu_{0} H_{m}^{2}}{2}\right)\left(2 \mathrm{~A} g_{m}\right)$ (using Equation(2.5))

$$
\begin{aligned}
& =\mu_{0} H_{m}^{2} A g_{m} \\
& =\frac{(B-\psi B r)^{2}}{\mu_{0}^{2}} \mu_{0} A g_{m}
\end{aligned}
$$

Energy in the airgaps $=\left(\frac{\mu_{0} B^{2}}{2}\right)\left(2 A g_{a}\right)$

Equations (2.8) and (2.9) add up to give the total energy in the system 
Thus the total total energy is

$E_{\text {total }}=\frac{\mathrm{AB}_{\mathrm{r}}^{2} \mathrm{~g}_{\mathrm{a}} \mathrm{g}_{\mathrm{m}}}{\mu_{\mathrm{o}}\left(\mathrm{g}_{\mathrm{a}}+\mathrm{g}_{\mathrm{m}}\right)}$

If the airgap $\mathrm{g}_{\mathrm{a}}$ is increased by $\mathrm{dg}$, the force

$\mathrm{F}=\frac{\mathrm{dE}_{\mathrm{total}}}{\mathrm{dg}}=\frac{\mathrm{AB}_{\mathrm{r}}{ }^{2} \mathrm{~g}_{\mathrm{m}}^{2}}{\mu_{\mathrm{o}}\left(\mathrm{g}_{\mathrm{a}}+\mathrm{g}_{\mathrm{m}}\right)^{2}}$

Equation (2.10) shows that the force is directly proportional to the square of the remanence of the magnet. So high remanence magnets like Ne-Fe-B produce much more force compared to the magnets with low remanence values. The equation also indicates that the force decreases with increase in airgap.

\subsubsection{Magnetic system with fringing flux}

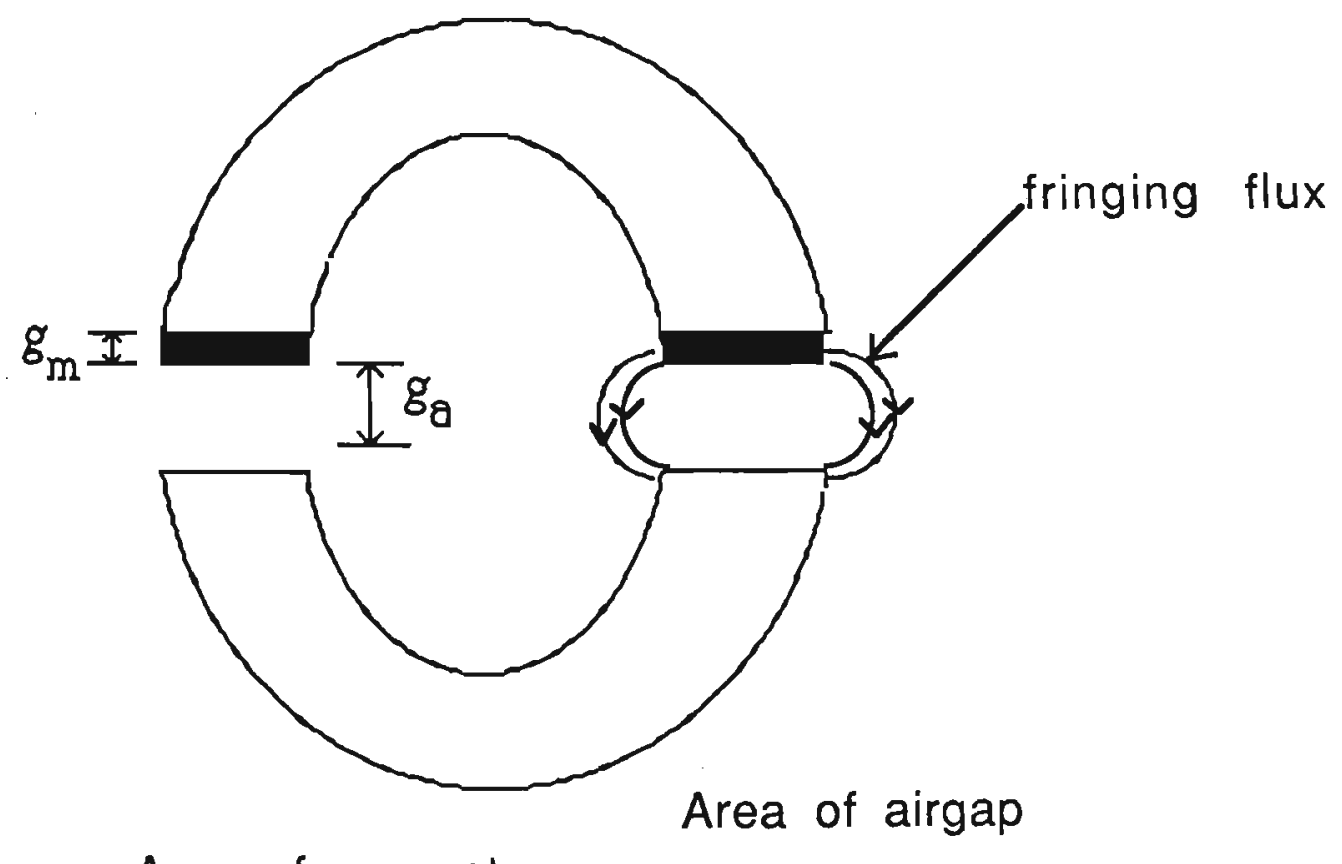

Area of magnet

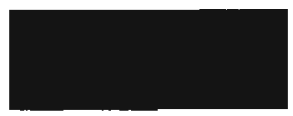

$A_{m}$

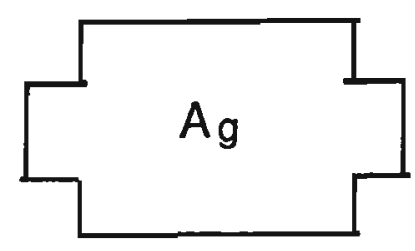

Figure 2.4 Magnetic system with fringing flux

The analysis presented in the previous section ignores flux fringing. But in practice their will be a fringing flux as shown in the Figure 2.4. Thus the effective area faced by the flux in the airgap is increased compared to the area in the magnet. The increase 
in area can be estimated by assuming a semi circular path for fringing flux, as shown in Figure 2.4.

The magnet cross-sectional area (Figure 2.4)

$\mathrm{A}_{\mathrm{m}}=\mathrm{A}$.

The fringing flux at the airgap is taken into account by artificially increasing A.

The cross sectional area faced by the flux in the airgap ( Figure 2.4)

$\mathrm{A}_{\mathrm{g}}=\mathrm{A}+\frac{\mathrm{ga}_{\mathrm{a}}}{2} \times$ (perimeter of the magnet)

(assuming that the additional area due to fringing is $\frac{\mathrm{ga}_{\mathrm{a}}}{2} \mathrm{x}$ (perimeter of the magnet))

Equation (2.10) may be modified by including fringing, and the force for different airgap distances may be calculated. The modified equation is very lengthy with a number of terms in the numerator as well as the denominator and therefore it is not presented here. The derivation of the modified equation is given in Appendix 2.

\subsection{Experimental Verification}

To verify the force/airgap relationship, a magnetic system similar to the one shown in Figure 2.3 was set up with two $\mathrm{C}$ cores and Ne-Fe-B magnets of $6.8 \mathrm{~mm}$ thickness and $82.5 \mathrm{~mm}$ perimeter. The area of cross section of the core was $334 \mathrm{~mm}^{2}$. Non magnetic materials of varying thickness were used to serve as airgaps. The force for different airgaps was measured by hanging weights from the lower ' $\mathrm{C}$ ' core to pull the cores apart. Figure 2.5 shows the comparison of computed and measured values of force for different airgaps ( $\mathrm{ga}_{\mathrm{a}}$ ).

Figure 2.5 shows that there is an error of around $13 \%$ in the calculated and measured values for zero airgap, and they are very close for airgap lengths from about $1 \mathrm{~mm}$ to 9 $\mathrm{mm}$. This indicates the fact that the expression used to calculate the energy density of the magnet is satisfactory. 


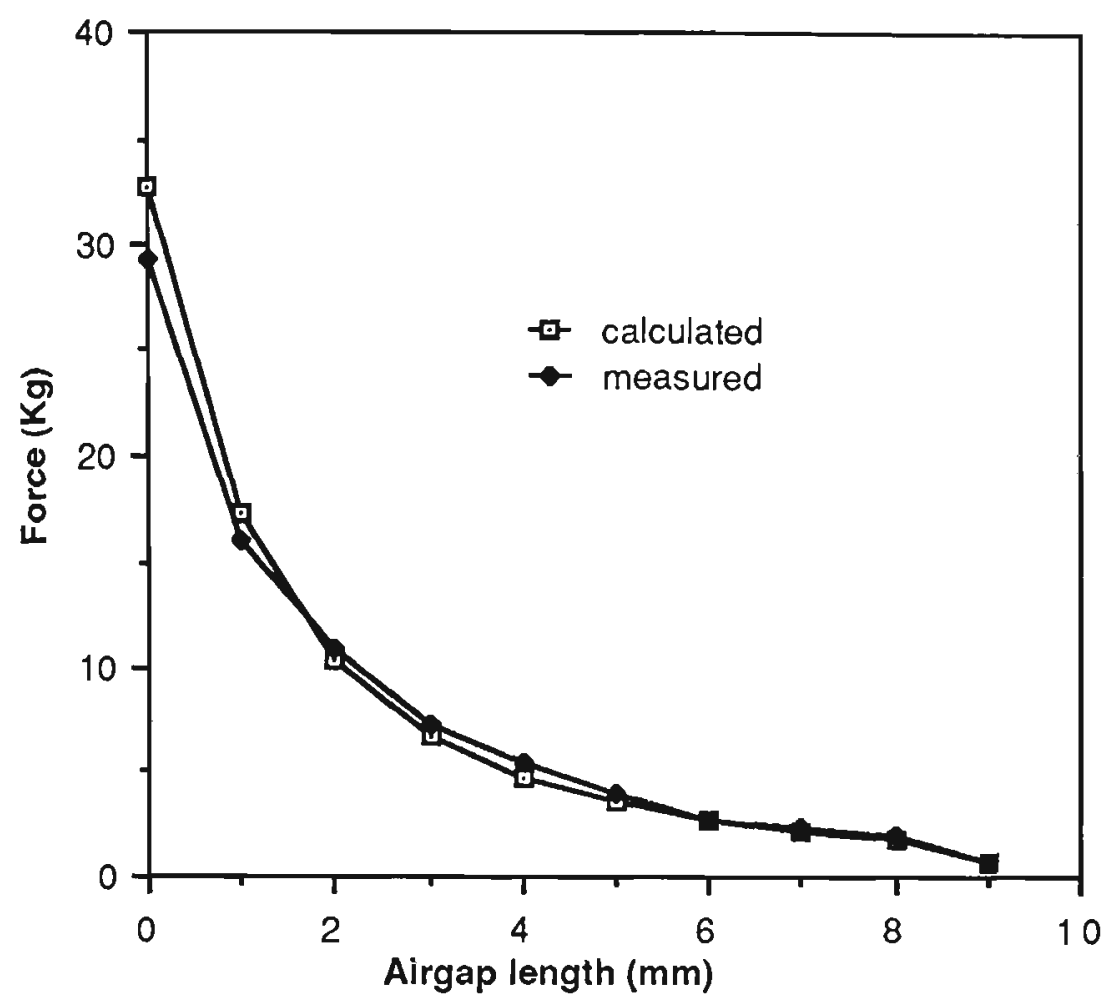

Figure 2.5 Airgap length versus force

\subsection{Torque Calculation of a Permanent Magnet Machine}

\subsubsection{The energy storage method.}

A simple hypothetical machine with permanent magnet rotor will be considered for analysis using the energy storage method. Figure 2.6 shows the machine. It is a two pole, two phase machine with four slots. The torque of this machine will be calculated using the energy storage method.

\section{Assumptions}

1. The permanent magnet is operating in the linear region.

2. Reluctance of the iron is negligible.

3. There is no flux fringing.

4. There is no skewing. 


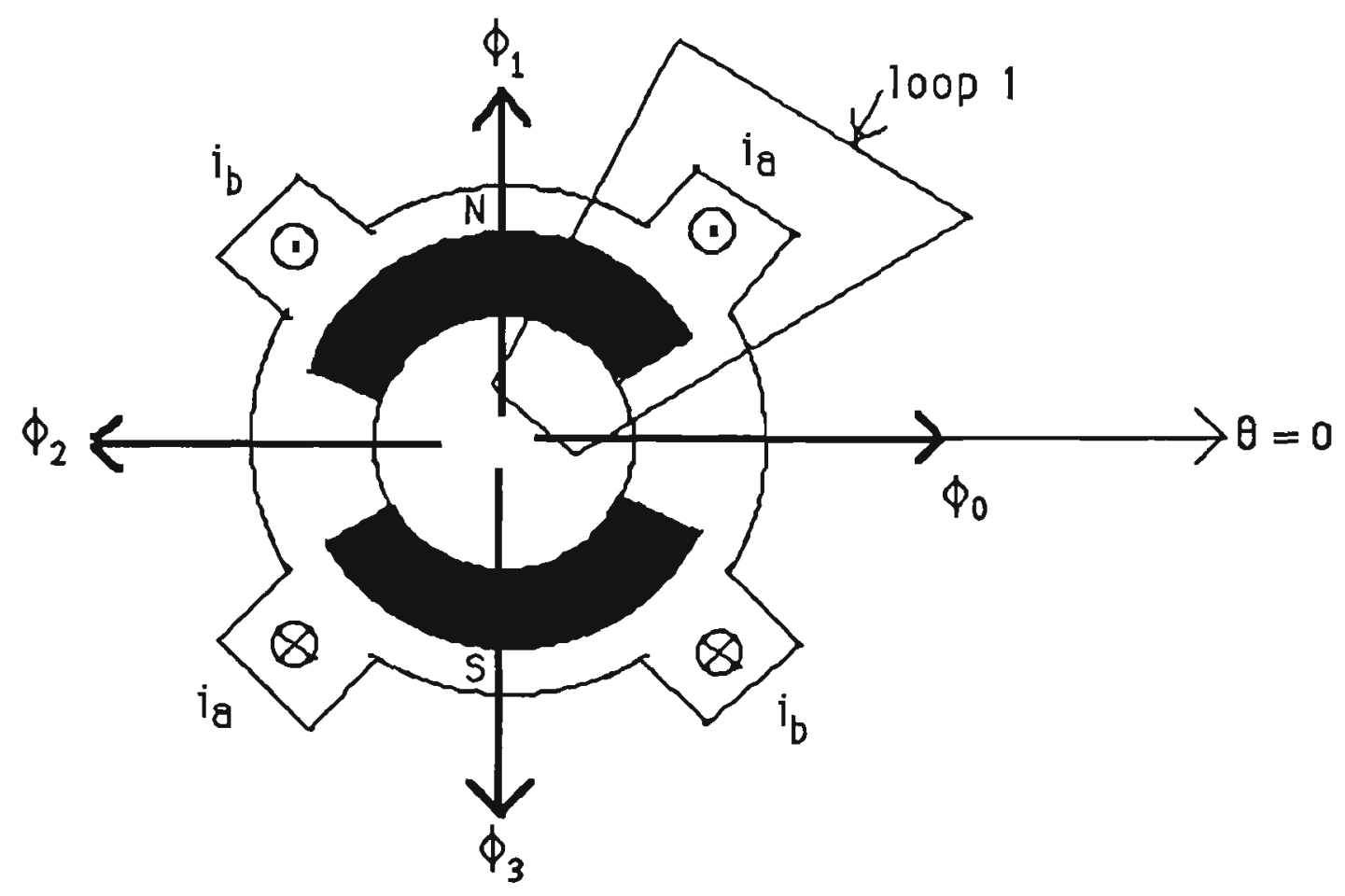

Figure 2.6 Permanent magnet machine with four teeth and two poles

\subsubsection{Stored energy}

For the machine shown in Figure 2.6, let $\phi_{0}, \phi_{1}, \phi_{2}, \phi_{3}$ be the flux through the teeth 0 to 3 respectively. $B(\theta)$ is the flux density in the airgap and is a function of the angle around the machine $\theta$.

By symmetry,

$$
\begin{aligned}
& \phi_{2}=-\phi_{0} \\
& \phi_{3}=-\phi_{1}
\end{aligned}
$$

and $\mathrm{B}(\theta+\pi)=-\mathrm{B}(\theta)$

Let $B_{0}$ be the flux density at tooth 0 , and $B_{1}$ at tooth $1 . B_{0}$ may change with $\theta$ across tooth 0 etc. The magnet polarity function, $\psi$, also varies with $\theta$.

Mmf around loop 1 can be written as

$\frac{1}{\mu_{0}}\left[\left\{B_{0}\left(\theta_{0}\right)-\psi\left(\theta_{0}\right) B_{r}\right\} g_{m}+B_{0}\left(\theta_{0}\right) g_{a}-\left\{B_{1}\left(\theta_{1}\right)-\psi\left(\theta_{1}\right) B_{r}\right\} g_{m}-B_{1}\left(\theta_{1}\right) g_{a}\right]=i_{a}$ 
(Where $\theta_{0}$ and $\theta_{1}$ represent the value of $\theta$ along the teeth 0 and 1 respectively.)

ie, $\mathrm{B}_{0}\left(\theta_{0}\right)-\mathrm{B}_{1}\left(\theta_{1}\right)=\frac{\mathrm{g}_{\mathrm{m}}}{\mathrm{g}}\left\{\psi\left(\theta_{0}\right)-\psi\left(\theta_{1}\right)\right\} \mathrm{B}_{\mathrm{r}}+\frac{\mu_{0} \mathrm{i}_{\mathrm{a}}}{\mathrm{g}}$

where $g=g_{a}+g_{m}$

and $g_{a}$ and $g_{m}$ are the thickness of the airgap and magnet respectively.

Similarly,

$\mathrm{B}_{1}\left(\theta_{1}\right)-\mathrm{B}_{2}\left(\theta_{2}\right)=\frac{\mathrm{g}_{\mathrm{m}}}{\mathrm{g}}\left\{\psi\left(\theta_{1}\right)-\psi\left(\theta_{2}\right)\right\} \mathrm{B}_{\mathrm{r}}+\frac{\mu_{0} \mathrm{i}_{\mathrm{b}}}{\mathrm{g}}$

From Equation (2.13)

$$
\begin{aligned}
\mathrm{B}_{2}\left(\theta_{2}\right) & =-\mathrm{B}_{0}\left(\theta_{2}-\pi\right) \\
& =-\mathrm{B}_{0}\left(\theta_{0}\right)
\end{aligned}
$$

Also, since the rotor is symmetrical

$$
\psi\left(\theta_{2}\right)=-\psi\left(\theta_{0}\right)
$$

Substituting Equations (2.16) and (2.17) in Equation (2.15),

$\mathrm{B}_{1}\left(\theta_{1}\right)+\mathrm{B}_{0}\left(\theta_{0}\right)=\frac{\mathrm{g}_{\mathrm{m}}}{\mathrm{g}}\left\{\psi\left(\theta_{0}\right)+\psi\left(\theta_{1}\right)\right\} \mathrm{B}_{\mathrm{r}}+\frac{\mu_{0} \mathrm{i}_{\mathrm{b}}}{\mathrm{g}}$

Adding Equations(2.14) and (2.18)

$\mathrm{B}_{0}\left(\theta_{0}\right)=\frac{\mathrm{B}_{\mathrm{r}} \psi\left(\theta_{0}\right) \mathrm{g}_{\mathrm{m}}}{\mathrm{g}}+\frac{\mu_{0}\left(\mathrm{i}_{\mathrm{a}}+\mathrm{i}_{\mathrm{b}}\right)}{2 \mathrm{~g}}$

Subtracting Equations(2.14) and (2.18)

$\mathrm{B}_{1}\left(\theta_{1}\right)=\frac{\mathrm{B}_{\mathrm{r}} \psi\left(\theta_{1}\right) \mathrm{g}_{\mathrm{m}}}{\mathrm{g}}+\frac{\mu_{0}\left(-\mathrm{i}_{\mathrm{a}}+\mathrm{i}_{\mathrm{b}}\right)}{2 \mathrm{~g}}$

Equations (2.19) and (2.20) give the flux density in tooth 1 and 2 in terms of current and magnet parameters. Flux through teeth 1 and 2 can be found by integrating Equations (2.19) and (2.20) over the respective teeth as shown below: 


$$
\begin{aligned}
& \phi_{0}=\int_{\text {tooth } 0} \mathrm{~B}_{0}\left(\theta_{0}\right) \operatorname{LRd} \theta \\
& \phi_{1}=\int_{\text {tooth } 1} \mathrm{~B}_{1}\left(\theta_{1}\right) \operatorname{LRd} \theta
\end{aligned}
$$

where $\mathrm{R}$ and $\mathrm{L}$ are the radius and length of the machine respectively.

Using the energy density expressions for magnet and air and using the flux density expressions developed in this section, the energy in the machine, $E_{\text {stored }}$ is calculated as (the derivation is given in Appendix 2)

$$
E_{\text {stored }}=\frac{R L g_{m} g_{a} B_{r}^{2}}{\mu_{0} g} \int_{\text {tooth } 0+\text { tooth } 1} \psi^{2} \mathrm{~d} \theta+\frac{\mu_{0} R L \theta_{t}\left(i_{a}{ }^{2}+i_{b}{ }^{2}\right)}{2 g}
$$

where $\theta_{\mathrm{t}}$ is tooth pitch in radians.

\subsubsection{Electrical energy input}

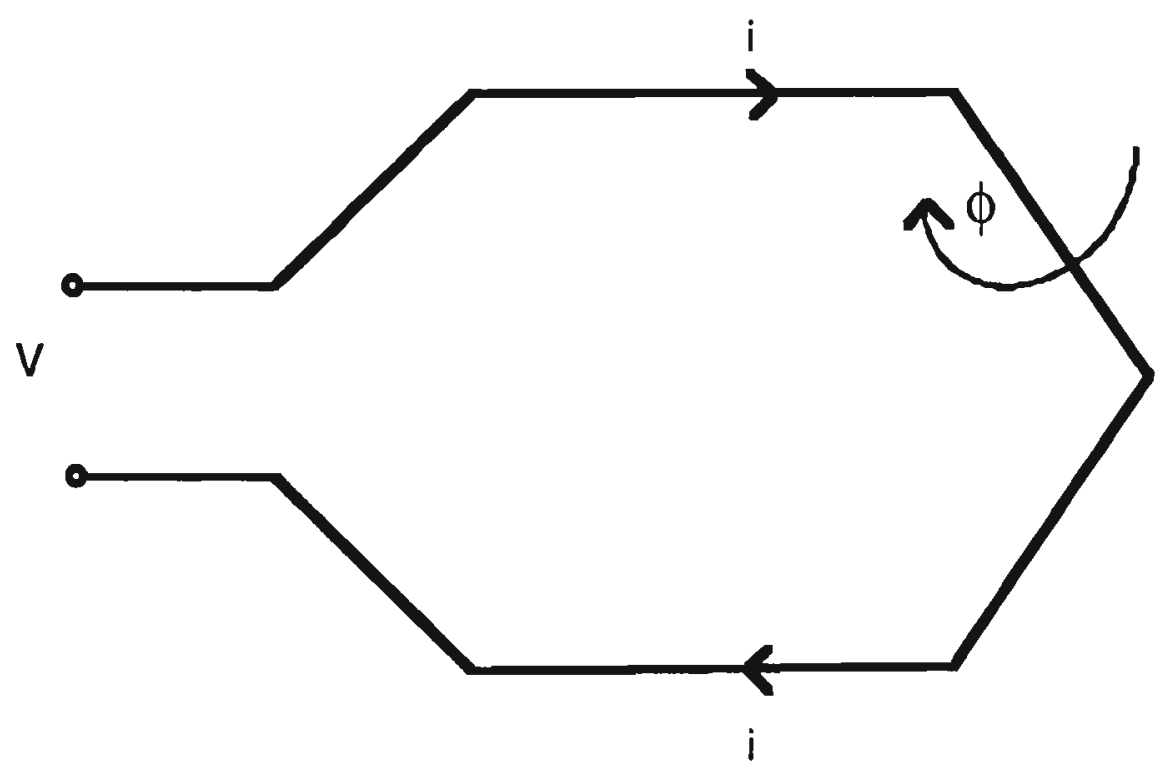

Figure 2.7 A coll carrying current

Figure 2.7 shows a coil carrying a current of i Amperes. There will be a flux of $\phi$ linking the turn as shown. The voltage induced in the coil will be $\mathrm{v}=-\frac{\mathrm{d} \phi}{\mathrm{dt}}$

Similarly voltage in a turn in phase 'a' of the two phase machine considered will be 
$v_{a}=-\frac{d\left(\phi_{0}+\phi_{3}\right)}{d_{t}}$

$v_{a}=-\frac{d\left(\phi_{0}-\phi_{1}\right)}{d_{t}}$

Voltage in phase $b$ will be

$v_{b}=-\frac{d\left(\phi_{0}+\phi_{1}\right)}{d_{t}}$

Energy added to the system $\mathrm{E}_{\mathrm{elec}}$ during time dt is given by

$E_{e l e c}=v_{a} i_{a} d t+v_{b} i_{b} d t$

$$
\begin{aligned}
& =\mathrm{i}_{\mathrm{a}}\left(d \phi_{1}-\mathrm{d} \phi_{0}\right)-\mathrm{i}_{\mathrm{b}}\left(d \phi_{0}+\mathrm{d} \phi_{1}\right) \quad \text { ( using Equationss(2.24) and (2.25)) } \\
& =-\left(\mathrm{i}_{\mathrm{a}}+\mathrm{i}_{\mathrm{b}}\right) d \phi_{0}+\left(\mathrm{i}_{\mathrm{a}}-\mathrm{i}_{\mathrm{b}}\right) \mathrm{d} \phi_{1}
\end{aligned}
$$

If this occurs as the rotor moves from $\varepsilon$ to $\varepsilon+\mathrm{d} \varepsilon, \varepsilon$ (Where $\varepsilon$ is the angle which defines the position of rotor with respect to stator (mechanical rad),

$d E_{\text {elec }}=-\left(i_{a}+i_{b}\right) \frac{d \phi_{0}}{d \varepsilon} d \varepsilon+\left(i_{a}-i_{b}\right) \frac{d \phi_{1}}{d \varepsilon} d \varepsilon$

Substituting for $\phi_{0}$ and $\phi_{1}$ from Equations (2.21) and (2.22) and simplifying (the process of simplification is given in Appendix 2);

$$
\begin{array}{r}
d E_{\text {elec }}=-\left(i_{a}+i_{b}\right) \frac{\operatorname{LRg}_{m} B_{r}}{g} d \varepsilon \frac{\partial}{\partial \varepsilon} \int_{\text {tooth } 1} \psi(\theta) d \theta+ \\
\left(i_{a}-i_{b}\right) \frac{\operatorname{LRg}_{m} B_{r}}{g} d \varepsilon \frac{\partial}{\partial \varepsilon} \int_{\text {tooth } 1} \psi(\theta) d \theta
\end{array}
$$

\subsubsection{The Motor Torque}

The energy transfer equation for the motor is given by

$\mathrm{dE}_{\text {elec }}=\mathrm{Td} \varepsilon+\mathrm{dE}_{\text {stored }}$ 
$\mathrm{T}=\frac{\mathrm{dE} \mathrm{elec}_{\mathrm{el}}}{\mathrm{d} \varepsilon}-\frac{\mathrm{dE}_{\text {stored }}}{\mathrm{d} \varepsilon}$

The first term in Equation (2.27) will give the useful torque whereas the second term will give the cogging torque.

Substituting for $\mathrm{dE}_{\mathrm{elec}}$ from Equation (2.26)

$$
\begin{aligned}
\mathrm{T}_{\text {useful }}= & \frac{\operatorname{LRg}_{\mathrm{m}} \mathrm{B}_{\mathrm{r}}}{\mathrm{g}}\left[\mathrm{i}_{\mathrm{a}}\left\{\frac{\partial}{\partial \varepsilon} \int_{\text {tooth } 1} \psi(\theta) \mathrm{d} \theta-\frac{\partial}{\partial \varepsilon} \int_{\text {tooth } 0} \psi(\theta) \mathrm{d} \theta\right\}-\right. \\
& \left.\mathrm{i}_{\mathrm{b}}\left\{\frac{\partial}{\partial \varepsilon} \int_{\text {tooth } 0} \psi(\theta) \mathrm{d} \theta+\frac{\partial}{\partial \varepsilon} \int_{\text {tooth } 1} \psi(\theta) \mathrm{d} \theta\right\}\right]
\end{aligned}
$$

The subscript "useful" indicates that the equation (2.28) gives the expression for the useful torque. In the equation (2.28), $\int \psi(\theta) \mathrm{d} \theta$ is a ramping function of rotor position, and the ramp slope depends on the number of magnet edges opposite the tooth. The term $\frac{\partial}{\partial \varepsilon} \int \psi(\theta) \mathrm{d} \theta$ in equation (2.28) is simply equal to the number of magnet edges opposite the tooth, summed with appropriate signs and multiplied by tooth pitch $\theta_{\mathrm{t}}$.

Substituting for $\mathrm{dE}_{\text {stored }}$ from Equation (2.23)

$$
\mathrm{T}_{\text {cogging }}=-\frac{\mathrm{RLgm} \mathrm{g}_{\mathrm{a}} \mathrm{B}_{\mathrm{r}}^{2}}{\mu_{\mathrm{o}} \mathrm{g}} \frac{\partial}{\partial \varepsilon} \underset{\text { tooth0+tooth1 }}{\int \psi^{2} \mathrm{~d} \theta}
$$

The subscript "cogging" indicate the Equation (2.29) gives the expression for cogging torque.

\section{Let}

$$
\begin{aligned}
& \theta_{\mathrm{t}} \frac{\partial}{\partial \varepsilon} \int_{\text {tooth } 0} \psi(\theta) \mathrm{d} \theta=\zeta(0), \\
& \theta_{\mathrm{t}} \frac{\partial}{\partial \varepsilon} \int_{\text {tooth } 1} \psi(\theta) \mathrm{d} \theta=\zeta(1) \text { and }
\end{aligned}
$$


$\frac{\mathrm{LRg} \mathrm{B}_{\mathrm{r}} \theta_{\mathrm{t}}}{\mathrm{g}}=\mathrm{A}$

Using the above, torque Equation (2.28) can be written as

$\mathrm{T}_{\text {useful }}=\quad \mathrm{A}\left[\mathrm{i}_{\mathrm{a}}\{\zeta(1)-\zeta(0)\}-\mathrm{i}_{\mathrm{b}}\{\zeta(0)+\zeta(1)\}\right]$

\subsubsection{The conventional ( force equation) method}

Using the conventional approach, which uses the force equation F = BIL for evaluating torque, the equation for torque may be written as (the derivation is given in Appendix 2)

$\mathrm{T}=2 \mathrm{~A}\left(\mathrm{i}_{\mathrm{a}} \psi\left(\theta_{\mathrm{a}}\right)+\mathrm{i}_{\mathrm{b}} \psi\left(\theta_{\mathrm{b}}\right)\right)$

where $\theta_{\mathrm{a}}, \theta_{\mathrm{b}}$ defines the position of the conductor of phase $\mathrm{a}$ and $\mathrm{b}$ along the stator, and, $\psi\left(\theta_{a}\right)$ and $\psi\left(\theta_{b}\right)$ are the value of $\psi$ opposite to the phase conductors $a$ and $b$ respectively. In this method, since a slotless machine has been considered for analysis, cogging torque will be zero. Therefore the equation (2.31) directly gives the useful torque.

\subsubsection{Comparison of the torques derived using the two methods}

The value of $\zeta$ for a particular tooth (in Equation (2.30)), or the value of $\psi$ for a conductor carrying a phase current (in Equation (2.31))) depends on the presence or absence of the magnet opposite to the tooth and the polarity of magnets. In other words they depend on the rotor position. Figures 2.8 (a) to (f) show the developed layout of a two pole two phase permanent magnet machine for different rotor positions. The values of $\psi\left(\theta_{\mathrm{a}}\right)$ and $\psi\left(\theta_{\mathrm{b}}\right)$ for each rotor position are indicated in the figure. Figure 2.9(a) shows $\int \psi(\theta)$ for tooth 0 and tooth 1 , and 2.9(b) shows $\zeta(0)$ and $\zeta(1)$ with respect to rotor position.

Using Figures 2.8 and 2.9, and equation 2.30 and 2.31, the Table 2.1 compares the torque using the energy calculation with the torque using the conventional method. In the table, $\mathrm{T}_{\text {energy }}$ is the torque calculated using the energy approach and $\mathrm{T}$ is the torque calculated using the conventional approach. 
(a)

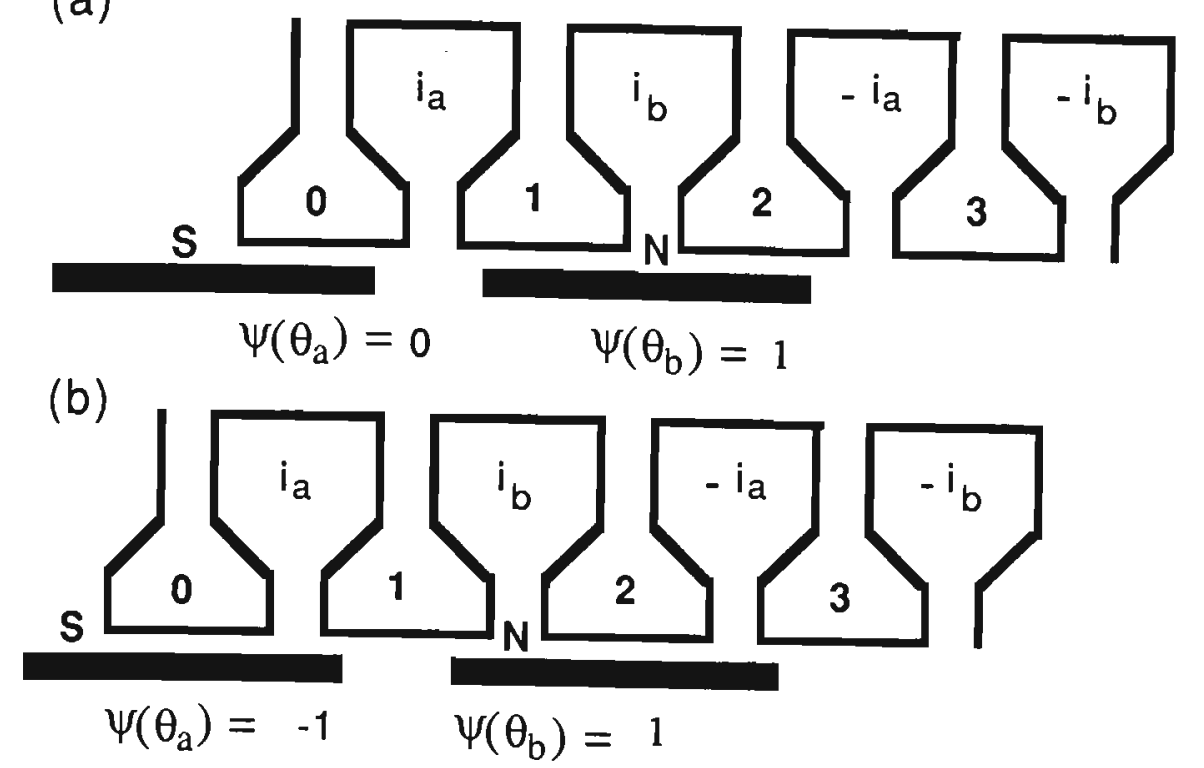

(c)

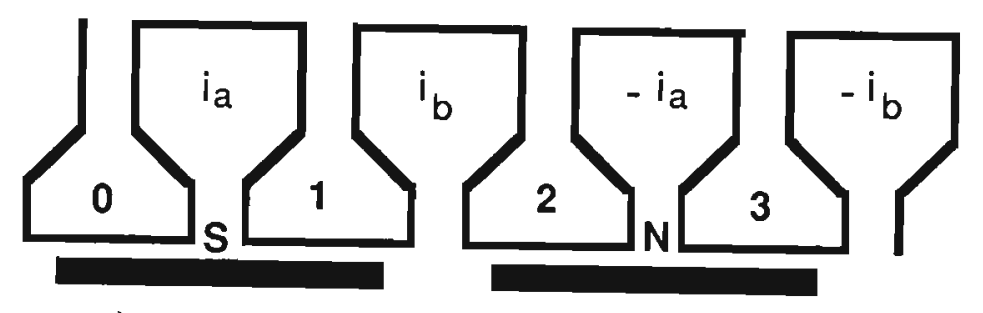

(d)

(e)

$$
\psi\left(\theta_{\mathrm{a}}\right)=-1 \quad \psi\left(\theta_{\mathrm{b}}\right)=0
$$

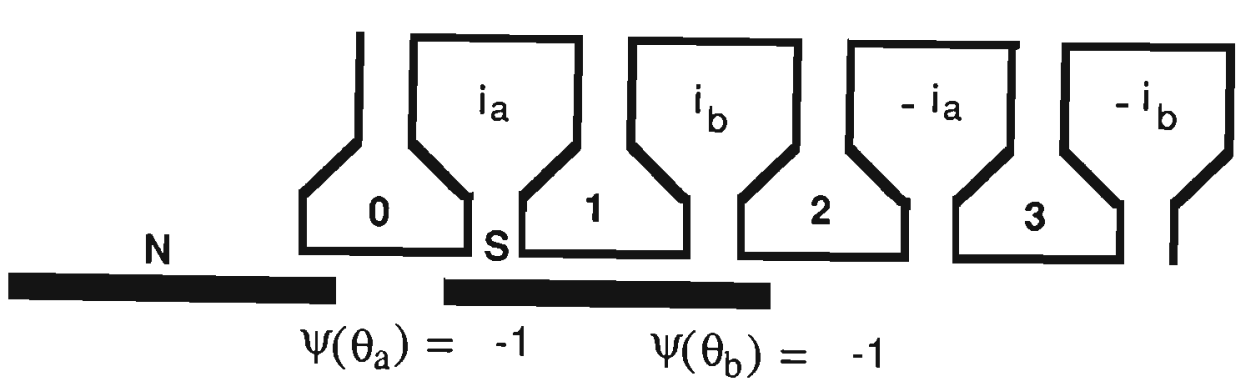

(f)

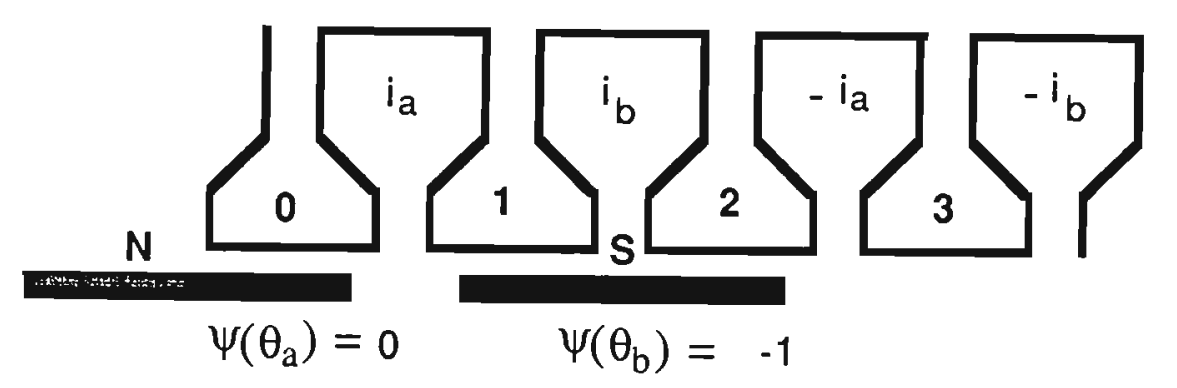

Figure 2.8 Developed layout of a two pole, two phase permanent magnet machine 
(a)

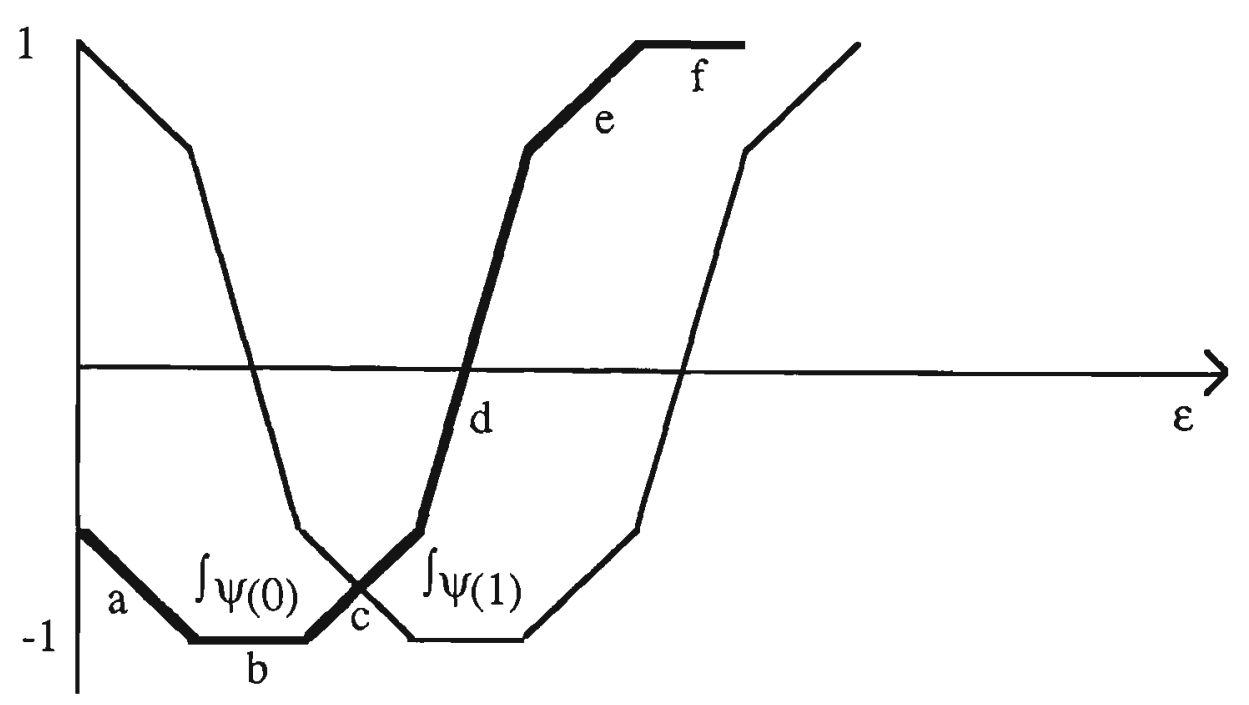

(b)

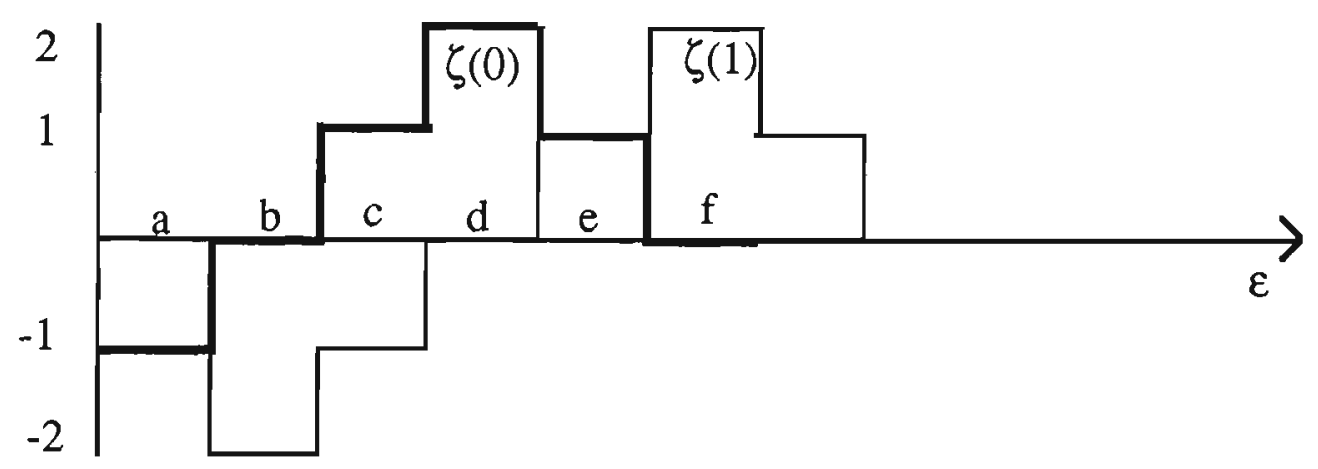

Figure 2.9 (a) $\int_{\psi d} d \theta$ and (b) $\zeta$ as a function of $\varepsilon$

\begin{tabular}{|c|c|c|c|c|c|c|}
\hline $\begin{array}{c}\text { rotor } \\
\text { position }\end{array}$ & $\zeta(1)$ & $\zeta(2)$ & $\psi\left(\theta_{\mathrm{a}}\right)$ & $\psi\left(\theta_{\mathrm{b}}\right)$ & $\mathrm{T}_{\text {energy }}$ & $\mathrm{T}$ \\
\hline $\mathrm{a}$ & -1 & -1 & 0 & 1 & $2 \mathrm{Ai}_{\mathrm{b}}$ & $2 \mathrm{Ai_{b }}$ \\
\hline $\mathrm{b}$ & 0 & -2 & -1 & 1 & $2 \mathrm{~A}\left(\mathrm{i}_{\mathrm{b}}-\mathrm{i}_{\mathrm{a}}\right)$ & $2 \mathrm{~A}\left(\mathrm{i}_{\mathrm{b}}-\mathrm{i}_{\mathrm{a}}\right)$ \\
\hline $\mathrm{c}$ & 1 & -1 & -1 & 0 & $-2 \mathrm{Ai} \mathrm{i}_{\mathrm{a}}$ & $-2 \mathrm{Ai} \mathrm{i}_{\mathrm{a}}$ \\
\hline $\mathrm{d}$ & 2 & 0 & -1 & -1 & $2 \mathrm{~A}\left(\mathrm{i}_{\left.\mathrm{a}+\mathrm{i}_{\mathrm{b}}\right)}\right)$ & $2 \mathrm{~A}\left(\mathrm{i}_{\mathrm{a}+\mathrm{i}}\right)$ \\
\hline $\mathrm{e}$ & 1 & 1 & 0 & -1 & $-2 \mathrm{Ai}$ & $-2 \mathrm{Ai}$ \\
\hline $\mathrm{f}$ & 0 & 2 & 1 & -1 & $2 \mathrm{~A}\left(\mathrm{i}_{\mathrm{a}}-\mathrm{i}_{\mathrm{b}}\right)$ & $2 \mathrm{~A}\left(\mathrm{i}_{\mathrm{a}}-\mathrm{i}_{\mathrm{b}}\right)$ \\
\hline
\end{tabular}

Table 2.1 Torque comparison 


\subsection{Torque in terms of Space Phasors}

For the machine shown in Figure 2.6, let $\theta=0$ at the centre of tooth 0.

Then the space phasors $\underline{\underline{i}}$ and $\Psi$, for the current direction shown in Figure 2.6 can be expressed as

$$
\begin{aligned}
\underline{i} & =\frac{1}{\sqrt{2}}\left\{i_{a}+i_{b}+j\left(-i_{a}+i_{b}\right)\right\} \\
\Psi & =\frac{1}{\sqrt{2}}\left\{\psi_{a}-\psi_{b}+j\left(\psi_{a}+\psi_{b}\right)\right\}
\end{aligned}
$$

Equations (2.32) and (2.33) define the direction and magnitude of the mmf produced by the stator current and rotor magnet respectively.

$$
\begin{aligned}
& \text { since } \theta_{\mathrm{t}} \frac{\partial}{\partial \varepsilon} \int \psi \mathrm{d} \theta=\zeta, \\
& \zeta \quad=\quad-\mathrm{j} \times \Psi \theta_{\mathrm{t}}
\end{aligned}
$$

Note that Equation (2.34) is true only when the slot opening is reduced to zero, which is the machine considered in the conventional approach

Using Equations (2.32), (2.33) and (2.34), Equation (2.31) can be written as

$$
\begin{array}{ll}
\mathrm{T} & =-2 \mathrm{~A} \times \operatorname{Im}\left(\mathrm{i} \Psi^{*}\right) \\
\text { and } & \\
\mathrm{T} & =-2 \mathrm{~A} \times \operatorname{Re}\left(\mathrm{i} \zeta^{*}\right)
\end{array}
$$

Equations (2.35) and (2.36) indicate that the torque of a permanent magnet machine can be expressed in terms of its current and magnet space phasors. Figure 2.10(a) shows the plot of the angle of $\Psi$ and $\zeta$ versus the rotor position $\varepsilon$, and the magnitude of $\Psi$ versus rotor position for a machine with a magnet pitch of $75 \%$ of a pole. Figure 2.10 (b) shows $\Psi$ (the magnitude and angle). The figure shows that the magnitude of the magnet space phasor jumps between 2 and $\sqrt{2}$ (the corners and the centre point of the sides of a squre). Figure 2.10(a) shows that the angle of the magnet space phasor changes for every 45 degrees shift in the rotor position. The change in the angle between the current and magnet space phasors changes the magnitude of the torque. The torque is proportional to the magnitude of the current and magnet space phasors and the sine of the angle between them ( this is proved in Appendix 2). Thus if $\beta$ is the angle between the current and maget space phasors then the torque can be expressed as 
$\mathrm{T}=2 \mathrm{~A}|\underline{\mathrm{i}}||\Psi| \sin \beta$, or

$\mathrm{T}=2 \mathrm{~A}|\underline{\mathrm{i}}| \underline{\underline{\zeta}} \mid \cos \beta$

(a)
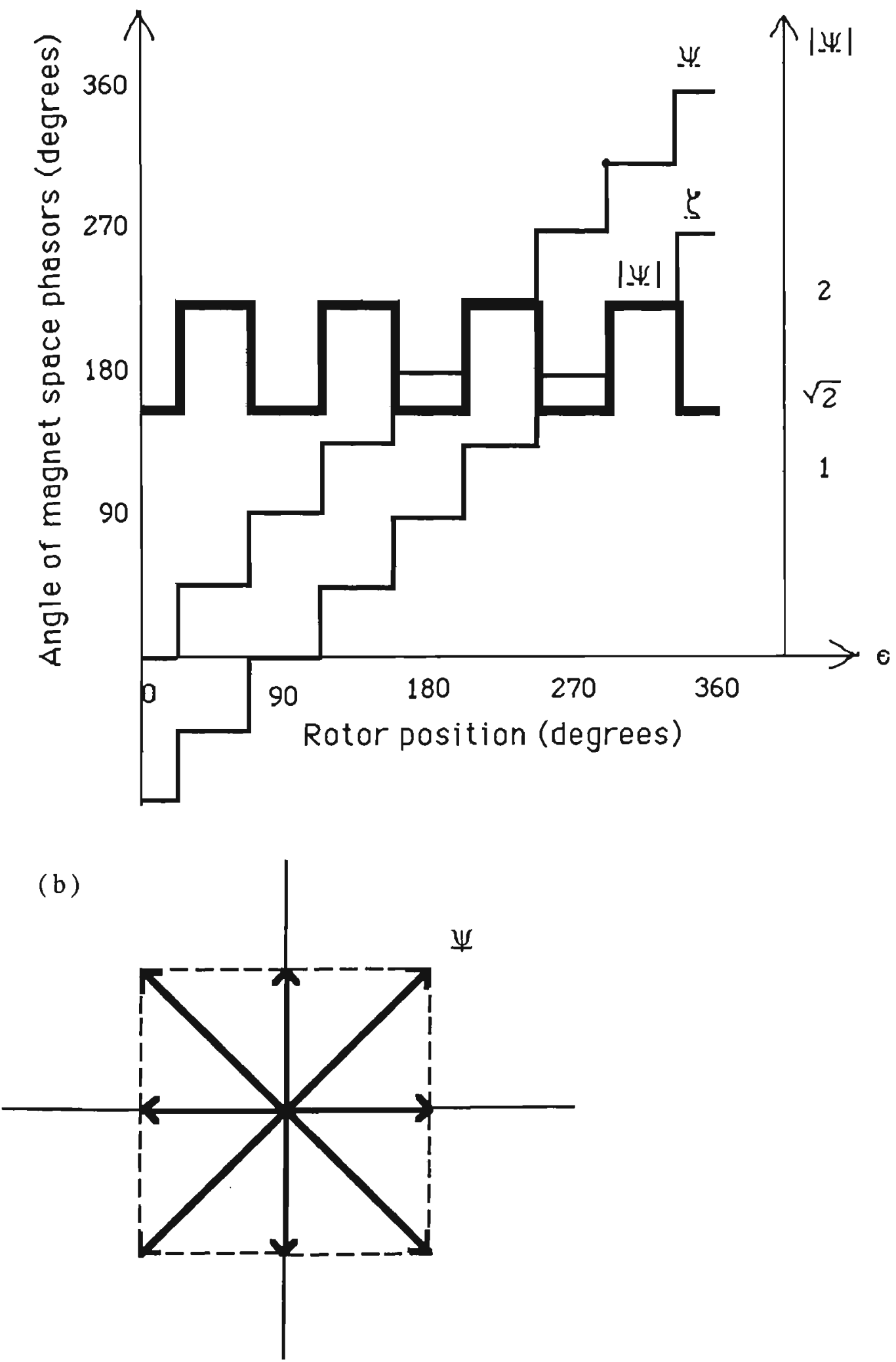

Figure 2.10 The magnet space phasors 


\subsection{Summary}

In this chapter an expression for the energy density of permanent magnets was derived. Force for a system with permanent magnet was calculated using the energy storage method and compared with the measured value. The torque produced by a hypothetical permanent magnet machine was theoretically derived and compared with the theoretical results from conventional approach. It was shown that the torque of a permanent magnet machine is proportional to the product of stator current and rotor magnet space phasors. 


\section{CHAPTER 3 \\ GENERALISED LINEAR MODEL}

\subsection{Introduction}

This chapter generalises the model developed in Chapter 3 to the case for any number of slots and phases. The stator and rotor space phasors are generalised using Discrete Fourier Transforms (DFT). A general expression is developed for useful torque. This DFT model will be most appropriate for machines with a low number of slots/pole since it takes into account the discrete nature of the machine. Although this chapter presents general theoretical conclusions, the servo motor can be analysed using the model of Chapter 2.

\subsection{The Discrete Fourier Transform (DFT)}

\subsubsection{Definition}

"The discrete Fourier transform is an operation that maps an Nth order sequence $\{f(k)\}$ to another Nth order sequence $\{F(n)\}^{\prime \prime}[39]$. The DFT handles data which are discrete in nature. It is periodic with periodicity $\mathrm{N}$. If a sequence of $\mathrm{N}$ terms is to be Fourier transformed then the sequence should have $N$ terms of finite value. If $f(k)$ has $\mathrm{N}$ terms of finite value in the time (or in this case, space) domain, the Fourier transform $\mathrm{F}(\mathrm{n})$ returns the values in the frequency domain.

The DFT pair is defined as [39]

$$
\begin{aligned}
& f(k)=\sum_{n=0}^{N-1} F(n) e^{2 \pi j n k / N} \quad \text { where } k=0,1 \ldots(N-1) \\
& F(n)=\frac{1}{N} \sum_{k=0}^{N-1} f(k) e^{-2 \pi j n k / N} \quad \text { where } n=0,1 \ldots(N-1)
\end{aligned}
$$

The term $e^{2 \pi j / N}$ can be replaced by a weighting kernel $W$

$$
W=e^{2 \pi j / N}
$$


Equation (3.1) is called the discrete Fourier transform and Equation (3.2) is called the inverse discrete Fourier transform.

A useful theorem is the "shifting theorem" which states that the DFT of $f(k-a)$ is $\mathrm{F}(\mathrm{n}) \mathrm{W}^{-n a}$. That is, an extra phase term appears in the transform.

\subsubsection{Suitability of DFT for machine analysis}

In the case of most electrical machines there is a periodicity, ie, the behaviour of each pole pair is identical. If $\mathrm{N}$ is the number of slots per pole pair, and if the flux and the current are treated as a system of discrete packets having $\mathrm{N}$ values pertaining to the $\mathrm{N}$ teeth in a pole pair, the DFT can be applied to a machine. Since electrical machines are in general discrete in nature, the currents and the resulting fluxes can be treated as a system of discrete pockets.

3

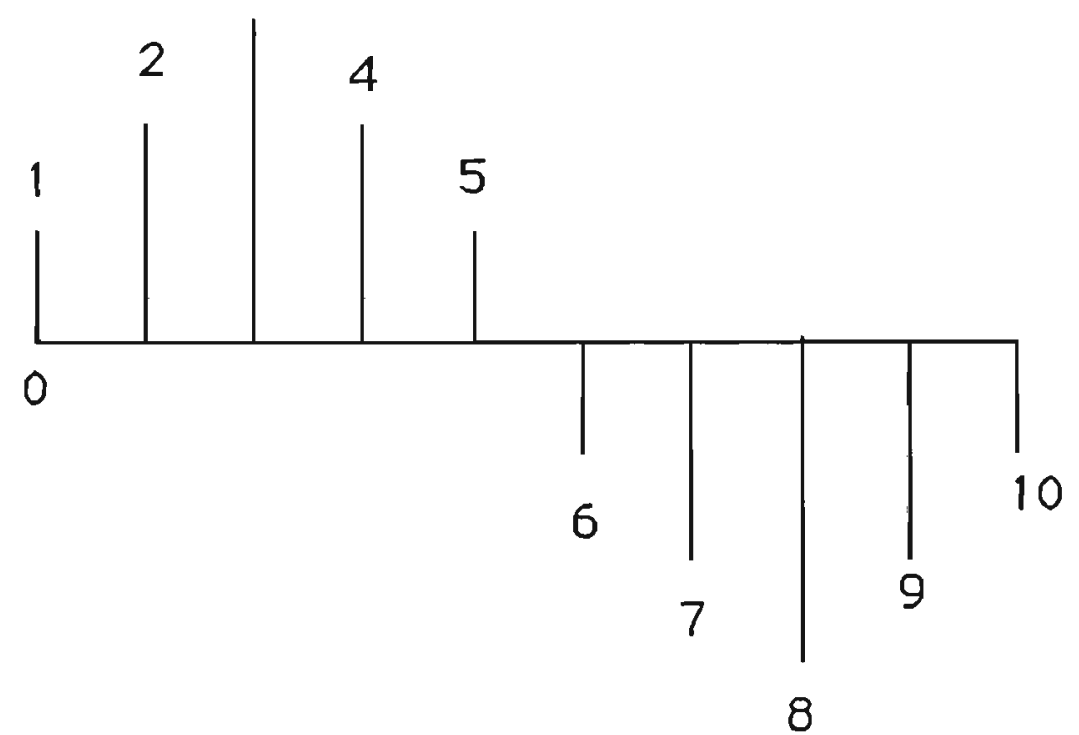

Figure 3.1 Space distribution of flux

Figure 3.1 shows the space distribution of flux, in discrete terms for a machine with ten teeth per pole pair. Each tooth is considered to have a definite value of flux. Since the ' $N$ ' teeth cover a pole pair and a pole pair covers $2 \pi$ electical radians, the values of flux densities are space shifted from each other by an angle $\frac{2 \pi}{N}$.

In general, for a machine, if $\mathrm{k}$ represents the tooth number, the flux of each tooth can be represented by $\phi(\mathrm{k})$. This will result in a sequence of $\mathrm{N}$ terms having finite values 
in the space domain with periodicity $N$. The discrete Fourier transform of $\phi(k)$ would then return $\Phi(\mathrm{n})$ (n varies from 0 to $N-1)$, the harmonic content of $\phi(k)$.

\subsubsection{Limitations of the DFT}

The transform may be usefully applied to systems where if an equation applies to the ' $n$ 'th tooth, then a similar equation applies to the ' $n+1$ ' th tooth. Thus the effect of slotting can be analysed but the rotor must be free of slots or any slotting on the rotor must be ignored. Also, machines with salient poles will be disqualified. In addition, since the DFT has the property of linearity, it becomes more difficult to use in the presence of saturation. However, permanent magnets in their linear region can be modelled quite adequately. The technique offers little promise for the analysis of an induction motor, but a useful analysis may be produced for a permanent magnet ac motor with surface mounted magnets. The analysis may be expected to give a slight improvement in accuracy in the analysis of machines with many slots per pole pair and the improvement may become quite significant in machines with few slots per pole pair. The DFT has not been widely applied to magnetic problems, but Katyl [40] shows the applicability of the Fast Fourier Transform (FFT) convolution to air coil magnetostatic problems.

\subsection{The Mathematical Model of a Permanent Magnet Machine with Surface Mounted Magnets Using DFT}

\subsubsection{Assumptions}

(1) The permanent magnet is operating in the linear region.

(2) The machine is not saturated.

(3) Flux fringing is negligible.

(4) The machine is not skewed.

Since the permanent magnet machine does not have slots in the rotor and the magnets are surface mounted, the conditions for application of the DFT are satisfied. 


\subsubsection{The Magnet Edge Function, $\zeta(\mathrm{k})$}

Using Equation (2.7) the flux density in the airgap due to the permanent magnet is

$$
\mathrm{B}=\frac{\psi \mathrm{B}_{\mathrm{r}} \mathrm{g}_{\mathrm{m}}}{\mathrm{gm}_{\mathrm{m}}+\mathrm{g}_{\mathrm{a}}}=\frac{\psi \mathrm{B}_{\mathrm{r}} \mathrm{gm}_{\mathrm{m}}}{\mathrm{g}}
$$

Therefore, airgap mmf due to permanent magnet $=\frac{B}{\mu_{0}} \mathrm{~g}=\frac{\psi \mathrm{B}_{\mathrm{r}} \mathrm{gm}_{\mathrm{m}}}{\mu_{\mathrm{o}}}$

The function $\psi$ in Equation (3.3) varies from tooth to tooth and also with different points in the same tooth. It is 1 or -1 where a magnet is present and zero elsewhere. Let $\psi_{\mathrm{a}}(\mathrm{k})$ be the mean value of $\psi$ over the ' $\mathrm{k}$ ' th tooth. The value of $\psi_{\mathrm{a}}(\mathrm{k})$ for a stator tooth depends on the extent to which the tooth is covered by the rotor magnets and the polarity of the magnets.

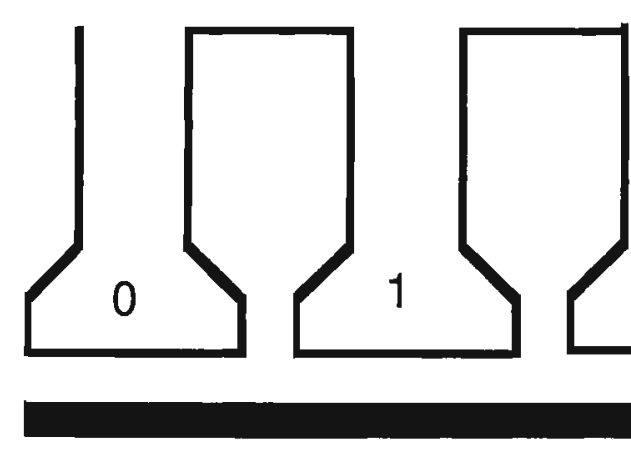

$\mathrm{N}$
$S$

(a) $\Psi_{\mathrm{a}}(0)=1, \Psi_{\mathrm{a}}(1)=1, \psi_{\mathrm{a}}(2)<0.5, \psi_{\mathrm{a}}(3)=-1, \psi_{\mathrm{a}}(4)=-1$ and $\psi_{\mathrm{a}}(5)>-0.5$

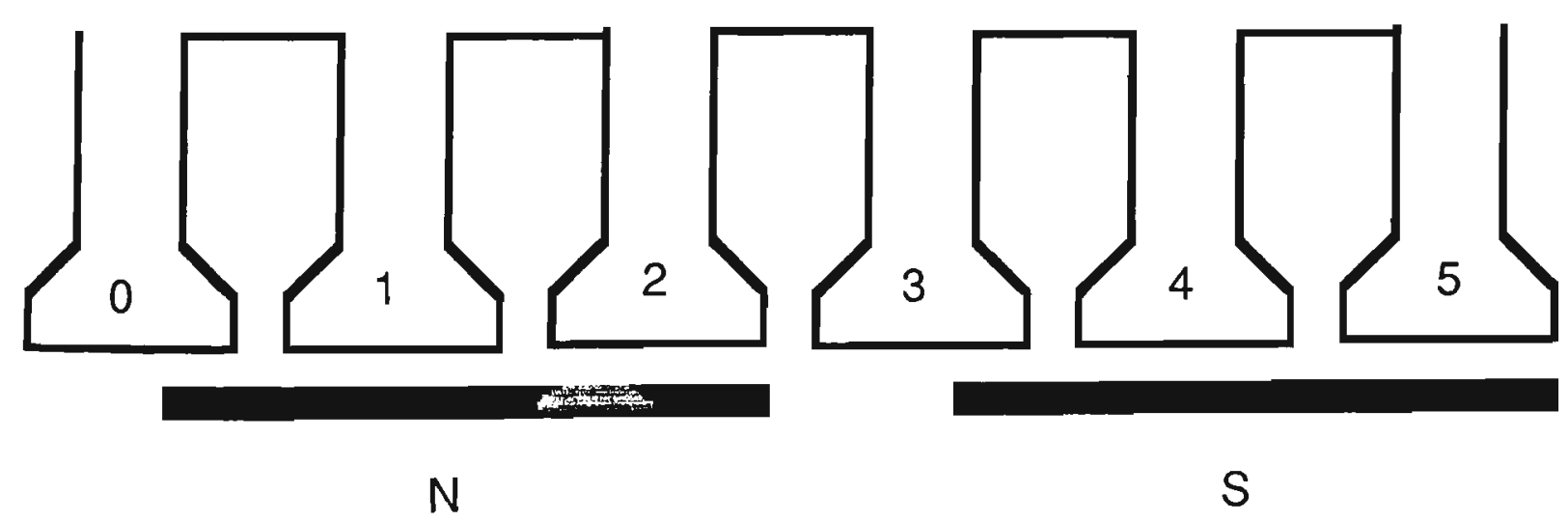

(b) $\Psi_{\mathrm{a}}(0)<0.5, \quad \Psi_{\mathrm{a}}(1)=1, \Psi_{\mathrm{a}}(2)=1, \quad \Psi_{\mathrm{a}}(3)>-0.5, \quad \Psi_{\mathrm{a}}(4)=-1$ and $\psi_{\mathrm{a}}(5)=-1$ 
Figure 3.2 shows two different rotor positions, and gives the value of $\psi_{\mathrm{a}}(\mathrm{k})$ for the six stator teeth indicated by 0 to $5(\mathrm{~N}=6)$. For the rotor position shown in Figure 3.2(a), since teeth 0 and 1 are completely covered by the magnet, the value of $\psi(0)$ and $\psi(1)$ will be 1 at all points along the tooth. Therefore, $\psi_{\mathrm{a}}(0)$ and $\psi_{\mathrm{a}}(1)$ take the value of 1 . The tooth 2 is only partly covered by the magnet which means that $\psi_{\mathrm{a}}(2)$ takes a value of 1 for the portion covered by the magnet, and zero for the portion which is not covered by the magnet. Since less than half of the tooth is covered by the magnet, $\psi_{\mathrm{a}}$ (2) will take a value which would be less than 0.5. A similar argument is true for teeth 3,4 and 5 except that the polarities of $\psi_{\mathrm{a}}(\mathrm{k})$ are reversed since the polarity of the rotor magnet is changed. Thus $\psi_{\mathrm{a}}(\mathrm{k})$ can take any value between -1 and +1 depending on the position of the rotor. The value of $\psi_{\mathrm{a}}(\mathrm{k})$ varies continuously between these two extremes as the position of the rotor is changed. (For a given tooth it can take values 1,0 and +1 for more than one rotor position depending on the increment in rotor position and the pitch of the magnet).

Now, consider a function, $\zeta$, such that, it takes different values for different teeth depending on the rotor position. Figure 3.3 (b) shows the function $\zeta(\mathrm{k})$, which is actually $\theta_{\mathfrak{t}} \frac{d \psi_{\mathrm{a}}(\mathrm{k})}{\mathrm{d} \varepsilon}$ (where $\theta_{\mathrm{t}}$ is the angular pitch of a tooth in mechanical radians) and takes the values $1,2,0,-1,-2$ depending on how many magnet edges are present under the tooth. For those rotor positions when $\psi_{\mathrm{a}}(\mathrm{k})$ takes the value of 1 or -1 , (depending on the polarity of the magnet ) tooth ' $\mathrm{k}$ ' is completely covered by the magnet and the number of magnet edges present opposite to tooth ' $k$ ' is 0 (portion $a-b$ in Figure 3.3(a)), and therefore $\zeta(\mathrm{k})$, takes the value 0 . When a rotor magnet edge moves in under the tooth due to a change in rotor position, there is a change in the value of $\psi_{\mathrm{a}}(\mathrm{k})$ and the rate of change then remains constant (b-c) till the magnet of opposite polarity enters under the same tooth. For those rotor positions represented by b-c in the Figure 3.3 (a), the number of magnet edges opposite to the tooth ' $\mathrm{k}$ ' is 1 , and since the slope of $b-c$ is negative (meaning that the positive polarity magnet is leaving the tooth ' $\mathrm{k}$ ' as $\varepsilon$ increases) the value of $\zeta(\mathrm{k})$, becomes -1 . Further change in rotor position brings in the edges of the other magnet also under the tooth $(\mathrm{k})$. The presence of two magnets with opposite polarity brings a change in $\psi_{\mathrm{a}}(\mathrm{k})$ again, and the change continues at a constant rate (c-d) but with double the slope, till the magnet of positive polarity leaves the tooth. For these rotor positions, the number of magnet edges present opposite to the tooth ' $\mathrm{k}$ ' is 2 , and $\zeta(\mathrm{k})$ takes the value -2 . This value indicates that the number of magnet edges present opposite to the tooth is 2 , and its negative sign indicates that the magnet of positive polarity is leaving the tooth, and the magnet of negative polarity is entering the tooth. When one magnet leaves the tooth there is again a change in $\psi_{\mathrm{a}}(\mathrm{k})$, and afterwards the slope remains constant $(\mathrm{d}-\mathrm{e})$ until the tooth is completely covered by 
the magnet. Accordingly $\zeta(\mathrm{k})$, takes the value -1 . Then this half cycle is repeated again as the position of the rotor changes and $\zeta(\mathrm{k})$ takes the shape shown in the Figure 3.3 (b).
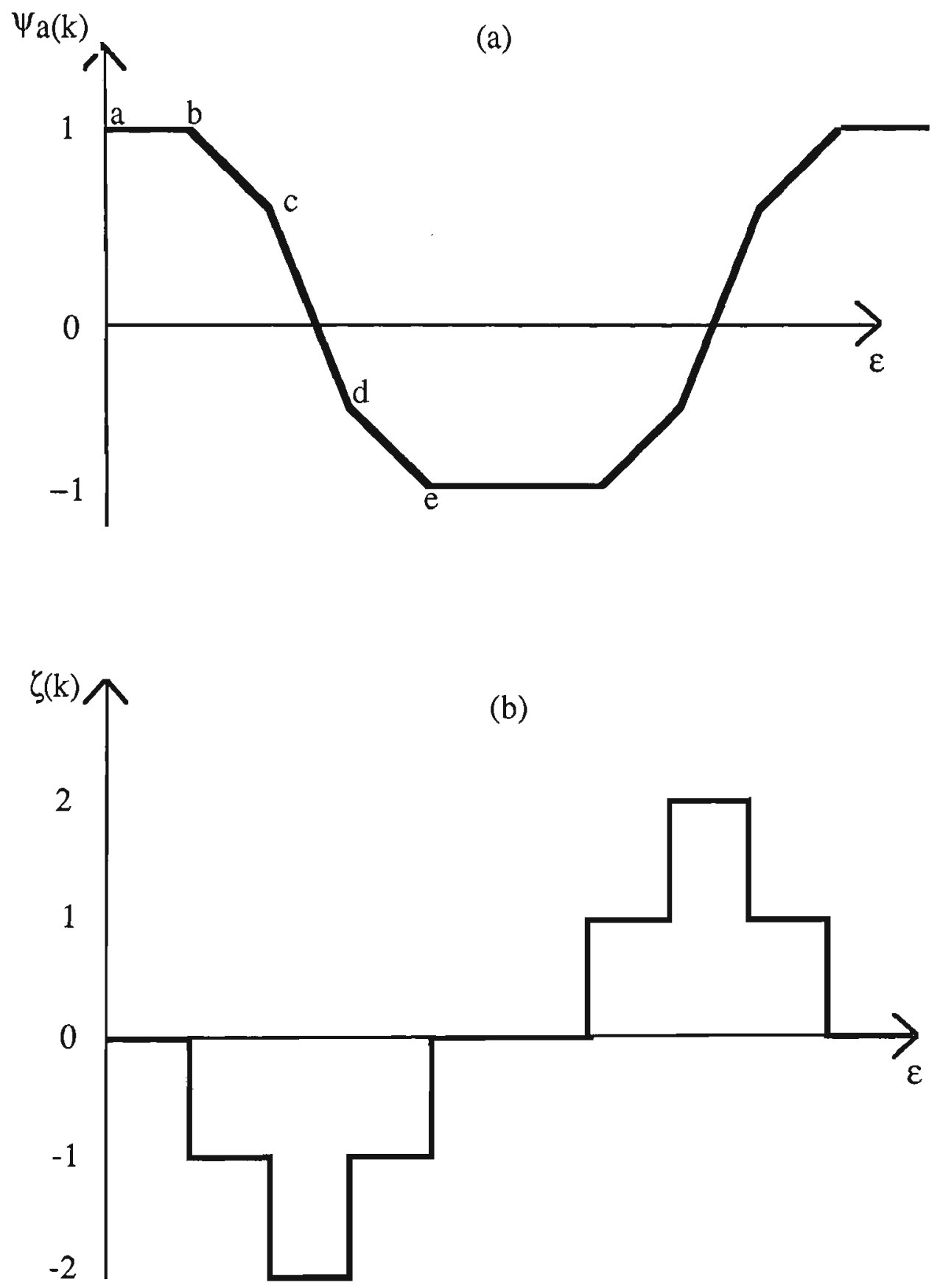

Figure 3.3 $\quad$ (a) $\psi_{\mathrm{a}}(\mathrm{k})$ and (b) $\zeta(\mathrm{k})$ as a function of $\varepsilon$

Thus, the value of $\zeta(\mathrm{k})$ indicates the presence or absence of the magnet edges opposite to a tooth, and also the polarity of the magnet if present. Therefore, complete knowledge of $\zeta(\mathrm{k})$ is equivalent to complete knowledge of the magnet fluxes. Once the values of $\zeta(\mathrm{k})$ are known, $\zeta(\mathrm{k})$ can be transformed and $Z(\mathrm{n})$, which is the transform of $\zeta(\mathrm{k})$, can be written as 
$Z(n)=\frac{1}{N} \sum_{k=0}^{N-1} \zeta(k) e^{-2 \pi j n k / N}$

\subsubsection{Useful Torque}

The useful torque of a machine using energy considerations can be obtained by differentiating the electrical energy input with rotor position. Considering a single coil, the useful torque due to a current ' $i$ ' in the coil can be written as,

$\mathrm{T}_{\text {useful }}=\mathrm{i} \frac{\mathrm{d} \lambda}{\mathrm{d} \varepsilon}$

Where $\mathrm{d} \lambda$ is the incremental flux linkage for the coil. Only the flux linkage due to rotor magnets changes with position and the flux linkage due to stator current does not change with position. Therefore, if $\mathrm{p}$ is the number of pole pairs, Equation (3.5) becomes the current multiplied by the sum of the derivative of $\psi_{\mathrm{a}}(\mathrm{k})$ of all the teeth enclosed by the coil multipled by $\frac{B_{r} g_{m} L R \theta_{t} p}{g}$. Hence, the torque due to a fully pitched single coil, with coil sides in slots ' $a$ ' and ' $a+\frac{N}{2}$ ' can be written as (proof is given in Appendix 3)

$$
\mathrm{T}=\mathrm{C} i \sum_{\mathrm{k}=0}^{\frac{\mathrm{N}}{2}-1} \zeta(\mathrm{k}+\mathrm{a})
$$

Where $C=\frac{B_{r} g_{m} L R \theta_{t} p}{g}$, the number of the slot between teeth ' $k$ ' and ' $k+1$ ' is $\mathrm{k}+1$.

Using equation (3.1), equation (3.6) can be written as

$$
T=C i \sum_{k=0}^{\frac{N}{2}}-1 \sum_{n=0}^{N-1} Z(n) e^{2 \pi j n(k+a) / N}
$$




$$
=\quad C i \sum_{n=0}^{N-1} Z(n) e^{2 \pi j a n / N} \sum_{k=0}^{\frac{N}{2}-1} e^{2 \pi j n k / N}
$$

After simplification (the process of simplification is given in Appendix 3) equation (3.7) reduces to

$$
T=C i \sum_{n=0}^{N-1} Z(n) e^{2 \pi j a n / N} e^{-\pi j n / N} \frac{j}{\sin \left(\frac{n \pi}{N}\right)}
$$

By symmetry, since $\zeta(k)=-\zeta\left(k+\frac{N}{2}\right), Z(n)$ will be equal to zero for even values of n.

For odd values of $\mathrm{n}$ the slot current due to a single coil can be expressed in DFT as (proof is given in Appendix 3)

$$
\begin{aligned}
& I(n)=\frac{2 \mathrm{i}}{N} e^{-2 \pi j n a / N} \\
& I^{*}(n)=\frac{2 \mathrm{i}}{N} e^{2 \pi j n a / N}
\end{aligned}
$$

Where * indicates the complex conjugate

Therefore Equation (3.8) can be written as

$$
T=C \frac{N}{2} \sum_{n=0}^{N-1} Z(n) I^{*}(n) e^{-\pi j n / N} \frac{j}{\sin \left(\frac{n \pi}{N}\right)}
$$

(When the actual machine parameters are substituted, the imaginary part of equation (3.11) will be zero.)

\section{Significance of the terms in Equation (3.11)}

The torque formula given by Equation (3.11) may be seen in the same light as the familiar formula for the continous case, which uses mmf space phasors. The term $e^{-j \pi n / N}$ arises because the axis for $k=0$ is on the centre of a slot for the current DFT and it is on the centre of a tooth for the magnet DFT. There is thus a separation of $\frac{\pi}{N}$ 
electrical radians. If the centre of slot 0 is selected as the point where the stator angle is zero, $\frac{\pi \mathrm{n}}{\mathrm{N}}$ radians have to be subtracted from the phase angle of the magnet DFT to produce a magnet space phasor in the same reference system. Or, equivalently, the centre of the tooth can be set to zero and in this case, an angle of $\frac{\pi n}{N}$ has to be added to the phase angle of current DFT.

The DFT themselves represent the stator and rotor mmfs. However the current DFT is rotated backward by 90 degrees in the fundamental and multiples of 90 degrees in the harmonics. The magnet DFT represents the edge of the magnet and the fundamental is also rotated 90 degrees backward on the average, from the centre of the north pole. Similarly, the magnet harmonics are rotated by multiples of 90 degrees.

\section{General winding}

Since all the equations of the machine are linear, the torque produced by currents in other slots can be found by superposition. That is, $I^{*}(n)$ for a pair of slots can be replaced by the sum of (the complex conjugates of) the DFTs for all pairs of slots. It is shown in Appendix(3) that if 's' is the pitch of the coil expressed in number of slots, for a machine with ' $m$ ' phases, the DFT of the current in a ' $m$ ' phase winding is (proof is given in Appendix 3)

$$
\begin{aligned}
I(n) & =\frac{4 j \underline{i}^{*}}{N} \sin \frac{n \pi s}{N} e^{-j \pi s n / N} \frac{\sin \frac{n \pi}{2 m}}{\sin \frac{n \pi}{N}} e^{-j \pi n(N / 2 m-1) / N}, \text { for odd values of ' } n \text { ' } \\
& =0 \quad \text { for even values of ' } n \text { ' }
\end{aligned}
$$

Where $\underline{\mathrm{i}}^{*}$ is the the complex conjugate of the current space phasor $\underline{\mathrm{i}}$ (defined in Appendix 3) which is given by

$$
\underline{\mathrm{i}}=\mathrm{i}_{0}+\mathrm{i}_{1} \mathrm{~W}(\mathrm{~N} / 2 \mathrm{~m})+\ldots \ldots \ldots+\mathrm{i}(\mathrm{m}-1) \mathrm{W}(\mathrm{m}-1) \mathrm{N} / 2 \mathrm{~m}
$$

In Equation (3.12) $\sin \frac{n \pi s}{N}$ is the pitch factor and the term $\frac{\sin \frac{n \pi}{2 m}}{\sin \frac{n \pi}{N}} e^{-j \pi n(N / 2 m-1) / N}$ sums up the mmfs due to the conductors in a phase belt vectorially, automatically taking into account the distributed nature of the winding. In the conventional machine analysis 
the effects of distributing and chording the winding are taken into account by including two correction factors ( distribution factor and the pitch factor). These two factors are calculated separately and the flux is multiplied with these reduction factors to calculate the correct level of flux. But the analysis using DFT takes these factors into account automatically as shown by the Equation (3.12).

Some appreciation of the DFT may be achieved by illustration. Using Equation (3.12), for a three phase machine with twelve slots per pole pair, and with a coil pitch of 5 slots $\left(\frac{5}{6}\right.$ pitch $)$

$$
\begin{aligned}
& I(1)=0.62 \underline{\underline{i}}^{*} \\
& I(3)=0.33 \underline{\mathrm{i}}^{*} \\
& I(5)=0.045 \underline{\mathrm{i}}^{*} \\
& I(7)=0.045 \underline{\mathrm{i}}^{*} \\
& I(9)=0.33 \underline{\mathrm{i}}^{*} \\
& I(1)=0.62 \underline{\mathrm{i}}^{*}
\end{aligned}
$$

and for a coil pitch of 4 slots

$$
\begin{aligned}
& I(1)=(0.5387+j 0.1444) \underline{i}^{*} \\
& I(3)=0 \\
& I(5)=-(0.039+j 0.144) \underline{i}^{*} \\
& I(7)=-(0.039-j 0.144) \underline{i}^{*} \\
& I(9)=0 \\
& I(11)=(0.5387-j 0.1444) \underline{i}^{*}
\end{aligned}
$$

This shows that, apart from the current space phasor, I (11) is the complex conjugate of I(1) and I (9) is the complex conjugate of I(3), and I (7) is the complex conjugate of $\mathrm{I}(5)$. The fundamental is contained in the combination of $\mathrm{I}(1)$ and $\mathrm{I}(11)$. The third harmonic is contained in the combination of I(3) and I(9), and so on. Figure 3.4 (a) and (b) shows the positions of I(1) and I(11), for two arbitrarly chosen current space phasors.

The model can be extended to handle machines with skewing. For the servo motor considered in this thesis, this model has been applied and the skewing has been included in the computer simulation. The machine has been divided into forty concentric rings (to obtain a smooth torque/position relationship) which are space shifted relative to each other to produce the effect of skew. 

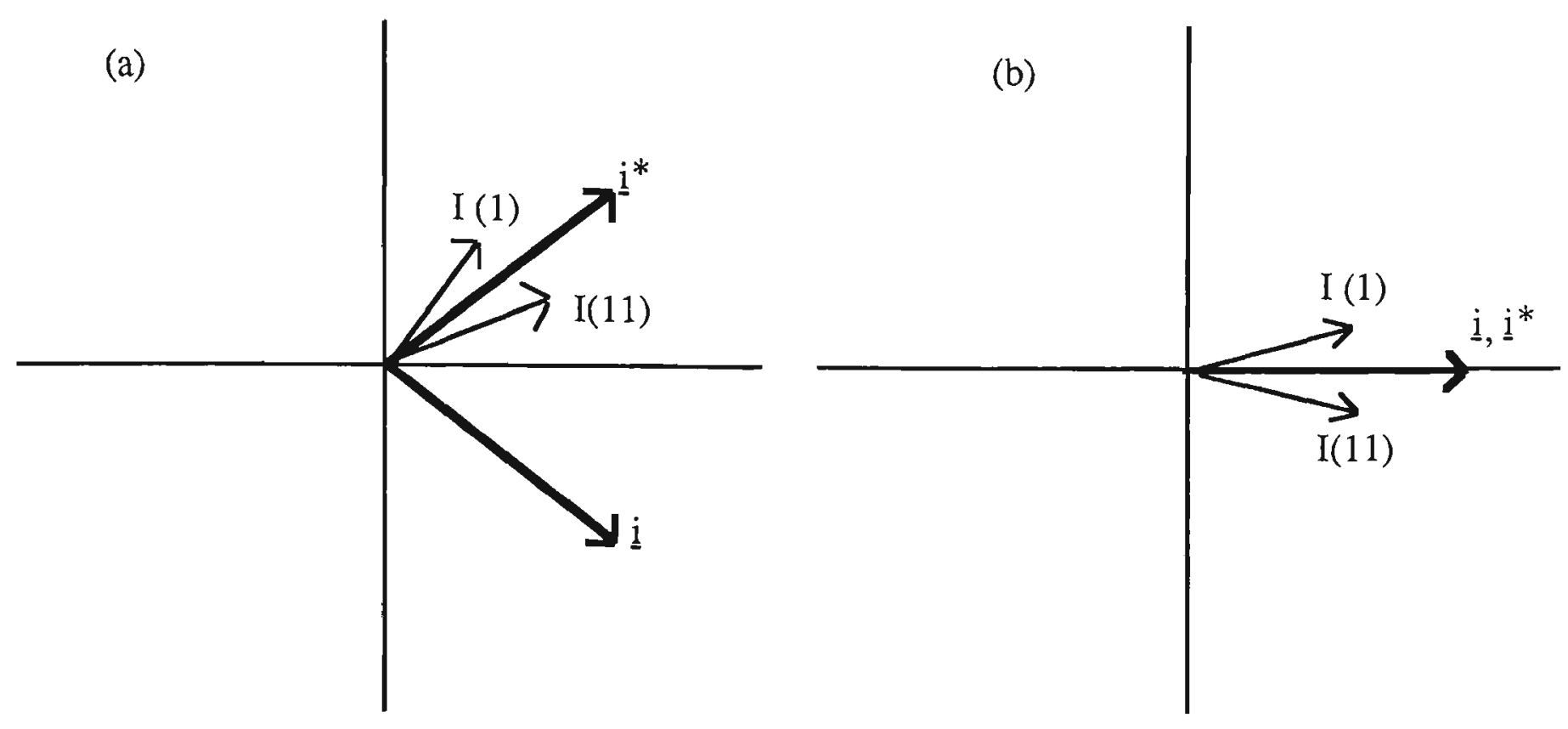

Figure $3.4 \quad I(1)$ and $I(11)$, for two different current space phasors

\subsection{Summary}

In this chapter a mathematical model was developed for an axial flux surface mounted permanent magnet machine using DFT. Fringing, saturation and skewing were neglected in the model and it was also assumed that the magnet operates in the linear region. An expression for useful torque was derived in terms of DFT. A new function, $\zeta(\mathrm{k})$, the value of which gives the sum of the number of magnet edges present opposite to a tooth, was introduced. 


\section{CHAPTER 4}

\section{COGGING TORQUE}

\subsection{Introduction}

In a permanent magnet machine cogging torque arises due to the tendency of the rotor magnets to lock on to the stator teeth. It arises due to the discrete nature of the machine and slotless machines will not have any cogging torque. "In a permanent magnet machine cogging torque arises from the interaction of rotor magnets with steel teeth on the stator. Cogging torque produces both vibration and noise which may be amplified in variable speed drives when the torque frequency coincides with a mechanical resonant frequency of stator or rotor. Cogging torque is also detrimental to the performance of position control systems such as robots and to the performance of speed control systems particularly at low speed" [29]. Therefore the prediction of cogging torque becomes important for permanent magnet machines.

Li and Slemon [29] predict the cogging torque using the coenergy concept and the finite element technique. De La Ree and Boules [27] develop a model which predicts cogging using the flux density distribution and the change of energy in the airgap. They do not appear to consider energy in the magnet. In this chapter, the cogging torque will be predicted by taking into account the energy in the airgap as well as the energy in the magnet. Since a machine with no skewing will have a high cogging torque, the model will be first tested for a machine without skew to see the correlation between the predicted and measured values of cogging torque. Then the model will be applied to a machine with skew and the results will be compared with the measured values of cogging torque.

\subsection{Calculation of Cogging Torque [41].}

\subsubsection{Assumptions}

The following assumptions are made

1. The permanent magnet is operating in the linear region. 
2. There is no flux fringing.

\subsubsection{Energy calculations for an axial flux permanent magnet machine}

Cogging torque can be evaluated by calculating the rate of change of stored energy with position when the current in the machine is zero. Thus it is independent of current and depends only on rotor position.

The stored energy in a machine pertaining to a tooth is made up of the following.

1. The energy under the tooth which in turn consists of energy in the airgap and in the magnet.

2. The energy in the magnet under the slot pertaining to the tooth.

It is assumed that there is no energy stored in the iron. Since flux fringing is ignored in the model, flux density is set to zero in the slot area.

Energy in the airgap under tooth ' $\mathrm{k}$ ' can be calculated by integrating the energy density of air over the volume of the tooth

Energy density in the air gap $=\frac{\mathrm{B}^{2}}{2 \mu_{\mathrm{O}}}$

Energy in the airgap under tooth ' $k$ ' (by fixing $\theta=0$ at the centre of tooth ' 0 ') is given by

$$
\begin{aligned}
& \mathrm{E}_{\mathrm{ta}}(\mathrm{k})=\frac{1}{2 \mu_{0}} \int^{\frac{2 \pi \mathrm{k}}{\mathrm{N}}+\frac{\theta_{\mathrm{t}}}{2}} \frac{\mathrm{B}^{2}(\mathrm{k}) \mathrm{g}_{\mathrm{a}} \text { LR }}{\mathrm{p}} \mathrm{d} \theta \\
& \frac{2 \pi \mathrm{k}}{\mathrm{N}}-\frac{\theta_{\mathrm{t}}}{2}
\end{aligned}
$$

Energy in the magnet under tooth ' $\mathrm{k}$ ' can be calculated by integrating the energy density of magnet over the volume of the tooth

From Equation (2.5)

Energy density in the magnet $=\frac{\mu_{0} \mathrm{H}^{2}}{2}$ 
From Equation (2.1) for a permanent magnet operating in its linear region

$$
\mathrm{H}=\frac{\left\{\mathrm{B}-\psi \mathrm{B}_{\mathrm{r}}\right\}}{\mu_{\mathrm{O}}}
$$

Therefore, energy in the magnet under tooth ' $k$ ' is given by

$$
\begin{gathered}
E_{t m}(k)=\frac{1}{2 \mu_{0}} \int_{\frac{2 \pi k}{N}+\frac{\theta_{t}}{2}}^{\frac{\left(B(k)-\psi(k) B_{r}\right)^{2} g_{m} L R}{p}} d \theta \\
p
\end{gathered}
$$

Energy in the magnet opposite to the slot pertaining to tooth ' $\mathrm{k}$ ' can be obtained by integrating the energy density of the magnet over the volume of the magnet projecting into the slot area pertaining to the tooth ' $k$ '. Therefore, the energy stored in the magnet, pertaining to slot ' $\mathrm{k}$ ' is:

$$
\begin{aligned}
& \frac{2 \pi \mathrm{k}}{\mathrm{N}}+\frac{\theta_{\mathrm{t}}}{2}+\theta_{\mathrm{S}}(\mathrm{k}) \\
& \mathrm{E}_{\mathrm{S}}(\mathrm{k})=\frac{1}{2 \mu_{\mathrm{o}}} \quad \int^{\mathrm{f}\left(\mathrm{B}(\mathrm{k})-\psi_{\mathrm{s}}(\mathrm{k}) \mathrm{B}_{\mathrm{r}}\right\}^{2} \mathrm{gm}_{\mathrm{m}} \mathrm{LR}} \mathrm{p} \mathrm{d} \theta \\
& \frac{2 \pi \mathrm{k}}{\mathrm{N}}+\frac{\theta_{\mathrm{t}}}{2}
\end{aligned}
$$

where the angle $\theta_{S}(\mathrm{k})$ defines the extent by which the magnet is projecting into the slot ' $\mathrm{k}$ ', which depends on the rotor position. $\psi_{\mathrm{s}}(\mathrm{k})$ is the value of $\psi$ opposite to the slot ' $k$ '.

The total energy $\mathrm{e}(\mathrm{k})$ pertaining to ' $\mathrm{k}$ 'th tooth/slot combination is

$$
\mathrm{e}(\mathrm{k})=\mathrm{E}_{\mathrm{ta}}(\mathrm{k})+\mathrm{E}_{\mathrm{tm}}(\mathrm{k})+\mathrm{E}_{\mathrm{S}}(\mathrm{k})
$$

Considering the fact that the cogging torque arises only due to flux set up by the magnet, the value of airgap flux density $\mathrm{B}(\mathrm{k})$ as in Equation (4.2) and (4.3) would be 
$\mathrm{B}(\mathrm{k})=\frac{\psi(\mathrm{k}) \mathrm{B}_{\mathrm{r} g \mathrm{~m}}}{\mathrm{~g}_{\mathrm{m}}+\mathrm{ga}_{\mathrm{a}}} \quad$ (from Equation $\left.(2.7)\right)$

Substituting this in Equations (4.2) and (4.3)

$$
\mathrm{E}_{\mathrm{ta}}(\mathrm{k})+\mathrm{E}_{\mathrm{tm}}(\mathrm{k})=\frac{\mathrm{LR} \theta_{\mathrm{l}} \mathrm{B}_{\mathrm{r}}^{2} \mathrm{~g}_{\mathrm{m}} \psi_{\mathrm{m}}(\mathrm{k})}{2 \mathrm{p} \mu_{\mathrm{o}}}\left[1-\frac{\mathrm{g}_{\mathrm{m}}}{\mathrm{g}}\right]
$$

Where, $\quad \psi_{\mathrm{m}}(\mathrm{k})=\frac{1}{\theta_{\mathrm{t}}} \int_{\frac{2 \pi \mathrm{k}}{\mathrm{N}}-\frac{\theta_{\mathrm{t}}}{2}}^{\frac{2 \pi \mathrm{k}}{2}} \psi^{2}(\mathrm{k}) \mathrm{d} \theta$

(There does not appear to be any useful way of representing $\psi_{\mathrm{m}}(\mathrm{k})$ in terms of the magnet edge function, $\zeta(\mathrm{k})$ )

Equation (4.4) can not be mathematically simplified since the limits of integration vary with the rotor position. When the model is computer simulated, the limits are estimated with respect to the the position of the rotor and corresponding energies opposite to the slots are estimated. The value of $\mathrm{e}(\mathrm{k})$ is found by adding this with the energy opposite to the tooth. Then the total stored energy can be calculated as:

$E_{\text {total }}=p e(k)$

The cogging torque is given by $\mathrm{T}=\frac{\partial \mathrm{E}_{\text {total }}}{\partial \varepsilon}$.

\subsection{Results}

\subsubsection{Single phase machine without stator offset and rotor skewing}

Figure 4.1 shows the developed layout of an axial flux machine without an offset between the two stators. In a machine without an offset the teeth of the two stators are exactly facing each other. In other words, there is no space shift between the windings of stator one and two. Using the developed model, the cogging torque was predicted for a laboratory machine which has neither offset nor skewing. The machine 


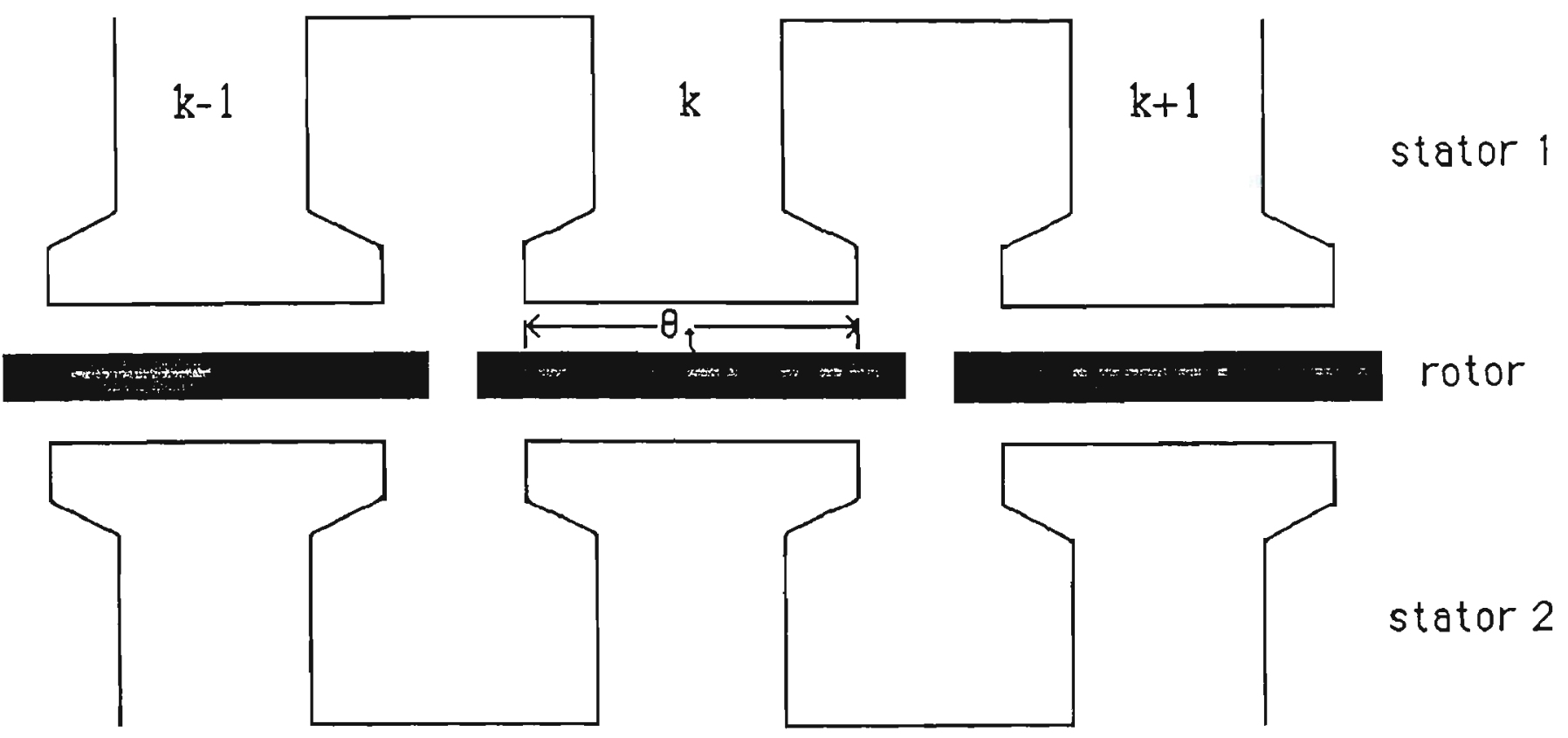

Fig ure 4.1 Developed layout of an axdal flux machine with one slot per pole and without offset.

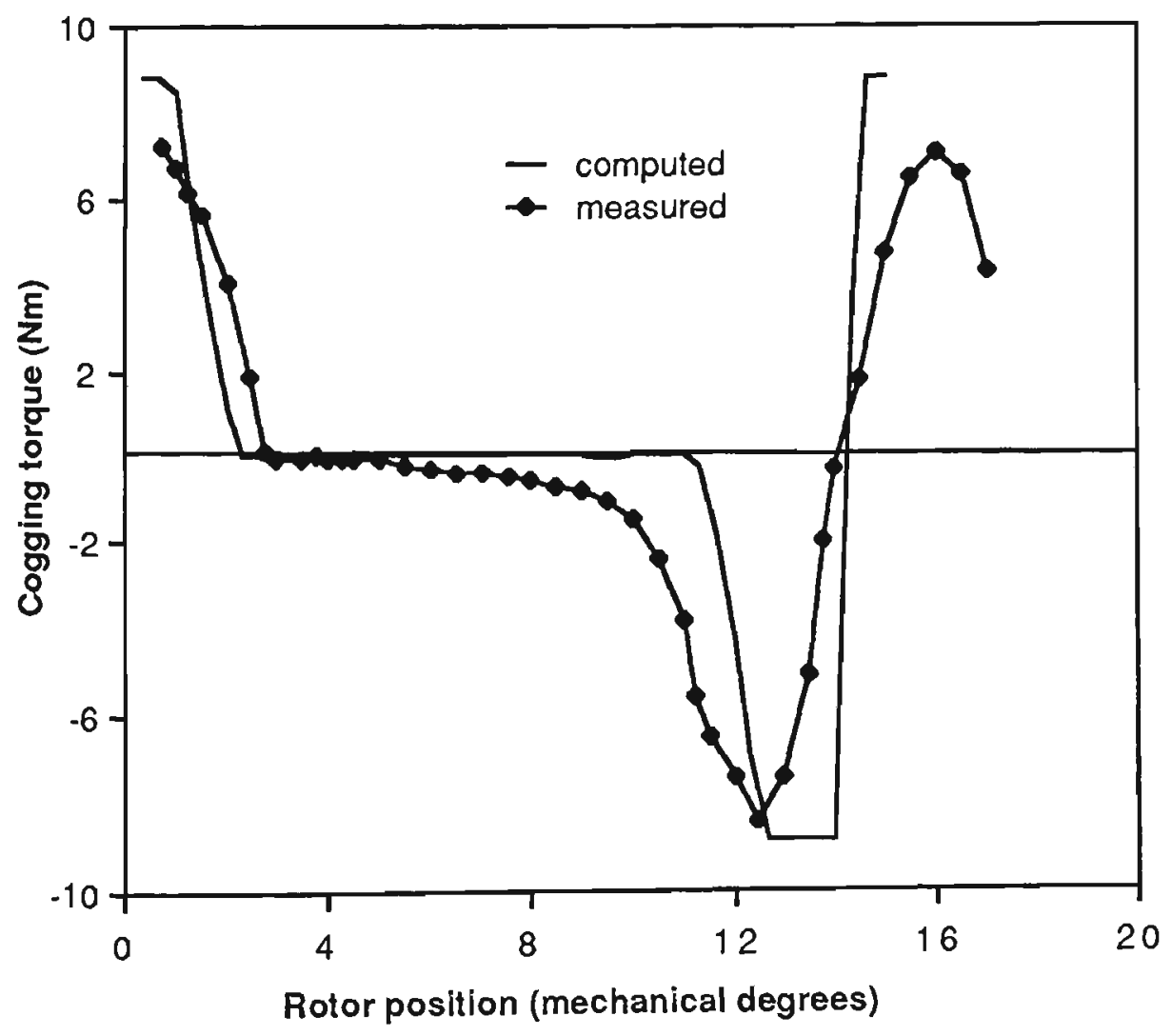

Figure 4.2 Cogging torque vs rotor position 
parameters are given in Appendix 4. It is a single phase machine with twenty four poles in the rotor and twenty four slots in the stator. Hence the machine has one slot per pole and is highly discrete. Since there is no skewing in the machine the cogging torque is very high. The computer simulation for predicting the cogging torque of this machine involves division of the machine into ten concentric circular rings, and calculation of the torque at the average radius of each of those ten segmented machines. The flow diagram of the computations is shown in Appendix 4. The cogging torque was measured experimentally using a strain gauge amplifier for different rotor positions. The results are presented in Figure 4.2 .

The maximum magnitude of the measured torque is less than the predicted torque. This could be due to the fact that the model takes neither saturation nor fringing into account. Because of the peculiar geometry of axial flux machines the tooth stem at the inner radius can become saturated even for zero stator current. Since the effect of fringing is neglected in the model, the predicted torque curve shows sharp changes between zero and peak torques.

\subsubsection{The servo motor}

Since the stators of the new servo motor are offset by half a tooth pitch, and the teeth of the two stators do not face each other, for the purpose of analysis the configuration of the machine is changed. The developed layout of the actual machine is shown in Figure 4.3 (a). Observing from the rotor, starting from the portion of the tooth marked 0 , ( in Figure 4.3 (a)) it looks as if the rotor faces the portion of the tooth marked 0 , and then the slot carrying current io, and the tooth portion marked 1 and then the slot carrying the other phase current $i_{1}$, and the tooth portion marked 2 and so on. This is depicted in Figure 4.3 (b) which looks as if the machine has four slots per pole pole pair on one stator and the other stator is slot free. This modified machine shown in Figure 4.3 (b) is used for analysis.

A new two phase axial flux permanent magnet servo motor was built for this project with an offset of half a slot pitch between the two stators. The machine has one phase on either side of the rotor. To give the space shift of 90 degrees electrical between the windings of the two phases, one stator of the machine is shifted by half a slot with respect to the other stator. This means that the slot of one stator would be facing the centre of the tooth of the other stator. The dimensions of the new machine are given in Appendix 4. The stators were made by winding a strip of steel on a circular former and the slots were cut with an end milling machine. The magnets are Nd-Fe-B which were 
cut with straight edges using a diamond saw. These methods prevented the proper skewing. The magnets were skewed by $70^{\circ}$ electrical since computer studies suggested that there would be little improvement in the cogging torque if they were skewed by $90^{\circ}$ and both the slots and magnets were straight sided.

(a)
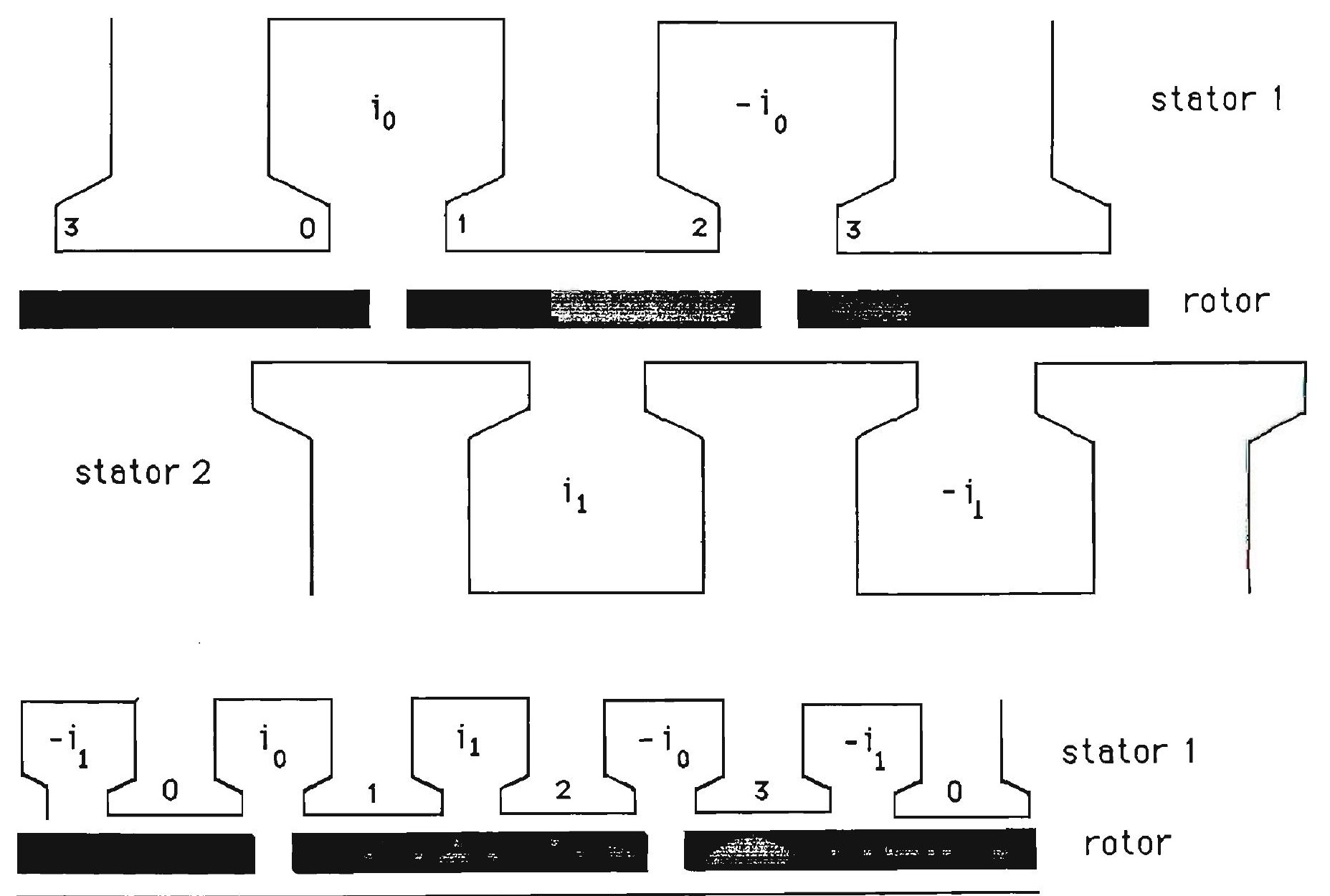

(b)

Figure 4.3 (a) The developed layout of the new servo motor

(b) The modified developed layout.

The new machine has sixteen poles and two slots per pole pair. Since the machine has an offset, the teeth of the two stators do not face each other. For the purpose of analysis, the configuration of the machine is changed. The developed layout of the modified machine shown in Figure 4.3 (b) is used to calculate the cogging torque.

Two teeth in the modified machine (for the application of the model) corresponds to one tooth in the actual machine. Since this machine has a skew, which is not taken into account in the model, for the computer simulation the machine was divided into forty 
concentric rings to obtain a smooth curve which could represent the variation of cogging torque with position. Figure 4.4 shows the cogging torque as predicted by the model and measured for the new servo motor. From the model it is found that the greatest contribution to cogging torque is made from the energy stored in the magnets opposite the slots.

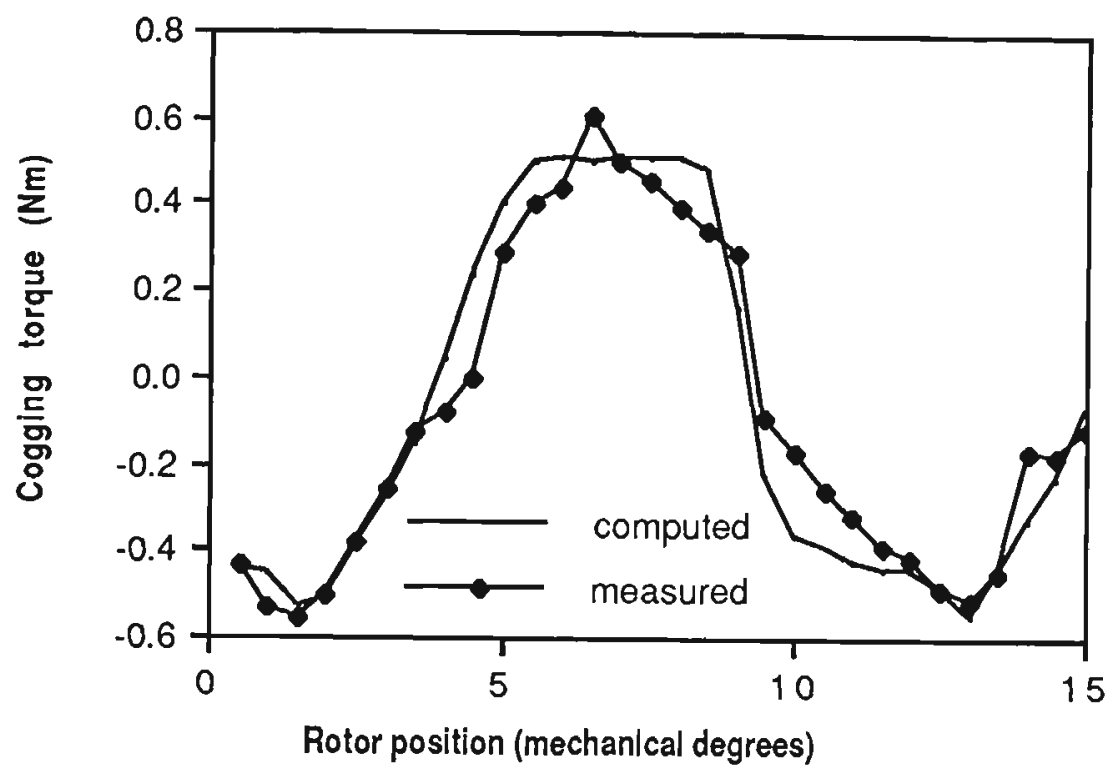

\section{Figure. 4.4 Cogging torque vs rotor position}

Considering the fact that the model ignores fringing, Figures 4.2 and 4.4 show that the model predicts the cogging torque reasonably well.

\subsection{Reduction of Cogging Torque}

Cogging torque is undesirable since it adversely affects the performance of the machine. Cogging torque is normally reduced by skewing either the magnets or the stator teeth. If the magnets are to be skewed then the machining of the magnet becomes very difficult. Permanent magnets are very brittle in nature which complicates the job further. Skewing of the stator also complicates the stator construction. The model developed in this chapter predicts a condition for zero cogging by proper selection of magnet pitch, without skewing either the stator teeth or the magnets.

The model predicts that the ideal magnet pitch for zero cogging torque is $=180-\frac{\mathrm{b} 360}{\mathrm{~N}}$ electrical degrees, where ' $b$ ' takes the value 1,2, 3 etc. This condition would be specially useful for machines with a large number of slots per pole pair ( $N$ ). A similar 
condition, for reduction of cogging torque in permanent magnet machines has been arrived at by Ackermann and his co- authors [30] using the co - energy concept.
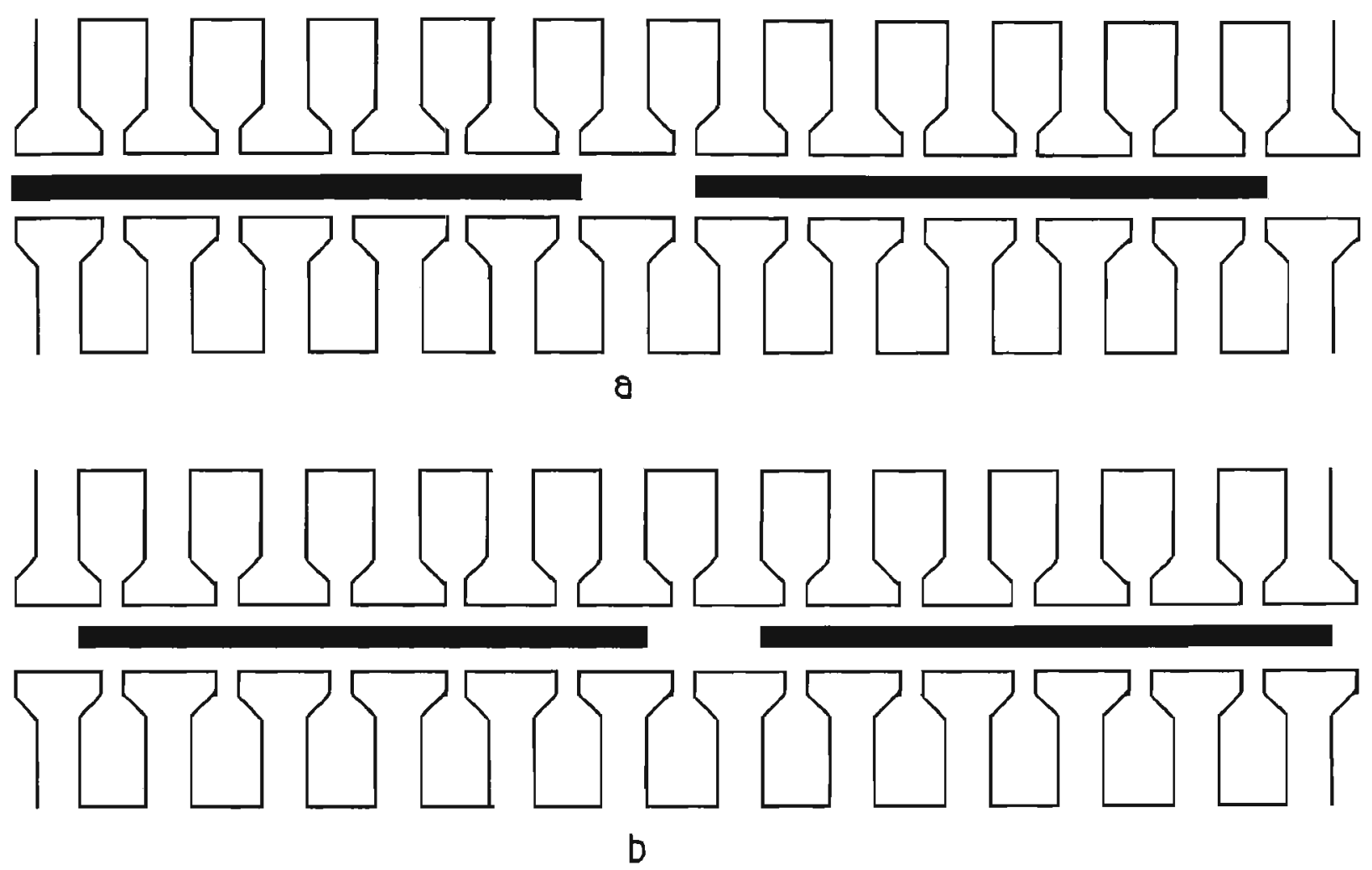

Figure 4.5 Developed layout of a machine which satisfies the condition for zero cogging.

Figure 4.5 (a) shows the developed layout of a pole pair of a machine, with 12 slots per pole pair. The magnets are pitched to satisfy the condition for zero cogging. They have a magnet pitch equal to 150 electrical degrees. Figure 4.5 (b) shows the same machine with the rotor shifted by a small angle. It can be seen from Figure 4.5(a) and Figure 4.5 (b) that the energy remains unchanged for the two different rotor positions. The energy lost near one end of the magnet due to the shift is gained at the other end of the magnet. Hence the change in energy with respect to position remains zero which leads to zero cogging. This will be the case in this machine for all rotor positions.

The maximum cogging torque for different values of magnet pitch was predicted for a machine with twelve slots per pole pair with and without skewing and the results are shown in Figure 4.6. All these predictions are based on the assumption that there is no fringing of flux into the slot opening. 


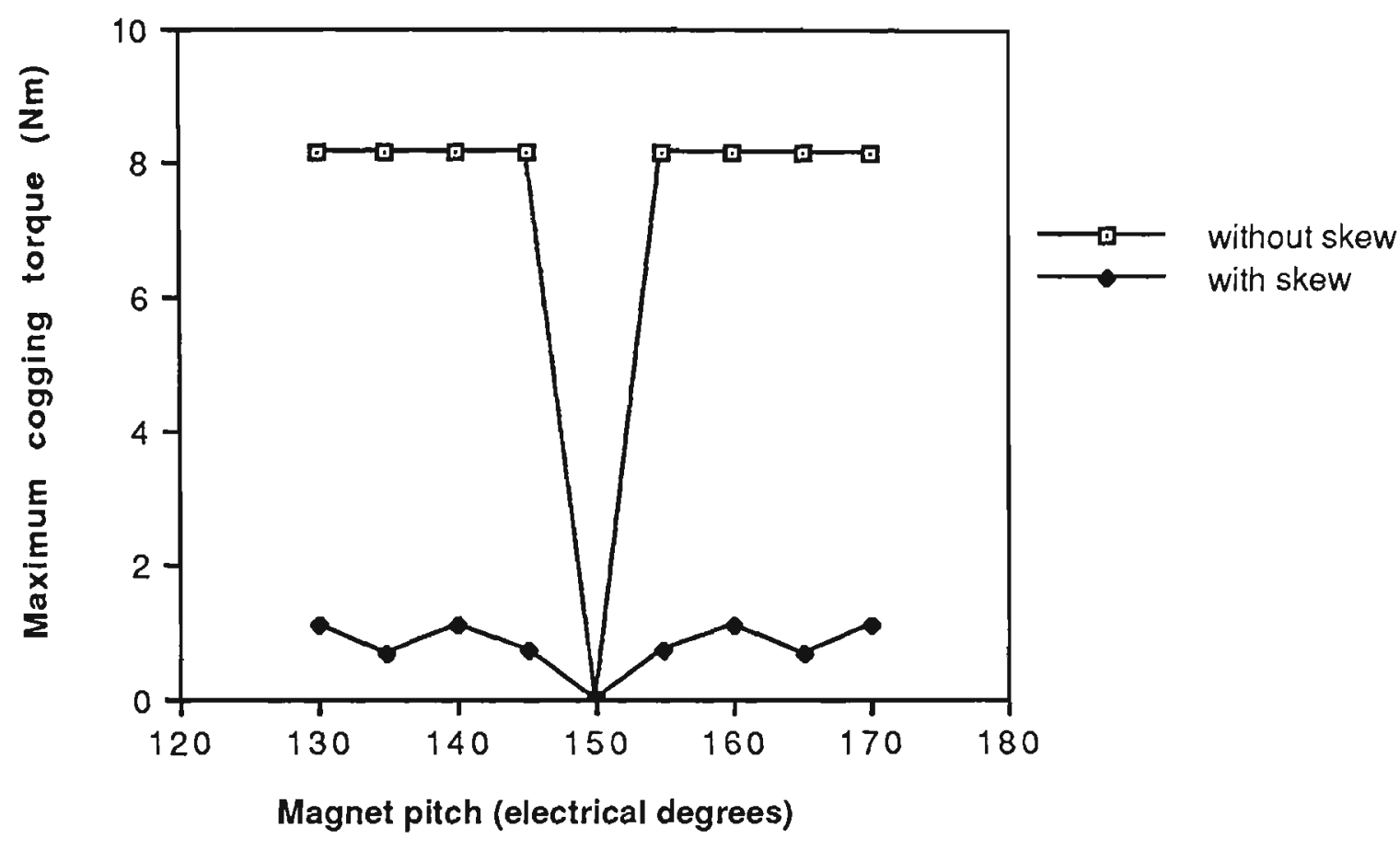

Figure 4.6 Maximum cogging torque vs magnet pitch for a machine with $\mathbf{N}=12$

There will be cogging torque if the magnet pitch differs even slightly from the specified optimum condition. It will be greatly reduced if the magnets or the stator teeth are skewed by one slot pitch as well. This is a sensible and achievable design criterion for many permanent magnet machines.

For the servo motor, $\mathrm{N}=4$, and therefore the greatest magnet pitch allowed is 90 electrical degrees $\left(180-\frac{360}{4}\right)$. To produce the most torque possible, it was decided to use magnets with larger pitch, and to minimise the cogging by skewing alone.

\subsection{Summary}

In this chapter cogging torque was calculated for two axial flux permanent magnet machines, one with skewing and the other without skewing using the model. Cogging torque was theoretically predicted for a laboratory machine which has no skewing and for the new servo motor which has skewing, and were compared with the experimental results. Fringing and saturation are neglected in the analysis. Allowing for these simplifications, the accuracy of prediction is good. A simple design technique was suggested to alleviate the cogging torque, but was found unsuitable for the new servo motor. 


\section{CHAPTER 5}

\section{USEFUL TORQUE}

\subsection{Introduction}

In the previous chapter the cogging torque of an axial flux permanent magnet machine was calculated, which is the torque when the stator has zero current. In this chapter the useful torque of the machine will be calculated. The useful torque of the machine depends on the magnitude of the stator current space phasor, the rotor current space phasor and the angle between the two. The model developed in Chapter 2 is used in this chapter to predict the useful torque of the new servo motor.

\subsection{Results}

The useful torque for the new two phase servo motor with sixteen poles has been predicted for different stator currents. As explained in Section 4.3.2 of the previous chapter the new machine has a stator offset and skew. To include the effect of offset in the model, it has been assumed that the motor has twice the number of the actual teeth with half of the original tooth pitch on one stator and the other stator is slot free as was described in the previous chapter and illustrated by Figure 4.3(b). The developed layout of the actual machine used in the analysis is shown in Figure 4.3 (b).

The modified arrangement has four slots per pole pair $(N=4)$. As mentioned in the previous chapter, since this machine has a skew, it was found that the machine has to be divided in to forty concentric rings to produce a smooth curve representing the variation of torque with rotor position. The torque has been calculated at the average radius of each of the rings considered.

Figure 5.1 shows computed torque using the model, without including cogging torque, for four sets of stator currents. The first curve correspond to the condition where each phase carries a current of 5 Amps. The second curve correspond to the condition where the first phase carries a current of $-5 \mathrm{~A}$ and the second phase carries a current of $+5 \mathrm{~A}$. The stator currents for the other curves are indicated in the Figure 5.1. In all four cases the magnitudes of the current space phasors are the same but they have a phase difference of 90 electrical degrees as shown in the Figure 5.2. Hence the 


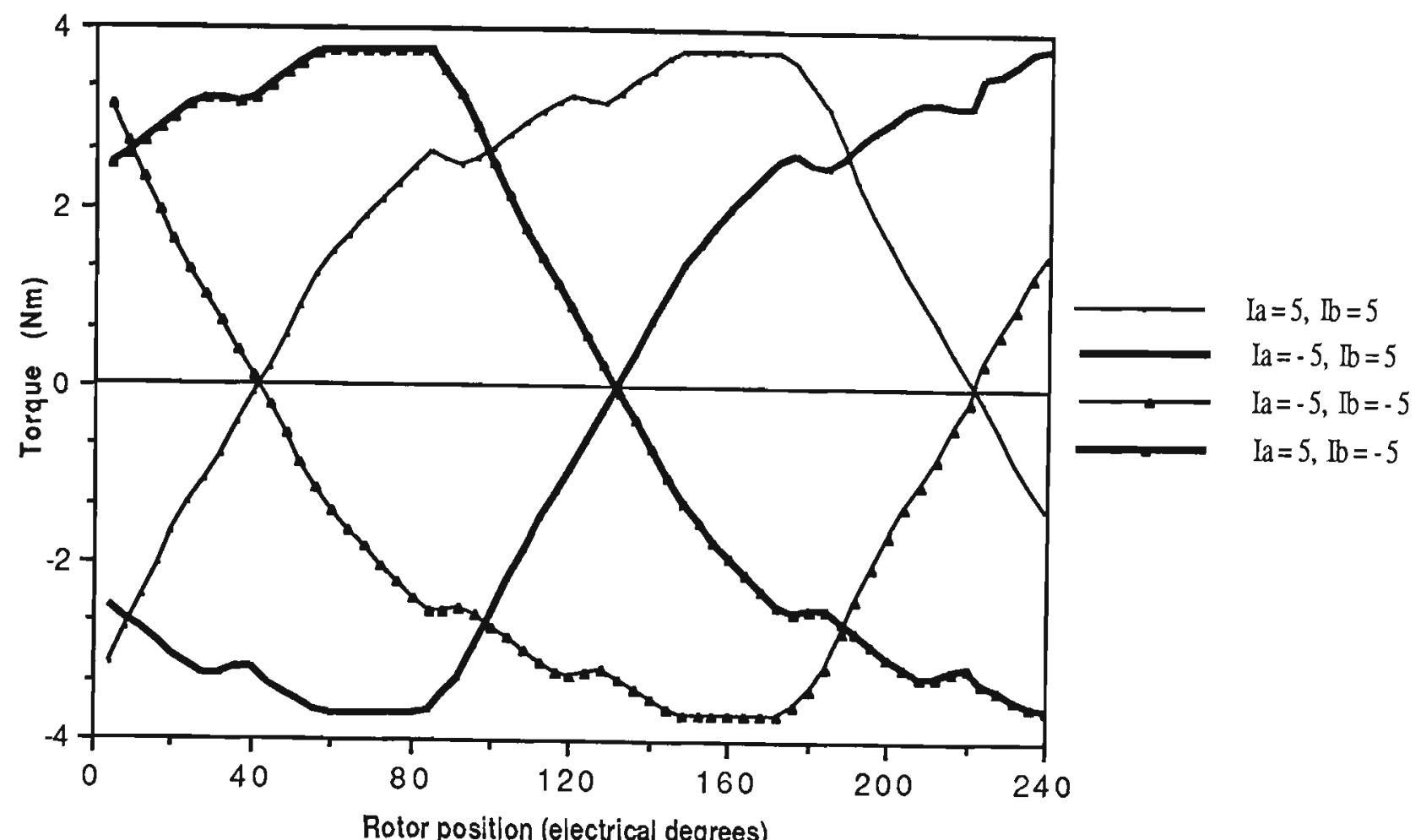

Figure 5. 1 Computed torque vs rotor position for different current space phasor positions

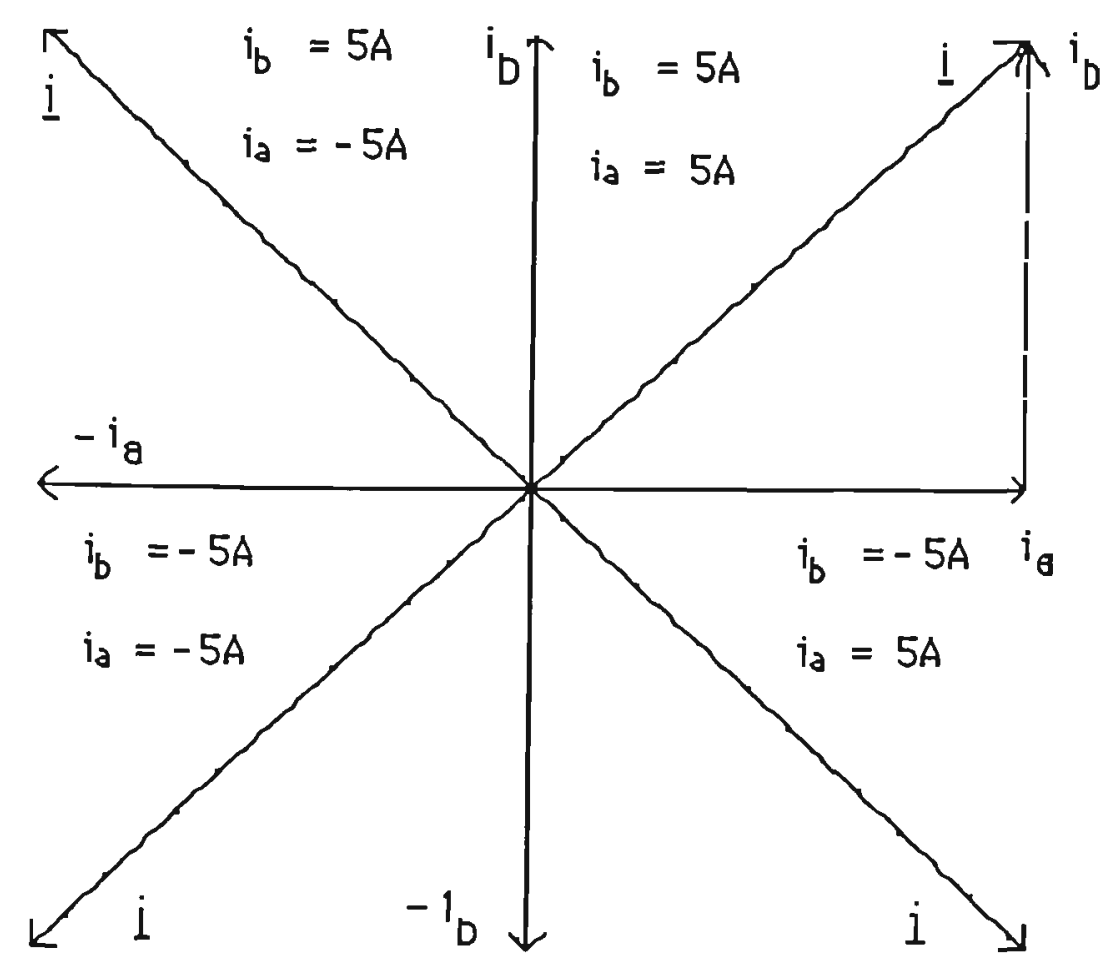

Figure 5.2 The current space phasors for four different sets of stator currents 
maximum torques are the same in each case but they will be shifted 90 electrical degrees. This shows up in the computed torque as indicated by the graphs in Figure 5.1 .

The predicted torque takes the shape shown in Figure 5.1 due to the combined effects of the geometry of the axial flux machine and the skewing of the rotor magnets. Since the tooth pitch and the magnet pitch vary along the radius of the machine, the overlap between teeth and magnet is different at different radii of the machine for the same rotor position. Figure 5.3 shows the variation of torque with rotor position curve for the outermost ring (indicated as ring 1 in Figure 5.3) and for the fifth ring (indicated as ring 5 in the Figure 5.3) towards the centre from the outermost ring of the machine, for $5 \mathrm{~A}$ in each stator phase.

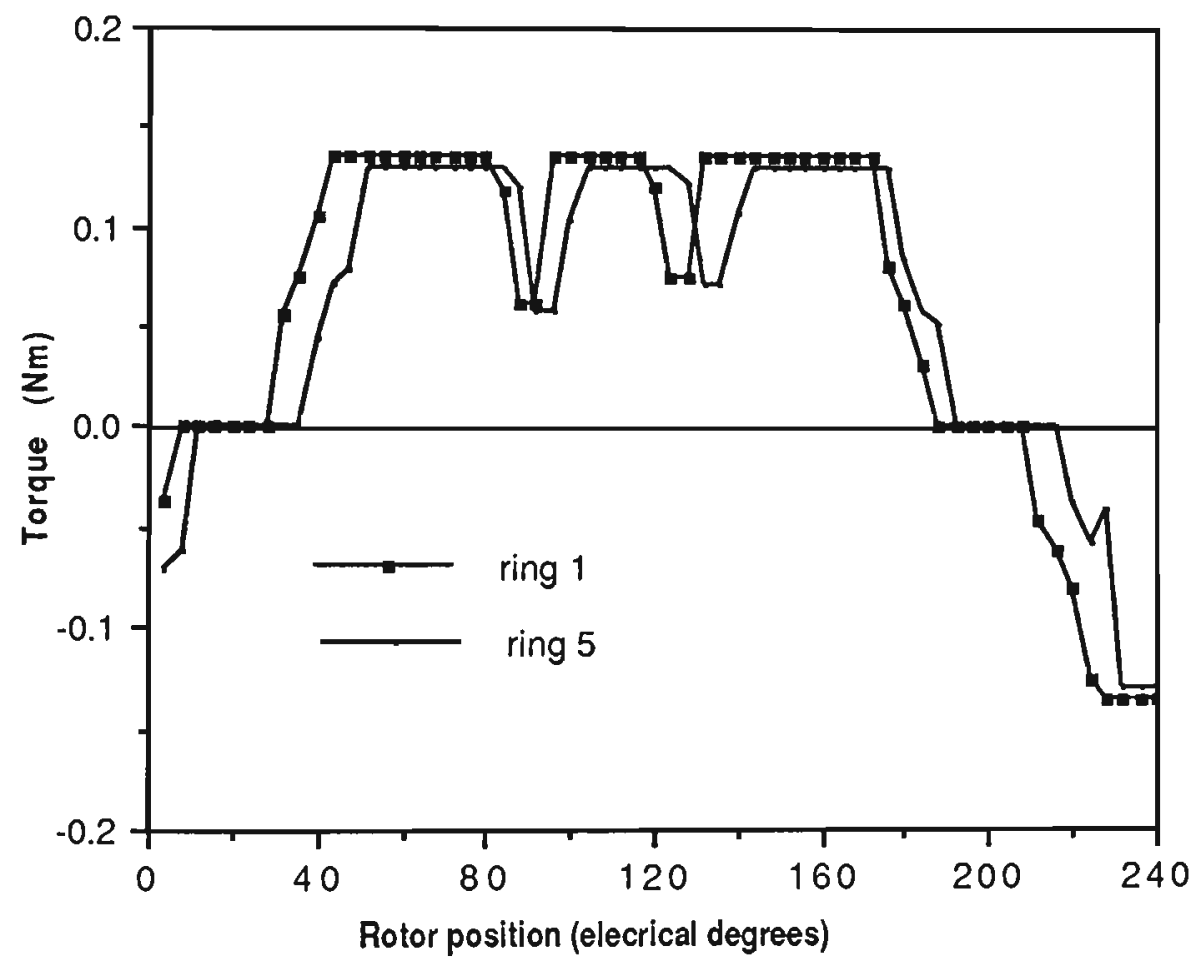

Figure 5.3 Torque versus rotor position for two rings of the machine

Figure 5.3 indicates that the torque developed is more in the outer most ring when compared to the other ring. The torque will be futher reduced in the rings closer to the centre of the machine. Since the torque is proportional to the radius, the torque increases with radius and hence there is a difference in the magnitute of the torque developed at various radii of the axial flux machine. Since the magnet pitch, tooth pitch and the skew changes with radius, there is a shift in shape and position in the torque curves for different radii. The curves are not smooth at various radii, as the change in energy does not rise or fall smoothly with position (the function $\zeta$ is discrete). When 
the teeth and slots are completely covered by the magnet for a few rotor positions, there will not be any change in energy $(\zeta=0)$ and hence the torque will be zero for these rotor positions. When a magnet leaves a tooth $(\zeta= \pm 1)$ or when the tooth comes under the influence of both north and south poles $(\zeta= \pm 2)$ due to the change in rotor position (this can happen since the rotor magnets are skewed), there will be a large change in energy and hence the jump in torque will be high. Since these changes happen at different positions for different rings, (due the the different magnet and tooth pitch and skewing) the overall torque takes the shape shown in Figure 5.1. As the subdivision of the machine into rings discretises it in the radial direction, the smoothness of the overall curve also depends the number of concentric rings. It was found that to obtain a smooth overall torque versus rotor position relationship from the model, the machine has to be divided into at least forty rings.

Torque tests were carried out on the new machine with dc current in the stator windings. Equal currents were passed through both windings. The torque measurements were made using a load cell attached to a torque arm. The zero position for the experiment is chosen arbitrarily. The results of measurements and theoretically computed results which include the cogging are shown in the following figures.

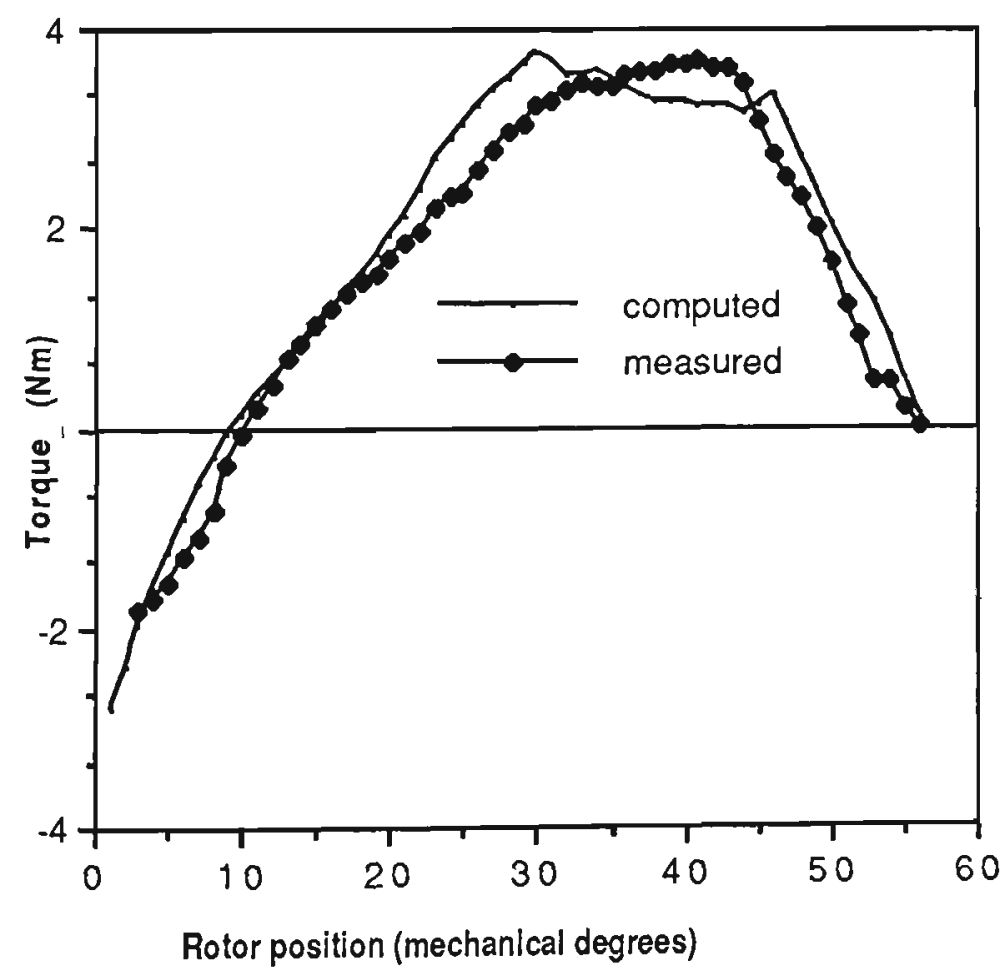

Figure 5.4 Torque vs rotor position for stator currents of $5 \mathrm{~A}$ 


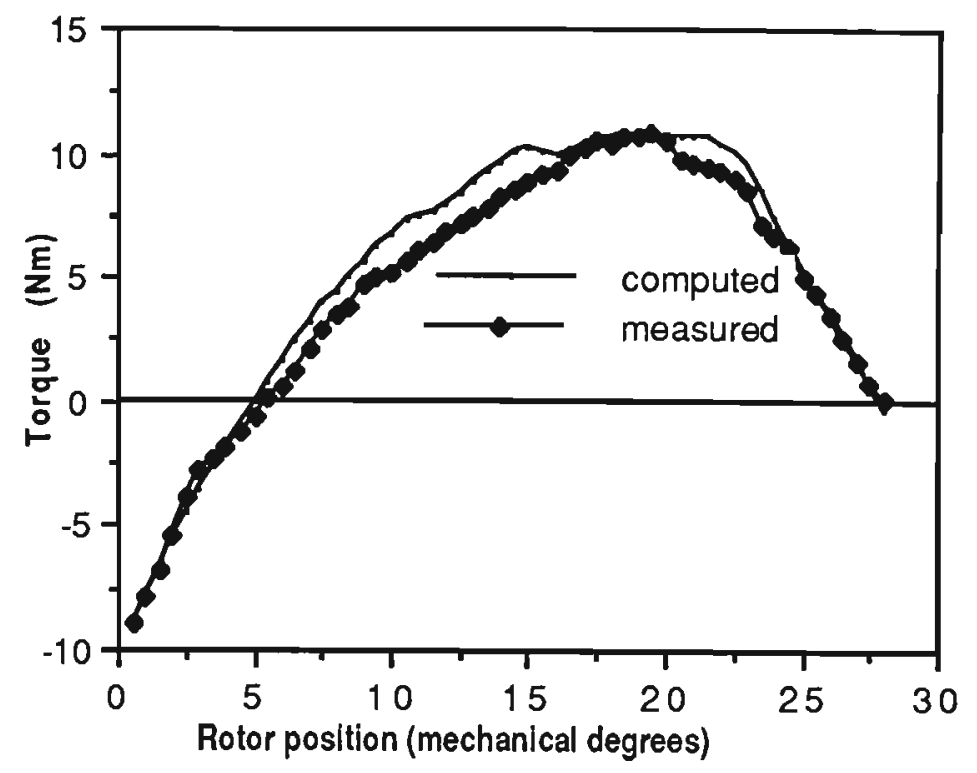

Figure 5.5 Torque vs rotor position for stator currents of $15 \mathrm{~A}$

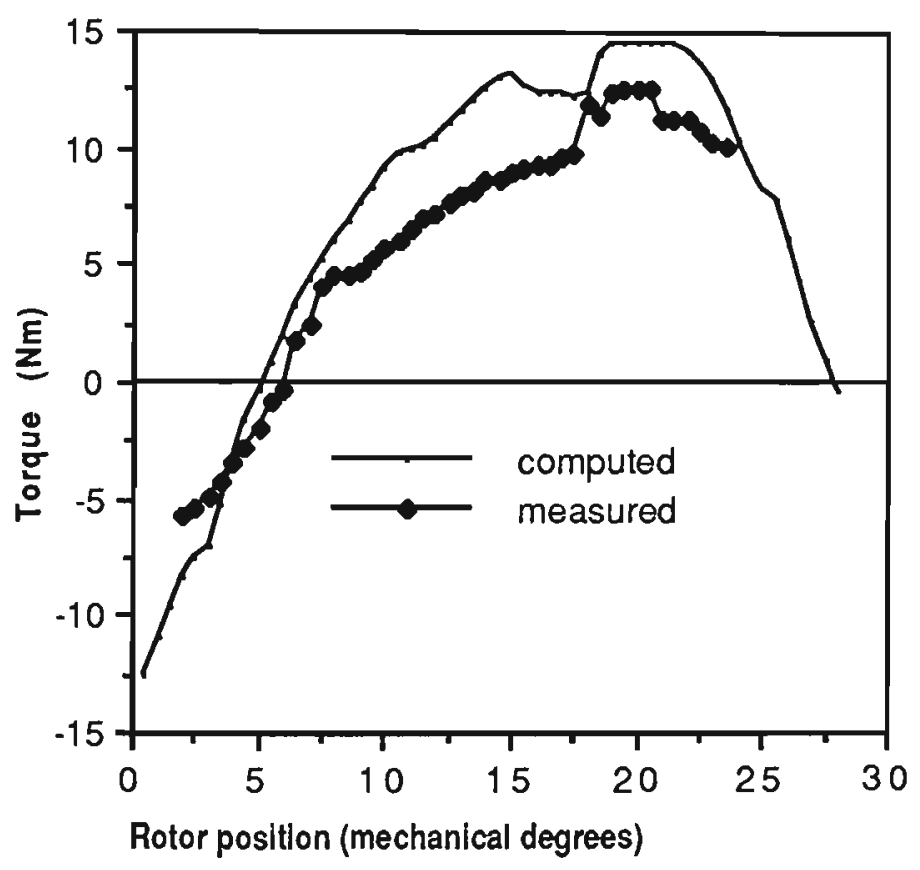

Figure 5.6 Torque vs rotor position for stator currents of $20 \mathrm{~A}$

Figures 5.4 and 5.5 which correspond to $5 \mathrm{~A}$ and $15 \mathrm{~A}$ of current in each stator show that the measured and predicted values of torque are reasonably close. Comparing Figure 5.4 and 5.5 the shape of the predicted torque curve differs for the two different current levels, since the cogging torque is comparable to the useful torque at certain rotor positions for the lower current, whereas it becomes less significant with the increase in stator current to $15 \mathrm{~A}$. Figure 5.6, the graph for stator currents of $20 \mathrm{~A}$ shows that the measured maximum value of torque is significantly less than the predicted one. This is due to the fact that the machine enters into saturation at high values of stator currents and the effect of saturation has not been included in the model. 
The measurements at $20 \mathrm{~A}$ were rushed for the fear of damaging the machine, which explains as to why the torque for many rotor positions has not been measured.

To determine the effect of saturation, the maximum torque of the machine for different stator currents were measured. Figures 5.4 and 5.5 show that the maximum torque occurs at approximately 18 mechanical degrees with respect to the arbitrarily chosen zero position. The rotor was locked at this peak torque position and the current in the windings was varied up to $48 \mathrm{~A}$. This limit was observed to avoid the danger of demagnetising the magnets and also corresponds to a very high current density of approximately $27 \mathrm{~A} / \mathrm{mm}^{2}$ in the copper wire. Figure 5.7 shows the computed maximum torque obtained using the linear model and measured torque, for different stator current levels.

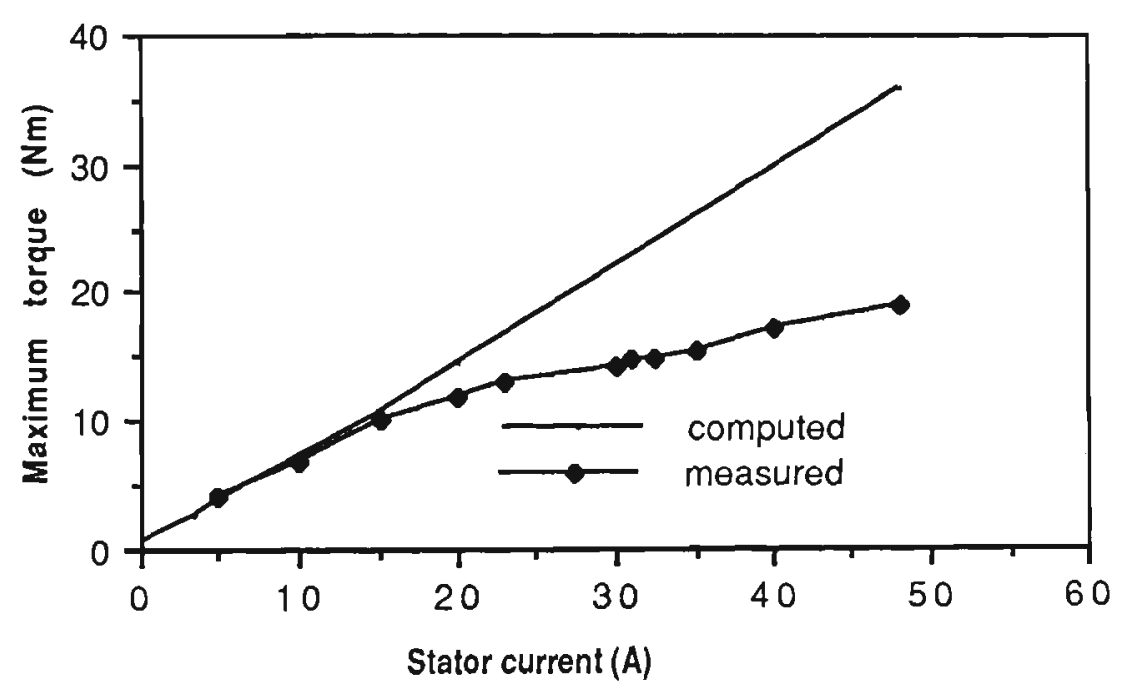

Figure 5.7 Maximum torque vs stator current

Figure 5.7 shows that once the current exceeds $15 \mathrm{~A}$ in the stator, saturation becomes important, and the linear model no longer predicts the torque correctly. Hence for predicting the torque of the machine under heavy currents a model which takes saturation into account has to be developed.

\subsection{Summary}

In this chapter, the measured and the calculated torques using the model developed in Chapter 2 were presented for an axial flux permanent magnet machine. The measured and predicted values agree reasonably well untill the machine enters into saturation. 
Once the machine enters saturation the linear model cannot be used to predict the torque and therefore a model which takes saturation into account has to be developed. 


\section{CHAPTER 6}

\section{MODEL WITH SATURATION}

\subsection{Introduction}

Results presented in the previous chapter show that saturation becomes significant when the current is heavy. Saturation is easily avoided in the back iron since the pole pitch is small and a substantial yoke is required to provide mechanical stiffness. This is achieved with almost no penalty in moment of inertia. The critical areas are in the stems and tips of the teeth.

As described previously, the peculiarities of the geometry of axial flux machines lead to tooth stems which are very much more narrow at the inner radius than at the outer radius. This can be seen clearly in Figure 1.4. Figure 6.1 shows the B H curve of the electrical sheet steel used in the machine which indicates that the machine enters heavy saturation when the flux density exceeds around $1.75 \mathrm{~T}$. Sensible design procedures result in the stems being just saturated at the mean radius when the machine is fully fluxed. As a result, the stems at the inner radius are saturated before any current flows in the stator.

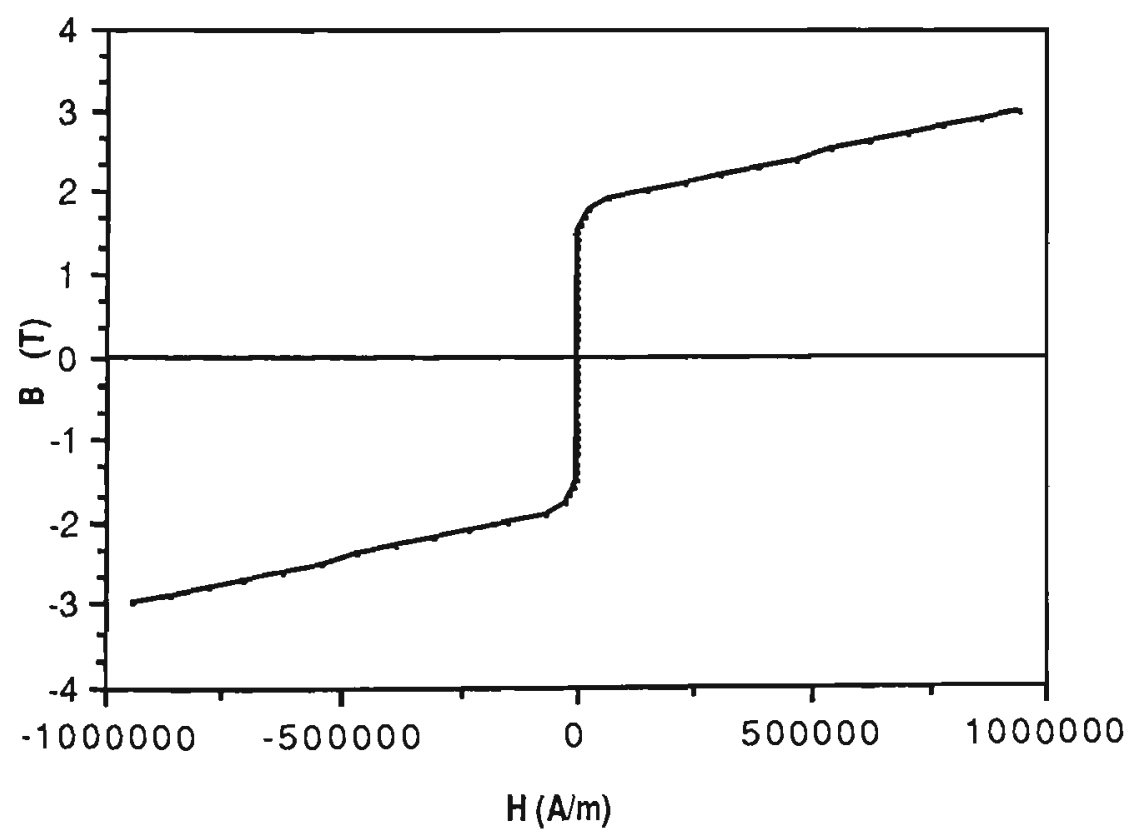

Figure 6.1 B H curve of LY - core 230 sheet steel

Figure 6.2 shows the various flux paths that can be present in the machine at a given instant. Fluxes $\phi_{1}$ and $\phi_{2}$ are the main airgap fluxes, fluxes $\phi_{3}$ and $\phi_{6}$ are the tooth tip 


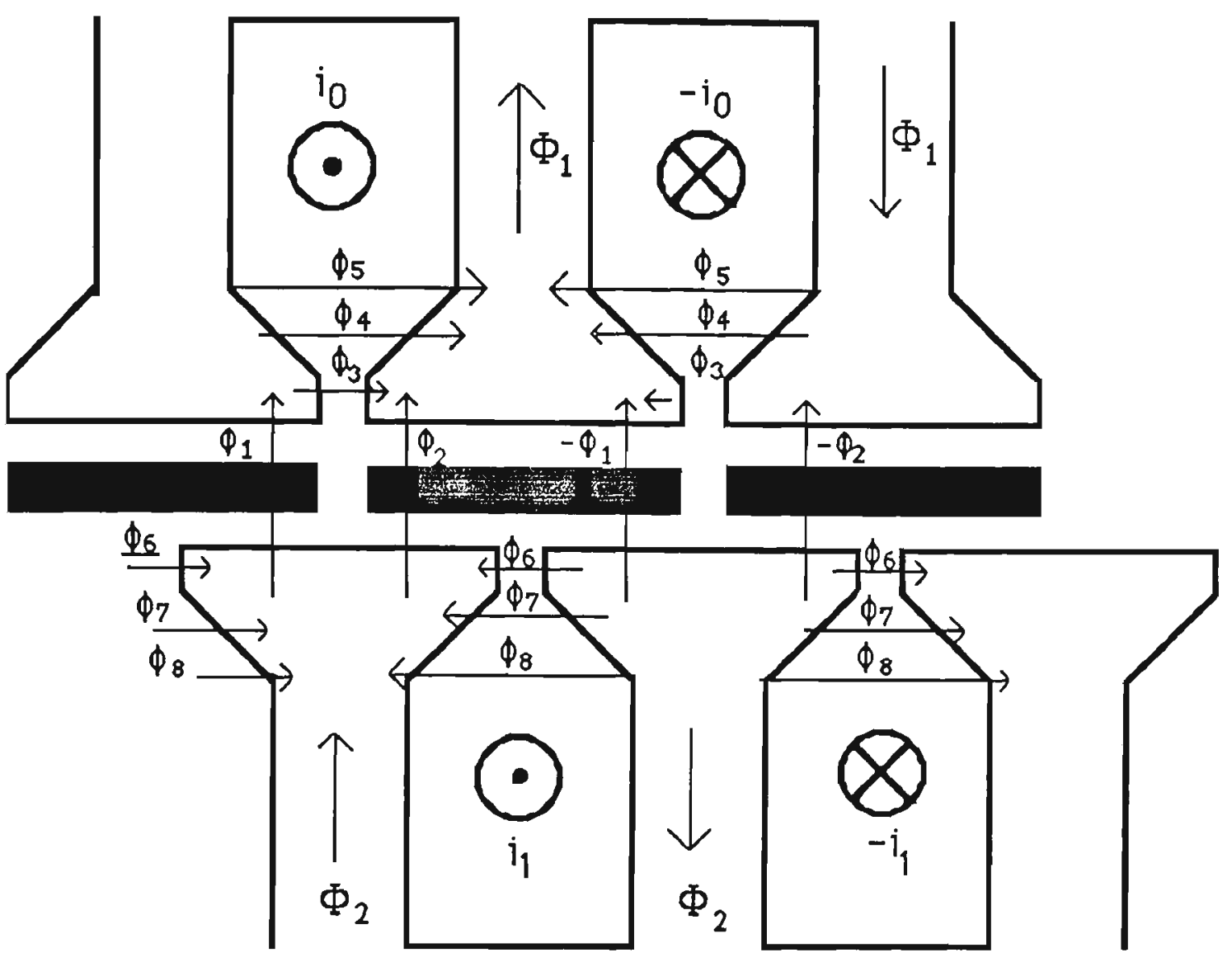

Figure 6.2 Fluxes crossing the teeth

leakage fluxes, fluxes $\phi_{4}$ and $\phi_{7}$ are the bevel leakage fluxes (Bevel leakage flux is the leakage flux that crosses the slot through the tapered portion of the tooth tip to enter the tapered portion of the opposite tooth tip. More explanation and derivation is given in Appendix 5) and fluxes $\phi_{5}$ and $\phi_{8}$ are the slot leakage fluxes. All these fluxes combined together can heavily saturate the tooth stem at the inner radius at high currents. When the tooth is fully covered by the magnet, the airgap flux will be maximum across the tooth. Heavy currents produce considerable leakage flux and this combined with the high airgap flux can saturate the tooth tips heavily. The model presented in this chapter takes into account all these leakage fluxes and also the effect of tooth stem and tooth tip saturation.

\subsection{The Model}

\subsubsection{The essence of the model}

The model is characterised by the following points.

1. Tooth tip leakage flux passes in a straight line from tooth tip to tooth tip. 
2. Leakage flux between the bevelled section of the tooth tips also passes directly across the slot.

3. Other slot leakage flux passes down the depth of the stem.

4. Flux density at the airgap is solved

(i) at the edges of each tooth

(ii) at the edges of each magnet and

(iii) at the centre of the gap between the two poles of the magnet if both the poles are present opposite to the tooth.

5. Flux density at the airgap is assumed to vary linearly between the points in (4) above.

6. Saturating elemental sections are assumed to have the B-H characteristic of the iron and the cross section of the corresponding iron section.

7. All flux entering the tooth passes down the tooth stem.

8. Useful torque is determined by computing the change in flux linkages with a change in rotor position.

Again, the motor is divided into forty concentric rings for the purpose of analysis.

Since the new servo motor magnets are skewed, for a particular rotor position, it is possible that a stator tooth is under the influence of both north and south poles of the rotor in one or more of the rings considered along the radius of the machine. Figure 6.3 shows a rotor position in which half of the tooth is completely covered by one pole and the other half is opposite to both the poles. In the model, mmf equations are solved in ten loops(indicated by numbers 1 to 10 in Figure 6.3). The portion of the tooth which is completely covered by the magnet is equally divided into five sections to determine the five points (indicated by numbers 1 to 5 in the figure) where the loops cross the airgap, with upper and lower teeth edges as the boundaries. For the other portion of the tooth mmf equations are solved at the edges of the upper and lower stator teeth (6 and 10 in Figure 6.3), at the edges of the magnets ( 7 and 9 in the figure) and at the midpoint between the edges( 8 in the figure). Loops 7 and 9 pass through the magnet, whereas loop 8 goes through the midpoint between the magnet edges (which is air). Solving ten loops assures us that all possibilities of magnet positions are covered. In all of these ten mmf loops there is a symmetry in the sense that the behaviour resulting from half of the mmf path is repeated in the other half of the paths. This happens because one half of the loop is the area of the rotor magnets with one polarity and the other half of the mmf loop lies in the area of rotor magnet with opposite polarity. 

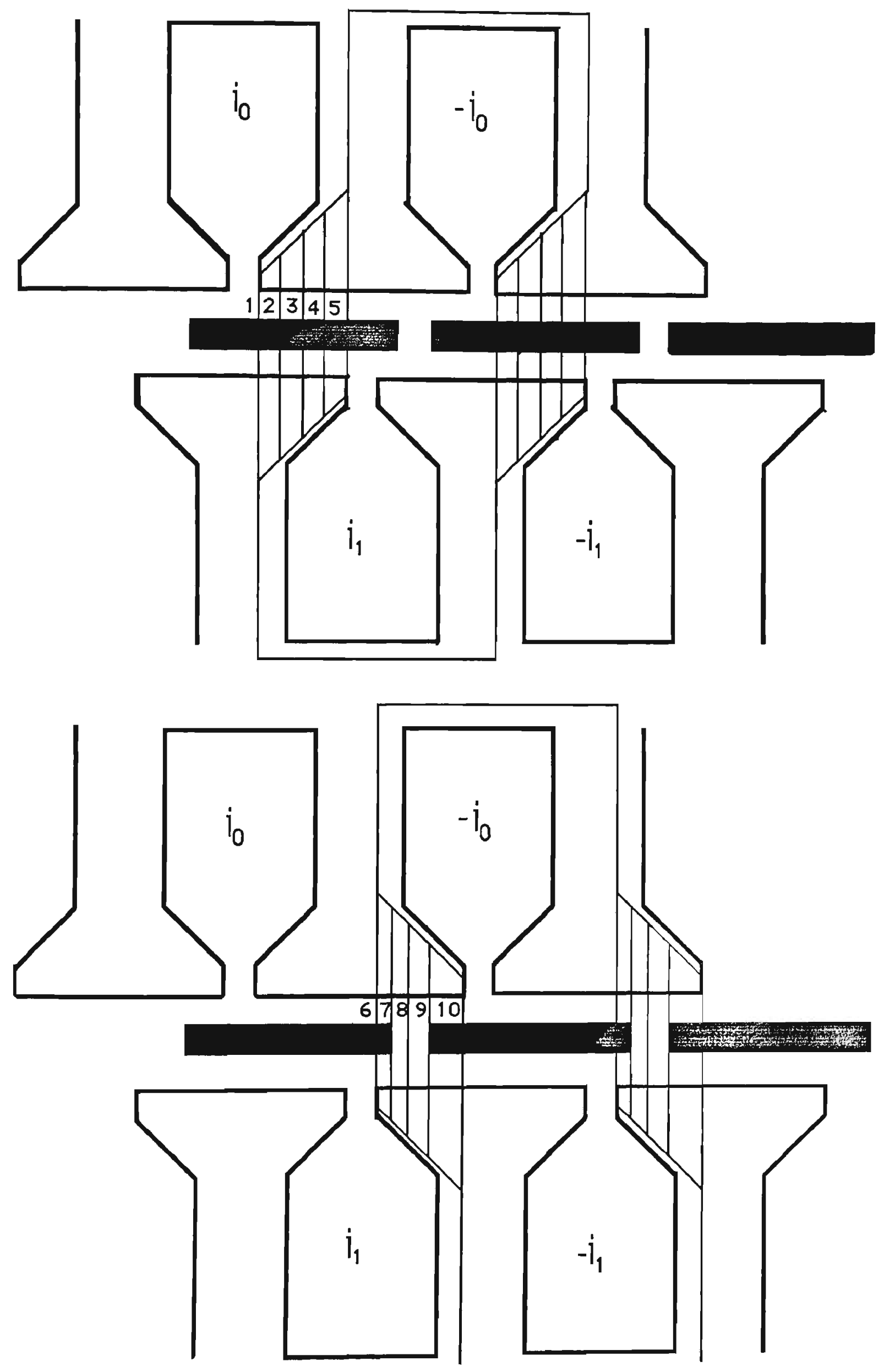

Figure 6.3 Mmf loops for a particular rotor position 
(a)

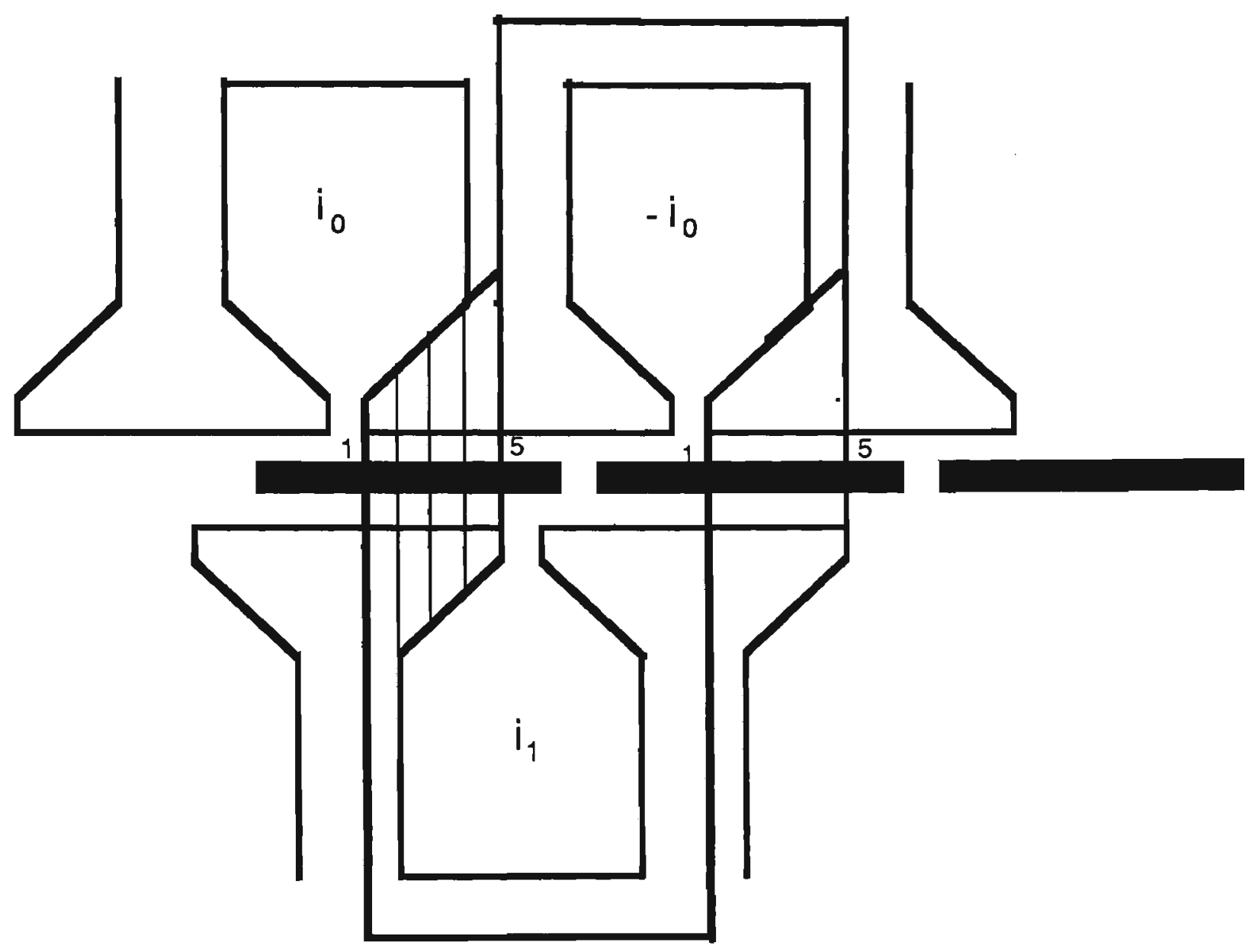

(b)

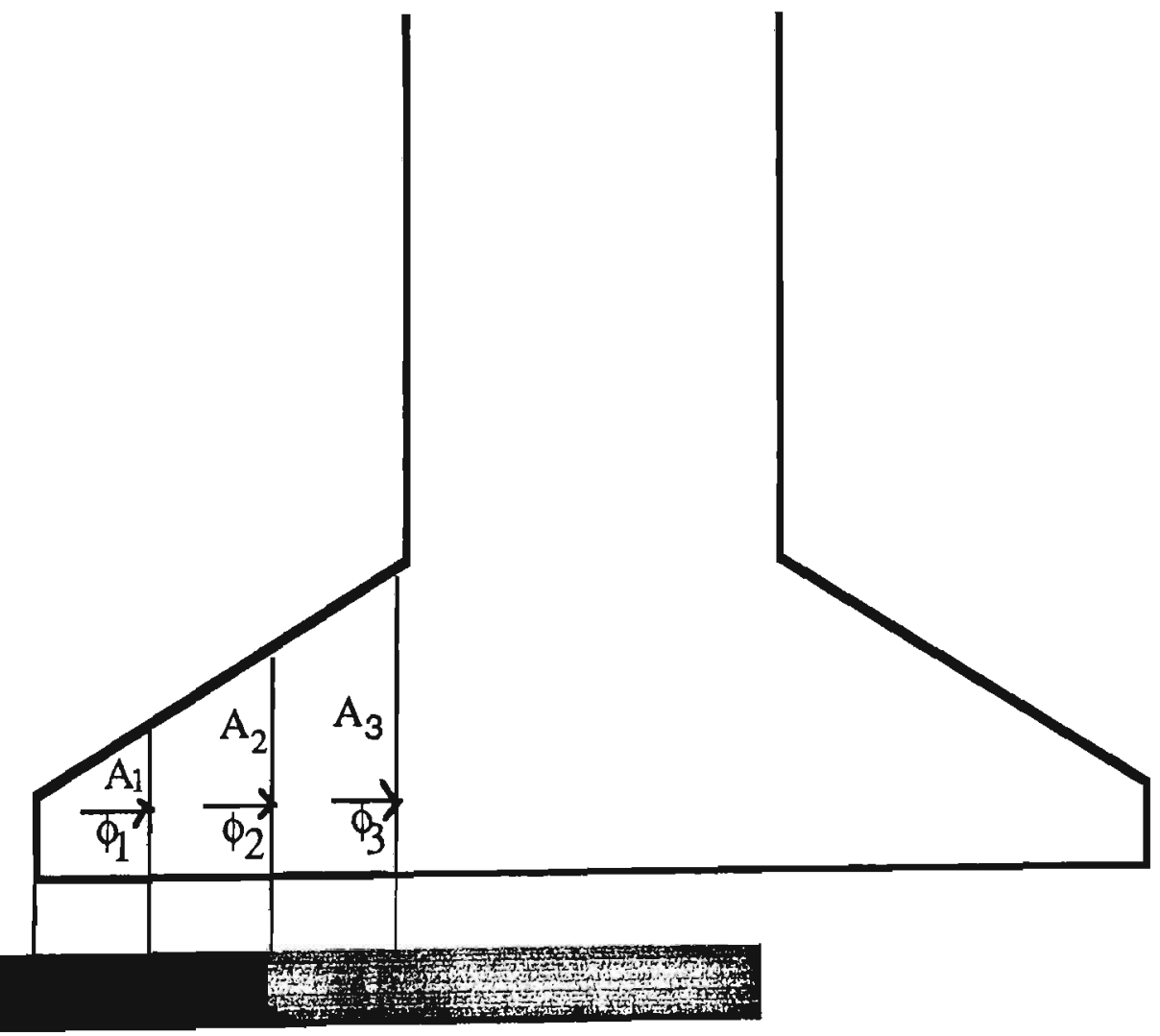

Figure 6.4 (a) Mmf loops 1 and 5

(b) Fluxes in the tooth tip 
Figure 6.4 (a) highlights the loops 1 and 5. Figure 6.4 (b) shows an enlarged tooth tip. The fluxes $\phi_{1}, \phi_{2}$, and $\phi_{3}$ shown in the figure are calculated from the knowledge of leakage (the calculations of all the leakage fluxes are given in Appendix 5) and the airgap flux densities. In the analysis it is assumed that the flux density $B_{1}\left(\phi_{1} / A_{1}\right)$ assumes only one value across the area $A_{1}$ (Figure 6.4b), and the flux density $B_{2}$ assumes only one value across the area $A_{2}$ and so on. This is only an approximation since the flux density will actually take different values across these areas. The assumption that the flux crosses these areas at right angles is also an approximation. Also the cross sectional area varies all along the tooth tip whereas one cross section area is assumed for each section, which again is an approximation. The details of calculation of the areas $\mathrm{A}_{1}$ and $\mathrm{A}_{2}$ etc. are given in Appendix 5.

The corresponding values of fluxes and areas are used to determine the flux density across the different sections of the tooth. For these flux densities, using the B-H curve of Figure 6.1, the corresponding values of the magnetic field strengths are determined and the mmf drops along the different section of the tooth tips are calculated. Since the area as well as the fluxes are different in these sections, the tooth attains different levels of saturation at different sections. Figures 6.5 (a) and (b) show half of the saturating elements of loops 1 and 5 respectively (the figure does not include any mmf sources). The other half of the saturating elements would be the mirror image of these elements along the axis A- AA. $R_{g}$ and $R_{m}$ are the reluctance of the airgap and magnet respectively. $R_{t s l}$ and $R_{t s u}$ are the saturating elements of the upper and lower tooth stems and $R_{\text {utt } 1}$ to Rutt3 are the the upper tooth tip saturating elements and $R_{1 t 11}$ to $R_{1 t 13}$ are the the lower tooth tip saturating elements. The subscript 1 or 5 is included while representing the saturating elements to indicate the corresponding loop number.

\subsubsection{Mmf equations}

For loop 1 shown in Figure 6.4a the mmf equation is :

$2\left\{\frac{\mathrm{B}[1] \mathrm{g}_{\mathrm{a}}}{\mu_{\mathrm{O}}}+\frac{(\mathrm{B}[1]-\psi[1] \mathrm{Br}) \mathrm{g}_{\mathrm{m}}}{\mu_{\mathrm{O}}}+\mathrm{h}_{\mathrm{ttu}}[1] \mathrm{ttl}_{\mathrm{u}}[1]+\mathrm{h}_{\mathrm{ttu}[2]} \mathrm{ttl}_{\mathrm{u}}[2]+\mathrm{h}_{\mathrm{ttu}[3]}\left[\mathrm{tt} \mathrm{l}_{\mathrm{u}}[3]+\right.\right.$
$\left.\mathrm{h}_{\mathrm{ts}}[1] \mathrm{tsl}+\mathrm{h}_{\mathrm{ts}}[2] \mathrm{tsl}\right\}=\left(\mathrm{i}_{1}-\mathrm{i}_{0}\right)$ 
(a)

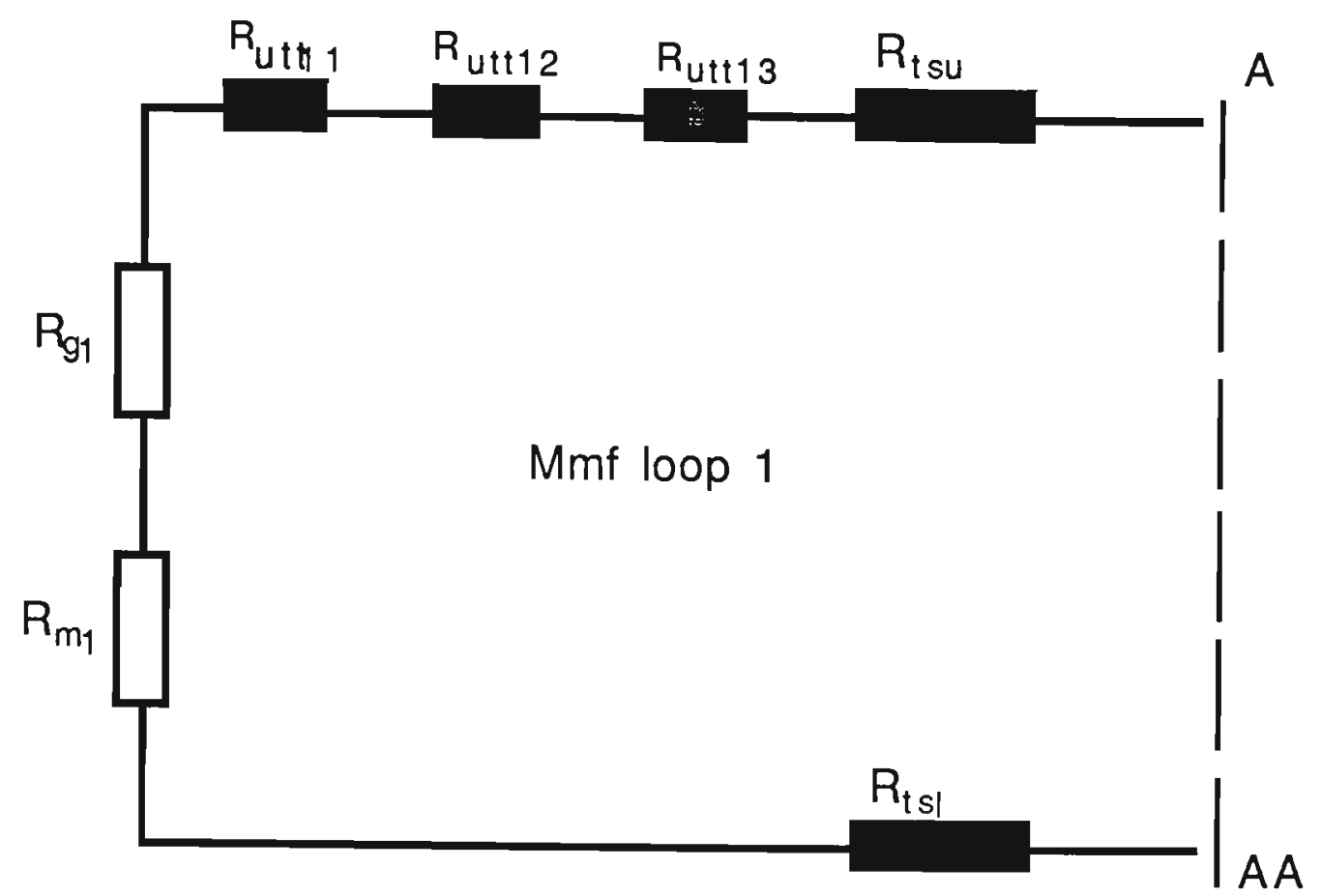

(b)

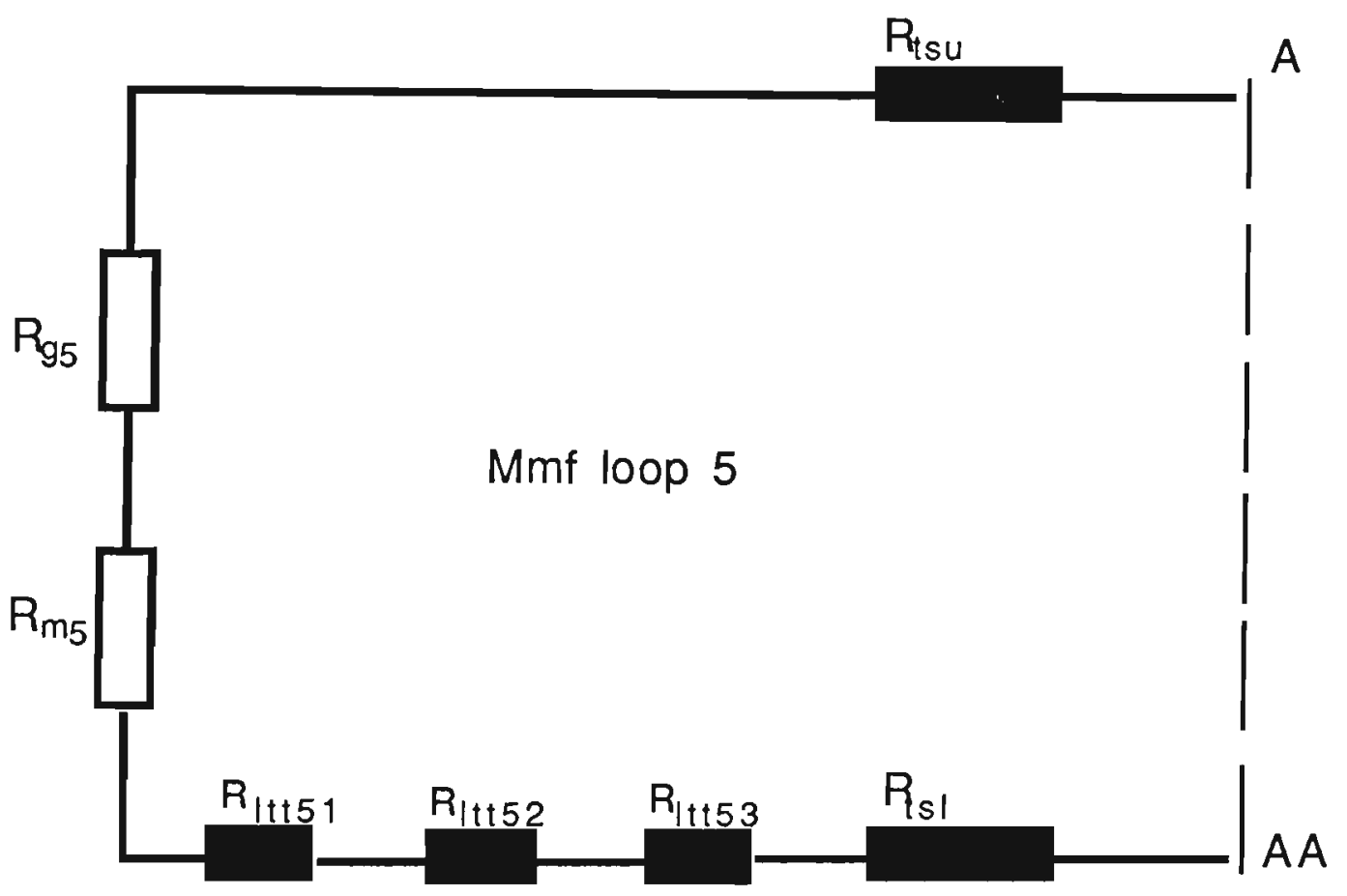

Figure 6.5 Magnetic reluctances of loops 1 and 5.

For loop 5 the mmf equation is :

$2\left\{\frac{\mathrm{B}[5] \mathrm{g}_{\mathrm{a}}}{\mu_{\mathrm{O}}}+\frac{(\mathrm{B}[5]-\psi[5] \mathrm{Br}) \mathrm{g}_{\mathrm{m}}}{\mu_{\mathrm{o}}}+\mathrm{h}_{\mathrm{ttl}[1]} \mathrm{ttl}_{1[1]}+\mathrm{h}_{\mathrm{ttl}[2]} \mathrm{ttl}_{1[2]}+\mathrm{h}_{\mathrm{ttl}}[3] \mathrm{ttl}_{1}[3]+\right.$ $\left.h_{t s}[1] t s l+h_{t s}[2] t s l\right\}=\left(i_{1}-i_{0}\right)$ 
where

\begin{tabular}{|c|c|c|}
\hline $\mathrm{B}[1]$ to $\mathrm{B}[5]$ & $=$ & flux density in the airgap for the loops 1 to 5 \\
\hline$\psi[1]$ to $\psi[5]$ & $=$ & $\psi$ at the airgap for the loops 1 to 5 \\
\hline $\mathrm{h}_{\mathrm{ts}}[1]$ and $\mathrm{h}_{\mathrm{ts}}[2]$ & $=$ & $\begin{array}{l}\text { magnet field strength in the upper tooth stem } \\
\text { and lower tooth stem respectively }\end{array}$ \\
\hline tsl & $=$ & tooth stem length \\
\hline $\mathrm{h}_{\mathrm{ttu}}[1], \mathrm{h}_{\mathrm{ttu}}[2]$ and $\mathrm{h}_{\mathrm{ttu}}[3]$ & $=$ & $\begin{array}{l}\text { magnetic field strength in the saturating } \\
\text { elements in the tooth tip of the upper tooth }\end{array}$ \\
\hline $\mathrm{ttl}_{\mathrm{u}}[1], \mathrm{ttl}_{\mathrm{u}}[2], \mathrm{ttl}_{\mathrm{u}}[1]$ & $=$ & $\begin{array}{l}\text { upper tooth tip length over which the } \\
\text { corresponding values of magnetic field strength } \\
\text { exist }\end{array}$ \\
\hline $\mathrm{h}_{\mathrm{tt} 1}[1], \mathrm{h}_{\mathrm{tt} l}[2]$ and $\mathrm{h}_{\mathrm{tt}}[3]$ & $=$ & $\begin{array}{l}\text { magnetic field strength in the saturating elements } \\
\text { in the tooth tip of the lower tooth }\end{array}$ \\
\hline $\operatorname{ttl}_{1[1]}, \mathrm{ttl}_{1[2]}, \mathrm{ttl}_{![1]}$ & $=$ & $\begin{array}{l}\text { lower tooth tip length over which the } \\
\text { corresponding values of magnetic field strength } \\
\text { exist }\end{array}$ \\
\hline
\end{tabular}

The mmf equations for loops $2,3,4$ and 6 to 10 will be similar to the above two equations with their corresponding flux densities and mmf drops from both upper and lower teeth.

Figure 6.6 shows the mmf loops 1 to 5 for a rotor position different to the one shown in Figure 6.3. In this case, besides the edges of the upper and lower teeth, the mmf equations are solved at the edge of the magnet, and at a point in the airgap close to the edge as well as at the midpoint of the magnet edge and the edge of the lower tooth. Since the other half of the tooth is completely covered by the magnet, another five equations are solved at 5 points at equal intervals between the edges of the upper and lower teeth. Thus, the points along the tooth at which the mmf equations are solved depend upon the rotor position. At each rotor position, the ten non linear mmf equations are solved to obtain the ten airgap flux densities along the airgap. 


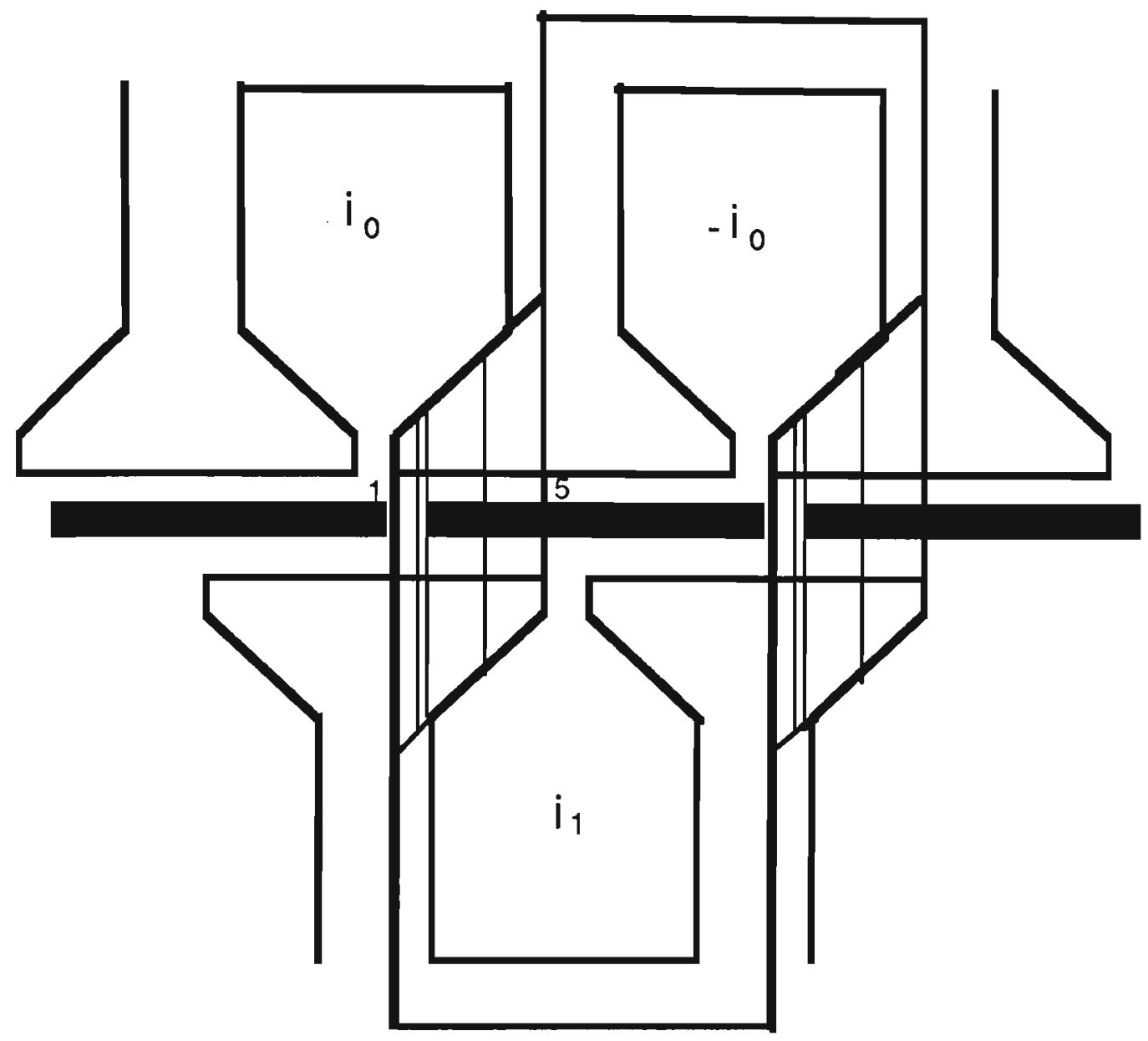

Figure 6.6 Mmf loops for a different rotor position
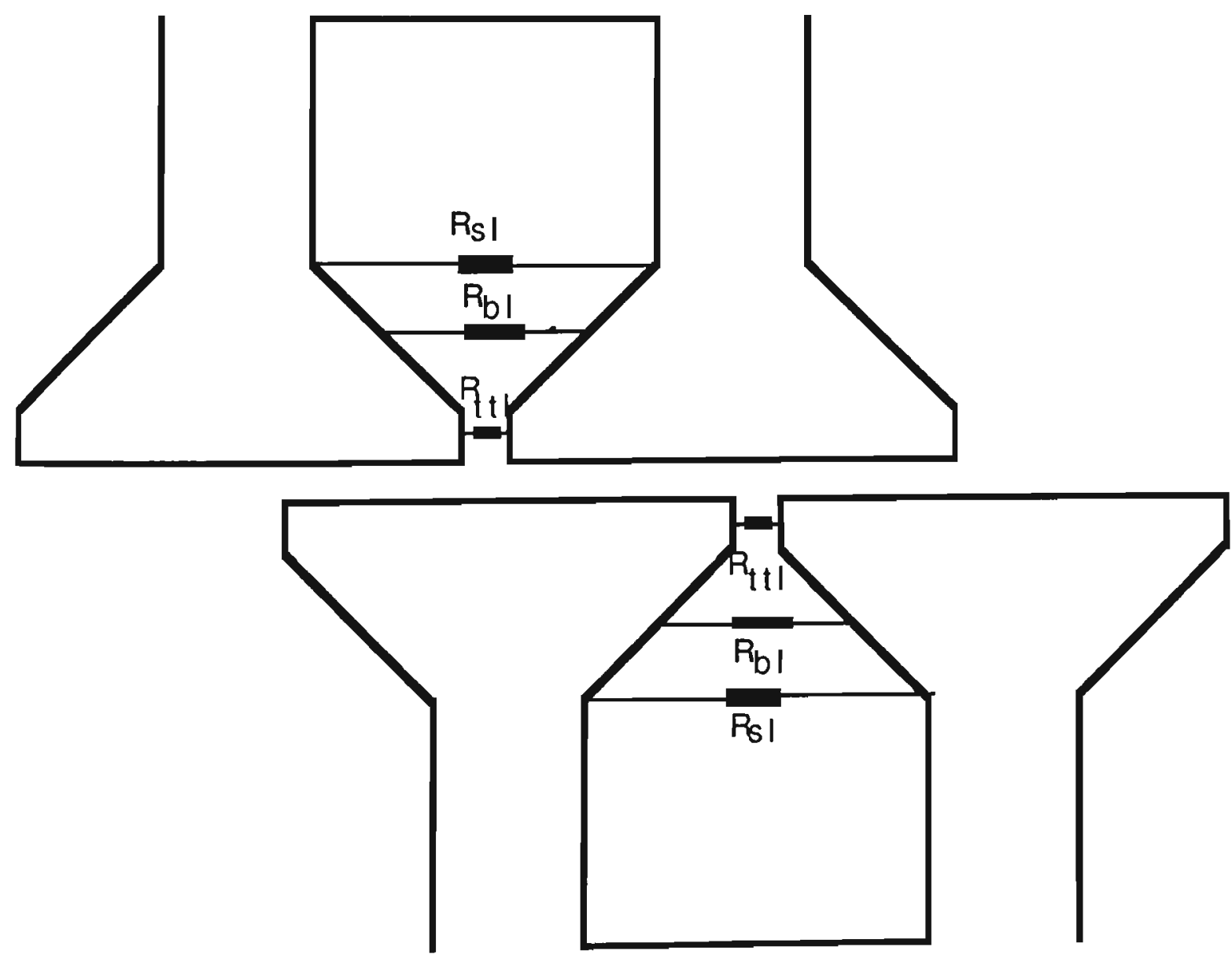

Figure 6.7 Leakage reluctances 


\subsubsection{Leakage fluxes}

In the model, the slot leakage reluctance $\left(R_{S l}\right)$ is lumped and is assumed to be present at the beginning of the tooth bevel as shown in Figure 6.7. The bevel leakage reluctance $\left(R_{b l}\right)$ is assumed to be present in the middle of the bevel. $R_{t t l}$ represents the tooth tip leakage reluctance. The calculation of all these leakage fluxes are carried out in Appendix 6.

\subsection{Computer Simulation}

In the computer simulation the machine has been divided into forty concentric rings as before. The ten non linear mmf equations are solved at the average radius of each of these rings for each rotor position.

To start with, for a given current the airgap flux densities were estimated using the linear model and these flux densities were used as the first approximate flux densities and were substituted in the mmf equations to find the "errors ". Then the flux densities were corrected and the new reduced "errors" were found. These iterations were to continue until the errors reduce to sufficiently small values to give a solution at that current and rotor position. It was found that this method could not solve the ten non linear equations simultaneously, especially at high currents. In the beginning the errors reduce and reach a local minimum and start increasing again, since the first flux densities with which the solution process was started was too far away from the actual flux densities when the machine is heavily saturated.

Many different methods were tried to solve these ten nonlinear simultaneous equations and finally a successful method was established. In this method the rotor is fixed at a particular position and the airgap flux densities across the airgap at the ten points are found using the linear model for zero current. The mmf equations are solved for the airgap flux densities. Since the current is zero in the machine this condition is relatively easy to solve. Then the current is incremented by a small step. Using the corrected flux density for zero current as the first approximation, the mmf equations for the new current is solved. It was found that an increment of $0.5 \mathrm{~A}$ achieves convergence. The current is incremented again and the mmf equations are solved with the recently corrected flux densities as the first approximation. Keeping the rotor at the same position this process is continued till the desired level of current is attained. The rotor 
position is then changed and the mmf equations were again solved starting with zero current condition. The torque which corresponds to the change in the rotor position is then calculated by calculating the change in energy related to those positions, from the airgap flux densities.

\subsection{Results}

The computer simulation was carried out for the new machine using the above indicated method and the flow diagram of the simulation is shown in Appendix 6. Figure 5.8 presented in the previous chapter is presented as Figure 6.8 here, with the addition of the calculated torque using the above described model, which includes saturation.

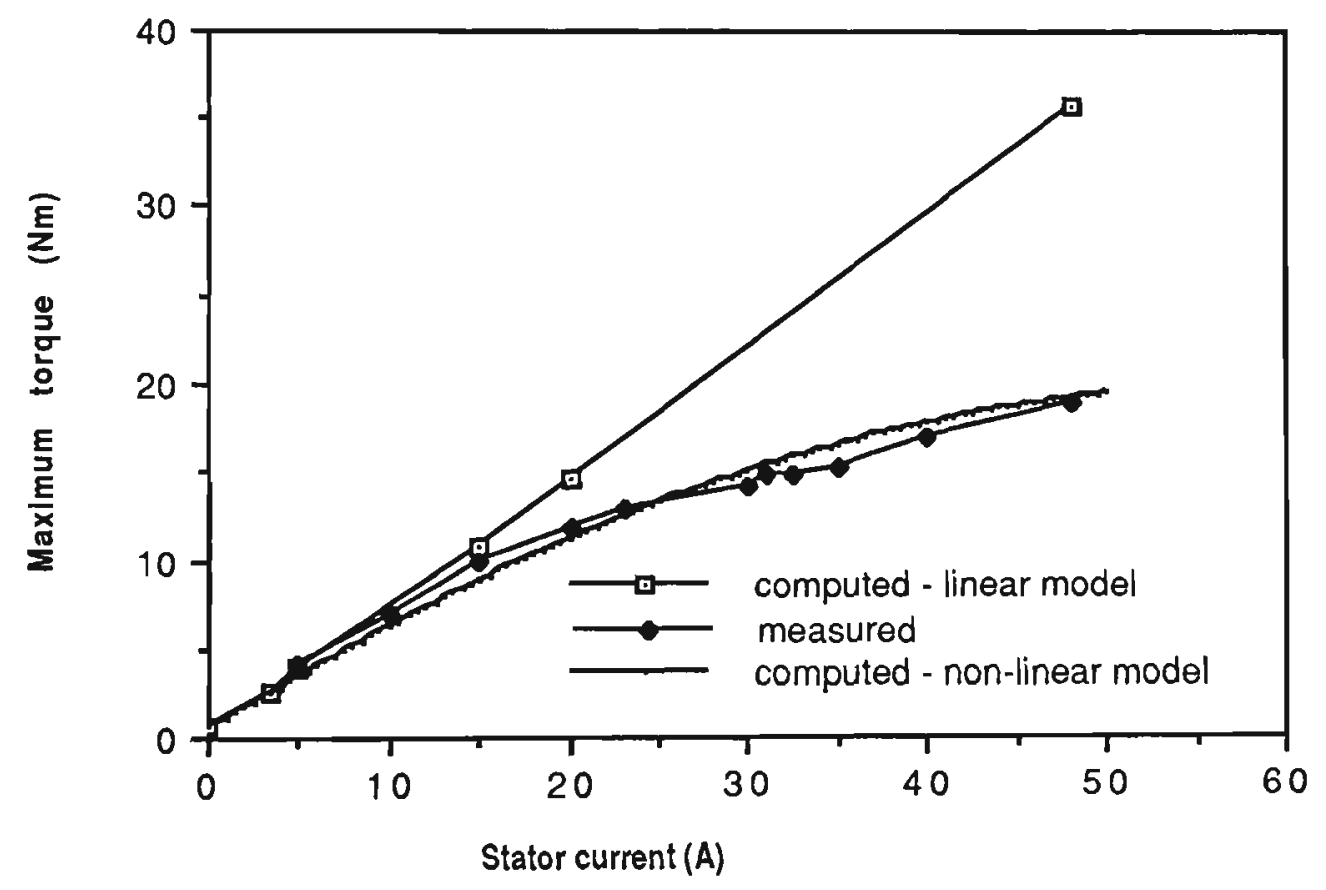

Figure 6.8 Maximum torque vs stator current.

Figure 6.8 shows that the new non-linear model predicts the torque reasonably well. The non-linear model has reduced the torque to a great extent when compared to the linear model at high stator currents. This improves the correlation between the measured and predicted values. 


\subsection{Summary}

In this chapter, a model which includes saturation was developed for an axial flux permanent magnet machine. The effect of tooth stem and tooth tip were included in the model and mmf equations were solved for different rotor positions and stator currents. The torque was calculated from the change in energy, using the airgap flux densities for the different rotor positions. The computer simulation was carried out and the maximum torque for the new machine for stator currents up to $50 \mathrm{~A}$ was calculated. The maximum torque for stator currents up to $48 \mathrm{~A}$ was compared with the computed torque. The model was found to predict the torque reasonably well. 


\section{CHAPTER 7}

\section{DESIGN OPTIMIZATION}

\subsection{Introduction}

Saturation reduces the torque produced by a machine to a great extent. At $48 \mathrm{~A}$ the torque produced by the machine is only about $7 \mathrm{Nm}$ above the torque produced at $15 \mathrm{~A}$. Though it is impossible to design a machine which will not enter saturation at any stage, it should be possible to optimize the torque for a given current by appropriate choice of machine dimensions. This requires the knowledge of the level of saturation at different parts of the machine at high currents and its dependence on the machine dimensions. The design optimization for maximum torque can be carried out for some, or all machine dimensions of the machine. Optimization of all the machine dimensions for maximum torque is a problem of very large proportions and is outside the scope of this thesis. During the development of the non-linear model it was found that the tooth tip has a major role to play in the torque development of a machine under saturated conditions. Therefore, in this chapter, the non-linear model developed in the previous chapter is used to determine all the information needed to find out a set of tooth tip dimensions which produce the maximum torque.

\subsection{Tooth Tips}

Tooth tips of a machine become heavily saturated under high currents due to the tooth tip leakage flux and the main airgap flux. This in turn reduces the airgap flux near the tooth tip and thereby the torque. This indicates that the tooth tip has a role to play in torque production (in terms of restricting the airgap flux). Thus by proper choice of tooth tip dimensions it is possible to optimize the torque for a given current. In this chapter the tooth tip dimensions are optimized for maximum torque, keeping the rest of the dimensions of the machine constant.

The worst tooth tip saturation occurs when the tooth tip is completely covered by the magnets and the stator current is very high. Using the model it was found that for equal current in two phases of the machine, the maximum torque occurs when a few outermost rings are completely covered by the magnets. Therefore, the results of airgap flux densities are presented only for the outermost ring where the worst tooth tip 
saturation occurs. In the model, the maximum torque is calculated by taking into account all the airgap fluxes.

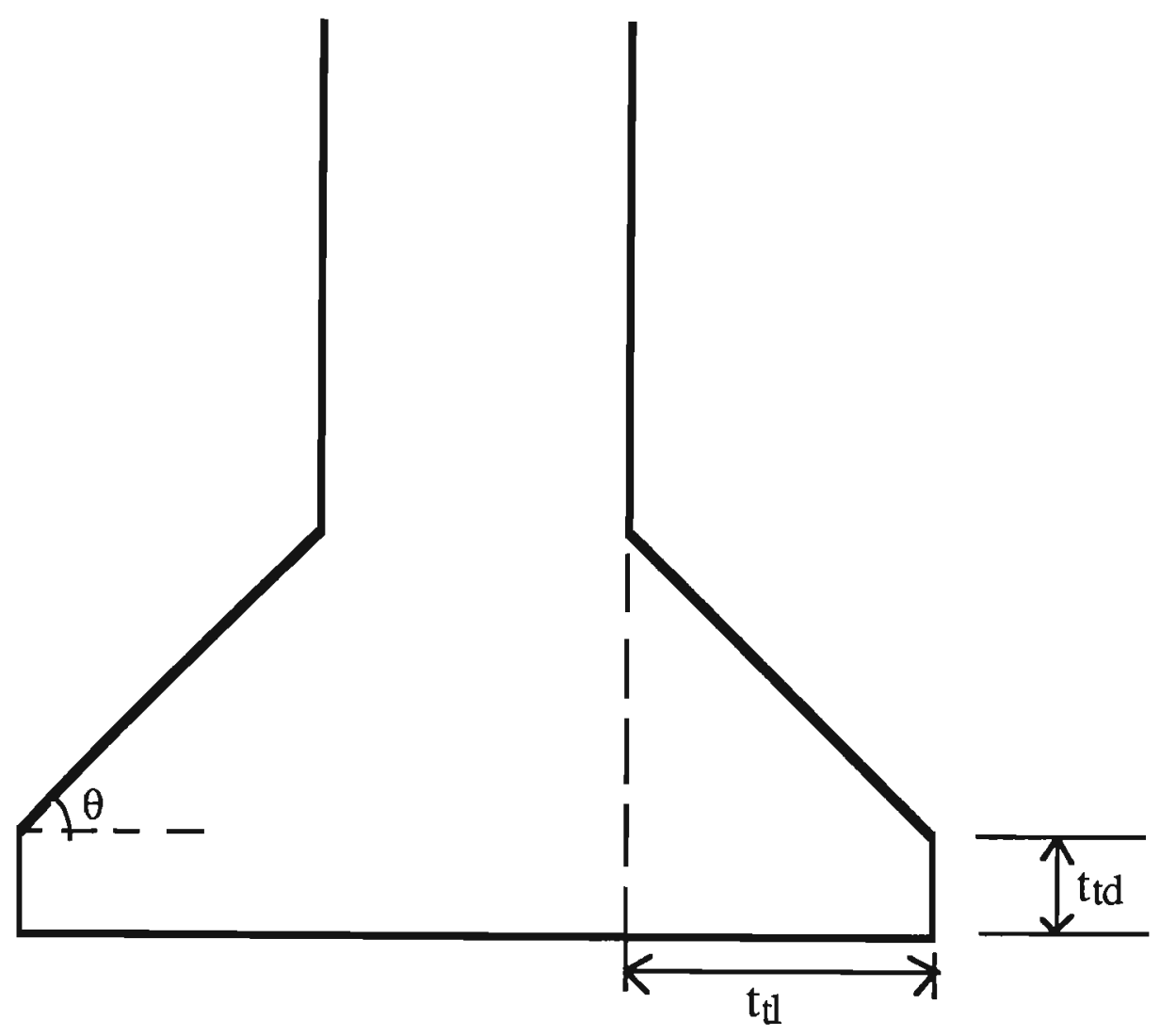

Figure 7.1 Tooth tip

Figure 7.1 shows an enlarged tooth tip. As shown in this figure ' $\theta$ ' is the bevel angle, ' $t_{\mathrm{td}}$ ' is tooth tip depth and ' $\mathrm{t}_{\mathrm{ll}}$ ' is the length of the tooth tip. If ' $\theta$ ' is small then the tooth tip will be highly saturated for small values of ' $t$ td' (since the area of cross section of the tooth tip is very small) leading to a reduction in the airgap flux near the tooth tip by offering a very high reluctance to airgap flux. This reduces the torque produced. The torque should increase as ' $t_{\mathrm{td}}$ ' increases but an increase in ' $t_{\mathrm{td}}$ ' also lets in more tooth tip leakage flux which tends to saturate both the tooth tip and the tooth stem, especially at high currents. This in turn, reduces the main airgap flux and thus the torque. Increase of ' $\theta$ ' may improve the flux level under the tooth tip but it lets in more bevel leakage flux which tends to saturate both the tooth tip and the tooth stem. Therefore an optimum combination of dimensions of ' $\theta$ ' and ' $t_{\mathrm{td}}$ ', which gives high effective flux across the air gap, leading to a high torque level is to be found.

To find the optimum tooth tip dimensions, the non-linear model developed in the previous chapter is used to determine the level of flux densities at different parts of the servo motor for various tooth tip dimensions, for a current of $50 \mathrm{~A}$ in each stator phase. In the analysis keeping ' $t_{\mathrm{tl}}$ ' constant $(2.5 \mathrm{~mm}),{ }^{\prime} \theta$ ' and ' $t \mathrm{tt}_{\mathrm{d}}$ ' are varied and the maximum 
torque and flux densities are calculated for the new servo motor. The tooth tip depth is varied from $0.25 \mathrm{~mm}$ to a maximum of $2 \mathrm{~mm}$ and the bevel angle is varied from 5 degrees to a maximum of 45 degrees. The following figures show the results of the analysis. In Figures (7.2), (7.4), (7.8), (7.9), (7.11) and (7.14), the numbers in the legends indicate the tooth tip depths in $\mathrm{mm}$, and in Figures (7.3), (7.5), (7.7), (7.10), (7.12) and (7.13), the numbers in the legend indicate the bevel angle in degrees. In the discussion to follow, one stator of the axial flux machine is refered as the upper stator and the other as lower stator.

Figures 7.2 to 7.5 show that the tooth tip flux density of the portion of the tooth tips near the slot opening of upper and lower stator for the outermost ring. The tooth tip flux densities take these values when the tooth tip is completely covered by the magnets. For the stator current considered, it happens to be the outermost ring for the maximum torque position.

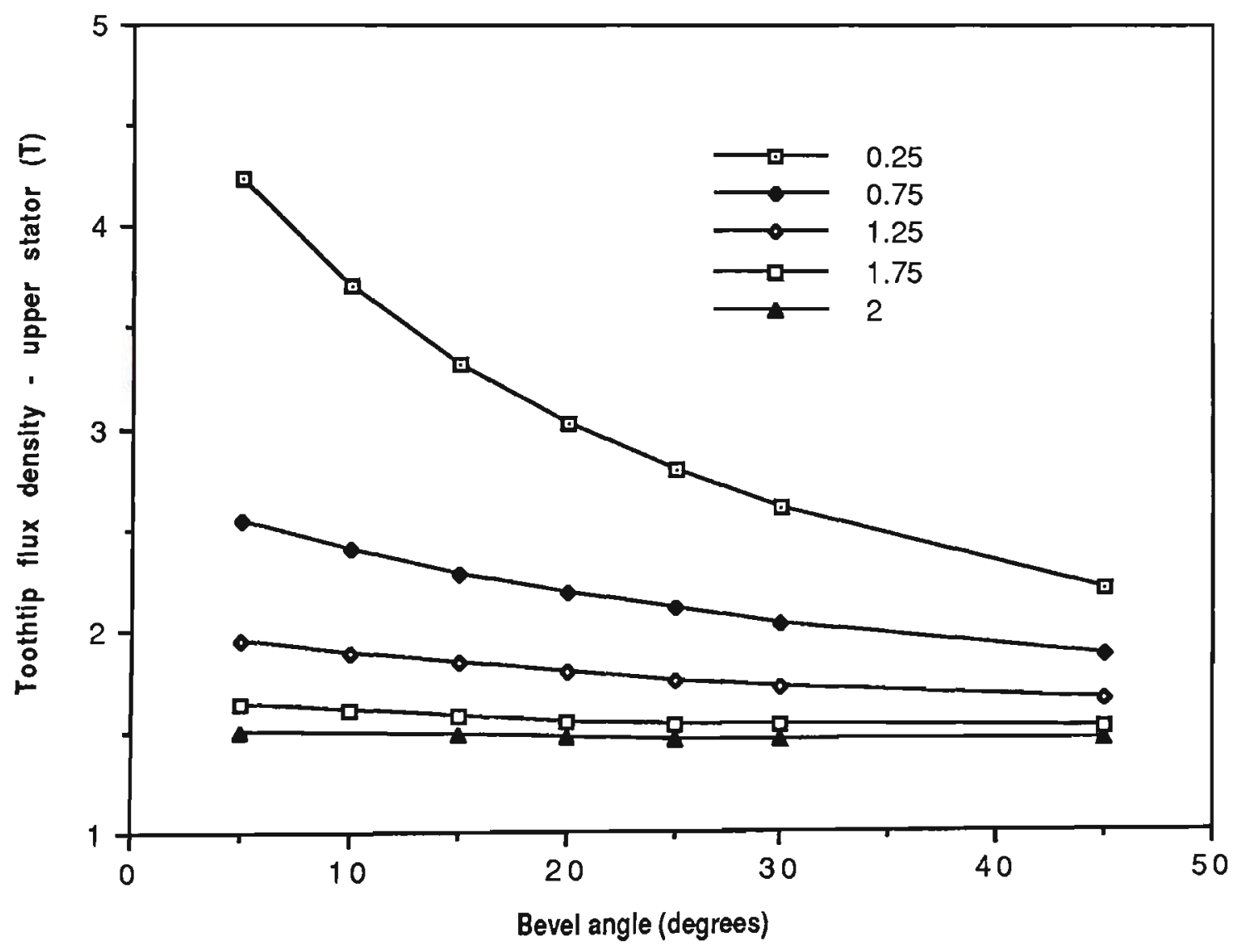

Figure 7.2 Bevel angle versus upper tooth tip flux density for different tooth tip depths 


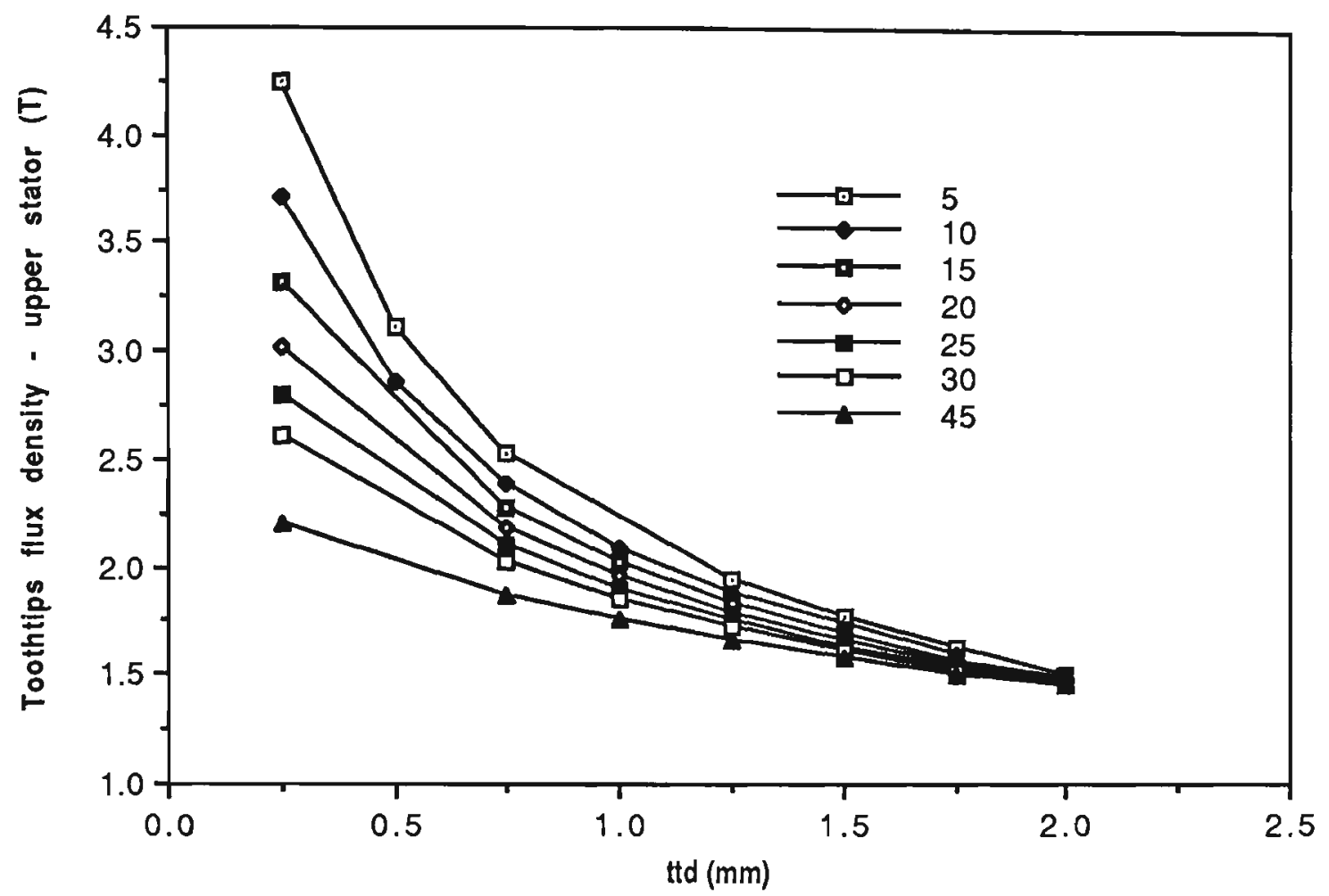

Figure 7.3 Upper tooth tip flux density versus tooth tip depth for different bevel angles

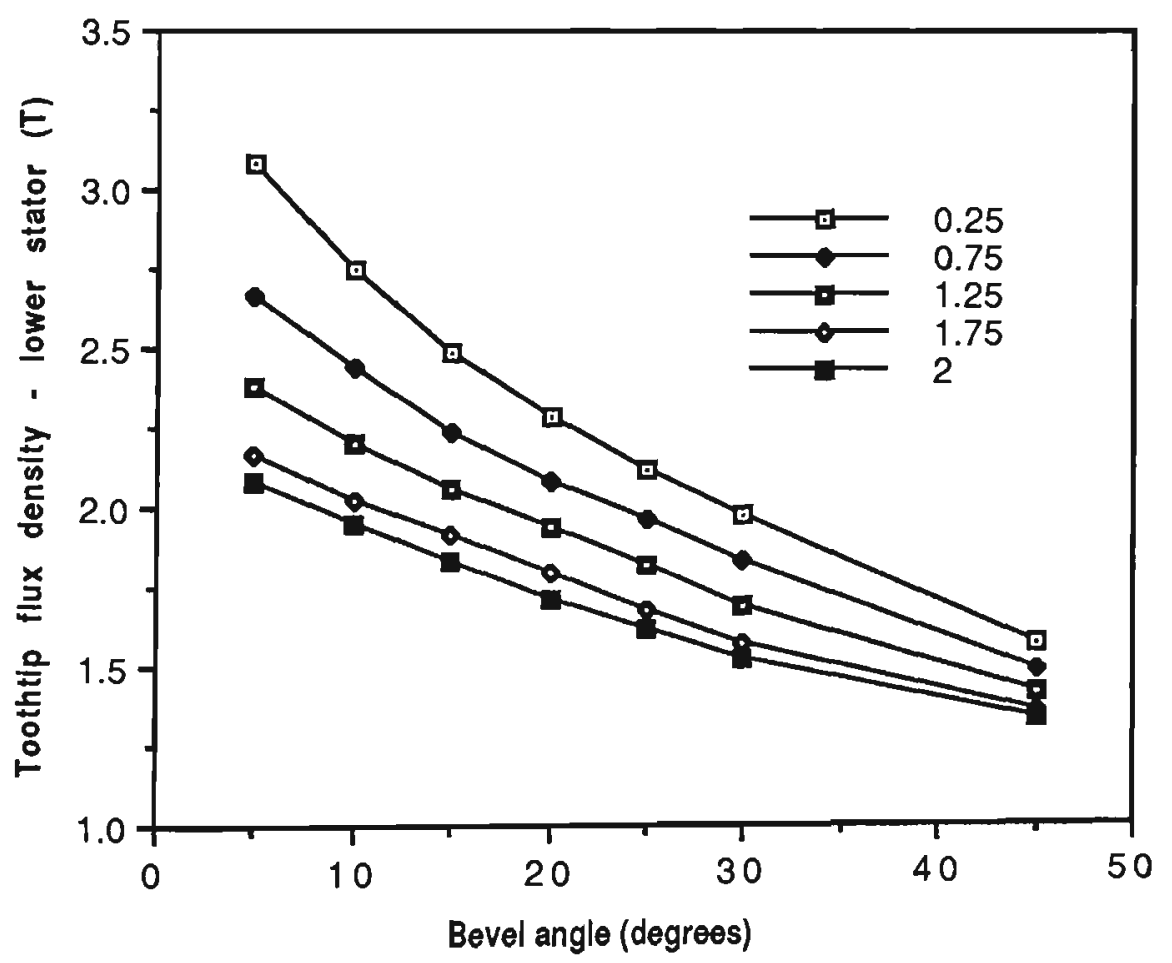

Figure 7.4 Lower tooth tip flux density versus bevel angle for different tooth tip depths 


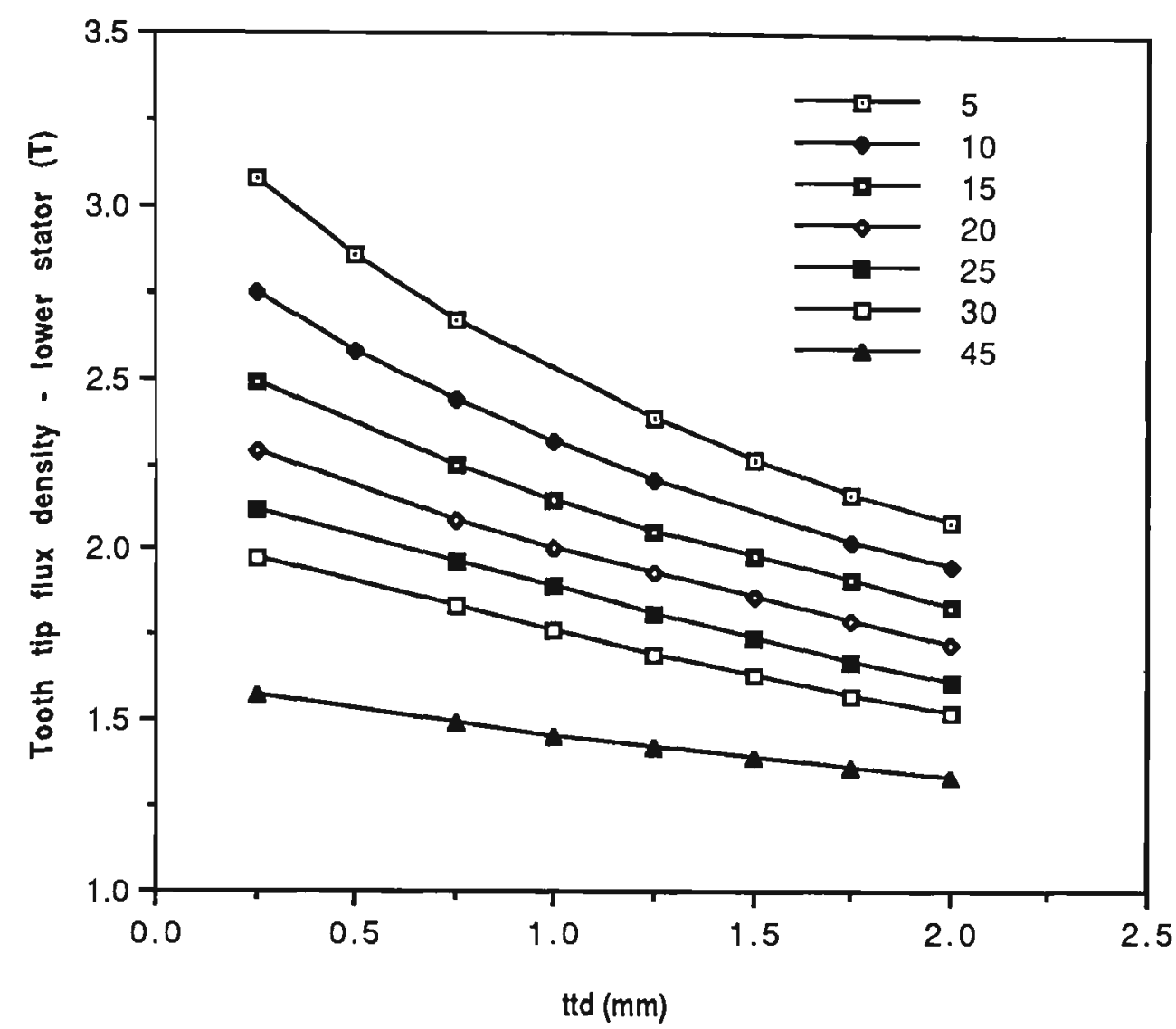

Figure 7.5 Lower tooth tip flux density versus tooth tip depth for different bevel angles

These figures show that the tooth tip saturation increases as the tooth tip becomes narrow. The worst tooth tip saturation occurs for a bevel angle of 5 degrees and tooth tip depth of $0.25 \mathrm{~mm}$. As shown by the Figures 7.2 to 7.5 , for these tooth dimensions, the flux density of the most saturated tooth tip in the upper stator is around $4.3 \mathrm{~T}$ and the lower stator tooth tip is around 3.1T. These extremely high flux densities occur over very small distances in the model.

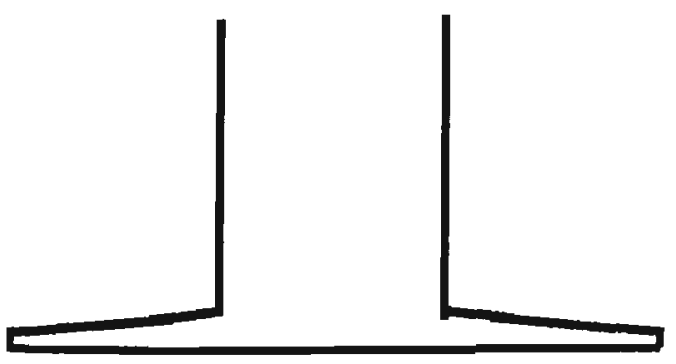

Figure 7.6 Tooth shape for a narrow tooth tip 
For a bevel angle of 5 degrees and the tooth tip depth of $0.25 \mathrm{~mm}$, the tooth tip is very narrow as shown by the Figure 7.6. Therefore the flux density in the tooth tip is very high especially if the tooth tip is completely covered by the magnet. This leads to a very low airgap flux density near the tooth tips but its value increases as the tooth is widened.

Figures 7.7 and 7.8 show the airgap flux densities of the outermost ring under the heavily saturated tooth tips (the portion of the tooth tip near to the slot) for different tooth tip depths $(0.25 \mathrm{~mm}$ to $2 \mathrm{~mm}$ ) and bevel angles ( 5 degrees to 45 degrees). These figures show that the airgap flux density near the tooth tip takes the value from 0 to $1 \mathrm{~T}$ depending on the tooth tip dimensions. A narrow tooth tip (heavily saturated tooth tip) leads to very low flux and therefore to low airgap flux density under the tooth tip. The flux density near the tooth tip varies widely in the case of $0.25 \mathrm{~mm}$ tooth tips when compared to $2 \mathrm{~mm}$ tooth tips. At a bevel angle of 45 degrees there is not much difference in the flux densities near the tooth tip for the different tooth tip dimensions, and the airgap flux density near the tooth tip is almost equal to the flux in other parts of the airgap for all tooth tip depths. For the range of tooth tip dimensions shown in the Figures 7.2 to 7.8 , the airgap flux density at the centre of a heavily saturated tooth takes values in the range 1 to $1.1 \mathrm{~T}$. These flux densities are calculated at the outermost ring and for the tooth which is completely covered by the magnets. This analysis (and the Figures 7.2 to 7.8 ) shows that the airgap flux near the tooth tip very much depends on the tooth tip dimensions. Since the torque depends on the airgap flux it is important to produce the highest possible level of flux density under the tooth tip.

\subsection{Effect of Tooth Tip Dimensions on the Tooth Stem Flux Density}

Figures (7.9) to (7.12) show the tooth stem flux densities of the upper and lower tooth stem of the machine for different tooth tip depths $(0.25 \mathrm{~mm}$ to $2 \mathrm{~mm})$ and bevel angles ( 5 degrees to 45 degrees). Since the tooth stems of the innermost ring are the most saturated, the figures show the flux densities only for the innermost ring for a current of $50 \mathrm{~A}$ in each stator winding, and for the rotor position for maximum torque. 


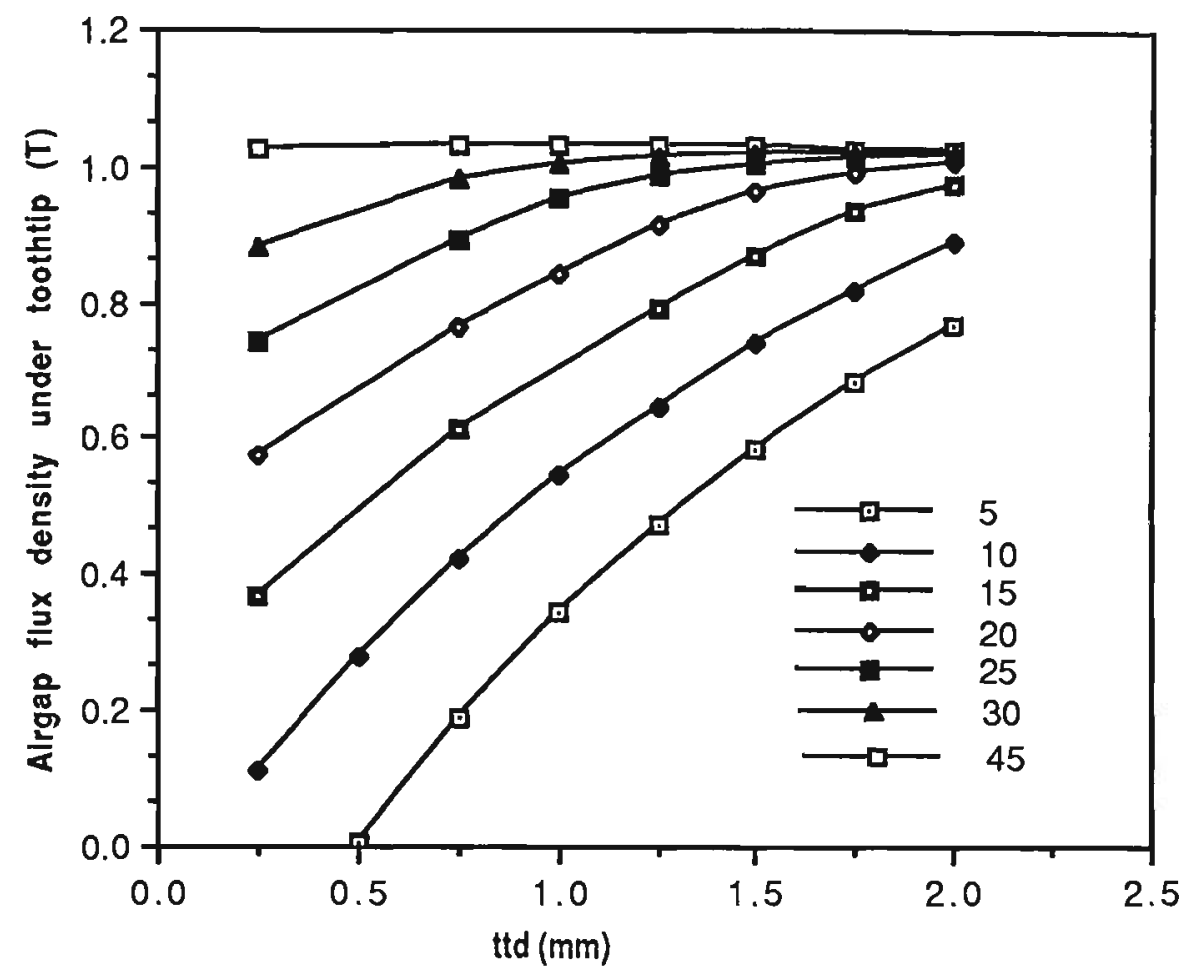

Figure 7.7 Airgap flux density versus tooth tip depth for different bevel angles

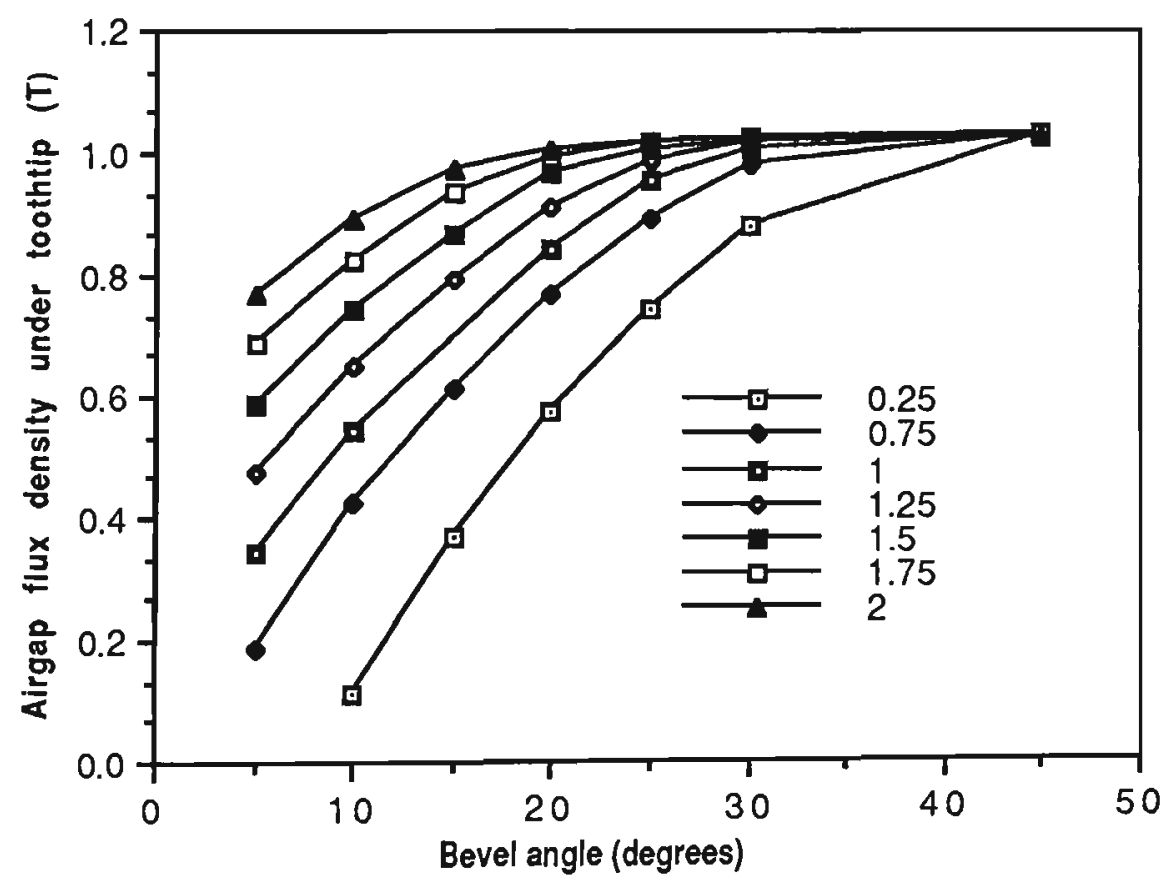

Figure 7.8 Airgap flux density versus bevel angle under the saturated tooth tip for different tooth tip depths 


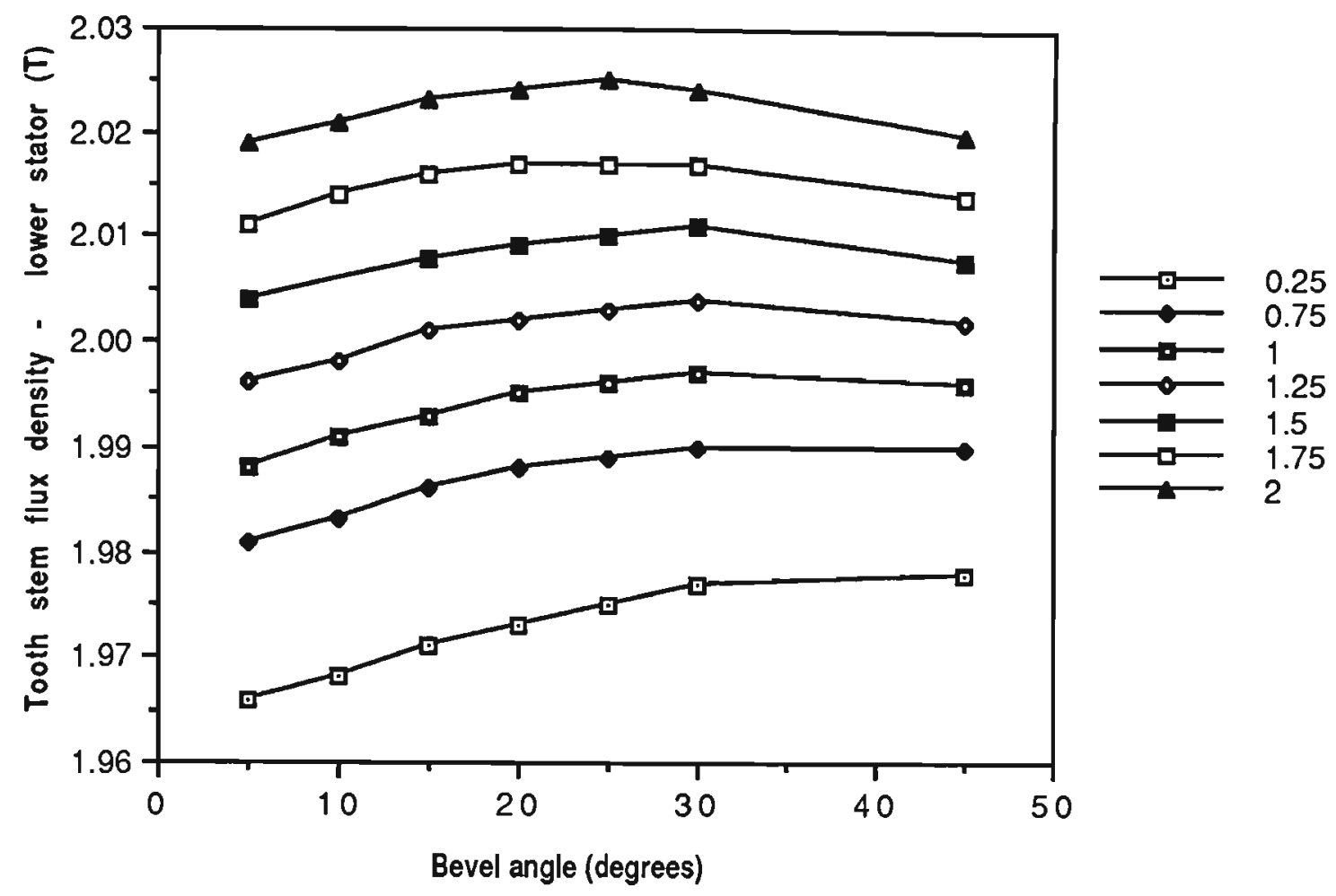

Figure 7.9 Lower stem flux density versus bevel angle for different tooth tip depths

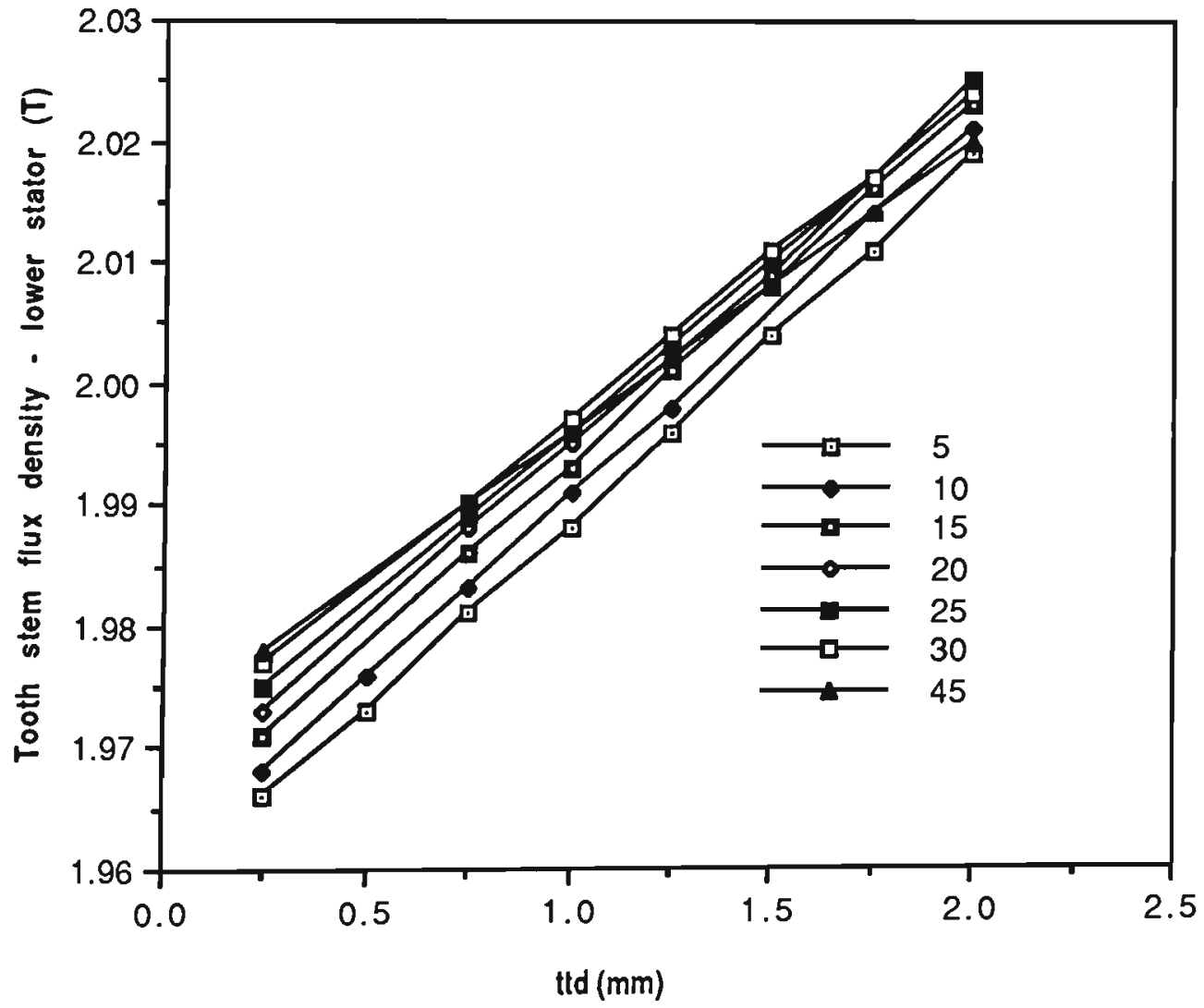

Figure 7.10 Lower stem flux densiy versus tooth tip depth for different bevel angles 


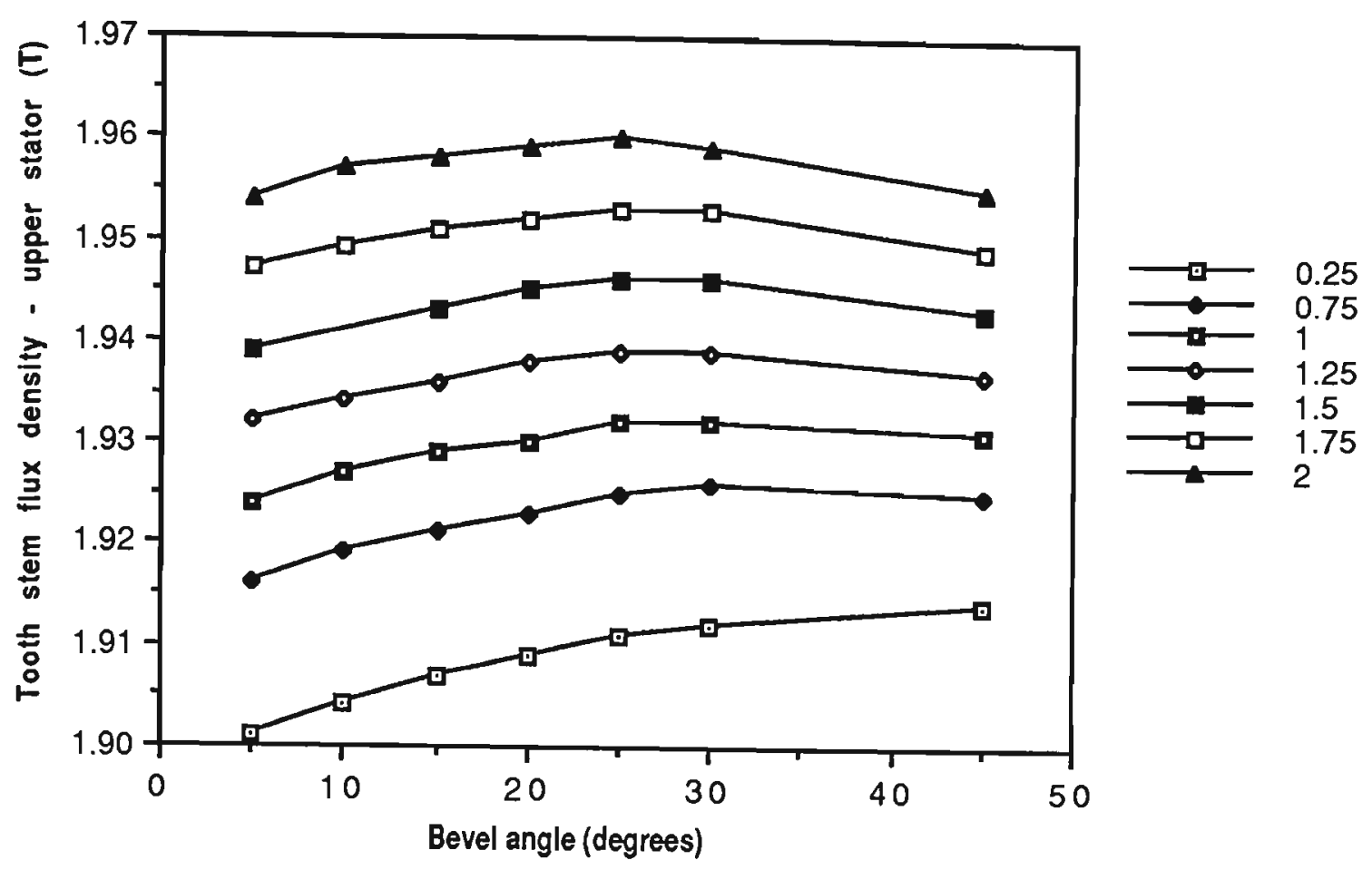

Figure 7.11 Upper stem flux density versus bevel angle for different tooth tip depths

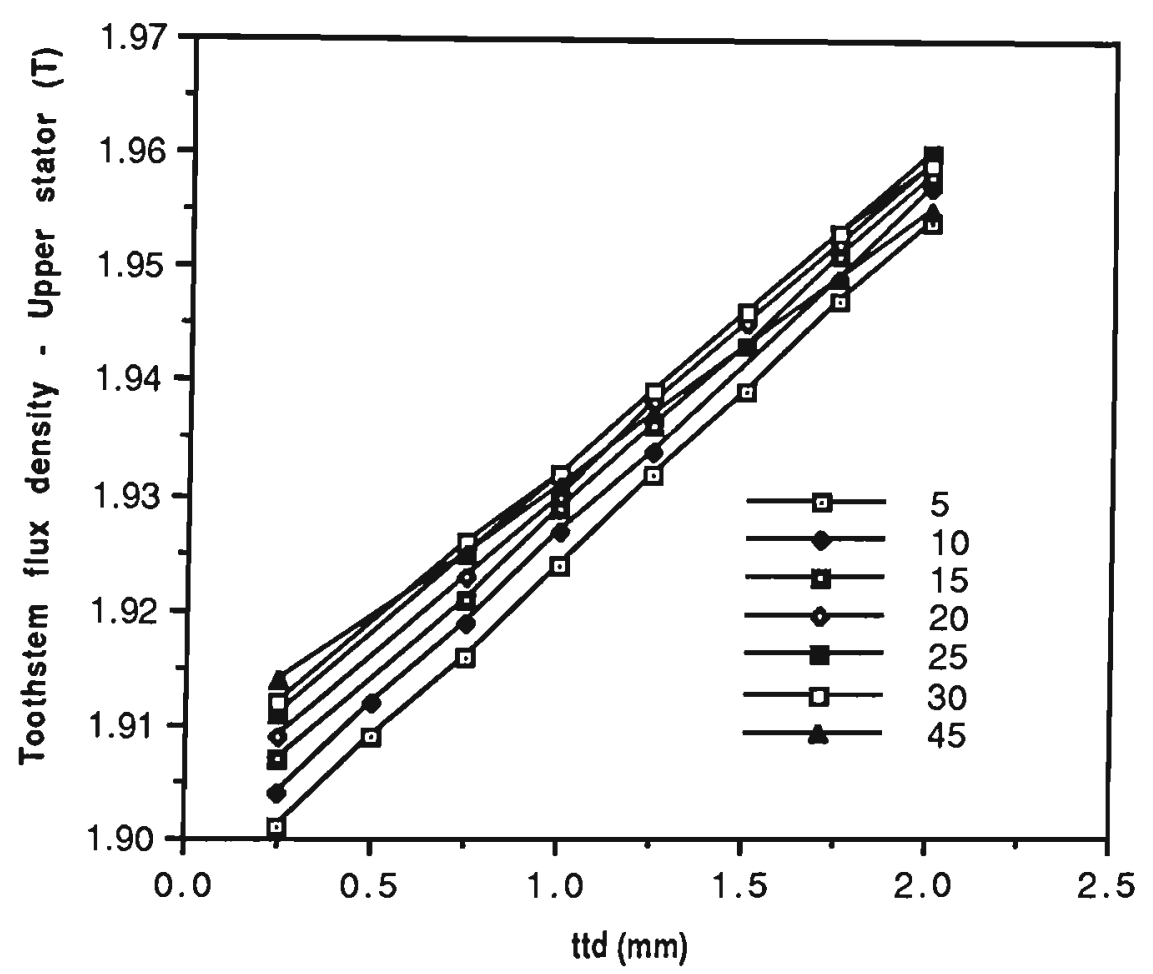

Figure 7.12 Upper stem flux density versus tooth tip depth for different bevel angles

Figures 7.9 to 7.12 show that the tooth stem becomes more saturated as the tooth tip depth increases. This is due to the fact that as the tooth tip depth increases, the tooth tip saturation decreases, and the increased cross section of the tooth tips increases the tooth tip leakage flux which enters the tooth stem, saturating it. If the stem becomes saturated, the main airgap flux which enters the tooth and goes through the stem is 
reduced. Figure 7.9 and 7.11 show that the increase in bevel angle increases the tooth stem flux density for the tooth tip depth of $0.25 \mathrm{~mm}$ and $0.75 \mathrm{~mm}$. For the other tooth tip depths considered, the increase in bevel angle increases the the tooth stem flux density till the bevel angle reaches about 30 degrees, and after that, the tooth stem flux density starts to decrease. Although the maximum decrease in flux density is about 0.005T (Figures 7.9 and 7.11 are magnified plots showing a very narrow band of flux density variation in the range of $1.96-2.03 \mathrm{~T}$ and $1.90 \mathrm{~T}-1.97 \mathrm{~T}$ respectively) this is very hard to explain since we expect the tooth stem flux density to go up as the tooth tip dimensions go up.

The analysis carried out so far shows that, the increase in tooth tip depth increases the airgap flux density near the tooth tip and decreases the airgap flux under the centre of the tooth (by saturating the tooth stem). Since the torque depends on the effective airgap flux, which is the combination of the flux under the tooth tip as well as the flux under the tooth, the tooth tip dimensions should be selected to give the highest effective airgap flux. Using the model developed in the previous chapter, torque calculations are carried out for different tooth tip dimensions. The results are presented in the following figures.

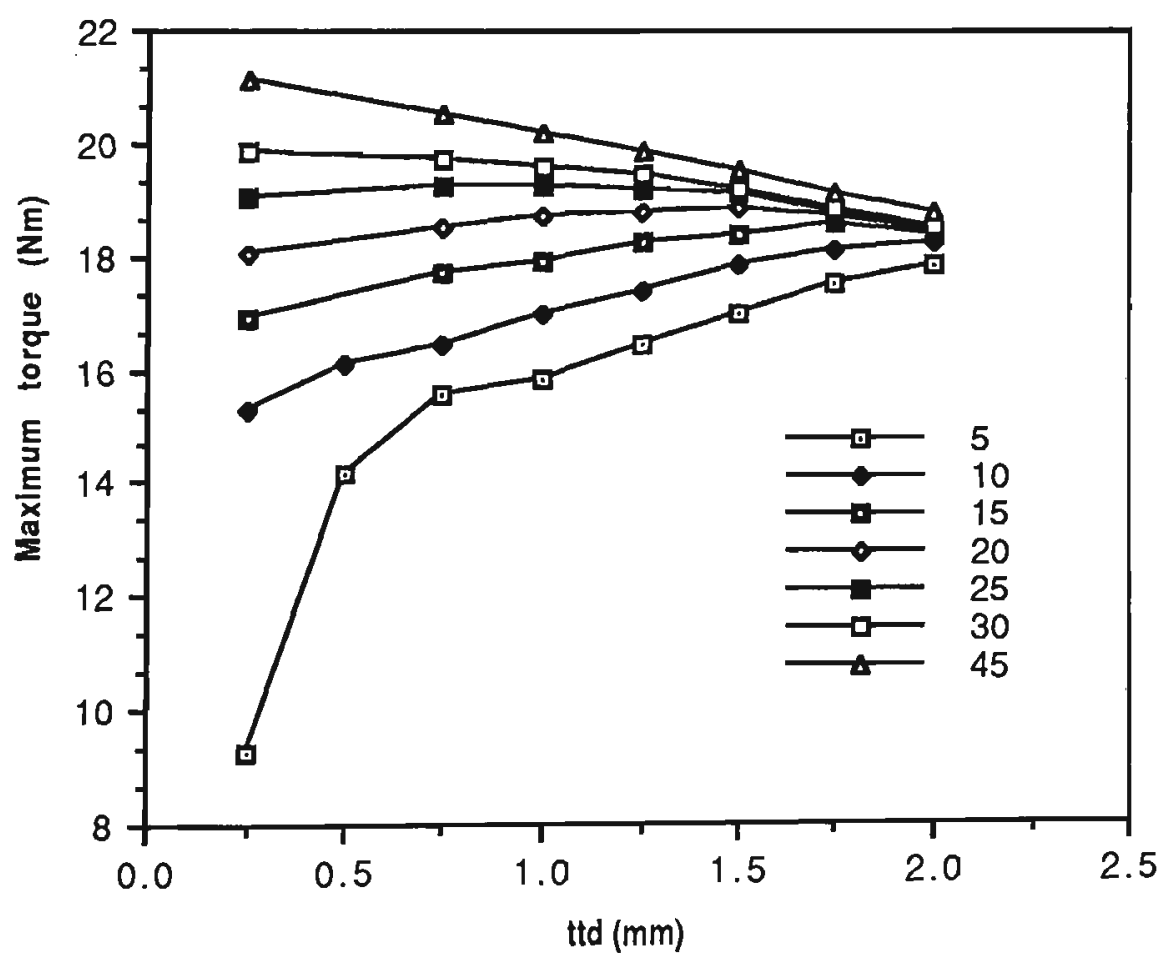

Figure 7.13 Maximum torque versus tooth tip depth for different bevel angles 


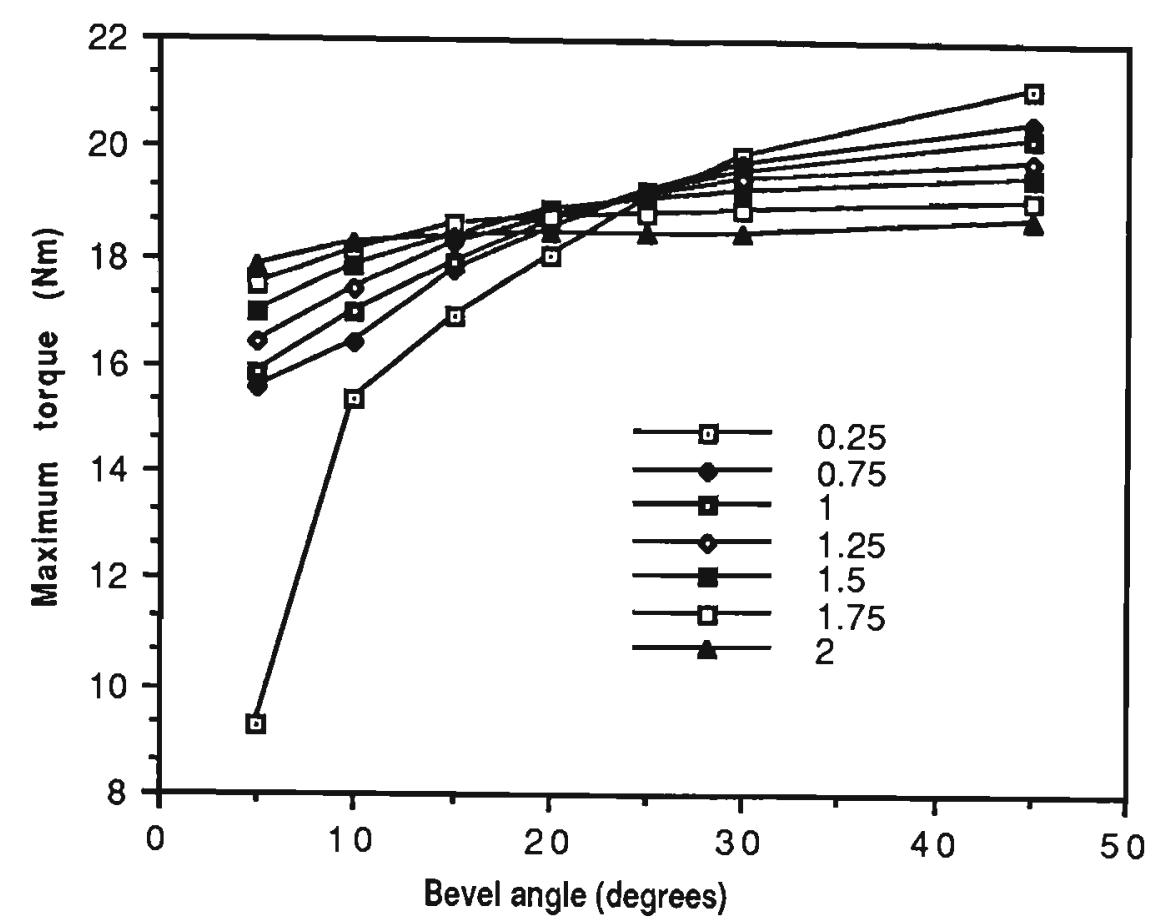

Figure 7.14 Maximum torque versus bevel angle for different tooth tip depths

Figures 7.13 and 7.14 show that in the range of tooth tip dimensions considered, the tooth tip depth of 0.25 produces the least torque with a bevel angle of 5 degrees and the same tooth tip depth produces the best torque value when the bevel angle is 45 degrees. Table 7.1 compares the values of the tooth tip flux densities of the outermost ring, tooth stem flux densities of the innermost ring and torque for the tooth tip depths of $0.25 \mathrm{~mm}$ and $2 \mathrm{~mm}$ with bevel angles 10 and 45 degrees.

The table shows that for the bevel angle of 10 degrees, a $2 \mathrm{~mm}$ tooth tip depth produces more torque than for the case of $0.25 \mathrm{~mm}$. The table also shows that for this condition the tooth tips are heavily saturated for a tooth tip of $0.25 \mathrm{~mm}$, restricting the airgap flux density (in the outer ring) near the tooth tip to $0.112 \mathrm{~T}$ which is almost 8 times less, when compared to the airgap flux density for a tooth tip depth of $2 \mathrm{~mm}(0.893 \mathrm{~T})$. Therefore less torque is produced when the tooth tip depth is $0.25 \mathrm{~mm}$. It is interesting to see that, since more tooth tip leakage flux flows through the stem, the tooth stem flux density is higher in the case of $2 \mathrm{~mm}$ when compared to $0.25 \mathrm{~mm}$.

For the bevel angle of 45 degrees, a $2 \mathrm{~mm}$ tooth tip depth produces less torque than a $0.25 \mathrm{~mm}$ tooth tip. In this case, airgap flux density near the tooth tip is almost the same for both the tooth tip depths. Since the area of tooth tip is more for the $2 \mathrm{~mm}$ compared to $0.25 \mathrm{~mm}$, more leakage flux flows into the tooth stem through the tooth tip and so the saturation in the tooth stem is higher. This in turn reduces the main airgap flux and therefore the torque. The maximum torque is obtained, when the tooth tip has a depth 
of $0.25 \mathrm{~mm}$, and the tooth bevel angle is 45 degrees, a combination for which both the stem and the tooth tip saturation levels lead to a more uniform flux densities across the airgap. The low tooth tip depth restricts the tooth tip leakage flux which enters the tooth thereby preventing heavy tooth stem saturation. This leads to high airgap flux under the tooth when compared to the higher tooth tip depth. The high bevel angle helps (by avoiding heavy saturation of the tooth tip) to maintain reasonable flux levels under the tooth tip. Thus the combined effect of low tooth tip depth and high bevel angle leads to high effective airgap flux and in turn high torque. The bevel angle was arbitralily restricted to 45 degrees. All the figures presented above suggest that (for a $t_{t l}$ of $2.5 \mathrm{~mm}$ ) a tooth tip depth of $0.25 \mathrm{~mm}$ and a bevel angle of 45 degrees are the best tooth tip dimensions for the new servo motor in terms of maximum torque production.

\begin{tabular}{|c|c|c|c|c|}
\hline $\mathrm{t}_{\mathrm{td}}(\mathrm{mm})$ & 0.25 & 2.00 & 0.25 & 2.00 \\
\hline$\theta$ (degrees) & 10 & 10 & 45 & 45 \\
\hline $\begin{array}{c}\text { Upper tooth } \\
\text { stem flux } \\
\text { density (T) }\end{array}$ & 1.904 & 1.957 & 1.914 & 1.955 \\
\hline $\begin{array}{c}\text { Lower tooth } \\
\text { stem flux } \\
\text { density (T) }\end{array}$ & -1.968 & -2.021 & -1.978 & -2.020 \\
\hline $\begin{array}{c}\text { Upper tooth tip } \\
\text { flux density (T) }\end{array}$ & 3.704 & 1.49 & 2.196 & 1.457 \\
\hline $\begin{array}{c}\text { Lower tooth tip } \\
\text { flux density (T) }\end{array}$ & -2.750 & -1.956 & -1.574 & -1.336 \\
\hline $\begin{array}{c}\text { Airgap flux } \\
\text { density under } \\
\text { the most } \\
\text { saturated tooth } \\
\text { tip (T) }\end{array}$ & 0.112 & 0.893 & 1.029 & 1.028 \\
\hline $\begin{array}{c}\text { Airgap flux } \\
\text { density under } \\
\text { the centre of } \\
\text { the tooth(T) }\end{array}$ & 1.038 & 1.030 & 1.035 & 1.029 \\
\hline \begin{tabular}{c} 
Torque (Nm) \\
\hline
\end{tabular} & 15 & 18 & 21 & \\
\hline
\end{tabular}

Table 7.1 Comparison of flux density and torque for four combinations of tooth tip depths and bevel angles 


\subsection{Summary}

The non-linear model developed in Chapter 6 is used in this chapter to find a set of tooth tip dimensions that would produce maximum torque for a given current. All the other dimensions of the machine are kept constant. The torque was calculated for various tooth tip dimensions and it was found that, for the new servo motor, the torque is maximum for a tooth tip depth of $0.25 \mathrm{~mm}$ and a bevel angle of 45 degrees. For these dimensions, the maximum torque can be expected to increse from the new servo machine's $18.4 \mathrm{Nm}$ to $21.2 \mathrm{Nm}$, for a stator current of $48 \mathrm{~A}$ in each stator. 


\section{CHAPTER 8}

\section{CONCLUSION}

In this project an axial flux permanent magnet servo motor was developed. The moment of inertia of the machine is kept low and its torque cabability is kept high by its unique design features which include

1. Low radius

2. High pole number

3. One phase in each stator and

4. One slot per pole per phase

Since energy considerations are to be used for torque calculations, the energy density of the permanent magnet is derived and verified experimentally. Two mathematical models were developed to handle the special problems that arise due to the peculiar geometry and discrete nature of the machine. Firstly, the linear model using DFT succeeds in predicting the behaviour of the machine at low stator currents, and secondy, the non-linear model takes the saturation in the stator iron into account. The linear model is also used to predict the cogging torque. The results predicted by the two models are compared with the experimental results and found that the models predict the torque resonably well.

The model which includes saturation is used to study the flux density at different parts of the stator iron at high stator current and to find a set of tooth tip dimensions (keeping the other dimensions of the machine constant) which give maximum torque.

The acceleration available from a machine is the average torque available from the machine over a complete rotation divided by the moment of inertia. For the new servo motor, although all torque measurements have been made only with $48 \mathrm{~A}$ in each winding, this figure will be approximately $70,000 \mathrm{rad} \mathrm{sec}^{-2}$. This may be compared with 37,500 rad sec-2 for a conventional high performance servo motor rated for the same peak torque [19]. This is a very considerable increase in performance. There is still scope for considerable development. The saturation model indicates that a significant increase in peak torque may be available by reducing the depth of the tooth tips. This has still to be investigated thoroughly. It will be also worthwhile to study the effects of fringing flux which was ignored in the analysis. 


\section{AUTHOR'S PUBLICATIONS}

[1] S. Geetha, D. Platt and B. S. P. Perera, "Cogging torque in permanent magnet axial flux machines", Proc.conf.Industrial Drives, Rockhampton, Queensland, Australia, Sept.1991, pp 158-163.

[2] S. Geetha and D. Platt, "Axial flux permanent magnet servo motor with sixteen poles", Proc. IEEE IAS Ann. Mtg., 1992, pp 286- 291.

[3] S. Geetha and D. Platt, "The effect of saturation on an axial flux permanent magnet servo motor", Paper under preparation for submission to IEEE Trans. on Magnetics.

[4] S. Geetha and D. Platt, "Discrete Fourier Transform in Electrical Machines with Application to Permanent Magnet Machines", Paper under preparation for submission to the journal, Electric Machines and Power Systems. 


\section{REFERENCES}

[1] G.R. Slemon, A. Straughen, "Electric Machines", Addison - Wesley Publishing Company, Sydney, 1980, p 179.

[2] D. Platt, "Permanent magnet synchronous motor with axial flux geometry", IEEE Trans. Magnetics,Vol. 25, No. 4, July 1989, pp 3076-3079.

[3] D. E. Hesmondhalgh, D. Tipping, "Slotless construction for small synchronous motors using Samarium Cobalt magnets", IEE PROC., Vol. 129, Pt.B, No. 5, September 1982, pp 251- 261

[4] N. A. Demerdash, R. H. Miller etc, "Comparison between features and performance characteristics of fifteen hp Samarium cobalt and Ferrite based brushless dc motors operated by same power conditioner", IEEE Trans. on PAS, Vol. PAS-102, No. 1, January 1983, pp 104 - 113.

[5] N. A. Demerdash and T. A. Nyamusa, "Comparison of effects of overload on parameters and performance of Samarium - Cobalt and Strontium-Ferrite radially oriented permanent magnet brushless dc motors", IEEE Trans. on PAS, Vol. PAS-104, No. 8, August 1985, pp 2223-2231.

[6] Tomy Sebastian and Gordon R. Slemon, "Transient torque and short circuit capabilities of variable speed permanent magnet motors", IEEE Trans. Magnetics,Vol. MAG- 23, No. 5, Sep. 1987, pp 3519-3621.

[7] Gordon R. Slemon and Xian Liu, "Modelling and design optimtzation of permanent magnet motors", Electric Machines and Power Systems, Vol 20, 1992, pp 71-92.

[8] Kunio Miyashita, etc "Development of a high speed 2-pole permanent magnet synchronous motor", IEEE Trans. on PAS, Vol. PAS-99, No. 6, Nov/Dec 1980, pp 2175 - 2180. 
[9] P. Campbell, D. J. Rosenberg and D. P. Stanton, "The computer design and optimization of axial field permanent magnet motors", IEEE Trans. on PAS, Vol. PAS-100, No. 4, April 1981, pp 1490- 1497.

[10] R. Krishnan and A.J. Beulter, "Performance and design of an axial field permanent magnet synchronous motor servo drive", Proc. IEEE IAS Ann. Mtg., 1985, pp. 634-640.

[11] Hiro Takano, Takashi Itoh, Kazuo Mori, Akira Sakuta and Takao Hirasa,"Optimum values for magnet armature winding thickness for axialfield permanent magnet brushless dc motors", IEEE Trans. Ind. Appl., Vol. 28, No. 2, Mar/A pril, 1992, pp 350- 357.

[12] Chris C. Jensen, Francesco Profumo and Thomas A. Lipo, "A low-loss permanent magnet brushless dc motor utilizing tape wound amorphous iron", IEEE Trans. Ind. Appl., Vol. 28, No. 3, May/June 1992, pp 115127.

[13] R. Krishnan, "Selection criteria for servo motor drives", Proc. IEEE IAS Ann. Mtg., 1986, pp 301 - 308.

[14] Philippe Viarouge, Michel Lajoie-Mazenc, and Christian Andrieux, "Design and construction of a brushless permanent magnet servomotor for directdrive application", IEEE Trans. Ind. Appl., Vol. 25, No. 1, Jan/Feb 1989, pp 107- 112 .

[15] George W. Younkin, D. McGlasson and Robert D. Lorenz,"Considerations for low - inertia ac drives in machine tool axix servo applications", IEEE Trans. Ind. Appl., Vol. 27, No. 2, Mar/Apr 1991, pp 262-267.

[16] Pragasen Pillay and Ramu Krishnan, "Application characteristics of permanent magnet synchronous and brushless dc motors for servo drives", IEEE Trans. Ind. Appl., Vol. 27, No. 5, Sep/Oct 1991, pp 986-996.

[17] Gordon R. Slemon, "On the design of high performance pm motors", Proc. IEEE IAS Ann. Mtg., 1992, pp 279- 285. 
[18] S. Geetha and D. Platt,"Axial flux permanent magnet servo motor with sixteen poles", Proc. IEEE IAS Ann. Mtg., 1992, pp 286- 291.

[19] Polymotor, 'Fastact Servomotor Catalogue', Polymotor Italiana S.p.A., Via Avosso, 94 . 16015 Casella (Genova-Italia).

[20] Alhamadi. M. A., N. A. Demerdash "Modelling effects skewing of rotor mounted permanent magnets on performance of brushless DC motor", IEEE Trans.EC,Vol. 6, No.4, Dec91, pp 721-729.

[21] V. B. Honsinger, "Performance of polyphase permanent magnet machines", IEEE Trans. PAS, Vol. PAS - 99, No.4 July/ Aug 1980, pp 1510 - 1518.

[22] N. A. Demerdash and T.W. Nehl, "Dynamic modelling Of brushless dc motors for aerospace actuation", IEEE Trans. on AES, Vol. AES-16, No. 6, November 1980, pp 811 - 821.

[23] M. A. Rahman and T. A. Little, "Dynamic performance of permanent magnet synchronous motors", IEEE Trans. on PAS, Vol. PAS-103, No. 6, June 1984, pp $1277-1283$.

[24] D. E. Hesmondhalgh, D. Tipping, "Torque availability from small synchronous motor using high coercivity magnets", IEE PRO.,Vol. 132, Pt. B, No.5, September 1985, pp 279 - 288.

[25] Tomy Sebastian, Gordon R. Slemon and M.A. Rahman, "Modelling of permanent magnet synchronous motors", IEEE Trans. Magnetics,Vol. MAG- 22, No. 5, Sep. 1986, pp 1069-1071.

[26] Tomy Sebastian and Gordon R. Slemon, "Transient modeling and performance of variable-speed permanent-magnet motors", IEEE Trans. Ind. Appl., Vol. 25, No. 1, Jan/Feb 1989, pp 101- 106.

[27] J. De La Ree and N. Boules, "Torque production in permanent - magnet synchronous motors", IEEE Trans. Ind. Appl., Vol. 25, No. 1, Jan/Feb 1989, pp 107- 112 . 
[28] Kwang - Heon Kim, Dong- Joon Sim, and Jong - Soo, "Analysis of skew effects on cogging torque and BEMF for BLDCM Cogging torque in permanent magnet synchronous motors", Proc. IEEE IAS Ann. Mtg., 1991, pp 191 - 197.

[29] T. Li and G. Slemon, "Reduction of cogging torque in permanent magnet motors", IEEE Trans. Magnetics, Vol. 24, No. 6, Nov 1988, pp 29012903

[30] B. Ackermann, J. H. H. Janssen, R. Sottek, R.I. Van Steen, "New technique for reducing cogging torque in a class of brushless dc motors", IEE Proc-B ., Vol. 139, No. 4, July 1992, pp 315- 320.

[31] F. Parasiliti, P. Poffet, "A model for saturation effects in high- field permanent magnet synchronous motor", IEEE Trans. EC, Vol. 4, No. 3, Sep89, pp 487-484.

[32] Nady Boules, "Design optimization of permanent magnet DC motors", IEEE Trans. Ind. App1., Vol. 26, No. 4, Jul/Aug 1990, pp 786-792.

[33] M. McCaig, "Energy relations in hard and soft magnetic materials", IEEE. Trans. on Magnectics, Vol. No. 6 Nov 1978, pp 986 - 988

[34] N. Gauthier and H. D. Wiederick, "Note on the magnetic energy density", Am. J. Phys. 50(8), Aug. 1982, pp 758 - 759

[35] Malcolm McCaig, Alan G Clegg, "Permanent Magnets in Theory and Practice", Pentech Press, London 1987

[36] P.Hammond, "Applied Electromagnetism", Pergamon Press, Oxford, 1971.

[37] M. Lajoie-Mazenc, R. Carlson, J. Hector, and J.J. Pesque, "Characterisation of a new machine with Ferrite magnets by resolving the partial differential equation for the magnetic field", Proc. IEE, Vol. 124, No. 8, Aug 1977, pp 697 - 701. 
[38] I. V. Mitchell,"Nd-Fe Permanent magnet magnets: Their present and future applications", Elsevier Applied Science Publishers, London, New York 1985.

[39] H. Joseph Weaver, "Application of Discrete and Continuous Fourier Analysis", John Wiley \& Sons, 1983, p91.

[40] Robert H. Katyl, "FFT calculation of magnetic fields in air coils", IEEE Trans. Magnetics, Vol. MAG- 16, No. 3, May1980, pp 545 -549.

[41] S. Geetha, and D. Platt, B. S. P. Perera, "Cogging torque in permanent magnet axial flux machines", Proc.conf.Industrial Drives, Rockhampton, Queensland, Australia, Sept.1991, pp 158-163.

[42] A.E. Fitzgerald, Charles Kingsley, Jr, Stephen D. Umans, "Electric Machinery ", Fifth edition, McGraw - Hill Book Company,1991, p 558. 


\section{APPENDIX 1 - MOMENT OF INERTIA OF THE ROTOR}

\section{Moment of inertia of a cylinder}

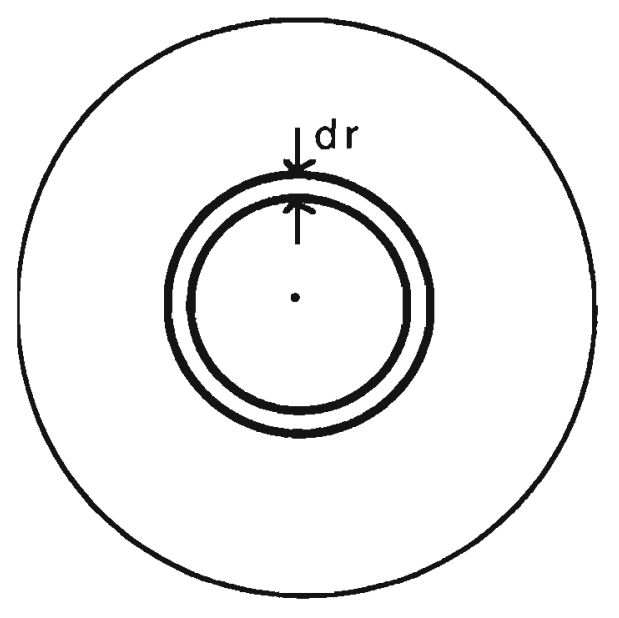

Figure 1 Cross section of a cylinder

Figure 1 shows the area of cross section of a cylinder. Considering a ring of incremental radius $\mathrm{dr}$, the moment of inertia $\mathrm{J}$ of a cylinder can be written as

$$
\begin{aligned}
J & =\int_{0}^{r} 2 \pi r \rho g_{m} r^{2} d r \\
& =\left(\pi \rho g_{m} r^{4}\right) / 2
\end{aligned}
$$

Where $r$ is the radius of the cylinder, $g_{m}$ is its axial thickness, and $\rho$ is the density of the cylinder material.

The rotor of the new servo motor is a thin disc, with magnets embedded in an aluminium frame. Figure 2 shows the rotor cross section, ignoring skewing. The rotor has sixteen poles. The distance between the magnets is constant all along the radius.

In Figure 2, the aluminium portion of the rotor is shown as shaded area. The moment of inertia of the magnets, shaft and the aluminium frame have to be calculated to find the moment of inertia of the rotor. Since the distance between the magnets is $4 \mathrm{~mm}$ and it does not vary with the radius, for a ring of incremental radius $\mathrm{dr}$, the portion of the circumference of a ring made of magnets can be expressed as 


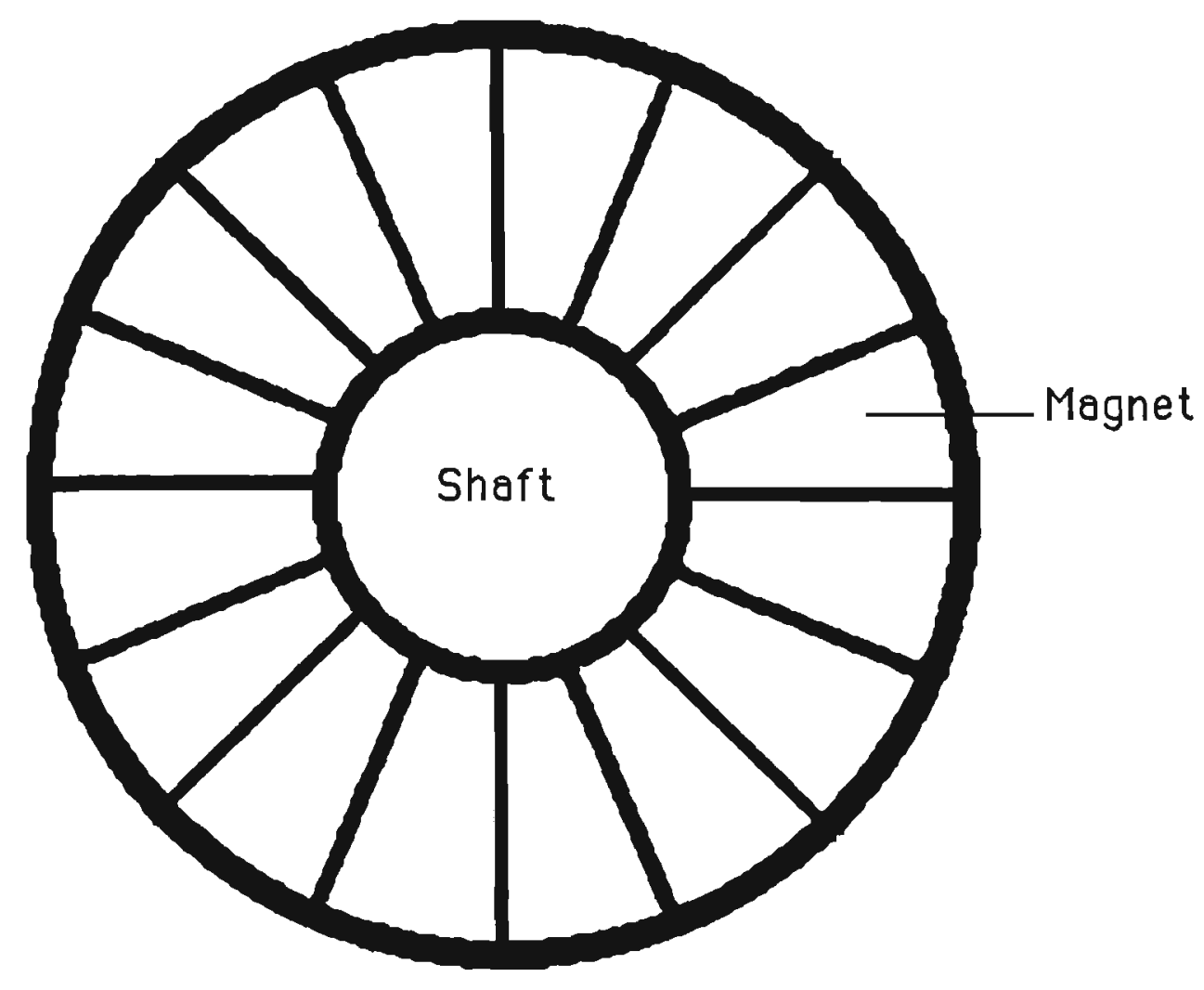

Aluminium frame

Figure 2 Rotor cross section

The circumference $=2 \pi \mathrm{r}-16 \times 4 \times 10^{-3}$

$$
=2 \pi \mathrm{r}-6.4 \times 10^{-2}
$$

Hence,

the moment of inertia of the magnets $=\int_{R_{i}}^{R_{0}}\left\{2 \pi r-6.4 \times 10^{-2}\right\} \rho g_{m} r^{2} d r$.

Where $R_{i}$ and $R_{0}$ is the inner and outer radius of the rotor disc magnets respectively. For the servo motor,

$$
\begin{array}{ll}
\mathrm{R}_{\mathrm{O}} & =51 \times 10^{-3} \\
\mathrm{R}_{\mathrm{i}} & =24 \times 10^{-3} \\
\mathrm{~g}_{\mathrm{m}} & =3.4 \times 10^{-3} \\
\rho & =7.8 \times 10^{3}
\end{array}
$$

Substituting in (2), 
the moment of inertia of the magnet part $=200 \times 10^{-6} \mathrm{~kg} \mathrm{~m}^{2}$

Using equation (1) the moment of inertia of the shaft of the machine can be evaluated as

Moment of inertia of the shaft

$$
=\quad 5.884 \times 10^{-6} \mathrm{~kg} \mathrm{~m}^{2}
$$

(The radius of the shaft is $7 \mathrm{~mm}$ and its axial length is $20 \mathrm{~mm}$ )

\section{Moment of inertia of the aluminium in the rotor disc}

The rotor aluminium frame is made up of three distinct parts, namely the outer frame in the form of a ring, an inner ring to bridge the gap between the shaft's outer radius and the rotor magnet's inner radius, and the aluminium portion that separates two magnets. Out of these three, the moment of inertia of the inner aluminium is very small and therefore can be neglected. The moment of inertia of the other two parts are calculated below.

The outer aluminium frame can be considered as a thin cylinder with an inner and an outer radius. In the case of the servo motor, it has an inner radius of $51 \mathrm{~mm}$ and an outer radius of $52 \mathrm{~mm}$. Using equation (1), the moment of inertia of the aluminium ring is calculated as

The moment of inertia of the aluminium ring $=31.58 \times 10^{-6} \mathrm{~kg} \mathrm{~m}^{2}$

The moment of inertia of the aluminium

separators

$$
\begin{aligned}
& =\quad \int_{R_{i}}^{R_{0}}\left\{16 \times 4 \times 10^{-3}\right\} \rho g m r^{2} \mathrm{dr} . \\
& =\quad 23.3 \times 10^{-6} \mathrm{~kg} \mathrm{~m}^{2}
\end{aligned}
$$

From equations (3), (4), (5) and (6),

the moment of inertia of the rotor $=(200+5.884+31.58+23.3) \times 10^{-6} \mathrm{~kg} \mathrm{~m}^{2}$.

The moment of inertia of the rotor $=261 \times 10^{-6} \mathrm{~kg} \mathrm{~m}^{2}$. 


\section{APPENDIX 2 - FORCE, ENERGY AND TORQUE CALCULATIONS}

1 Force in a magnetic system with fringing flux.

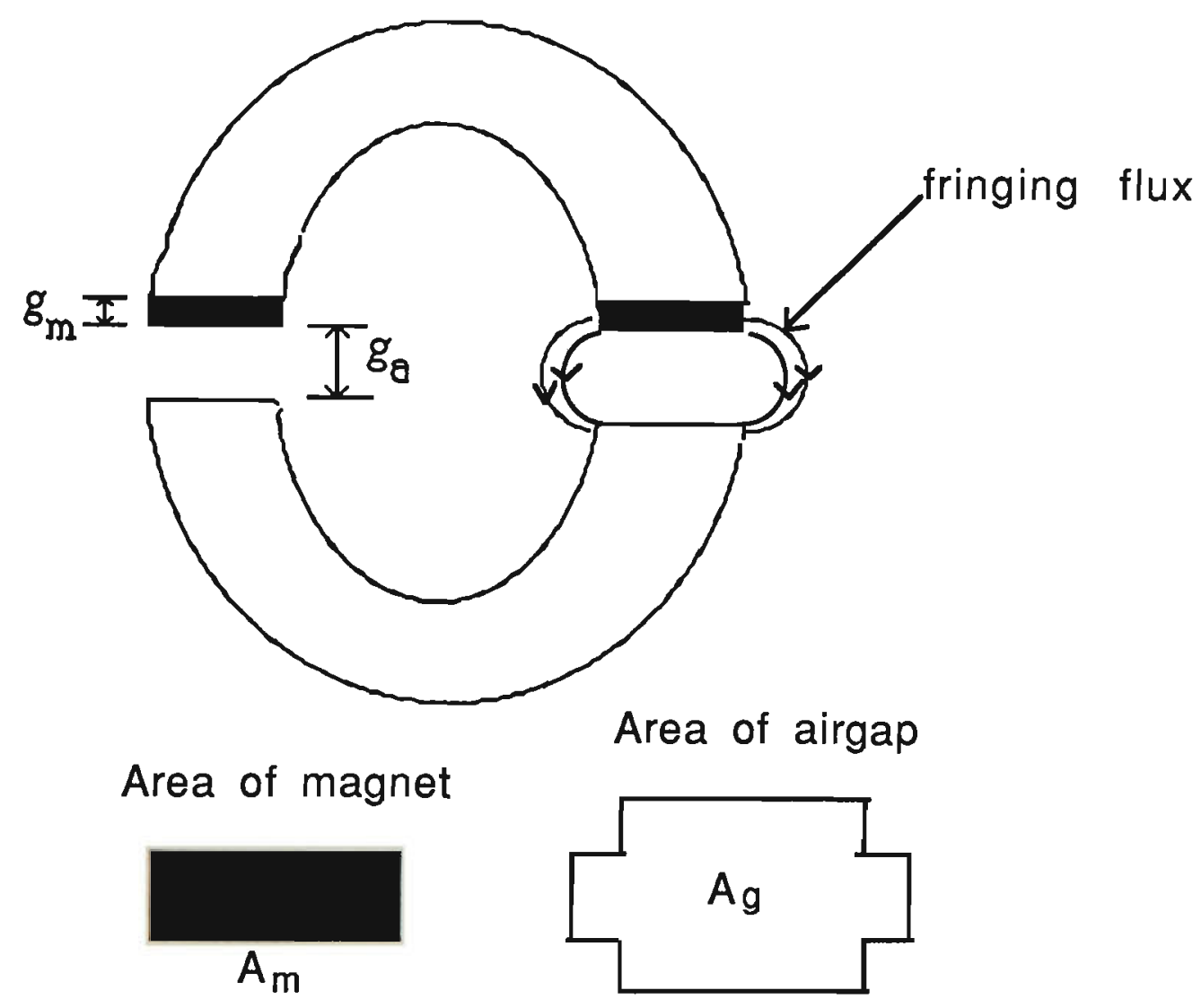

Figure 1 Magnetic system with fringing flux

For a magnetic system shown in Figure 1, the cross sectional faced by the flux

in the magnet $=\mathrm{A}$

in the airgap

$=A+\frac{g_{a}}{2}$ (perimeter of the magnet)

(assuming that the additional area due to fringing is $\frac{\mathrm{ga}_{\mathrm{a}}}{2}$ (perimeter of the magnet)) 
If $B_{m}$ is the flux density in magnets and $l$ is the perimeter of the magnets, the flux density in airgaps is

$$
B_{a}=\frac{B_{m} A}{\left(A+\frac{g_{a} l}{2}\right)}
$$

For the system shown in Figure 1

$2\left(\mathrm{H}_{\mathrm{a}} \mathrm{g}_{\mathrm{a}}+\mathrm{H}_{\mathrm{m}} \mathrm{g}_{\mathrm{m}}\right)=0$

$\frac{\mathrm{B}_{a} \mathrm{~g}_{\mathrm{a}}}{\mu_{0}}+\frac{\left(\mathrm{B}_{\mathrm{m}}-\mathrm{B}_{\mathrm{r}}\right) \mathrm{g}_{\mathrm{m}}}{\mu_{0}}=0$

Substituting for $\mathrm{B}_{\mathrm{a}}$ from equation (1)

$$
\begin{aligned}
& \frac{B_{m} A g_{a}}{\left(A+\frac{g_{a}}{2}\right)}+\left(B_{m}-B_{r}\right) g_{m}=0 \\
& B_{m}=\frac{\left(B_{r} g_{m}\left(A+\frac{g_{a} l}{2}\right)\right)}{A\left(g_{a}+g_{m}\right)+\frac{g_{a} g_{m} 1}{2}}
\end{aligned}
$$

Energy in the airgap $=\frac{\mathrm{B}_{\mathrm{a}}^{2}}{2 \mu_{\mathrm{o}}}\left(2 \mathrm{ga}\left(\mathrm{A}+\frac{\mathrm{gal}}{2}\right)\right)$

Energy in the magnet $=\frac{\left(\mathrm{B}_{\mathrm{r}}-\mathrm{B}_{\mathrm{m}}\right)^{2} 2 \mathrm{~g}_{\mathrm{m}} \mathrm{A}}{2 \mu_{0}}$

Total energy $E_{\text {total }}=\frac{B_{a}^{2}}{2 \mu_{0}}\left(2 g a\left(A+\frac{g a l}{2}\right)\right)+\frac{\left(B_{r}-B_{m}\right)^{2} 2 g_{m} A}{2 \mu_{0}}$

Substituting for $\mathrm{B}_{\mathrm{a}}$ from equation (1)

$$
\begin{aligned}
\text { Total energy } E_{\text {total }} & =\frac{1}{\mu_{\mathrm{o}}}\left\{\frac{\mathrm{B}_{\mathrm{m}}^{2} \mathrm{~A}^{2} \mathrm{ga}}{\left(\mathrm{A}+\frac{\mathrm{gal}}{2}\right)}+\left(\left(\mathrm{B}_{\mathrm{r}}-\mathrm{B}_{\mathrm{m}}\right)^{2} \mathrm{~g}_{\mathrm{m}} \mathrm{A}\right\}\right. \\
& =\frac{\mathrm{A}}{\mu_{\mathrm{o}}}\left\{\mathrm{B}_{\mathrm{m}}^{2}\left[\frac{\mathrm{Aga}}{\left(\mathrm{A}+\frac{\mathrm{gal}}{2}\right)}+\mathrm{g}_{\mathrm{m}}\right]+\mathrm{B}_{\mathrm{r}}{ }^{2} \mathrm{~g}_{\mathrm{m}}-2 \mathrm{~B}_{\mathrm{r}} \mathrm{B}_{\mathrm{m}} \mathrm{g}_{\mathrm{m}}\right\}
\end{aligned}
$$

Substituting for $\mathrm{B}_{\mathrm{m}}$ from equation (2) and simplifying 
Total energy $E_{\text {total }}=\frac{A}{\mu_{0}}\left\{\frac{x}{y}+B_{r}^{2} g_{m}+\frac{a}{b}\right\}$

Where

$$
\begin{aligned}
\mathrm{x}= & \mathrm{ga}^{3}\left(2 \mathrm{~B}_{\mathrm{r}}^{2} \mathrm{gm}^{2} \mathrm{Al}^{2}+\mathrm{B}_{\mathrm{r}}^{2} \mathrm{gm}^{3} \mathrm{l}^{3}\right)+\mathrm{ga}^{2}\left(8 \mathrm{~B}_{\mathrm{r}}^{2} \mathrm{gm}^{2} \mathrm{~A}^{2} \mathrm{l}+6 \mathrm{~B}_{\mathrm{r}}^{2} \mathrm{gm}^{3} \mathrm{Al}\right) \\
& +\mathrm{ga}_{\mathrm{a}}\left(8 \mathrm{~B}_{\mathrm{r}}^{2} \mathrm{gm}^{2} \mathrm{~A}^{3}+12 \mathrm{~B}_{\mathrm{r}}^{2} \mathrm{gm}^{3} \mathrm{~A}^{2} \mathrm{l}\right)+8 \mathrm{~B}_{\mathrm{r}}^{2} \mathrm{gm}^{3} \mathrm{~A}^{3}
\end{aligned}
$$

Force is obtained by differentiating equation (5) with respect to the airgap length $\mathrm{g}_{\mathrm{a}}$

Force $=\frac{\mathrm{dE}_{\text {total }}}{\mathrm{dg}_{\mathrm{a}}}$

Equation (6) in combination with (5) is used to calculate the force - airgap relationships shown in figure 2.5 of chapter 2.

\section{Energy calculations of a two phase four teeth machine}

\section{Stored energy}

Figure 2 shows the permanent magnet machine with four teeth and two poles, which was considered for analysis in chapter 2 .

The energy stored in the machine can be calculated from the knowledge of energy densities of air and magnet.

The energy density of the air $=\frac{\mathrm{B}^{2}}{2 \mu_{\mathrm{o}}}$

From equation (2.5)

The energy density of the magnet $=\frac{\mu_{0} \mathrm{Hm}^{2}}{2}$ 


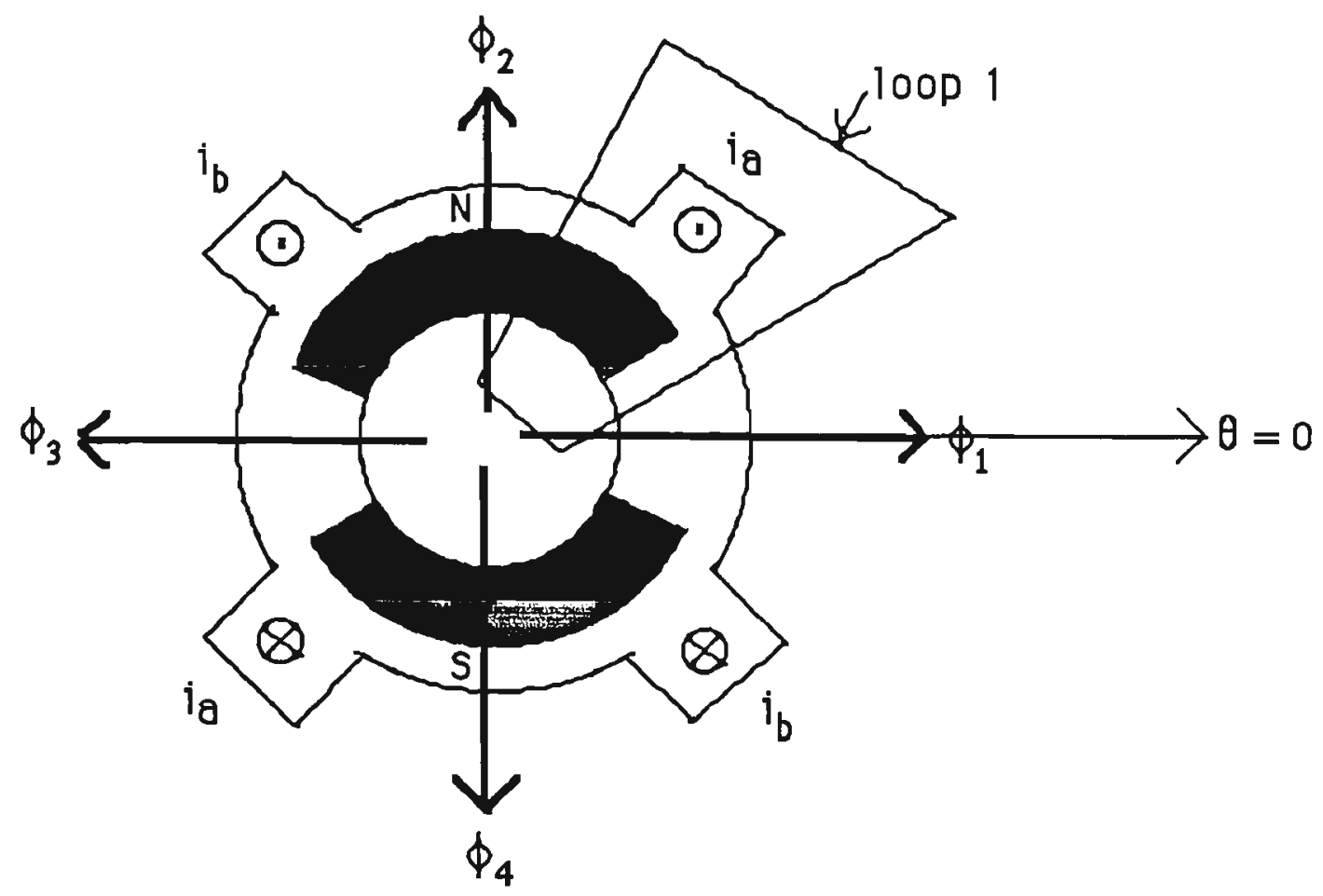

Figure 2- Permanent magnet machine with four teeth and two poles.

From equation (2.1)

$\mathrm{B}=\mu_{\mathrm{oH}}+\psi \mathrm{Br}$

$\mathrm{H}_{\mathrm{m}}=\frac{\mathrm{B}-\psi_{\mathrm{Br}}}{\mu_{0}}$

Using equations (7), (8), and (9), energy in section $d \theta$ of the machine can be written as $\mathrm{dE}=\frac{1}{2 \mu_{0}}(\mathrm{~B}-\psi \mathrm{Br})^{2} \mathrm{~g}_{\mathrm{m}} \mathrm{LRd} \theta+\frac{1}{2 \mu_{\mathrm{O}}} \mathrm{B}^{2} \mathrm{~g}_{\mathrm{a}} \mathrm{LRd} \theta$

Therefore energy in the machine is

$E_{\text {stored }}=\frac{\mathrm{LR}}{2 \mu_{\mathrm{o}}} \int\left\{(\mathrm{B}(\theta)-\psi(\theta) \mathrm{Br})^{2} \mathrm{~g}_{\mathrm{m}}+\frac{1}{2 \mu_{\mathrm{o}}} \mathrm{B}^{2}(\theta) \mathrm{g}_{\mathrm{a}}\right\} \mathrm{d} \theta$

From equations (2.19) and (2.20) we have 
$\mathrm{B}_{0}\left(\theta_{0}\right)=\frac{\mathrm{B}_{\mathrm{r}} \psi\left(\theta_{0}\right) \mathrm{g}_{\mathrm{m}}}{\mathrm{g}}+\frac{\mu_{\mathrm{o}}\left(\mathrm{i}_{\mathrm{a}}+\mathrm{i}_{\mathrm{b}}\right)}{2 \mathrm{~g}}$

$\mathrm{B}_{1}\left(\theta_{1}\right)=\frac{\mathrm{B}_{\mathrm{r}} \psi\left(\theta_{1}\right) \mathrm{g}_{\mathrm{m}}}{\mathrm{g}}+\frac{\mu_{\mathrm{o}}\left(-\mathrm{i}_{\mathrm{a}}+\mathrm{i}_{\mathrm{b}}\right)}{2 \mathrm{~g}}$

Using equations (10), (11) and (12) the total energy in the machine can be written as

$$
\int\left\{\left[B_{r} \psi(\theta) g_{m}+\mu_{o}\left(i_{a}+i_{b}\right)\right]^{2} \frac{1}{g}-\right.
$$

tooth 1

$\left.\left.2\left[B_{r} \psi(\theta) g_{m}+\mu_{o}\left(i_{a}+i_{b}\right)\right] \frac{g_{m} B_{r} \psi(\theta)}{g}+g_{m} B_{r}^{2} \psi(\theta)^{2}\right\}\right) d \theta$

$+\int\left\{\left[B_{r} \psi(\theta) g_{m+} \mu_{o}\left(-i_{a}+i_{b}\right)\right]^{2} \frac{1}{g}-2\left[B_{r} \psi(\theta) g_{m}+\mu_{o}(-\right.\right.$

tooth2

$\left.\left.\left.\left.\mathrm{i}_{\mathrm{a}}+\mathrm{i}_{\mathrm{b}}\right)\right] \frac{\mathrm{g}_{\mathrm{m}} \mathrm{B}_{\mathrm{r}} \psi(\theta)}{\mathrm{g}}+\mathrm{gm}_{\mathrm{m}} \mathrm{B}^{2} \psi(\theta)^{2}\right\}\right) \mathrm{d} \theta$

After simplification this reduces to

$$
\begin{aligned}
& \mathrm{E}_{\text {stored }}=\frac{\mathrm{RLgmg} \mathrm{B}_{\mathrm{r}}^{2}}{\mu_{\mathrm{o}} \mathrm{g}} \int_{\text {tooth } 0} \psi(\theta)^{2} \mathrm{~d} \theta+\frac{\mathrm{RL} \mu_{\mathrm{o}}\left(\mathrm{i}_{\mathrm{a}}+\mathrm{i}_{\mathrm{b}}\right)^{2}}{4 \mathrm{~g}} \int_{\text {tooth } 0} \mathrm{~d} \theta+ \\
& \frac{\mathrm{RLgmga} \mathrm{B}_{\mathrm{r}}^{2}}{\mu_{\mathrm{o}} \mathrm{g}} \int_{\text {tooth } 1} \psi(\theta)^{2} \mathrm{~d} \theta+\frac{\mathrm{RL} \mu_{\mathrm{o}}\left(\mathrm{i}_{\mathrm{a}}+\mathrm{i}_{\mathrm{b}}\right)^{2}}{4 \mathrm{~g}} \int_{\text {tooth } 1} \mathrm{~d} \theta \\
& E_{\text {stored }}=\frac{\mathrm{RLg}_{\mathrm{m}} \mathrm{ga}_{\mathrm{a}} \mathrm{B}^{2}}{\mu_{\mathrm{o}} \mathrm{g}} \int_{\text {tooth0+tooth1 }} \psi^{2} \mathrm{~d} \theta+\frac{\mu_{\mathrm{oRL}} \theta_{\mathrm{t}}\left(\mathrm{i}_{\mathrm{a}}^{2}+\mathrm{i}_{\mathrm{b}}^{2}\right)}{2 \mathrm{~g}}
\end{aligned}
$$

Where $\theta_{\mathbf{t}}$ is the tooth pitch in radians.

\section{Electrical energy input}


$E_{\text {elec }}=v_{a} i_{a} d t+v_{b} i_{b} d t$

$$
\begin{aligned}
& =\mathrm{i}_{\mathrm{a}}\left(\mathrm{d} \phi_{2}-\mathrm{d} \phi_{1}\right)-\mathrm{i}_{\mathrm{b}}\left(\mathrm{d} \phi_{1}+\mathrm{d} \phi_{2}\right) \\
& =-\left(\mathrm{i}_{\mathrm{a}}+\mathrm{i}_{\mathrm{b}}\right) \mathrm{d} \phi_{1}+\left(\mathrm{i}_{\mathrm{a}}-\mathrm{i}_{\mathrm{b}}\right) \mathrm{d} \phi_{2}
\end{aligned}
$$

If this occurs as the rotor moves from $\varepsilon$ to $\varepsilon+\mathrm{d} \varepsilon$, then

$d E_{\text {elec }}=-\left(i_{a}+i_{b}\right) \frac{d \phi_{1}}{d \varepsilon} d \varepsilon+\left(i_{a}-i_{b}\right) \frac{d \phi_{2}}{d \varepsilon} d \varepsilon$

Using equations (2.21)

$$
\begin{aligned}
\phi_{0} & =\int\left\{\frac{B_{r} \psi\left(\theta_{0}\right) g_{m}}{g}+\frac{\mu_{o}\left(i_{a}+i_{b}\right)}{2 g}\right\} L R d \theta \\
\text { tooth0 } & \frac{\operatorname{LRg}_{m} B_{r}}{g} \int \psi\left(\theta_{0}\right)+\frac{\mu_{o} L R \theta_{t}\left(i_{a}+i_{b}\right)}{2 g} \\
& =\frac{\partial \phi_{0}}{\partial \varepsilon}=\frac{\operatorname{LRg}_{\text {tooth } 0} B_{r}}{g} \frac{\partial}{\partial \varepsilon} \int_{\text {tooth } 0} \psi\left(\theta_{0}\right)
\end{aligned}
$$

Similarly

$$
\frac{\partial \phi_{1}}{\partial \varepsilon}=\frac{\mathrm{LRgm}_{\mathrm{m}} \mathrm{B}_{\mathrm{r}}}{\mathrm{g}} \frac{\partial}{\partial \varepsilon} \int_{\text {tooth } 1} \psi\left(\theta_{1}\right)
$$

Substituting equation (16) and equation(17) in equation (15)

$$
\begin{aligned}
& \mathrm{dE}_{\mathrm{elec}}=-\left(\mathrm{i}_{\mathrm{a}}+\mathrm{i}_{\mathrm{b}}\right) \frac{\operatorname{LRg} \mathrm{B}_{\mathrm{r}}}{\mathrm{g}} \mathrm{d} \varepsilon \frac{\partial}{\partial \varepsilon} \int_{\text {tooth } 0} \psi\left(\theta_{0}\right) \mathrm{d} \theta_{0}+ \\
& \left(\mathrm{i}_{\mathrm{a}}-\mathrm{i}_{\mathrm{b}}\right) \frac{\operatorname{LRg}_{\mathrm{m}} \mathrm{B}_{\mathrm{r}}}{\mathrm{g}} \mathrm{d} \varepsilon \frac{\partial}{\partial \varepsilon} \int_{\text {tooth } 1} \psi\left(\theta_{1}\right) \mathrm{d} \theta_{1}
\end{aligned}
$$


3 Torque calculation using force equation (the conventional method).

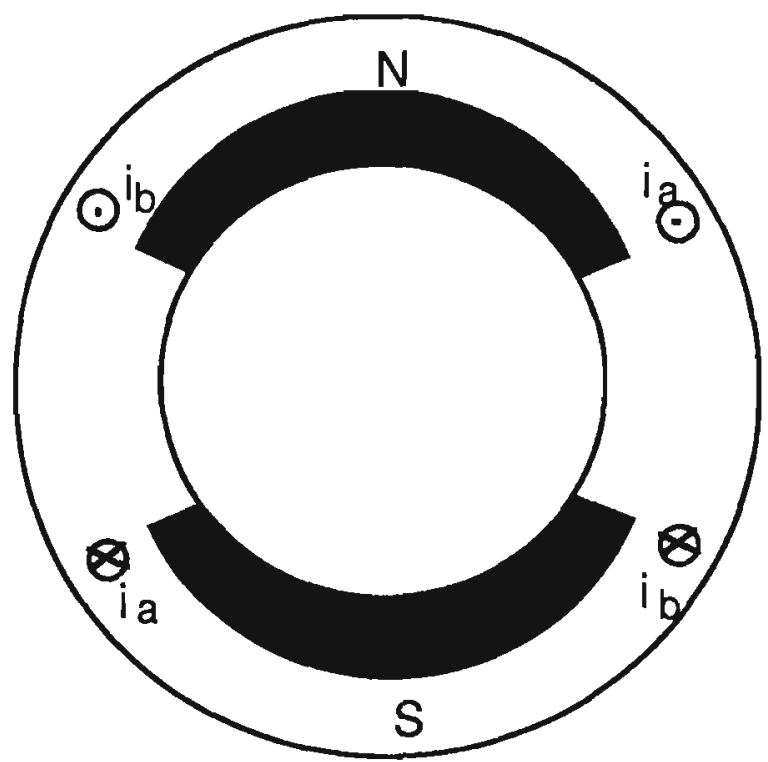

Figure 3 Two phase permanent magnet machine with no slots

Figure 3 shows the two phase permanent magnet machine under consideration. Assumptions

1) The permanent magnet is operating in the linear region.

2) The machine has no slots and the conductors are in the airgap

Force in a conductor of length $\mathrm{L}$, carrying current $\mathrm{I}$, placed in a magnetic field with flux density $B$ is given by

$\mathrm{F}=\mathrm{BIL}$

Hence torque produced by a single turn in a machine with radius $\mathrm{R}$ would be

$\mathrm{T}=2 \mathrm{RBIL}$

For the two phase machine shown in figure 3

$\mathrm{T}=\left(\mathrm{i}_{\mathrm{a}} \mathrm{B}_{\mathrm{a}}+\mathrm{i}_{\mathrm{b}} \mathrm{B}_{\mathrm{b}}\right) \mathrm{R} 2 \mathrm{~L}$

The flux linking the conductor is set up only by the magnet and therefore

$\mathrm{B}_{\mathrm{a}}=\frac{\mathrm{B}_{\mathrm{r}} \mathrm{g}_{\mathrm{m}} \psi\left(\theta_{\mathrm{a}}\right)}{\mathrm{g}}$

$\mathrm{B}_{\mathrm{b}}=\frac{\mathrm{B}_{\mathrm{r}} \mathrm{g}_{\mathrm{m}} \psi\left(\theta_{\mathrm{b}}\right)}{\mathrm{g}}$

Where $\theta_{a}, \theta_{b}$ defines the position of the conductor of phase $\mathrm{a}$ and $\mathrm{b}$ along the stator. Substituting equations (2.31) and (2.32) in (2.30)

$\mathrm{T}=\frac{2 \mathrm{RLB} \mathrm{B}_{\mathrm{r}} \mathrm{g}_{\mathrm{m}}}{\mathrm{g}}\left(\mathrm{i}_{\mathrm{a}} \psi\left(\theta_{\mathrm{a}}\right)+\mathrm{i}_{\mathrm{b}} \psi\left(\theta_{\mathrm{b}}\right)\right)$ 


\section{Torque in terms of space phasors}

From equations (2.32) and (2.33), the current and magnet space phasors can be expressed as

$\underline{\underline{i}}=\frac{1}{\sqrt{2}}\left\{i_{a}+i_{b}+j\left(-i_{a}+i_{b}\right)\right\}$

$\Psi=\frac{1}{\sqrt{2}}\left\{\psi_{a}-\psi_{b}+j\left(\psi_{a}+\psi_{b}\right)\right\}$

Let magnitude of $\underline{\underline{i}}$ is $\mathrm{x}$

$$
x=\frac{\sqrt{\left\{i_{a}+i_{b}\right\}^{2}+\left[i_{b}-i_{a}\right]^{2}}}{\sqrt{2}}
$$

Let magnitude of $\Psi$ is $\psi$

$$
y=\frac{\sqrt{\left\{\psi_{a}-\psi_{b}\right\}^{2}+\left[\psi_{a}+\psi_{b}\right]^{2}}}{\sqrt{2}}
$$

Let $\alpha$ be the angle made by $\Psi$, and $\theta$ be the angle made by $\underline{i}$ with the positive real axis.

$$
\begin{aligned}
\text { Let } \beta & =\alpha-\theta, \text { then } \\
\sin \beta & =\sin \alpha \cos \theta-\cos \alpha \sin \theta \\
& =\frac{\left\{\psi_{a}+\psi_{b}\right\}}{\sqrt{2} y} \frac{\left[i_{b}+i_{a}\right]}{\sqrt{2} x}-\frac{\left\{\psi_{a}-\psi_{b}\right\}}{\sqrt{2} y} \frac{\left[i_{b}-i_{a}\right]}{\sqrt{2} x} \\
& =\frac{\left(\psi_{a} i_{a}+\psi_{b} i_{b}\right)}{x y}
\end{aligned}
$$

$|\underline{i}||\psi| \sin \beta=\psi_{\mathrm{a}} \dot{\mathrm{i}}_{\mathrm{a}}+\psi_{\mathrm{b}} \mathrm{i}_{\mathrm{b}}$

Substituting equation (24) in (23)

$\mathrm{T}=\frac{2 \mathrm{RLB} \mathrm{B}_{\mathrm{m}}}{\mathrm{g}}|\underline{\mathrm{i}}||\underline{\psi}| \sin \beta$

Since $\zeta$ is shifted by 90 degrees from $\psi$ equation (25) can also be written as

$$
\mathrm{T}=\frac{2 \mathrm{RLB} \mathrm{B}_{\mathrm{m}}}{\mathrm{g}}|\underline{\mathrm{i}}| \underline{\zeta} \mid \cos \beta
$$




\section{APPENDIX 3 - TORQUE AND CURRENT IN TERMS OF DISCRETE FOURIER TRANSFORM}

\section{Useful Torque}

The useful torque of a machine using energy considerations, can be obtained by differentiating the electrical energy input with rotor position. Considering a single coil the useful torque due to a current ' $i$ ' in the coil can be written as,

$\mathrm{T}_{\text {useful }}=\mathrm{i} \frac{\mathrm{d} \lambda}{\mathrm{d} \varepsilon}$

Where $\mathrm{d} \lambda$ is the incremental flux linkage for the coil. Only the flux linkage due to rotor magnets change with position and the flux linkage due to stator current does not change with position. If there are $\mathrm{p}$ pole pairs in a machine, then the

Flux due to rotor magnets alone $=\frac{\mathrm{pB}_{\mathrm{r}} g_{\mathrm{m}} \psi_{\mathrm{a}}(\mathrm{k}) \mathrm{LR} \theta \mathrm{t}}{\mathrm{g}}$

Where $C=\frac{B_{r} g_{m} L R \theta_{t} p}{g}$$$
=\mathrm{C} \psi_{\mathrm{a}}(\mathrm{k})
$$

So, equation (1) becomes the current multiplied by the sum of differentiation of $\psi_{\mathrm{a}}(\mathrm{k})$ of all the teeth enclosed by the coil. If the coil is fully pitched, then the coil span is from ' 0 ' th to $\left(\frac{N}{2}-1\right)$ slot. The teeth covered by the coil depends on where the winding is actually placed. Let 'a' be the slot in which one coil side of the coil is placed. Then equation (1) becomes

$$
\mathrm{T}=\mathrm{Ci} \sum_{\mathrm{k}=0}^{\frac{\mathrm{N}}{2}-1} \zeta(\mathrm{k}+\mathrm{a})
$$

In general for a ' $\mathrm{m}$ ' phase machine with $\mathrm{N}$ number of slots per pole pair and with a winding pitch of ' $s$ ' slots 


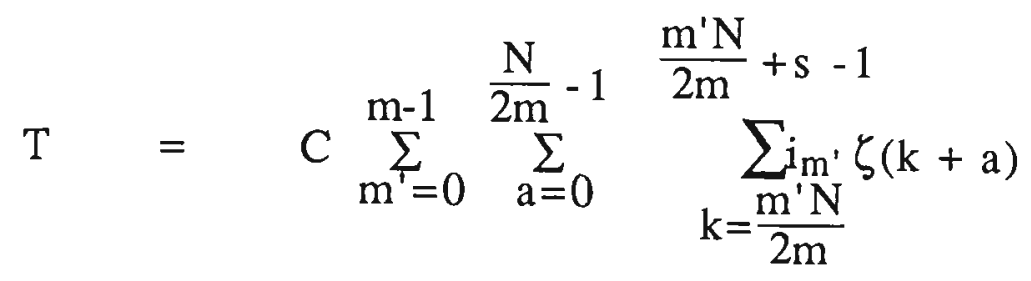

\section{The useful torque in terms of DFT}

From equation (3.7) the useful torque due to a single coil can be written as

$\mathrm{T}=\mathrm{C} i \sum_{\mathrm{n}=0}^{\mathrm{N}-1} \forall(\mathrm{n}) \mathrm{e}^{2 \pi \mathrm{jan} / \mathrm{N}} \sum_{\mathrm{k}=0}^{\frac{\mathrm{N}}{2}-1} \mathrm{e}^{2 \pi \mathrm{jnk} / \mathrm{N}}$

Now,

$$
\begin{array}{ll}
\sum_{\mathrm{k}=0}^{\frac{N}{2}-1} \mathrm{e}^{2 \pi j n k / N} & =\sum_{\mathrm{k}=0}^{\frac{N}{2}-1} e^{2 \pi j n k / N+\pi j n / N-\pi j n / N} \\
& =e^{-\pi j n / N} \sum_{k=0}^{\frac{N}{2}-1} e^{\pi j n(2 k+1) / N}
\end{array}
$$

The terms in the summation are a series of unit vectors whose real parts sum to zero. Figure 1 shows the summation vectorially, for the case when $N=12$, for two values of $\mathrm{n}$, namely 1 and 3 .

If half of the imaginary part is L, from Figure 1(a)

$$
\begin{array}{ll}
\sin \frac{\pi \mathrm{n}}{\mathrm{N}} & =\frac{1 / 2}{\mathrm{~L}} \\
\mathrm{~L} & =\frac{1}{2 \sin \frac{\pi \mathrm{n}}{\mathrm{N}}}
\end{array}
$$


(a) $\mathrm{N}=12, \mathrm{n}=1$

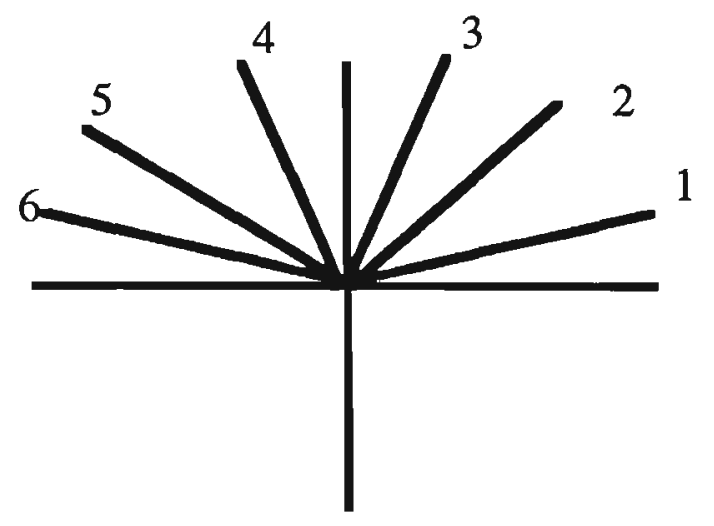

Unit vectors

(b) $N=12, n=3$

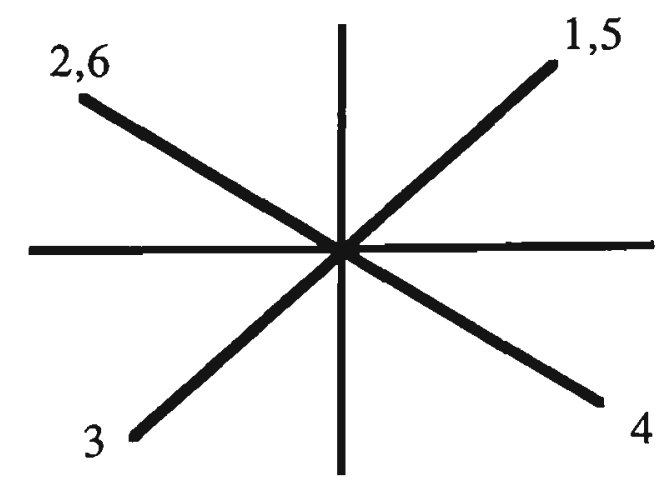

Unit vectors

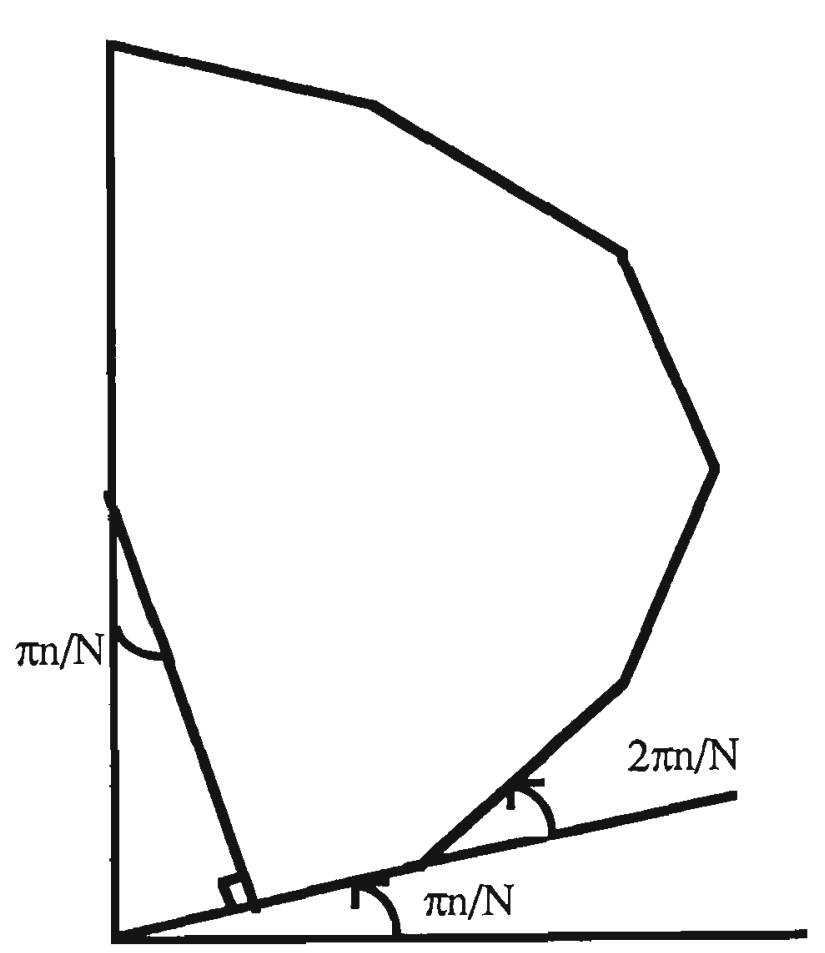

Sum of unit vectors

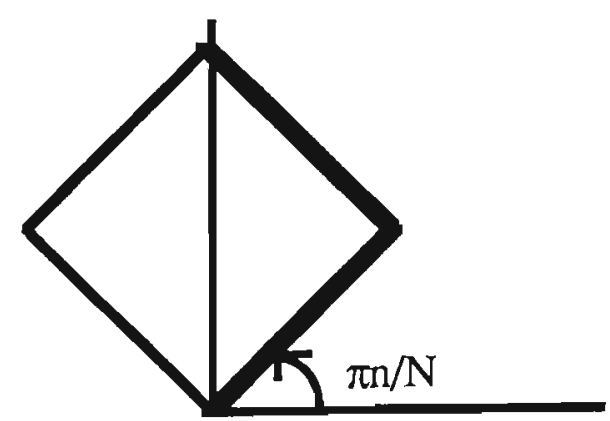


Therefore,

$$
\sum_{k=0}^{\frac{N}{2}-1} \pi j n(2 k+1) / N=\frac{j}{\sin \frac{\pi n}{N}}
$$

Using (3) and (4) the torque equation (3.7) can be written as

$$
T=C i \sum_{n=0}^{N-1} \forall(n) e^{2 \pi j a n / N} e^{-\pi j n / N} \frac{j}{\operatorname{Sin}\left(\frac{n \pi}{N}\right)}
$$

\section{Numbering of Phases}

In order to take into account any arbitrary number of phases, it becomes necessary to number the phases differently from the usual practice. Rather than dividing the full 360 electrical degrees by $\mathrm{m}$, it is preferable to divide only 180 degrees and this produces consistent distribution of phases for all values of $m$ (odd and even). For example when $\mathrm{m}=2$ then

$\mathrm{W}^{-\mathrm{b}}=\mathrm{e}^{-\mathrm{j} \pi / 2}$

that is two phases 90 degrees apart. When $\mathrm{m}=3$ then

$W^{-b}=e^{-j \pi / 3}$

that is three phases 60 degrees apart. If the current in the centre phase is reversed, then it is clear that the system is balanced three phase system. When $m=4$ then

$W^{-b}=e^{-j \pi / 4}$

that is four phases 45 degrees apart, and so on. This is illustrated graphically in Figure 2. 

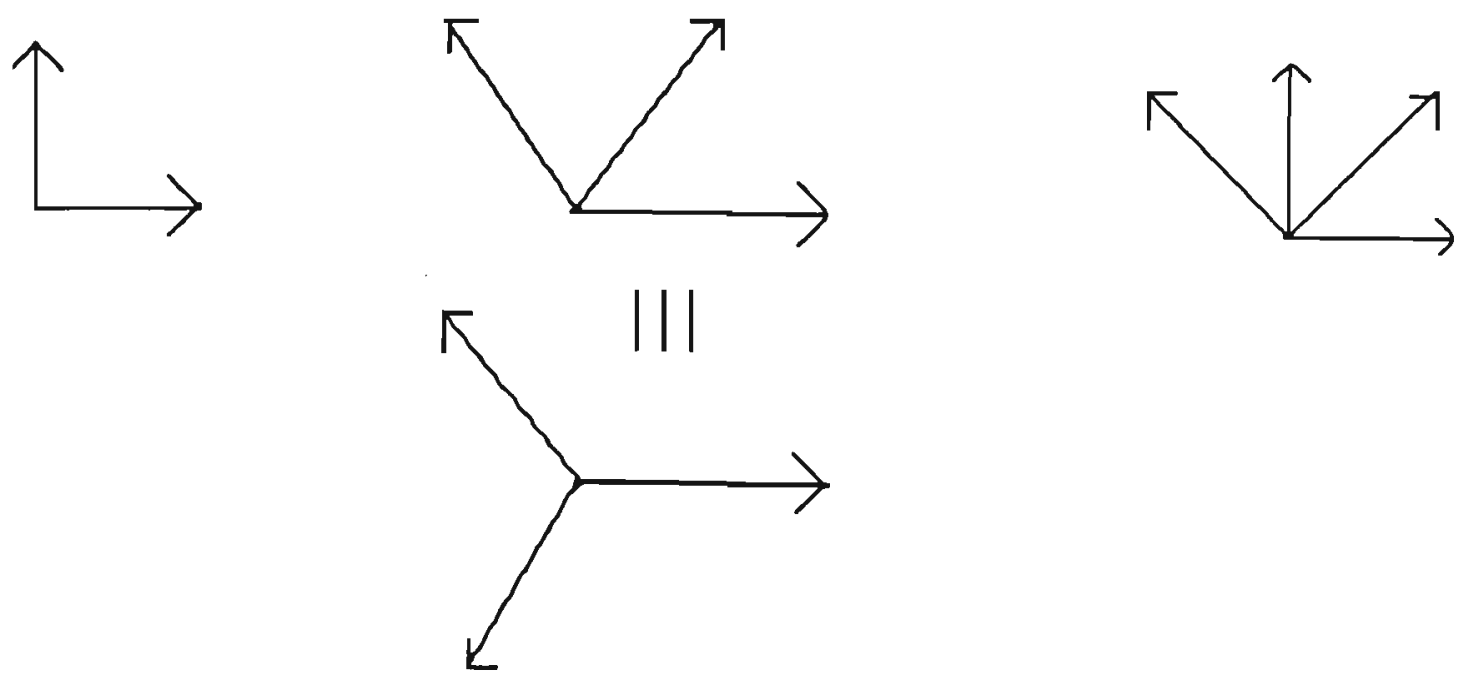
(a) Two phase
(b) Three phase
(c) Four phase

Figure 2 Phase distribution with two, three and four phases

\section{The Slot Current in Discrete Terms}

To represent current as discrete packets pertaining to each slot, the currents of each slot should be defined individually. In a multi phase machine, the current belonging to one phase is present only in some slots and is zero in other slots. Therefore, to define the slot current, a function which takes a definite value for a specified condition and zero elsewhere should be used. A delta function suits this requirement well. If we choose a delta function $\delta(\mathrm{k})$ such that

$$
\begin{aligned}
\delta(k)= & 1 \text { for } k=0 \\
& =0 \text { otherwise }
\end{aligned}
$$

Consider a machine with $\mathrm{N}$ slots per pole and fully pitched coils and let a slot 'a', carries the phase current through a single turn coil ( for simplicity ). Now, the slot current $\mathrm{i}(\mathrm{k})$ can be expressed in $\delta(\mathrm{k})$ as

$i(k)=i\left[\delta(k-a)-\delta\left(k-\left\{\frac{N}{2}+a\right\}\right)\right]$

Transforming equation(4), 
$\mathrm{I}(\mathrm{n})=\frac{\mathrm{i}}{\mathrm{N}} \Delta(\mathrm{n}) \mathrm{W}^{-\mathrm{an}}\left[1-\mathrm{W}^{(\mathrm{N} / 2) \mathrm{n}}\right]$

$I(n)=\frac{i}{N} W^{-a n}\left[1-e^{j \pi n}\right]$

Since from the definition of $\delta(k), \Delta(n)$ takes the value 1 for any value of ' $n$ '.

Equation (7) is zero for even values of N. For odd values of $\mathrm{N}$

$I(n)=\frac{2 i}{N} e^{-2 \pi j n a / N}$

In general the slot current $\mathrm{i}(\mathrm{k})$ due to phase " 0 " can be expressed in $\delta(\mathrm{k})$ as

$$
\begin{aligned}
i_{0}(k)=\sum_{a=0}^{\left(\frac{N}{2 m}-1\right.} i_{0}[\delta(k-a)-\delta(k-\{s+a\})]+ \\
i_{0}\left[-\delta\left(k-\left\{\frac{N}{2}+a\right\}\right)+\delta\left(k-\left\{\frac{N}{2}+s+a\right\}\right)\right]
\end{aligned}
$$

In this expression $\frac{\mathrm{N}}{2 \mathrm{~m}}$ represents a phase belt, since $\mathrm{N}$ is the number of slots per pole and $\mathrm{m}$ is the number of phases in the machine. ' $\mathrm{s}$ ' is the pitch of the winding in terms of slots.

Equation (9) gives the current in a slot due to phase "0"only.

In general the slot current $i_{m^{\prime}}(k)$ due to any phase " $\mathrm{m}^{\prime}$ " can be expressed as

$$
\begin{aligned}
i_{m^{\prime}}(k)= & \sum_{a=0}^{\left(\frac{N}{2 m}-1\right)} i_{m^{\prime}}\left[\delta\left(k-\left\{\frac{m^{\prime} N}{2 m}-a\right\}\right)-\delta\left(k-\left\{\frac{m^{\prime} N}{2 m}+s+a\right\}\right)-\right. \\
& \left.\delta\left(k-\left\{\frac{m^{\prime} N}{2 m}+\frac{N}{2}+a\right\}\right)+\delta\left(k-\left\{\frac{m^{\prime} N}{2 m}+\frac{N}{2}+s+a\right\}\right)\right]
\end{aligned}
$$

Hence the slot current $i(k)$ due to all phases can be obtained by varying ' $m$ ' from " 0 " to "m - 1 " and finding the summation. 
$i(k)=\sum_{m^{\prime}=0}^{m-1} \sum_{a=0}^{\left(\frac{N}{2 m}-1\right)} i_{m^{\prime}}\left[\delta\left(k-\left\{\frac{m^{\prime} N}{2 m}-a\right\}\right)-\delta\left(k-\left\{\frac{m^{\prime} N}{2 m}+s+a\right\}\right)-\right.$
$\left.\quad \delta\left(k-\left\{\frac{m^{\prime} N}{2 m}+\frac{N}{2}+a\right\}\right)+\delta\left(k-\left\{\frac{m^{\prime} N}{2 m}+\frac{N}{2}+s+a\right\}\right)\right]$

Transforming equation (11), using shifting theorem of DFT and simplifying,

$$
\begin{aligned}
& I(n)=\sum_{m^{\prime}=0}^{m-1} \sum_{a=0}^{\left(\frac{N}{2 m}-1\right)} \frac{i^{\prime}}{N} W^{-n a} W^{\prime}\left\{-n m^{\prime} N\right\} / 2 m\left(1-W^{-n s}\right)\left(1-W^{-(n N / 2)}\right) \\
& I(n)=\sum_{m^{\prime}=0}^{m-1} \frac{i_{m^{\prime}}}{N} W^{-n}\left\{-n m^{\prime} N\right\} / 2 m \sum_{a=0}^{\left(\frac{N}{2 m}-1\right)} W^{-n a}\left(1-W^{-n s}\right)\left(1-W^{-}(n N / 2)\right) \\
& I(n)=\frac{i^{*}}{N} \sum_{a=0}^{\left(\frac{N}{2 m}-1\right)} W^{-n a}\left(1-W^{-n s}\right)\left(1-W^{-(n N / 2)}\right)
\end{aligned}
$$

Where $\underline{\mathrm{i}}$ is the current space phasor in the complex plane and is given by

$$
\underline{\mathrm{i}}=\mathrm{i} 0+\mathrm{i} 1 \mathrm{~W}(\mathrm{~N} / 2 \mathrm{~m})+\ldots \ldots \ldots+\mathrm{i}(\mathrm{m}-1) \mathrm{W}(\mathrm{m}-1) \mathrm{N} / 2 \mathrm{~m}
$$

and $\underline{i}^{*}$ is its complex conjugate.

$$
\begin{aligned}
\left(1-W^{-n s}\right) & =\left(1-e^{-j(2 \pi / N) s n}\right) \frac{\left(e^{j(\pi / N) s n}\right)}{\left(e^{j(\pi / N) s n}\right)} \\
& =\frac{\left(e^{j(\pi / N) s n}-e^{-j(\pi / N) s n}\right)}{\left(e^{j(\pi / N) s n}\right)} \\
& =2 j \sin (\pi s n / N) e^{-j(\pi n s / N)} \\
& \\
\left(1-W^{-(n N / 2)}\right) & =(1-e-j \pi n) \\
& =2 \quad \text { for odd values of ' } n^{\prime} \\
& =0 \text { for even values of ' } n^{\prime}
\end{aligned}
$$




$$
\left(\frac{N}{2 m}-1\right) \quad W^{-n a}=\sum_{a=0}^{\left(\frac{N}{2 m}-1\right)} e^{-j 2 \pi / N n a}
$$

Since $N / 2 m$ represents a phase belt, this summation sums up the N/2m phasors vectorially.

The magnitude of the resultant vector would be [42] $\frac{\sin \frac{n \pi}{2 m}}{\sin \frac{n \pi}{N}}$ and the direction of the vector will be given by e-j $\pi n(N / 2 m-1) / N$ Therefore,

$$
\sum_{a=0}^{\left(\frac{N}{2 m}-1\right)} W^{-n a}=\frac{\sin \frac{n \pi}{2 m}}{\sin \frac{n \pi}{N}} e^{-j \pi n(N / 2 m-1) / N}
$$

Substituting equations (13), (14) and (15) in equation (12)

$$
\begin{aligned}
I(n) & =\frac{4 j \underline{i}^{*}}{N} \sin \frac{n \pi s}{N} e^{-j \pi s n / N} \frac{\sin \frac{n \pi}{2 m}}{\sin \frac{n \pi}{N}} e^{-j \pi n(N / 2 m-1) / N} \text {, for odd values of ' } n \text { ' } \\
& =0 \quad \text { for even values of ' } n \text { ' }
\end{aligned}
$$

Equation (16) gives the slot current in DFT in terms of phase currents and machine parameters. 


\section{APPENDIX 4 - COMPUTER SIMULATION OF COGGING TORQUE}

\section{Machine parameters used in the calculation of cogging torque.}

Single phase machine without offset and skewing.

$\begin{array}{lll}\text { Remanence of the magnet } & = & 1.1 \mathrm{~T} \\ \text { Number of slots per pole pair } & = & 2 \\ \text { Number of pole pairs } & = & 12 \\ \text { Outer radius } & =64 \mathrm{~mm} \\ \text { Inner radius } & =\quad 38.5 \mathrm{~mm} \\ \text { Airgap } & = & 0.2 \mathrm{~mm} \\ \text { Magnet thickness, gm } & = & 7 \mathrm{~mm} \\ \text { Effective total airgap, g } & =7.2 \mathrm{~mm} \\ \text { Maximum magnet pitch } & =158.5 \text { electrical degrees } \\ \text { Minimum magnet pitch } & =144.3 \text { electrical degrees } \\ \text { Maximum tooth pitch } & =158.5 \text { electrical degrees } \\ \text { Minimum tooth pitch } & = & 144.3 \text { electrical degrees }\end{array}$

Two phase machine with offset and skewing

$\begin{array}{lll}\text { Remanence of the magnet } & = & 1.1 \mathrm{~T} \\ \text { Number of slots per pole pair } & = & 4 \\ \text { Number of pole pairs } & = & 8 \\ \text { Outer radius } & = & 51 \mathrm{~mm} \\ \text { Inner radius } & = & 24 \mathrm{~mm} \\ \text { Airgap } & = & 3.2 \mathrm{~mm} \\ \text { Magnet thickness, gm } & = & 3.6 \mathrm{~mm} \\ \text { Effective total airgap, g } & = & 144.05 \text { electrical degrees } \\ \text { Maximum pitch of the magnet } & =103.61 \text { electrical degrees } \\ \text { Minimum pitch of the magnet } & =81.0 \text { electrical degrees } \\ \text { Maximum tooth pitch } & =70.90 \text { electrical degrees } \\ \text { Minimum tooth pitch } & \end{array}$




\section{Computer simulation of cogging torque.}

The computer simulation divides the machine into the number (specified by the user) of small rings and calculates the cogging torque at average radius of each of these rings. The increments to be given for the radius, tooth pitch and magnet pitch from one ring to the next ring are calculated using the maximum and minimum values of these parameters and the number of rings by which the machine is to be divided. Every time when the torque is calculated for a new ring, the pitches and radius are incremented to get the current value of the parameters. The simulation program follows the steps shown below.

1) Read all the machine parameters.

2) Read the number of rings of the machine.

3) Calculate the radius, tooth pitch, magnet pitch and skew increments per ring.

4) Calculate the machine parameters for the innermost ring.

5) Fix the rotor in a position.

6) Calculate the magnet tooth overlap and there by $\psi_{\mathrm{a}}(\mathrm{k})$ for each tooth by using the information obtained from step(4) and(5)

7) Calculate the extent by which the magnets are projecting out of the tooth using the magnet tooth overlap.

8) Using step 6 and 7 and using the equations 4.2 to 4.5 (from chapter 4) calculate the total energy in the machine. This energy corresponds to the current rotor position.

9) Increment the rotor position and repeat the steps 6 to 8 .

10) Calculate the change in stored energy due to the change in rotor position.

11) Using the step(10) determine the torque for the ring under consideration.

12) Increment the machine parameters to carry out the calculations for next ring. 
13) Repeat the steps 5 to 12 , until the torque for all the rings of the machine has been calculated.

14) Add the torque of the different rings to get the cogging torque.

15) Repeat steps 5 to 14 to get the cogging torque for a range of rotor positions. 


\section{APPENDIX 5 - LEAKAGE FLUX CALCULATIONS AND COMPUTER SIMULATION OF SATURATION MODEL}

\section{Leakage flux calculations.}

\section{Assumptions;}

1) The leakage fluxes travel in a straight line paths (as shown in Figures 1 and 2).

2) Saturation in the iron parts of the machine is negligible.

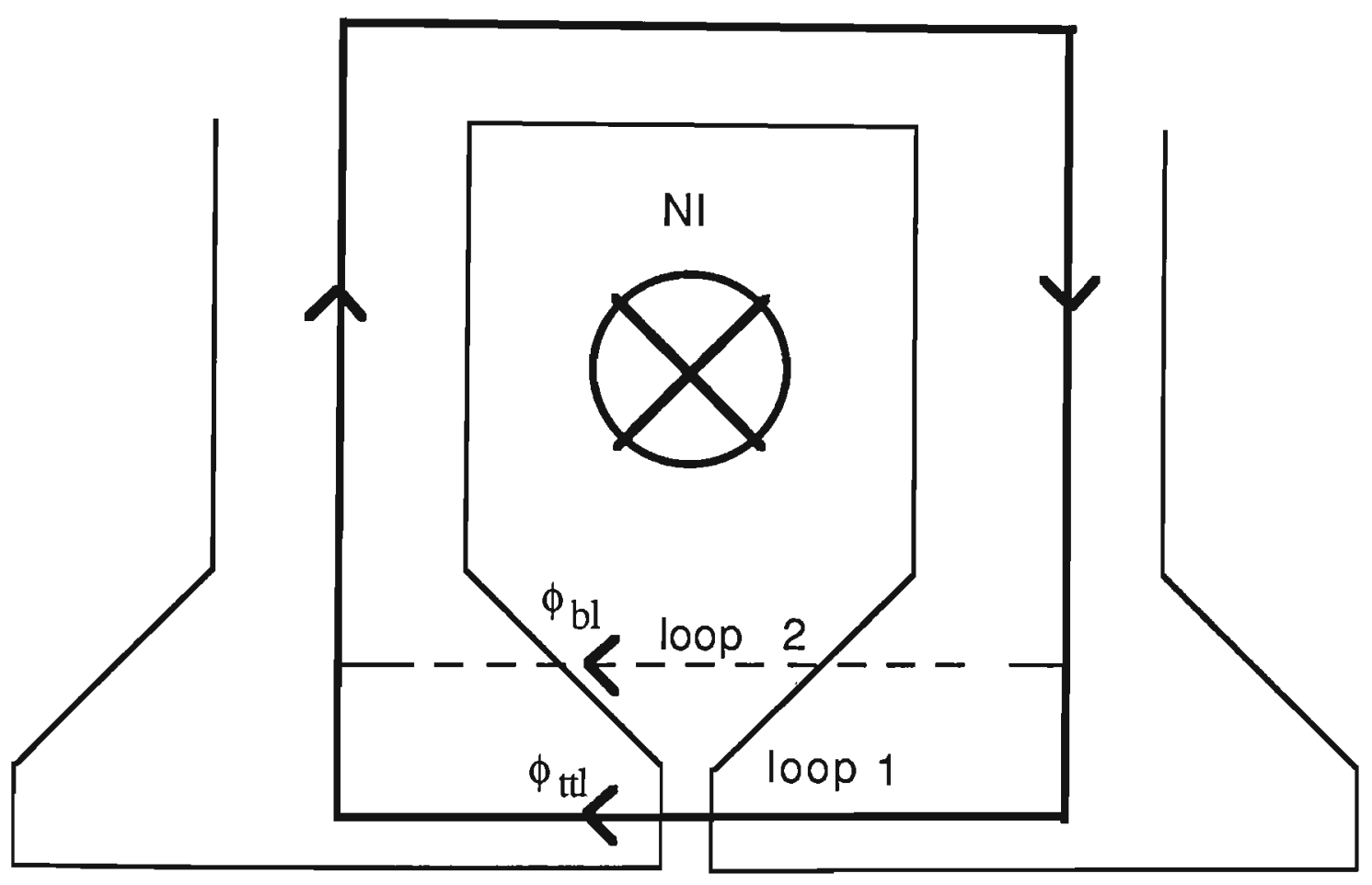

Figure 1 Tooth tip and bevel leakage flux.

Tooth tip and bevel leakage flux.

The tooth tip leakage flux $\phi_{\mathrm{tul}}$ is the leakage flux that crosses the slot opening, and enters the adjacent tooth through the tooth tip of that tooth. The path of the tooth tip leakage is shown as loop 1 in Figure 1. The bevel leakage flux $\phi_{b l}$ is the leakage flux that crosses the tappered section of the slot ( the bevel), and enters the opposite tooth through the bevel of that tooth. The path of the bevel leakage is shown as loop 2 in Figure 1. 
Since the mmf drop along the loop is equal to the current enclosed in the loop

For the mmf loop $1 \mathrm{NI}=\frac{\mathrm{B}_{\mathrm{ttl}}}{\mu_{\mathrm{o}}} \mathrm{w}_{\mathrm{so}}$

For the mmf loop $2 \mathrm{NI}=\frac{\mathrm{B}_{\mathrm{b}}}{\mu_{\mathrm{o}}} \mathrm{w}_{\mathrm{b}}$

Where $\mathrm{N}$ and $\mathrm{I}$ are the number of turns in the slot and the current through them respectively, and $\mathrm{B}_{\mathrm{tl}}$ and $\mathrm{B}_{\mathrm{b}}$ are the flux densities of the two loops in the slot, and $\mathrm{w}_{\mathrm{so}}$ and $w_{b}$ are the width of the slot opening and bevel respectively. Since $w_{b}$ varies along the bevel the average value of the bevel width would be assumed as $w_{b}$.

from equation (1)

$$
\begin{aligned}
B_{t t l} & =\frac{N I \mu_{0}}{w_{\text {so }}} \quad \text { and hence } \\
\phi_{t t l} & =\frac{N I \mu_{0}}{w_{\text {so }}} L d_{\text {so }}
\end{aligned}
$$

where $\mathrm{L}$ is the length of the machine and $\mathrm{d}_{\text {so }}$ is the depth of the slot opening.

Similarly from equation (2)

$\phi_{\mathrm{bl}}=\frac{\mathrm{NI} \mu_{\mathrm{O}}}{\mathrm{w}_{\mathrm{b}}} \mathrm{L} \mathrm{d}_{\mathrm{b}}$

where $d_{b}$ is the depth of the bevel portion of the tooth.

Equation (3) and (4) give the tooth tip and leakage flux densities respectively in terms of the machine parameters and the stator current.

\section{The slot leakage flux}

Slot leakage flux is the leakage flux which crosses the main slot area all through the depth of the slot.

If ' $d$ ' is the depth of the slot and ' $w$ ' is the width of the slot, then at a depth ' $x$ ' ( shown in Figure 2 ) the mmf equation can be written as 
$\mathrm{NI} \frac{\mathrm{x}}{\mathrm{d}}=\frac{\mathrm{B}}{\mu_{\mathrm{o}}} \mathrm{w}$ from which

$B=\frac{N I \mu_{0}}{w d} x$

Total slot leakage flux crossing the slot over the depth $\mathrm{d}$ is

$$
\int_{0}^{\mathrm{NII} \mu_{\mathrm{o}}} \frac{\mathrm{w}}{w d} \mathrm{Lxdx}=\frac{\mathrm{LNI} \mu_{\mathrm{o}} \mathrm{d}}{2 \mathrm{w}}
$$

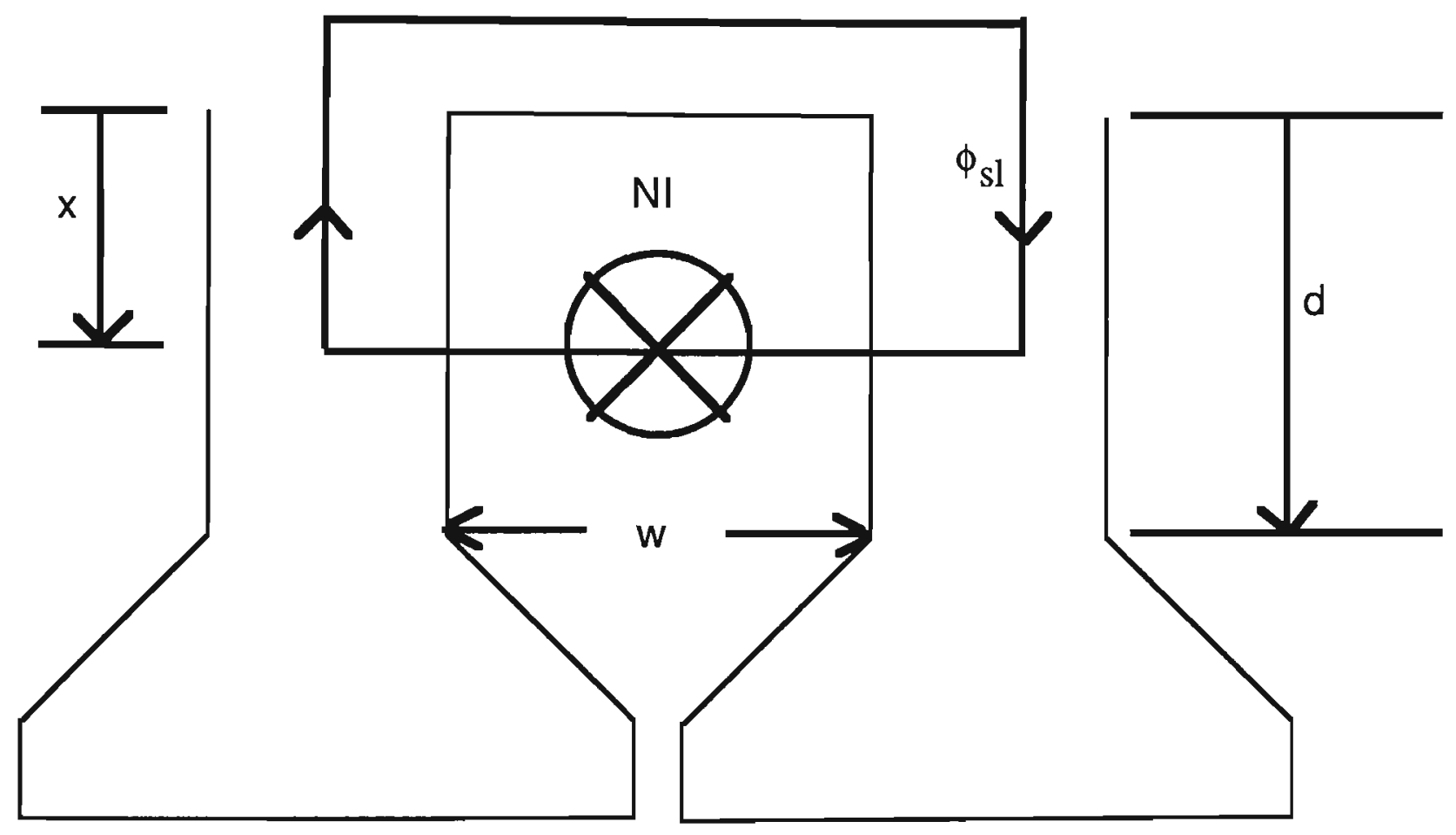

Figure 2 Slot leakage flux

Equation (5) gives the total leakage flux due to the current I. In the saturation model of the machine it is assumed that the slot leakage flux defined by equation (5) crosses the slot at the joint of the main slot and the bevelled section of the slot. (ie. at a distance ' $d$ ' from the bottom of the slot) 
2 Calculation of the area of cross section of the tooth.

To calculate the flux density across the different section of the tooth tip, the area of cross section of the tooth tip through which the flux goes through should be calculated. Since the points at which the area across the tooth needs to be calculated depends on the rotor position, a general expression, which takes this in to account has to be derived. In the model it is assumed this area is the area of that section which is perpendicular to the bevel and pass through the point on the tooth tip face at which the area needs to be calculated. Figure 3 shows a tooth tip. In the figure ' $x$ ' is a variable which defines the point on the tooth tip across which the area has to be estimated.

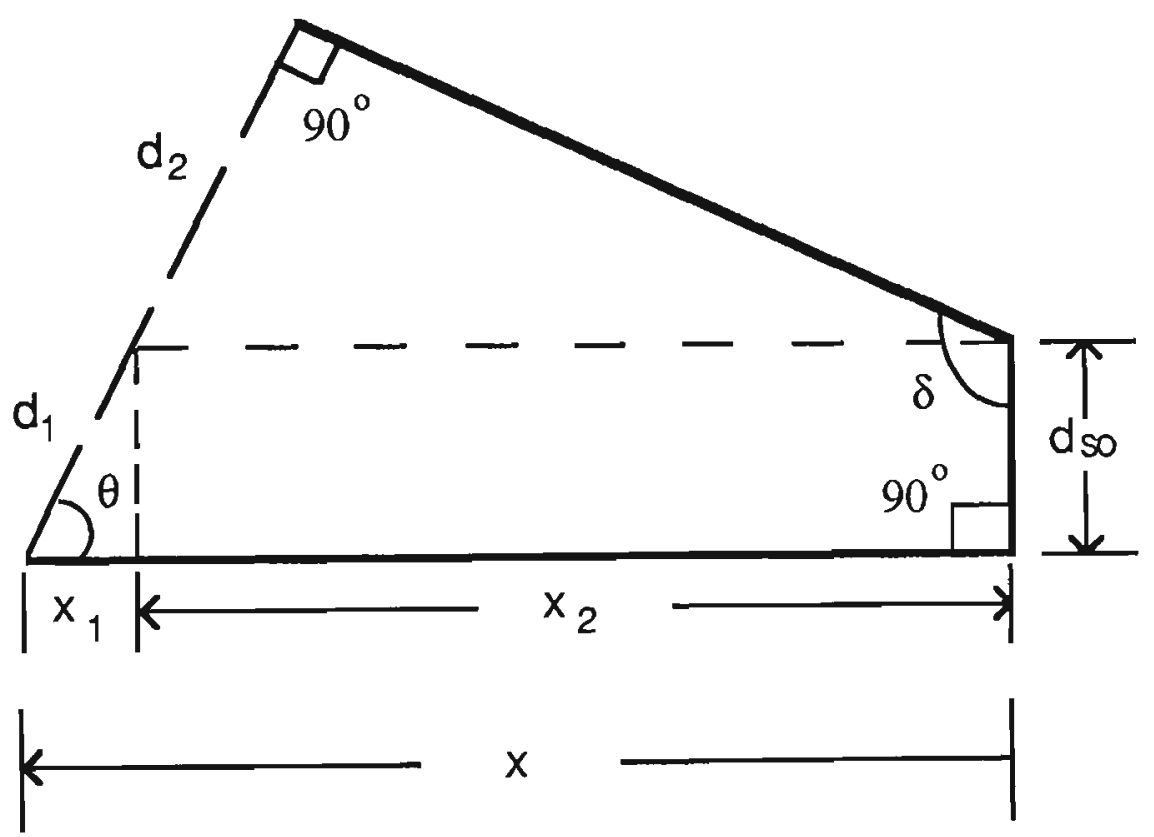

\section{Figure 3 Tooth tip}

To calculate the area at a cross section, the depth of the tooth tip $\left(d_{1}+d_{2}\right)$ at the point defined by $x$ has to be calculated and multiplied with the length of the machine. The values of $\delta$ and $\mathrm{d}_{\text {so }}$ (Figure 3 ) will be known from the tooth tip dimensions.

In Figure 3

$\theta=360-(\delta+180)$

$\sin \theta=\frac{d_{\text {so }}}{d_{1}}$ 
$\mathrm{d}_{1}=\frac{\mathrm{d}_{\mathrm{so}}}{\sin \theta}$

(6)

$$
\begin{aligned}
& \tan \theta=\frac{d_{s o}}{x_{1}} \\
& x_{1}=\frac{d_{s o}}{\tan \theta}
\end{aligned}
$$

$$
x_{2}=x-\frac{d_{s o}}{\tan \theta}
$$

$$
\begin{aligned}
& \cos \theta=\frac{d_{2}}{x_{2}} \\
& d_{2}=\cos \theta x_{2}=\cos \theta\left(x-\frac{d_{S o}}{\tan \theta}\right) \quad \text { (using equation (8)) }
\end{aligned}
$$

$$
=\cos \theta\left(x-\frac{d_{s o} \cos \theta}{\sin \theta}\right)
$$

$d=d_{1}+d_{2}=\frac{d_{S o}}{\sin \theta}+\cos \theta x-\frac{d_{S o} \cos ^{2} \theta}{\sin \theta}$ (using equations (6) and (9))

$$
\begin{aligned}
& =\frac{d_{s o}}{\sin \theta}\left\{1-\cos ^{2} \theta\right\}+\cos \theta x \\
& =\frac{d_{S O}}{\sin \theta}\left\{\sin ^{2} \theta\right\}+\cos \theta x \\
& =d_{S O} \sin \theta+x \cos \theta
\end{aligned}
$$

Equation (10) gives the perpendicular depth of the tooth for any given value of $\mathrm{x}$. Hence the area can be calculated as ' $d$ ' times ' $L$ ', where ' $L$ ' is the length of the machine.

\section{Computer simulation}

The computer simulation of saturation model follows the steps given below.

1) Read all the machine parameters. 
2) Read the number of rings of the machine.

3) Calculate the radius, tooth pitch, magnet pitch and skew increments per ring.

4) Calculate the machine parameters for the innermost ring.

5) Fix the rotor in a position.

6) Set the stator phase currents to zero.

7) Using the machine parameters of the current ring, and the current rotor position determine the teeth magnet overlap

8) Using the information obtained in step (7) fix the ten points across the teeth at which the mmf equations are to be solved.

9) Using the information obtained in step (7) fix the limits up to which each of these flux densities exists across the teeth.

10) Using the information obtained in step (7) (the presence and absence of the magnet across the teeth and the polarity) find the $\psi$ for all the ten points across the tooth.

11) Using the information obtained in step 9 and 10 find the flux densities at the ten points.

12) Assuming that the flux densities vary linearly between the points, find the flux across each little section and hence the flux through the lower and upper tooth stem.

13) Using the fluxes through the upper and lower stem calculate the flux densities across the stem.

14) From the $\mathrm{BH}$ loop determine the value of $\mathrm{H}$, which corresponds to the stem flux densities.

15) From the knowledge of the tooth tip dimensions, and the flux near the tooth tip calculate the flux density across the sections of the tooth tip. 
16) Using the information obtained in steps 11 to 15 , and the ten mmf equations calculate the ten mmf drops along the ten mmf loop path and calculate the "errors" in the drops.

17) Check whether the "errors" are within the acceptable range. If there are within acceptable range go to the step 20. If there are not in the acceptable range follow the steps below.

18) Using the "error" values and the ten current flux density values calculate a new set of flux density values. (this is done by forming ten linear simultaneous equations using the "errors", the ten mmf equations and the current flux densities, and solving them using Gaussian elimination method)

19) Go To steps 12.

20) Use the flux densities to calculate the stored energy and the electrical energy for the current rotor position and the stator phase current current. Increment the current by $0.5 \mathrm{~A}$. Use the the current value of the flux densities as the first approximation for the incremented current level.

21) Check whether the current has reached the desired level. If not go to step 12. If the current has reached the desired level, increment the rotor position.

22) Check whether the rotor position has been changed enough number of times to get the desired number of torque position relationship. If not go to step 7. Otherwise follow the steps below.

23) If the rotor position has been incremented enough number of times, then calculate all the toques pertaining to different currents for the change in rotor positions from the knowledge of energy. Increment the machine parameters to suit the next ring.

24) Check whether the whole machine has been covered along the radius (by checking the incremented machine parameters).

25) If the whole machine has not been covered then go to step 5. If the whole machine has been covered then follow the step below. 
26) Using the information obtained from step 23 calculate the overall torque for different current by adding the torque of all rings corresponding to each current.

\section{The machine parameters}

$\begin{array}{lll}\text { Remanence of the magnet } & = & 1.1 \mathrm{~T} \\ \text { Number of slots per pole pair } & = & 4 \\ \text { Number of pole pairs } & = & 51 \mathrm{~mm} \\ \text { Outer radius } & = & 24 \mathrm{~mm} \\ \text { Inner radius } & = & 27 \mathrm{~mm} \\ \text { Slot depth } & = & 7 \mathrm{~mm} \\ \text { Slot width } & = & 2 \mathrm{~mm} \\ \text { Slot opening } & = & 1.5 \mathrm{~mm} \\ \text { Tooth tip depth at opening } & = & 15^{\circ} \\ \text { Bevel angle over slots } & = & 0.2 \mathrm{~mm} \\ \text { Turns per phase } & = & 3.4 \mathrm{~mm} \\ \text { Airgap } & = & 3.6 \mathrm{~mm} \\ \text { Magnet thickness, gm } & = & 144.05 \text { electrical degrees } \\ \text { Effective total airgap, g } & = & 81.0 \\ \text { Maximum pitch of the magnet } & =10.90 \text { electrical degrees } \\ \text { Minimum pitch of the magnet } & & \end{array}$

